Portland State University

PDXScholar

Winter 3-11-2016

\title{
Cyclist Path Choices Through Shared Space Intersections in England
}

\author{
Allison Boyce Duncan \\ Portland State University
}

Follow this and additional works at: https://pdxscholar.library.pdx.edu/open_access_etds

Part of the Environmental Design Commons, Transportation Commons, and the Urban Studies and Planning Commons

Let us know how access to this document benefits you.

\section{Recommended Citation}

Duncan, Allison Boyce, "Cyclist Path Choices Through Shared Space Intersections in England" (2016). Dissertations and Theses. Paper 2704.

https://doi.org/10.15760/etd.2700

This Dissertation is brought to you for free and open access. It has been accepted for inclusion in Dissertations and Theses by an authorized administrator of PDXScholar. Please contact us if we can make this document more accessible: pdxscholar@pdx.edu. 


\title{
Cyclist Path Choices Through Shared Space Intersections in England
}

\author{
by
}

\begin{abstract}
Allison Boyce Duncan requirements for the degree of

\author{
Doctor of Philosophy \\ in \\ Urban Studies
}

Dissertation Committee:

Sy Adler, Chair

Jennifer Dill

James Strathman

Hyeyoung Woo
\end{abstract}

A dissertation submitted in partial fulfillment of the

\section{Portland State University \\ 2016}


C 2016 Allison Boyce Duncan 


\begin{abstract}
In the last several years, there has been growing worldwide interest in making streets safer for all users-pedestrians, cyclists, and motorists. One approach, shared space, is a traffic calming technique as well as urban design concept. This technique strives to fully integrate the roadway into the urban fabric by removing elements such as lane markings, curbs, and traffic signs. By removing these elements and creating a more plaza-like space, these sites become ambiguous and no user group as priority. The technique is relatively new, and the majority of existing research concerns pedestrians only. This mixed methods research focused on six intersections in England with the goal of understanding how bicycle riders perceive and travel through shared space intersections. Using video observations of the six sites in three cities, three shared and three control, this project analyzed the variations in the paths cyclists rode through the intersections. Data were collected on several variables related to both the cyclists and their interactions with the site itself such as helmet use and riding through crosswalks. Path analysis required the development a new evaluative variable in order to compare individual paths by how much deviation there was in each path ridden as compared to other cyclists. Site-specific surveys addressed the perceptions, bicycling experience, demographics, and path and route preferences by cyclists at both shared space and control intersections. The analysis indicated that cyclists rode similarly through both shared and control intersections, and that a large percentage of riders preferred to ride farther from motor vehicles when given the space to do so. This project offered further insight in how to best design shared space projects for nonmotorized users by looking at the
\end{abstract}


spatial layout and the elements that most influenced a rider's path choice. Results indicated that, in these cases, shared space was not the panacea for nonmotorized users as some literature suggests, but nonetheless appeared to be a valid form of traffic calming. This research offered further insight in how to best design shared space projects for nonmotorized users by looking at the spatial layout and the elements that most influenced a rider's path choice 


\section{DEDICATION}

This is for my husband for his patience and support on this long, crazy ride. 


\section{ACKNOWLEDGEMENTS}

This research was generously supported by a National Institute for Transportation and Communities (NITC) Dissertation Fellowship.

My thanks to my committee for encouraging me on this logistically-challenging, international adventure. I greatly appreciate all of your support as well all of the pushes I needed to keep going.

I must thank the PSU PhD Students in Transportation group (PhT). They have been both friends and an invaluable support and feedback group. I relied on them for their valuable perspectives at all stages of my dissertation.

Finally, I would like to thank the City of Coventry and the Village of Poynton for their help in this research. 


\section{TABLE OF CONTENTS}

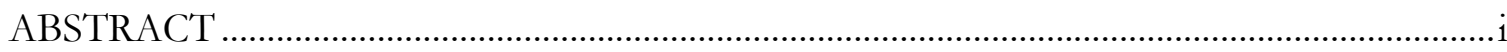

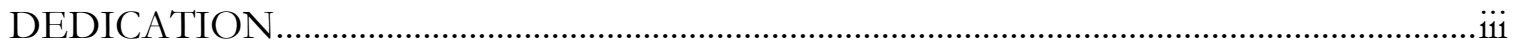

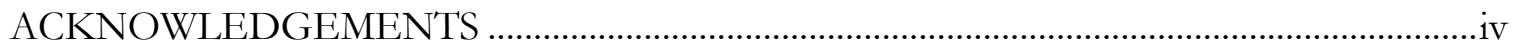

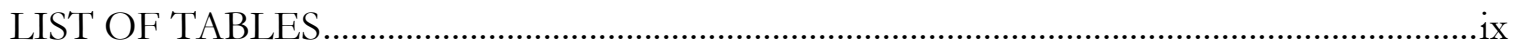

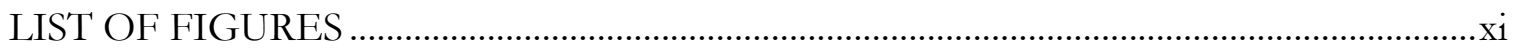

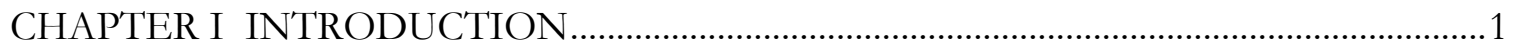

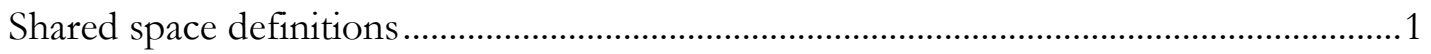

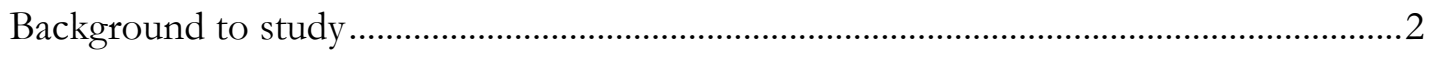

Shared space urban design principles ..........................................................................................

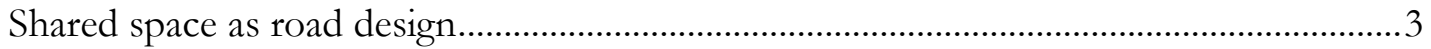

Contributions to shared space theory ………..................................................................

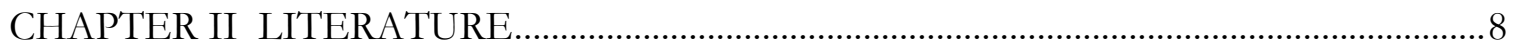

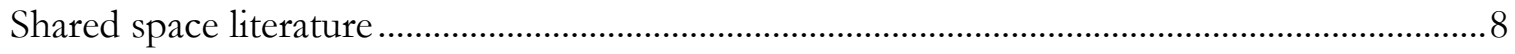

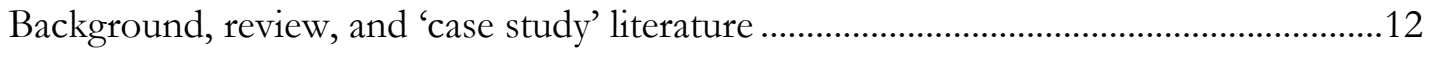

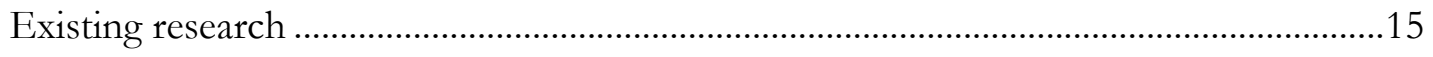

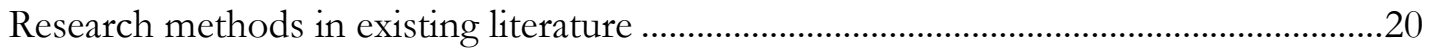

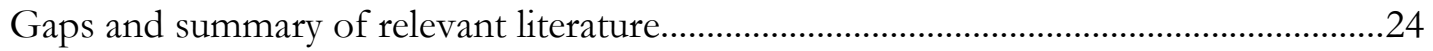


Contributions to shared space literature

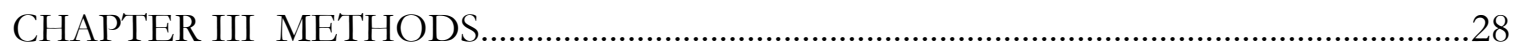

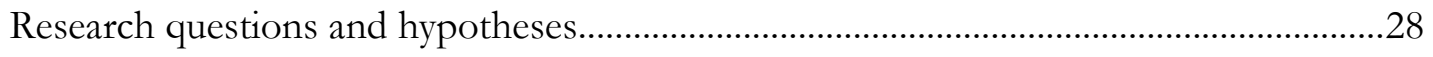

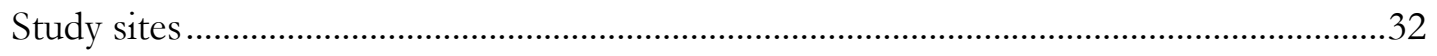

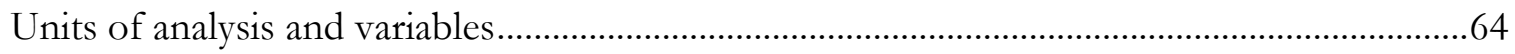

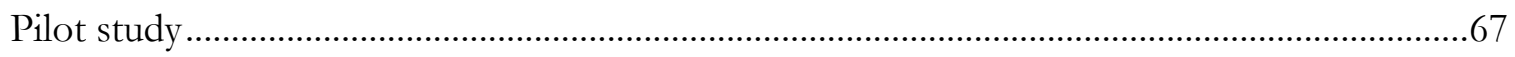

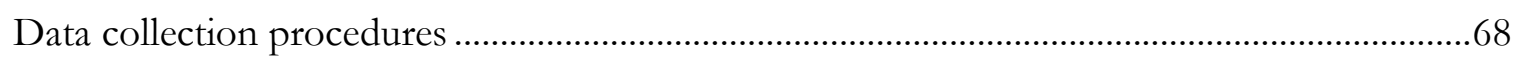

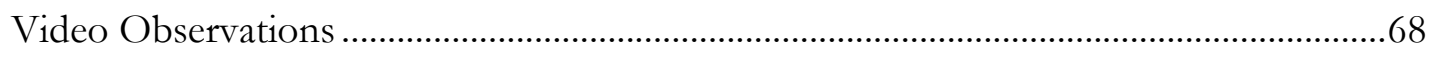

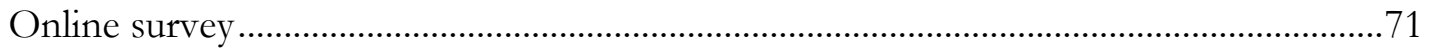

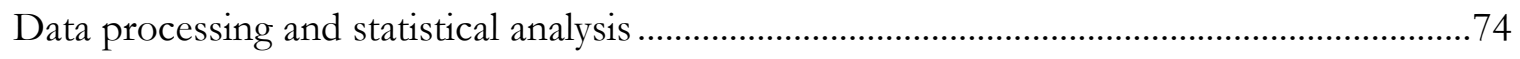

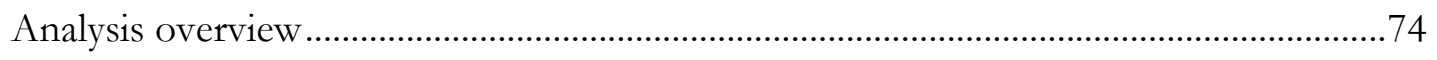

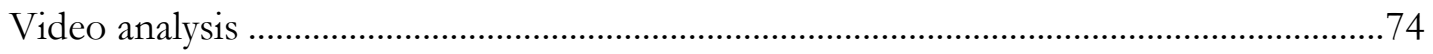

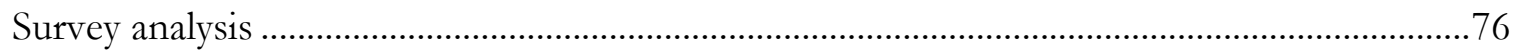

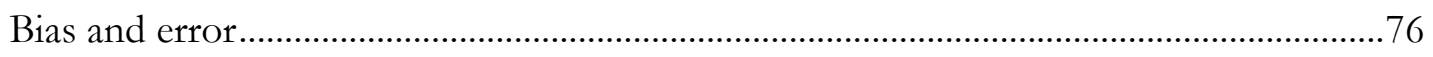

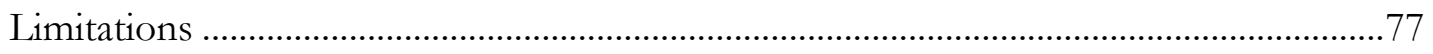

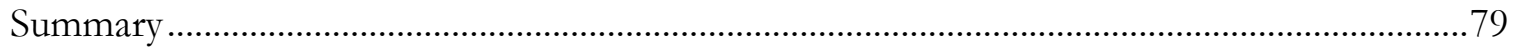

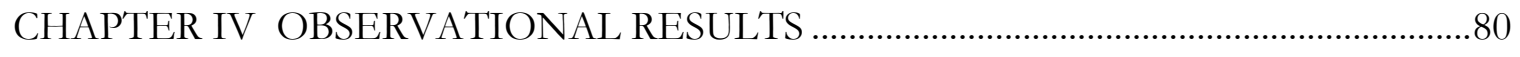

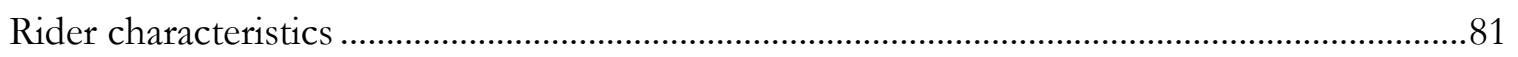


Gender

Helmet use .83

Bicycle type .86

Rider behaviors .87

Sidewalk and crosswalk use .87

Walking behavior. .92

Curb use.

Traffic volumes

Node Differences. 101

Analysis of node difference by site 106

Summary of results.

Contributions to shared space literature 136

CHAPTER V SURVEY RESULTS 138

Summary of results 145

CHAPTER VI DISCUSSION

Traffic volumes

Characteristics and path choice.

Behavior and path choice... 


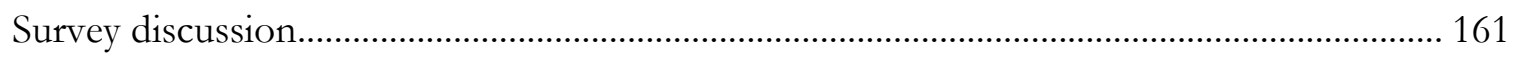

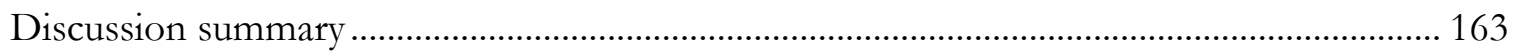

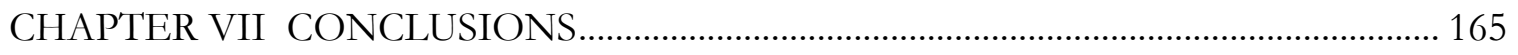

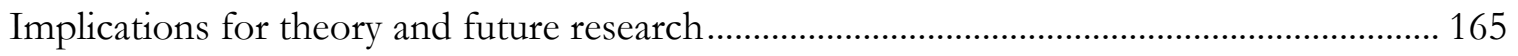

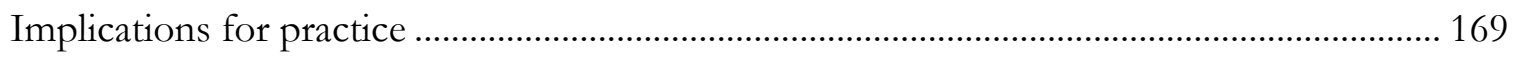

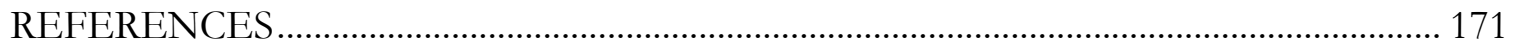

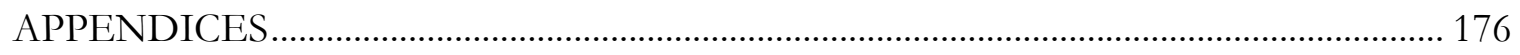

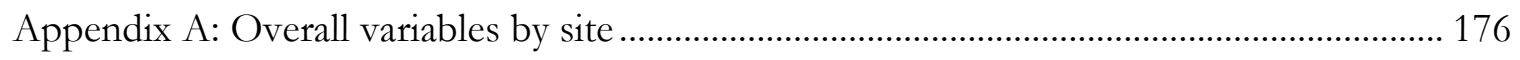

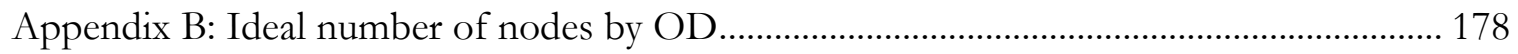

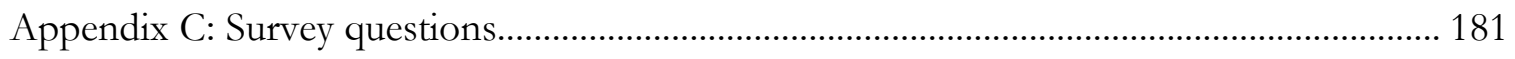

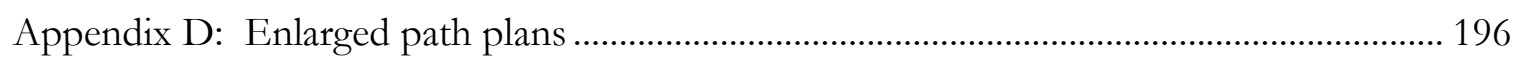

Appendix E: Figures regrouped by study site type................................................................ 229 


\section{LIST OF TABLES}

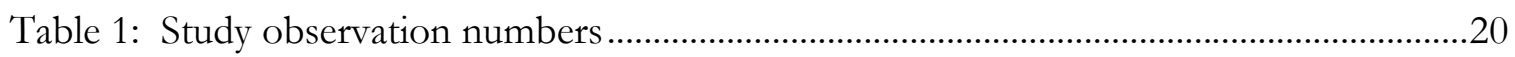

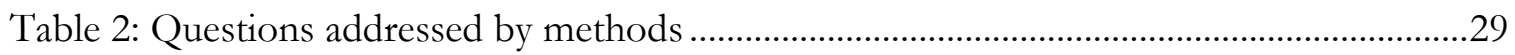

Table 3: Site matrix of all applicable elements ............................................................................62

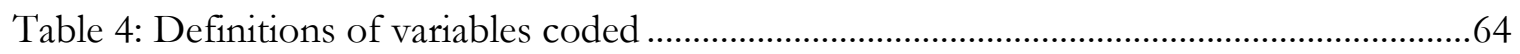

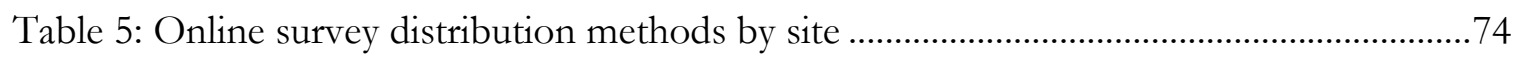

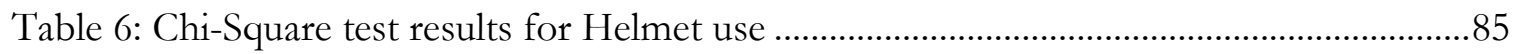

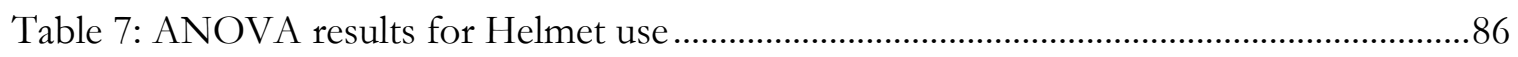

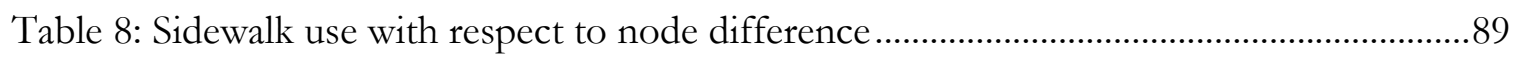

Table 9: Crosswalk use with respect to node difference ...........................................................91

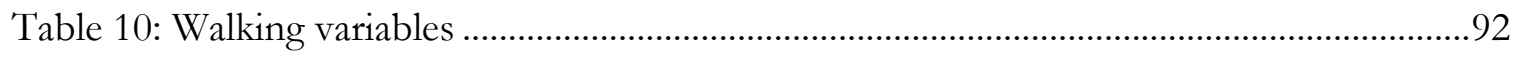

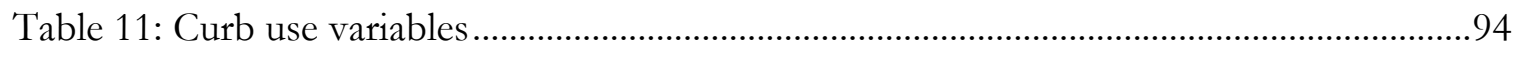

Table 12: Origin-Destination means (OD) and standard deviations........................................ 102

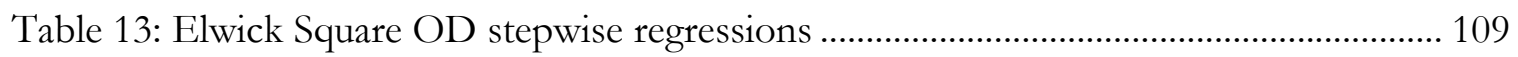

Table 14: Poynton OD stepwise regressions ....................................................................... 114

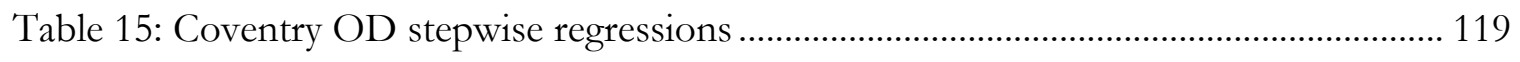

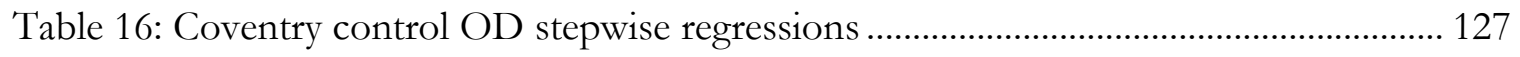

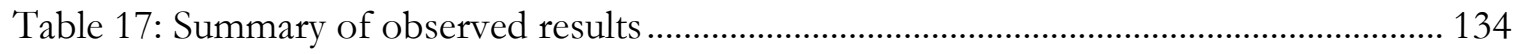


Table 18: Survey respondent characteristics.. 


\section{LIST OF FIGURES}

Figure 1: Example traffic flow diagram for cyclists and pedestrian paths

Figure 2: Turtle path distances off straight lines

Figure 3: Study sites .33

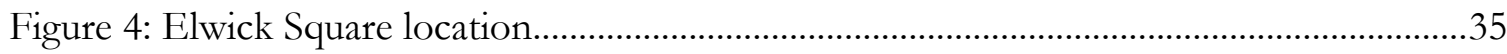

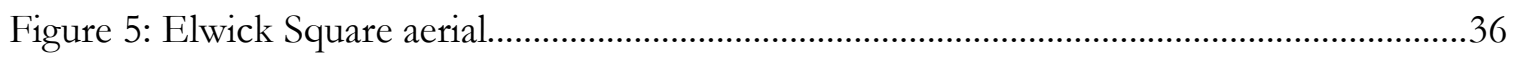

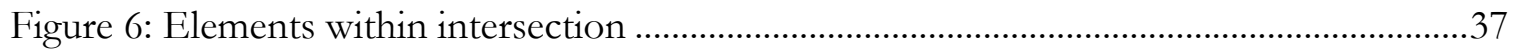

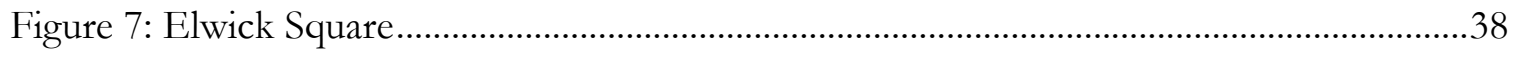

Figure 8: Elwick Square showing the marked crosswalk .........................................................39

Figure 9: Elwick Square with the light posts, planters, and textured paving............................40

Figure 10: Elwick Road leading into Elwick Square ................................................................. 41

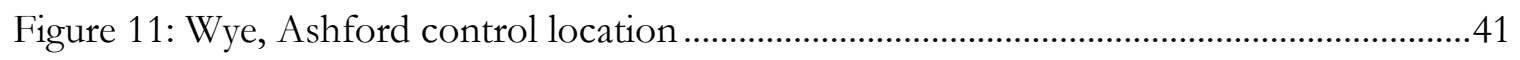

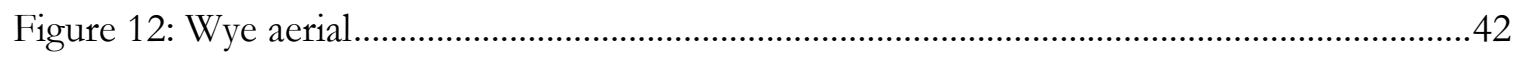

Figure 13: Elements within the Wye intersection......................................................................43

Figure 14: Wye signpost indicating national cycle route...........................................................44

Figure 15: View of Wye intersection facing east......................................................................

Figure 16: View of Wye intersection facing west ..................................................................45

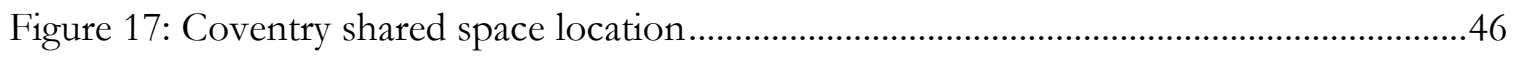


Figure 18: Aerial view of Coventry intersection

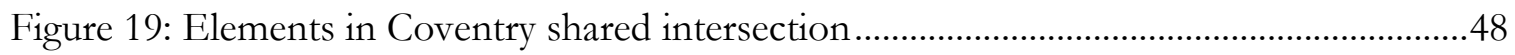

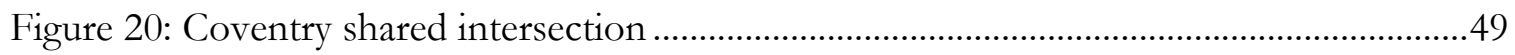

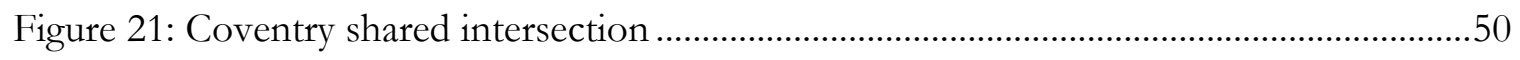

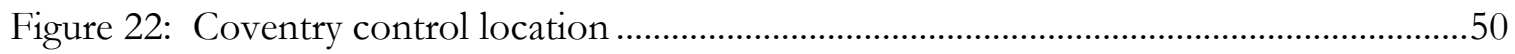

Figure 23: Coventry control aerial image ....................................................................................

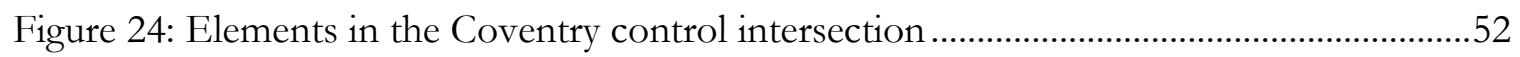

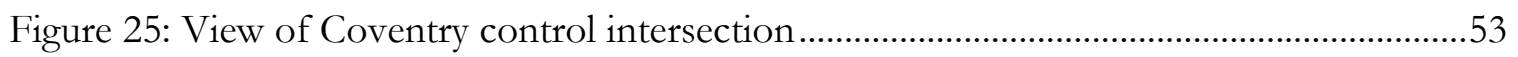

Figure 26: View of road with bike lane leading to Coventry control intersection .....................54

Figure 27: Poynton shared space location ..............................................................................54

Figure 29: Elements in the Poynton intersection ....................................................................56

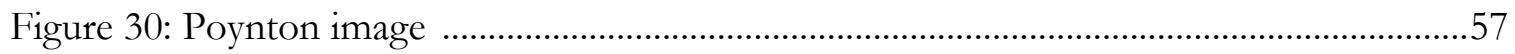

Figure 31: Poynton crosswalk and paving detail....................................................................58

Figure 32: View of Poynton intersection facing southwest ....................................................59

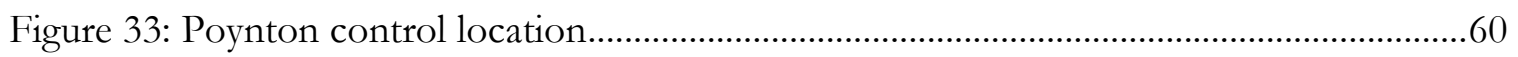

Figure 34: Elements in Poynton control intersection .............................................................60

Figure 35: View of Poynton control intersection ..................................................................61

Figure 36: View of Poynton control intersection facing northwest.........................................62 
Figure 37: Example of path comprised of nodes and ideal paths......

Figure 38: Example of survey question asking about path choice, Poynton.............................67

Figure 39: Video camera equipment, Elwick Square …….........................................................

Figure 40: Video camera and tripod setup, Wye........................................................................ 71

Figure 41: Data processing sheet, Poynton example …………....................................................

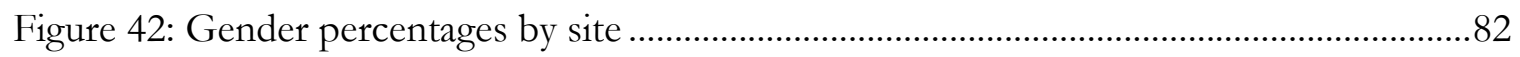

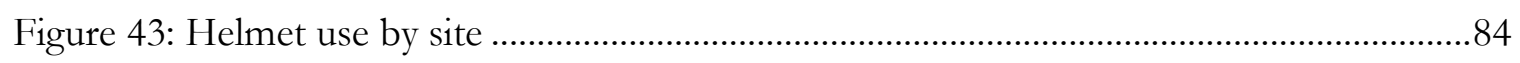

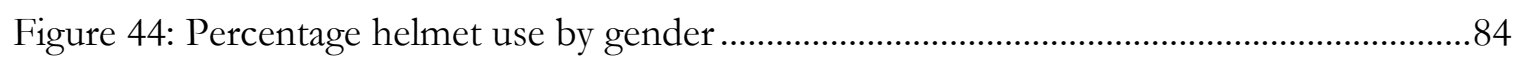

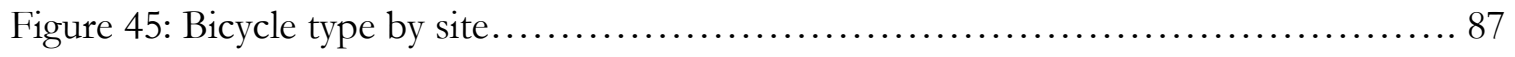

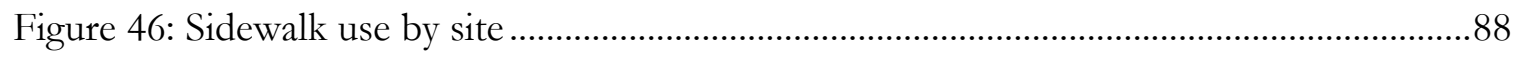

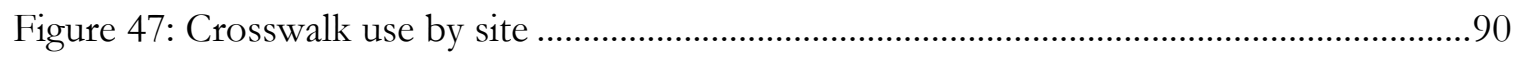

Figure 48: Average hourly number of vehicles................................... 94

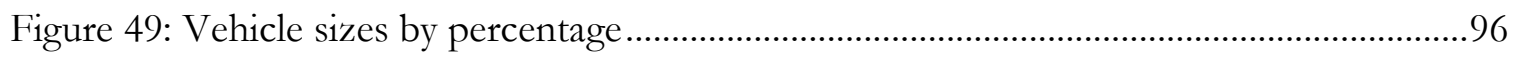

Figure 50: Wye--representative traffic volume .........................................................................96

Figure 51: Elwick Square--representative traffic volume ........................................................97

Figure 52: Coventry control--representative traffic volume …................................................98

Figure 53: Coventry shared--representative traffic volume.......................................................99

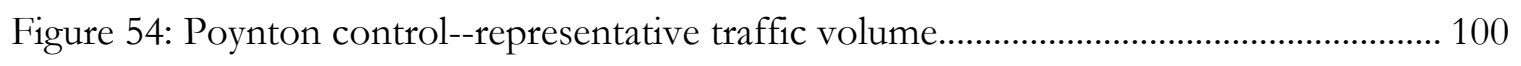


Figure 55: Poynton shared--representative traffic volume.

Figure 56: Variance in node difference by site 105

Figure 57: Coefficient of variation by site type 106

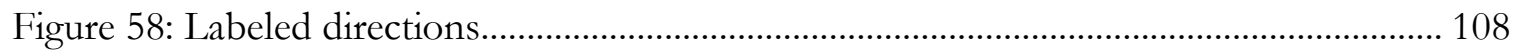

Figure 59: Elwick Square mean node difference per OD 108

Figure 60: NSE 110

Figure 61: NWS and SNW

Figure 62: NS

Figure 63: Labeled directions. 113

Figure 64: Poynton mean node difference per OD

Figure 65: WE and EW 115

Figure 66: Poynton NESW and SWNE 116

Figure 67: Other bike paths 117

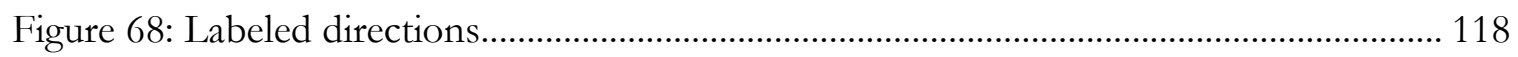

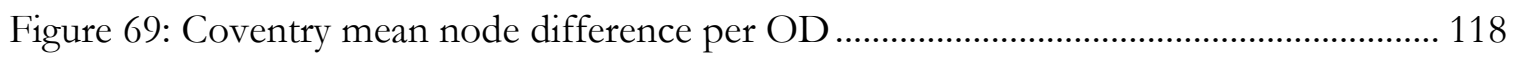

Figure 70: WE and EW 120

Figure 71: NS 121

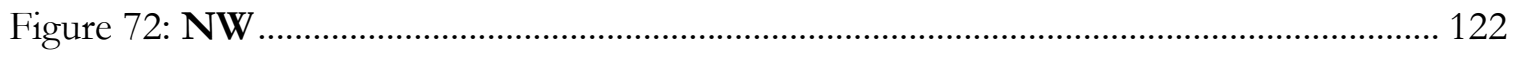


Figure 73: $\mathbf{E N}$ and $\mathbf{N E}$

Figure 74: WN

Figure 75: Sidewalk use

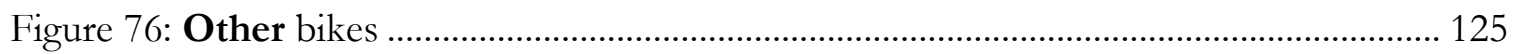

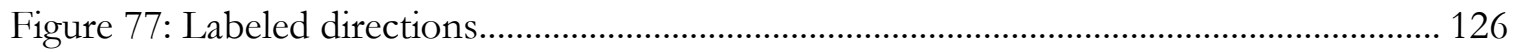

Figure 78: Coventry control mean node difference per OD ................................................. 126

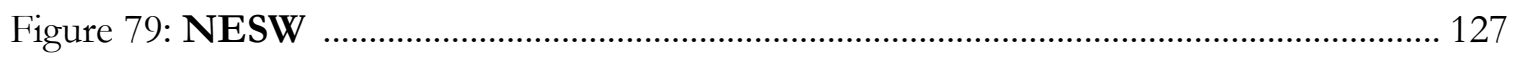

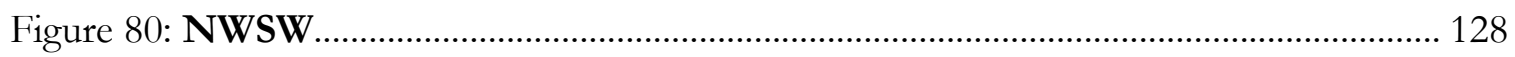

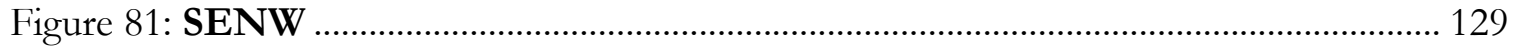

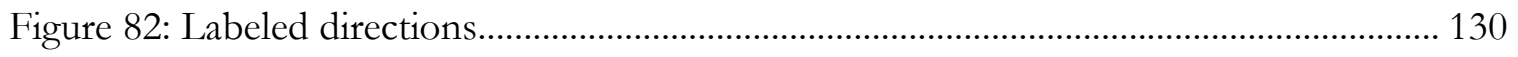

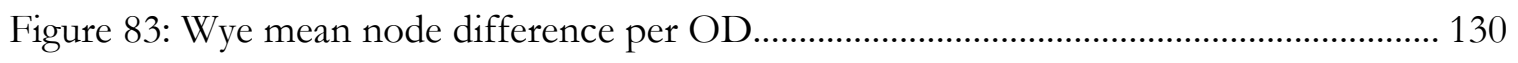

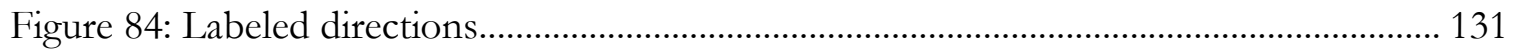

Figure 85: Poynton control mean node difference per OD …................................................. 131

Figure 86: Poynton female paths (left) and male paths (right) ............................................. 159

Figure 87: Elwick Square female paths (left) and male paths (right) ..................................... 160

Figure 88: Coventry female paths (left) and male paths (right) ............................................ 160

Figure 89: Coventry control female (left) and male paths (right) .......................................... 161 


\section{CHAPTER I}

\section{INTRODUCTION}

For the last several decades, the American roadway system has been designed and built for motor vehicles. In the last several years, though, there has been growing worldwide interest in making streets safer for all users-pedestrians, cyclists, and motorists. Some of the various movements started include Livable Streets, Complete Streets, Green Streets, and Shared Space (also known as Naked Streets. There has been movement in Europe, Great Britain, and New Zealand toward more frequent adoption of the shared space technique of traffic calming in various urban locations. This is a new area of study; the shared space concept has only been around since the 1980's when the projects started small and few but now are gradually increasing in size and number.

\section{Shared space definitions}

Shared space is a traffic calming technique as well as a design concept; shared space theorists seek the return of the public realm to the members of the community by creating equal access for everyone. The primary goal when designing such intersections is to reduce vehicle speeds, thus improving safety for pedestrians, bicyclists, and motorists without unduly interfering with traffic flow. These designs represent a retreat from the segregation and regulation that has defined transportation engineering for decades. While there is a growing body of research surrounding the shared space movement-predominantly Dutch studies-- 
much is still not yet known or understood about this design concept (Heinz 2010,

Schlabbach n.d., Schonauer et al. 2011, Kaparias et al. 2013).

According to the Shared Space Institute:

The salient feature of Shared Space streets is not just that they are 'naked' i.e. that traffic signs are removed, but that they are designed to be fully part of the public realm and not just a conduit for traffic. In other words, the whole right-of-way of the Shared Space street is designed to be an integral extension of the surrounding land-use context. Therefore, all users have equal access. A vehicle is considered to be just another user that must negotiate space on an equal footing with shoppers, bikers, skaters, pedestrians, playing children and so on. The idea is to make the street legible so that the users can understand that it is a shared environment and then behave accordingly. (Lutz, p4)

\section{Background to study}

\section{Shared space urban design principles}

One of the primary goals of shared space projects is to give the roadways back to the people. By making the roadways more plaza-like, and heavily calmed, the community is more likely to gather and use the space for more than simple mobility. In further investigating shared space, the question arises as to which design elements are essential to achieve the shared space end product of a plaza-like intersection with equal access for all modes. Additionally, the other question is whether these designs do successfully encourage more multi-modal use of the space, and if so-do any modes feel less welcome? Given the goals and theories behind the shared space concept, it is expected that users of all modes may feel less safe. 


\section{Shared space as road design}

A city's rights of way are, generally, 25-35\% of its developed area (Macdonald 2011).

Creating safer and more livable streets can contribute greatly to improved quality of life, higher levels of physical activity, increased sense of community, and increased sense of safety. Two of the ways to improve a street's livability is to decrease motor vehicle speeds by traffic calming (Appleyard, 1980) or by installing woonerfs (home zones) (Biddulph, 2012).

The creation of a successful Shared Space design may take many forms, appropriate to each site's unique opportunities and constraints. However, some common techniques include:

- Removal of curbs

- Removal of stop signs and traffic lights

- Removal of center lane striping

- Entry monument and pavement change to indicate change in driving environment (distinguish from standard roads)

- Leveling of site to simulate a public square

- Incorporation of a consistent paver, usually textured, throughout entire site (blurring boundaries for pedestrians and drivers)

- Incorporation of street furniture and landscaping to create a more inviting space for all users

- Inclusion of geometric devices to direct drivers through the site while slowing their speed (Hamilton-Baillie, 2005; Lutz, n.d.)

Few projects are 'pure' examples of a shared space design; many incorporate multiple

techniques to create the desired end product. DfT (2011) created a Classification

Questionnaire (p2.6) to determine where on a shared space spectrum a road design falls.

The goal of this study is to evaluate forms (also called showcase projects) of the design and how cyclists navigate as well as perceive them. 


\section{- PURPOSE OF THE STUDY}

Cyclist behavior is linked to perception; users will ride through an intersection in ways they feel are either safest, most efficient, or a combination of the two (Chaurand et al. 2012, Cho et al. 2009). Understanding why cyclists behave in certain ways in shared spaces as compared to traditional intersections will be more difficult to answer. The literature offers up some possible reasons why cyclists may react to the intersections, such as environmental load and arousal theory. A mixed method approach of both observation and survey data may clarify which theories best explain cyclist behavior. Shared space is touted to be an improvement over the more commonly seen transportation intersections with standard road elements such as curbs and traffic signals. In order to understand if bicycle riders benefit from these newer road designs, this research compares existing shared space intersections with similar control intersections. The goal is to understand if cyclists ride differently through shared space sites than non-treatment sites, and if so, why.

\section{- PROBLEM STATEMENTS}

Given the overview of the relevant literature, and the research gaps found to date, several potential issues came to light that focus the direction of this study.

- Shared space is one of a handful of roadway treatments touted to improve safety for vulnerable users. It is relatively new and the majority of the existing research deals only with pedestrians only. There has been very little research regarding safety for cyclists in these spaces.

- Shared space is just beginning to be adopted or considered in the United States. 
There are multiple reasons for this, but interest is growing. In order to facilitate understanding and potential adoption and of this design technique and/or its elements, the goal of this dissertation was to increase understanding of how cyclists perceive and travel through shared space intersections.

- There is a lack of research evaluating the cyclist perspective of Shared space projects (Kaparias et al. 2013).

- There is very little research looking at a cyclist's movements on the smaller scale (path) of an intersection as compared to the larger scale (route) that examines a cyclist's route choice.

- Cyclists are neither motor vehicle drivers nor pedestrians. There is little research on this, but what there is discusses how cyclists do not have the same requirements as pedestrians or drivers (while having some overlapping needs with both other modes). They also have a unique perspective about how they travel and perceive the space they travel through (Forsyth \& Krizek, 2011).

\section{- RESEARCH QUESTIONS}

- What perceptions of shared space intersections do cyclists have?

- For instance, do cyclists feel safer in these intersections; do they perceive that drivers yield to them more, or at least notice them more (better communication), than in regular intersections (better yielding behavior)?

- Do cyclists perceive that they notice all users more than in regular intersections?

- Does this perception vary according to cyclist type/experience level or demographics? (Are 'strong and fearless' cyclists more likely to have lower arousal levels than a more timid cyclist?)

- How did cyclists actually maneuver through a shared space intersection? 
- Do cyclists ride through the shared space intersections differently than nonshared space intersections? For instance, do they skirt the area that would be the curb or do they venture farther out into the 'public square' portion of the intersection?

- Do the more complex intersections result in greater path variation?

- Do the busier intersections result in greater path variation?

- How would cyclists prefer to ride through the shared space intersections?

- What elements (from infrastructure to other modes/users) prevent cyclists from riding where they would most prefer?

- Does this vary depending on demographics or bicycle-riding experience?

- Did the presence of a shared space intersection influence route choice by cyclists?

\section{Contributions to shared space theory}

Shared space is not generally promoted as being useful for increasing bicycling. It is seen more as a general urban design and transportation safety concept designed to help vulnerable users improve their roadway experience. However, cities around the world are increasingly interested in increasing their bicycling mode share, and there are many techniques designers, planners, and engineers may employ to encourage more bicycling-including shared space. And if this concept is going to be implemented more frequently, then it is imperative that we understand how cyclists experience these street treatments. The concepts behind shared space are also predicated on the Dutch culture from which it originally evolved. My research also adds to the growing body of work looking at shared space projects in countries other than the Netherlands. 
The underlying principles of shared space include risk homeostasis, passive safety, arousal theory, and environmental load and look at how humans in general respond to situations that are boring, stressful, or overwhelming. The underlying concept behind shared space makes the general assumption that different modes will respond similarly, as well as be served equally, by the application of a shared space treatment.

The existing literature recognizes the need for more research into how various user groups experience shared space projects (Hammond 2013). My examination of the less-studied bicycling user group under the effects of shared space designs will broaden the understanding of how these vulnerable users actually respond to the intersections by looking at how they ride through them as well as asking them how they perceive them. As Forsyth and Krizek (2011) discuss, bicyclists are neither pedestrians nor drivers due to their flexibility in navigating space. That flexibility may indicate that cyclists will respond better than drivers or pedestrians, but, because of cyclists' more nebulous position in the transportation hierarchy, shared space may end up being more of a disadvantage instead. 


\section{CHAPTER II}

\section{LITERATURE}

Shared space literature

This chapter will discuss several background theories in the literature that are foundational to the concept of shared space. I will also cover the existing shared space literature and relevant research on nonmotorized users, pedestrians and bicycle riders, as well as the current gaps in the literature related to shared space and bicycle use.

\section{Linking theory to research}

There are several underlying models of behavior that the literature links to the underlying behavior observed and desired in shared space projects. According to Hammond (2013),

"The principals [sic] of shared space utilizes socio-cognitive psychological theory and models of behaviour, including risk homeostasis, arousal theory and environmental load and there is a wider need to understand how different road users might engage with shared space design" $(\mathrm{p} 79)$.

\section{- Cycling requirements for traffic infrastructure}

Forsyth \& Krizek (2011) wrote one of the only articles directly addressing the potentially unique requirements of cyclists as compared to other road users. The authors propose that cyclists have different urban design needs due to the different requirements cyclists have 
with respect to their "speed, height, exposure, lighting requirements and parking needs" (p532). The authors conclude with a call for more research on the types of cyclists and perhaps more research (authors appear torn) on the design requirements for cyclists. A shared space project is both a form of urban design as well as a type of transportation infrastructure; Forsyth \& Krizek's (2011) study illustrates that cyclists therefore may perceive and navigate shared space infrastructure differently than other modes.

The following concepts are considered some of the underlying principles of shared space design:

\section{- Risk homeostasis}

The concept of risk homeostasis (risk compensation) states that "...people at any moment of time compare the amount of risk they perceive with their target level of risk and will adjust their behaviour in an attempt to eliminate any discrepancies between the two" (Wilde 1998, p90). Numerous studies back up this theory, including observations of driver behavior with antilock brakes (Grant 1993 via Wilde 1998), with street lighting (Björnskau 1996 via Wilde 1998) and with airbags (Peterson 1995 via Wilde 1998). In each instance, a change toward a safer environment, such as installation of streetlights, resulted instead in faster vehicle speeds and less attentive drivers. However, there are researchers who doubt that there is a risk homeostasis effect. For instance, Evans (2004) states, "In my own view it has for far too long been much ado about nothing” (p351, his emphasis). 
Streff \& Geller's (1988) experimental study on risk compensation involved a go-kart track and seat belt use; they found only partial confirmation of the theory. Drivers going from unbuckled to buckled (riskier to safer) improved lap times faster than the drivers in the reverse situation. They did not find, though, that drivers who went from safer to riskier had slower times. A follow up questionnaire of the participants found that the group who went from the safer to riskier situation "reported feeling significantly less safe", and the participants who went from riskier to safer during the experiment felt safer with the seat belts.

In line with risk compensation is passive safety. This concept (proposed by Haddon in the 1950's) states that drivers cannot be stopped from doing risky driving behaviors, so the roadways and vehicles must be designed to prevent crashes from happening instead (Dumbaugh, 2005). If a crash does happen, the consequences will be minimized; the driver will walk away uninjured. The passive approach to safety appears to have done all it can, and we now need to look at changing actual behavior. The passive safety approach has benefited motorists while not taking vulnerable users into account.

These two concepts are interrelated by the shared space idea that making an intersection appear less safe (decreasing its passive safety features, for instance) will decrease risky behavior by road users. However, a downside to making a road feel less safe is that the perception of risk increases among the site's users and may increase their concern about the space. 


\section{- Arousal theory}

Arousal theory, also called the Yerkes-Dodson Law (from 1908 research), posits that there is a relationship between an individual's level of arousal and task performance. Thiffault and Bergeron (2003) write "[arousal] theory suggests that performance is poor when arousal is either weak or very strong” (p383). The classic example of this is the bored airline pilot: As Hanoch (2004) explains, when an individual's level of arousal is too low (drowsy, bored, etc.) his/her performance suffers. Similarly, when someone is overly aroused emotionally his or her task performance suffers as well.

The unpredictability of the shared space environment inserts novelty into the intersection. According to Thiffault and Bergeron (2003), "the first presentation of a stimulus, or the presence of a novel or incongruous stimulus in the environment, leads to increased arousal and a mobilization of attention" (p384). Once a driver, and presumably a cyclist, has seen this stimulus multiple times, the stimulus fades. But a change in the stimulus restores the improvement of the driver's mental arousal and his/her attention. The continuous unpredictability of the shared space intersection, hypothetically, should keep all users more mentally stimulated and alert.

\section{- Environmental load}

Moser (1988) states that:

[The] complexity and abundance of urban stimuli produce what has been called 'environmental overload' (Cohen, 1978). An individual's capacity to process 
information is limited and 'overload' occurs when the urban environment exceeds this limit (Korte, 1978). Subjects exposed to overstimulation tend consequently to neglect or ignore peripheral stimuli (Cohen and Lezak, 1977; and react more strongly to the dominant aspects of different situations to which they are exposed (p288).

Moser speculates that a stressful urban environment may either affect a user by a "narrowing and focusing of [his/her] attention" or lead to some form of behavior or travel modification like "avoidance reactions" where the user decides the environment is too stressful to handle (Moser, 1988, p288).

This theory relates to shared space because an intersection can, for instance, distract drivers enough that they do not notice pedestrians and/or cyclists due to the driver's narrowed attention $^{1}$. A goal of a shared space design is the removal of at least some of those potential distracters to enable a driver to devote more attention to the intersection and its users.

\section{Background, review, and 'case study' literature}

Most of the articles regarding shared space are actually background literature that discusses various existing projects as well as the background concepts and theories associated with it (Luca et al. 2012, Gerlach 2008, Hamilton-Baillie 2008, 2009, n.d., Hamilton-Baillie \& Jones n.d.). Additionally, the same showcase projects appear again and again in all types of literature (the Laweiplein, Drachten, Elwick Square, Poynton, etc.). Countries such as the

${ }^{1}$ See the Moonwalking Bear Awareness video (http://www.awarenesstest.co.uk/video/moonwalking-bear-awareness-test) for a demonstration of this effect. 
Netherlands, Germany, and England are home to the majority of shared space projects, but there is increasing international interest, and discussion in the literature, including in the United States, Australia, New Zealand, and Canada.

The majority of the general papers written about shared space are laudatory. There is an abundance of non-peer reviewed articles that promote this, as well as several peer-reviewed review articles that discuss the general concepts of shared space. More recently, however, there are some articles and reports which take a more critical or questioning stance about the concepts behind shared space (Methorst \& Gerlach 2007; Moody \& Melia 2013).

Luca, et al. (2012) discuss several case study/project examples, but only in a general sense and end with a series of "practical lessons learned": "The road tells the story; make room for people; the users have a say; details can make or break the design; better chaotic than pseudo-safe" (p59-61). Methorst and Gerlach (2007) review some existing projects in detail but also question many of the assumptions that shared space is grounded in, such as: 'dangerous is very safe' and 'road users are responsible for their own safety' (p15). They do emphasize that shared space is a flexible design philosophy, and "conclude that in all show cases objective traffic safety indeed has improved compared with the old situation" (p16). ${ }^{2}$ Gerlach's 2008 article is often cited and discusses a few projects which occur less frequently in the literature, such as Kevelaer's Roemonder square, and Bocholt's King Street. Another

\footnotetext{
${ }^{2}$ Emphasis in original article
} 
frequently cited report is by Quimby \& Castle (2006). This report was prepared for Transport of London and covers a variety of simplified street design techniques, in addition to shared space, and their pluses and minuses. It reviews several projects in the UK. It only mentions bicycles twice in the entire 51-page report.

Articles which review shared space research cover a variety of topics, such as public participation in the shared space development process (Pel 2012, Ronsdal 2010), pedestrian perceptions of shared space (Moody \& Melia 2013, Hammond 2013, Kaparias, et al. 2010) and drivers' perceptions of sharing space with pedestrians (Kaparias, et al. 2011). In their 2010 article, Kaparias, et al., summarize the general findings that other researchers have teased out about the perception of shared space:

The confidence of pedestrians does not rise immediately after the implementation of a shared space scheme, but is more likely to build up with time and experience, in a similar way as in an ice rink with skaters of different skills (Hamilton-Baillie, B., 2008; Jaredson S., 2002).

The full benefits of shared space are likely to be achieved when vehicle flows are relatively low, vehicle speeds are effectively controlled and there are features in the space that encourage pedestrian activity (e.g., appropriate selection of materials, street furniture and other design elements, such as vertical water jets, central bicycle parking, simple drainage details and monuments) (Reid, S. et al., 2009).

A certain discomfort towards shared space is expressed by elderly and disabled road users, as these seem to feel an increased threat from vehicles in such environments. This can be addressed by providing lines of tactile surfacing, colour contrasting, street furniture and regularly spaced lampposts, but more importantly through the 
introduction of a so-called "safe space" (Deichmann, J, 2008, p3).

\section{Existing research}

\section{Visually-impaired literature}

The existing shared space research concerning vulnerable users falls into two categories: cycling-related and other. The non-cycling literature is generally pedestrian-related with some research done via observations and/or surveys and interviews (Guide Dogs UK 2012, Parkin \& Smithies 2012, Norgate 2012). The primary concern that literature raises (both reports and articles) is the difficulty visually impaired and older adult users have in navigating shared space projects. The Guide Dogs UK research found that in shared space sites, visually-impaired users had difficulty discerning boundaries due to lack of curbs distinguishing road from sidewalk. The respondents in this work stated they found bicyclists most concerning due to their silence in travel. Several articles have suggested various techniques to improve the shared space mitigation to better assist visually impaired users, such as textured paving and the removal of bollards (Guide Dogs UK 2012). Parkin \& Smithies (2012) found that guideline paving, central delineators, and $30 \mathrm{~mm}$ slopes had best results for mobility impaired users. Their survey respondents included suggestions for sidewalks just for pedestrians, locating benches and other street furniture closer to buildings, and installing street lights on buildings instead of on lamp posts. 


\section{General pedestrian literature}

Kaparias, et al., have conducted more research with respect to shared space than any other researchers looking at drivers, pedestrians, and cyclists. In their 2013 article, they examine Exhibition Road in London before and after its redevelopment into a shared space. They note that at some crossings along Exhibition Road pedestrians actually wait longer to cross than pre-construction, but in other sections the pedestrians wait less time. In general, drivers' behavior seems "relatively unchanged to the before-situation despite the layout redevelopment, with the exception of the fact that less (sic) drivers now do not slow down and, subsequently, wait for pedestrians to clear" (p12). Their 2011 research surveyed drivers regarding pedestrians in shared space scenarios. The survey factors included "vehicular traffic (high-low), pedestrian density (high-low), presence of children and elderly (many-few), shared space size (big-small), level of lighting (bright-dark), vehicle size (big-small) and provision of street furniture (yes-no) (p1)." The survey found that the presence of many pedestrians unsettled drivers and made them less willing to share the street.

Edquist \& Corben's (2012) report reviews collision data from 18 shared space projects in the Netherlands and the UK. This Australian report gathered available pre- and postdevelopment collision data and found mixed results (p9). Some shared space projects have improved overall safety while two show a small increase. The majority of projects show no change in crash rates-but the crash numbers were already very rare. The data are not complete, and the authors note that, "... it is not yet established that Shared Spaces are safer 
than traditional road environments, it is also not established that they are any less safe. Thus Shared Spaces and similar models may well fill an important gap in the available palette of road designs. It is, however, important that new implementations continue to be evaluated" (p24).

Researchers recognize the increasing interest and have begun modeling shared space as well. Schönauer, et al. (2012) are creating a modeling tool for shared space projects including motor vehicles, pedestrians, and bicycles. They have chosen to create a simulation tool because of the growing interest in shared space:

A growing number of cities are interested in experimenting with shared space zones but are uncertain about safety issues and the effectiveness of the design. Although mature simulation tools exist for conventional road designs, no such tool is available for shared space designs because of the added degrees of freedom in movement and more-complex social interactions (p114).

Other researchers have surveyed pedestrians in shared space with respect to their feelings of safety and comfort. Hammond (2013) had several overarching themes come out of the discussions and on-street interviews. The positive themes addressed feelings of improved safety and increased social interaction, as well as appreciation for the new paving materials and aesthetic improvements. The negative themes that emerged criticized the curbs, the "ambiguity and confusion" the space often caused due to more random pedestrian movements, and that motor vehicles can still inhibit social interactions. However, there were concerns about sharing the space with motor vehicles — and the older the respondents 
were the greater their concern (but this difference was not found to be significant). Overall, $74 \%$ of the respondents noted that they preferred the new space to the older design, and $57 \%$ "felt that they were able to stop and socialize within the shared space street" (p92).

Moody and Melia (2013) did video observations and on-street interviews of pedestrians at Elwick Square (in part replicating the MVA Consultancy study in 2010) and found that, "Of the people interviewed, $90 \%$ had experienced the previous scheme and $80 \%$ claimed they felt safer in the previous layout" (p7).

\section{Cyclist literature}

Bicyclists are an understudied user group. There is one study to date that specifically examines this dissertation's topic (Kaparias, et al. 2013), and the authors themselves note in their conclusion that this is an under-researched topic. The Kaparias, et al, 2013 study observed how cyclists used Exhibition Road in London pre- and post-installation. Their results indicate that current riding speed is slower than pre-installation, which may indicate that "the increased level of sharing introduced by the redevelopment has brought about a reduction in cyclist speeds" (p7), and the majority of survey respondents felt the new design was either 'safe' or 'neutral' (p9)

The 2007 Noordelijke Hogeschool Leeuwarden (NHL) report's Evaluation of the Laweiplein lumps cyclists and pedestrians into the same section and evaluates how users maneuver through the space. The Laweiplein experienced a decrease in crash rates after 
reconstruction of the intersection showing dramatic decreases in number of crashes (injury accidents, serious injuries, dead, minor injuries, damage only). The researchers also found that some cyclists crossed at the marked crosswalks and some shared the lanes with drivers. They also found an increased use of hand signals by cyclists. Their survey found that the perception of traffic safety among drivers and cyclists has decreased since the implementation. Pedestrian perception is relatively unchanged. The perception of personal safety has improved among all groups surveyed, including the elderly. 


\section{Research methods in existing literature}

\section{Observation literature}

Most of the studies cited observed nonmotorized users by video but a few projects observed and counted in-person. There was an enormous range in the hours of observations as well as number of sites observed. Table 1 lists the observational details of several relevant nonmotorized transportation studies. These studies formed the basis for this research's video observation methodology by showing the minimum and maximum ranges of variables such as number of observed cyclists, number of sites, range of observational hours, and range of observational days.

Table 1: Study observation numbers

\begin{tabular}{|c|c|c|c|c|c|c|}
\hline Authors & $\begin{array}{c}\text { Observed } \\
\text { user } \\
\text { group }\end{array}$ & $\begin{array}{c}\text { Observation } \\
\text { locations }\end{array}$ & $\begin{array}{c}\# \\
\text { observed }\end{array}$ & $\begin{array}{c}\text { Time } \\
\text { observed }\end{array}$ & $\begin{array}{c}\text { Total } \\
\text { observed } \\
\text { time }\end{array}$ & $\begin{array}{c}\text { Total \# } \\
\text { sites }\end{array}$ \\
\hline $\begin{array}{l}\text { Carter et } \\
\text { al. (2007) }\end{array}$ & Cyclists & $\begin{array}{l}\text { United } \\
\text { States, } \\
\text { various }\end{array}$ & $\begin{array}{c}3831 \\
\text { cyclists }\end{array}$ & $1.75 \mathrm{hr} / \mathrm{site}$ & $\begin{array}{c}129 \\
\text { hours }\end{array}$ & $\begin{array}{c}67 \\
\text { intersectio } \\
\text { ns }\end{array}$ \\
\hline $\begin{array}{l}\text { Garrard } \\
\text { et al. } \\
(2008)\end{array}$ & Cyclists & $\begin{array}{l}\text { Melbourne, } \\
\text { Australia }\end{array}$ & $\begin{array}{c}\text { 6,589 } \\
\text { cyclists }\end{array}$ & $\begin{array}{l}\text { 4hr AM, } \\
\text { 2hr PM }\end{array}$ & $\begin{array}{c}660 \\
\text { hours }\end{array}$ & 15 sites \\
\hline $\begin{array}{l}\text { Johnson } \\
\text { et al. } \\
(2010)\end{array}$ & Cyclists & $\begin{array}{c}\text { Melbourne, } \\
\text { Australia }\end{array}$ & $\begin{array}{c}13 \\
\text { cyclists }\end{array}$ & & $\begin{array}{c}127 \\
\text { hours }\end{array}$ & \\
\hline $\begin{array}{l}\text { Kaparias } \\
\text { et al. } \\
(2013)^{*}\end{array}$ & Cyclists & $\begin{array}{l}\text { London, } \\
\text { England }\end{array}$ & $\begin{array}{c}\text { Ave } 30.5 \\
\text { (pre) } \\
54.3 \\
\text { (post) }\end{array}$ & $\begin{array}{l}8 \mathrm{am}-6 \mathrm{pm} \\
\text { (5 days) }\end{array}$ & $\begin{array}{c}20 \text { hrs } \\
\text { pre, } 30 \\
\text { hrs post }\end{array}$ & 1 \\
\hline Moody & Pedestrians & Ashford, & 281 peds & & & \\
\hline
\end{tabular}




\begin{tabular}{|c|c|c|c|c|c|c|}
\hline $\begin{array}{l}\text { \& Melia } \\
(2013) *\end{array}$ & & England & & & & \\
\hline $\begin{array}{l}\text { Osberg } \\
\text { et al. } \\
\text { (1998) }\end{array}$ & Cyclists & $\begin{array}{c}\text { Paris, France } \\
\text { Boston, } \\
\text { Mass. }\end{array}$ & $\begin{array}{c}5808 \\
\text { cyclists }\end{array}$ & & $181 \mathrm{hrs}$ & 17 Streets \\
\hline $\begin{array}{l}\text { Parkin \& } \\
\text { Smithies } \\
(2012)\end{array}$ & Pedestrians & $\begin{array}{l}\text { Bolton, } \\
\text { England }\end{array}$ & 5 peds & & & \\
\hline $\begin{array}{l}\text { Sakshaug } \\
(2010)\end{array}$ & Cyclists & $\begin{array}{l}\text { Lund, } \\
\text { Sweden }\end{array}$ & & $9 \mathrm{hr} / \mathrm{day}$ & 24 hours & \\
\hline $\begin{array}{l}\text { Sisiopiku, } \\
\text { \& Akin. } \\
(2003)\end{array}$ & Pedestrians & $\begin{array}{c}\text { East Lansing, } \\
\text { Michigan }\end{array}$ & & $30 \mathrm{~min}$ & $\begin{array}{l}16-18 \\
\text { hours }\end{array}$ & \\
\hline $\begin{array}{l}\text { Zhuang } \\
\& \mathrm{Wu} \\
(2012)\end{array}$ & Pedestrians & $\begin{array}{l}\text { Hang Zhou, } \\
\text { China }\end{array}$ & 254 peds & 6 hours & 12 hours & \\
\hline $\begin{array}{l}\text { Zook, et } \\
\text { al. (2012) }\end{array}$ & Pedestrians & $\begin{array}{l}\text { Atlanta, } \\
\text { Georgia }\end{array}$ & & $30 \mathrm{~min}$ & 45 hours & 5 sites \\
\hline
\end{tabular}

(* Indicates shared space studies)

\section{Analysis in existing literature}

The NHL report evaluating the Laweiplein produced traffic flow diagrams (Figure 1) for cyclists and pedestrians; the 2013 Moody \& Melia article mapped the paths pedestrians took through their Elwick Square study site. 

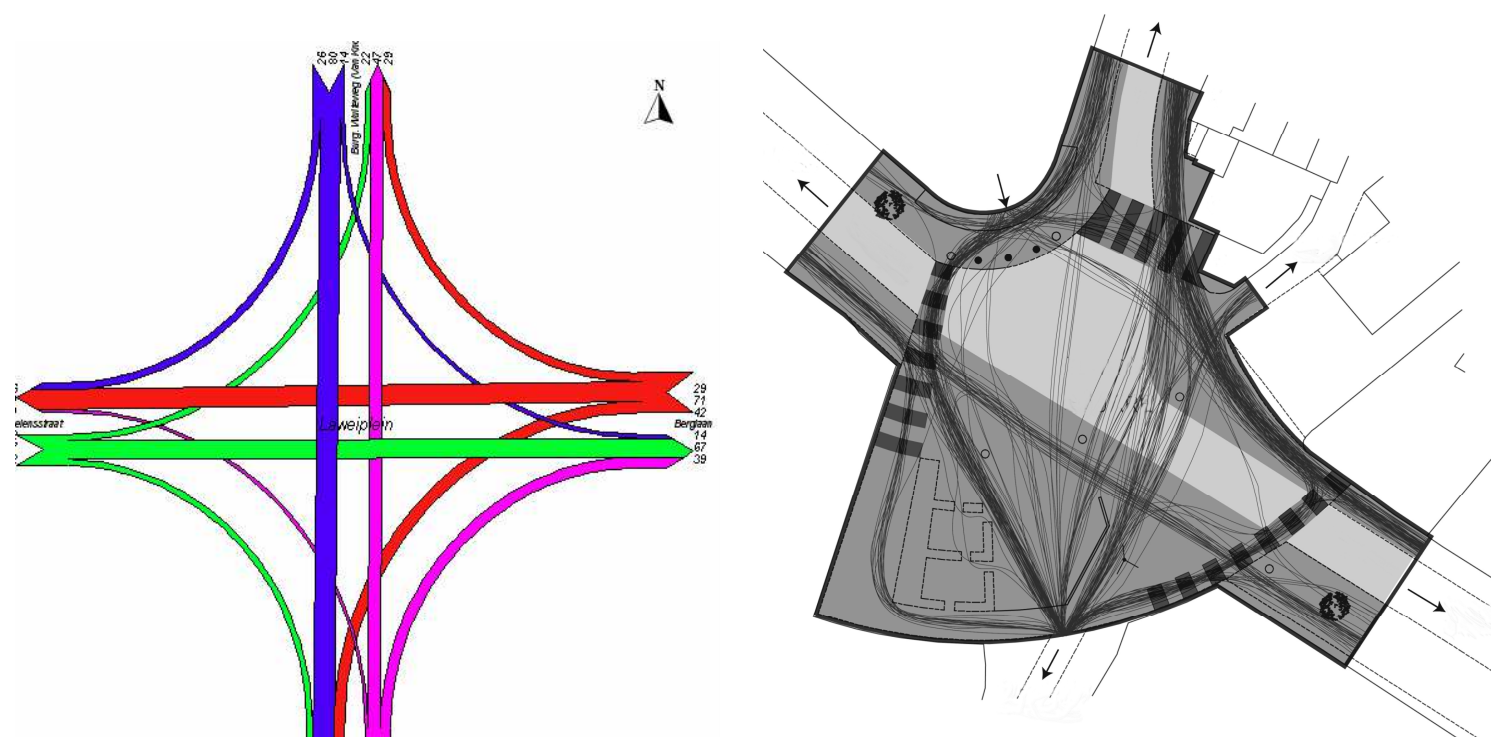

Figure 1: Example traffic flow diagram for cyclists (NHL, p33) and pedestrian paths (Moody \& Melia, p6)

Kaparias, I. et al. (2013) looked at how cyclists use Exhibition Road in London-a relatively new shared space scheme. The authors used video observations from pre-implementation (20 hours) and post-implementation (30 hours) as well as measured the speed of cyclists preand post-implementation. The speed was used to "give an indication on whether the reduced flow or the increased interaction has had a greater impact" (p6). It was also used to distinguish between more frequent/experienced cyclists and other types (e.g., regular commuters vs. recreational). They also looked at how many cyclists chose to "cycle outside the vehicle zone"; the "number of contra-flow cyclists"; the "number of dismounting cyclists"; the "group behaviour of cyclists"; and the "number of cyclists using shared bikes" (p6). They found an increase in the number of cyclists riding through the site after project implementation, an increase in people riding side by side, and an increase in people riding 
against the flow of traffic. They state, "From a cyclist perception point of view, ... generally positive effects of the redevelopment seem to be identified in the pavement surface, in the provision of bicycle facilities, in the perceived ease of movement and in the perceived safety. Clarity, however, seems to be an issue potentially needing further attention for cyclists" (p11).

The existing study (Moody \& Melia, 2013) that most closely resembled the objectives of this project, an observation of paths taken by pedestrians across Elwick Square, did no actual analysis. Venturing further afield, an analysis of the movement patterns of three species of turtles in Illinois has applicability (Beaudry et al. 2008). Those researchers measured the paths various turtle species took by tracing back thread spooled from bobbins taped to their backs. The starting assumption was that turtles traveled in straight lines; actual paths taken were then mapped, digitized, and the actual distance taken from the predetermined straight line's origin and destination calculated (they called this the "the $\mathrm{x}, \mathrm{y}$ residual") (Beaudry et al., p2552). The thread paths were also sampled regularly along their lengths and the " $75^{\text {th }}$ and $95^{\text {th }}$ percentiles of the positional residuals were identified, and generalized curves were fitted to these values" (Beaudry et al., p2552). 

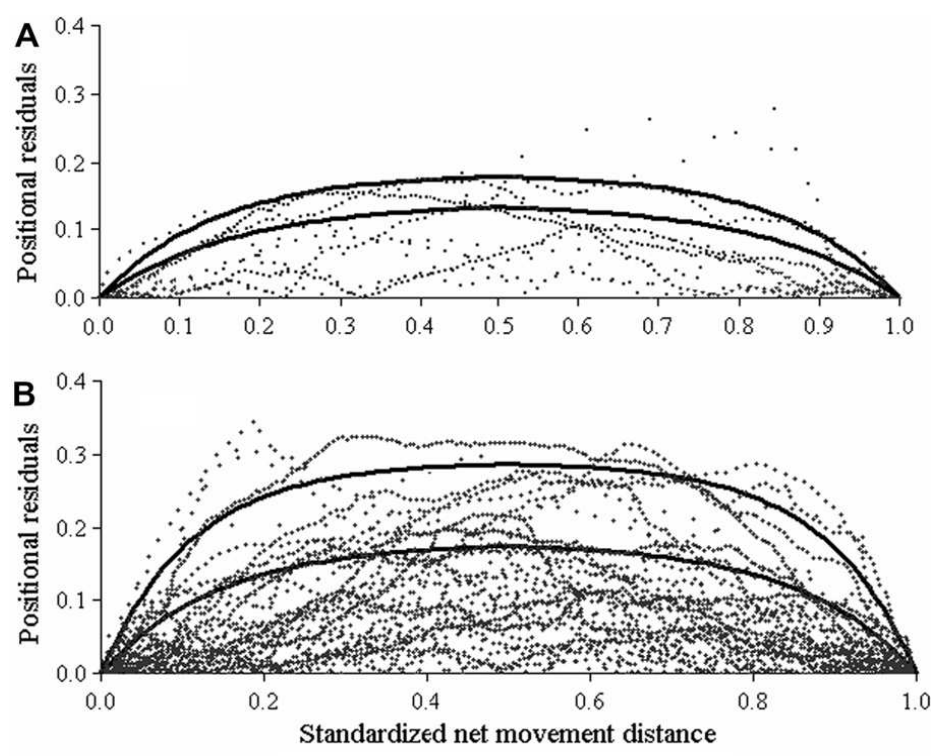

Figure 2: Turtle path distances off straight lines

\section{Gaps and summary of relevant literature}

There is little work done on examining the actual routes cyclists take at the scale of an intersection or section roadway. Of the articles, which discuss research on shared space infrastructure, only one specifically examines how cyclists use and perceive the redesigned spaces. The rest of the articles examine either how pedestrians, including visually impaired and older adults, navigate or perceive shared space or how drivers navigate or perceive shared space. While general discussion about shared space talks about making travel through the sites safer for 'vulnerable users', the literature only focuses on one form of vulnerable user - the pedestrian.

Kaparias et al. (2013) note the void in the literature saying:

While the present study has thrown some light into the under-explored topic of cyclist behaviour and perception towards street designs with elements of shared 
space, research in this direction continues. It is important to extend the scale of the study to other sites so as to be able to extract more generic conclusions and investigate how cyclist behaviour and perceptions vary with different conclusions and extents of shared space features. In particular, it would be interesting to introduce a cultural dimension to the analysis, and investigate how the behaviour and perceptions change between different cities and countries. This will form a solid basis towards the overall goal of ensuring that the needs and peculiarities of all road users, including cyclists, are fully addressed in new designs (p10-11).

Beyond the 2013 Kaparias et al., work, there are no existing studies that examine bicycle rider behavior in shared space intersections. There are many studies that look at intersectionscale interactions and perceptions — but they only look at pedestrians. There also are many studies that examine a cyclist's route choice via survey and/or GPS, which is a larger scale than appropriate for this project.

This project will further the research on shared space and bicyclists as well as examine these users in a country beyond the Netherlands thus adding more cultural breadth as well as other forms of the design that Kaparias et al., note are missing and relevant.

The existing vulnerable user research focuses primarily on pedestrians, their perceptions and experiences in shared space projects, and has some conflicting findings. In England, several authors focus on the concerns of the visually-impaired. Parkins \& Smithies (2012) learned that visually-impaired users prefer to navigate shared sites closer to building edges which keeps them away from traffic, and they and Guide Dogs UK (2012), offer suggestions for mitigation which include textured paving, street furniture closer to buildings, and bollard 
removal.

When looking at general pedestrian use, Kaparias et al., (2011) found that surveyed drivers felt less inclined to share the space when faced with large numbers of pedestrians, but Endquist \& Corbin's 2012 paper showed that the majority of shared space projects did not experience an increase in crash rates. Hammond (2013) surveyed pedestrians and found that many felt safer in the new spaces but disliked the confusion the spaces engendered. In contrast, Moody \& Melia (2013) found the vast majority of their respondents felt less safe in the new spaces.

Kaparias et al. $(2011,2013)$ were the only authors to observe and survey bicycle riders. The majority of survey respondents felt the new shared design was safer, and post-

implementation observations found an increase in the number of cyclists riding through but a decrease in their riding speed. There was also an increase in people riding side by side as well as people riding against the flow. The NHL (2007) report looked at all vulnerable users in one group and found a decrease in crash rates but a decrease in the perception of safety by cyclists (but not pedestrians).

\section{Contributions to shared space literature}

My research builds primarily upon the literature that looked at the nonmotorized use of shared space projects. Given that intersections are typically the most dangerous segment of a cyclist's ride, it makes sense to look more closely at the movements and behaviors that happen in those spaces. My work is unique in first, analyzing bicycle travel exclusively at the 
intersection level of analysis, and second, in the variables collected and analyzed with respect to those cycling paths through the intersections. There is an understandable focus in the literature on the safety of these spaces; the concept is new and it unsettles many people. I do not look directly at the safety of cyclists riding through shared space intersections. Instead, my research takes a more site-specific approach; my observations and analyses are more similar to a post-occupancy evaluation in that I look at how cyclists use the sites as well as how elements may or may not influence that use.

The current collection of literature is small and somewhat narrowly focused. As Kaparias et al. (2013) said though, "It is important to extend the scale of the study to other sites so as to be able to extract more generic conclusions and investigate how cyclist behavior and perceptions vary with different conclusions and extents of shared space features....This will form a solid basis towards the overall goal of ensuring that the needs and peculiarities of all road users, including cyclists, are fully addressed in new designs" (p10-11). 


\section{CHAPTER III}

\section{METHODS}

This chapter will first consider how each method related to answering the research questions and related hypotheses. I then discuss each of the six study sites, their locations, site designs, and any relevant elements on or surrounding the study sites themselves. A detailed explanation of the collected variables, units of analysis, and data collection procedures for both video observations and online surveys will then follow. This chapter will conclude with discussion on both methods' limitations as well as any limitations with the collected variables.

This study examined, through video observation and online surveys, the path choices cyclists made when traveling through three selected shared space intersections as well as their perceptions of the space. This study focused on intersections and squares exclusively for this research given the importance intersection design plays in the safety of bicyclists (Carter et al. 2007, Räsänen et al. 1998, Reynolds et al. 2009, Chaurand et al. 2012, Johnson et al. 2010). The study sites, discussed in-depth below, represent a range of design detail and complexity as well as vehicular traffic.

\section{Research questions and hypotheses}

This is mixed methods research. The research questions listed below in Table 2 designate which method, video or survey, addressed each research question. Some questions could 
only be answered by surveys, and others could only be answered by observation. Table 2 elaborates on how each method was used to answer each research question.

Table 2: Questions addressed by methods

\begin{tabular}{|c|c|c|}
\hline $\begin{array}{c}\text { General research } \\
\text { questions }\end{array}$ & Video observations & Online surveys \\
\hline $\begin{array}{l}\text { 1a. What perceptions of } \\
\text { shared space intersections } \\
\text { do cyclists have? }\end{array}$ & & $\begin{array}{l}\text { Survey questions asked } \\
\text { cyclists what their perceptions } \\
\text { are for study sites and control } \\
\text { sites. }\end{array}$ \\
\hline $\begin{array}{l}\text { 1b. Do cyclists perceive } \\
\text { better motorist behavior in } \\
\text { the shared space } \\
\text { intersections? }\end{array}$ & & $\begin{array}{l}\text { Survey questions asked } \\
\text { cyclists what their perceptions } \\
\text { are for study sites and control } \\
\text { sites. }\end{array}$ \\
\hline $\begin{array}{l}\text { 2. How do cyclists actually } \\
\text { maneuver through a shared } \\
\text { space intersection? }\end{array}$ & $\begin{array}{l}\text { Video observations and } \\
\text { analysis tracked cyclist } \\
\text { paths through } \\
\text { intersections. }\end{array}$ & $\begin{array}{l}\text { Survey asked cyclists to } \\
\text { indicate which paths they } \\
\text { choose. May be more } \\
\text { perceptual than accurate, } \\
\text { though. }\end{array}$ \\
\hline $\begin{array}{l}\text { 3. How would cyclists } \\
\text { prefer to ride through the } \\
\text { observed shared space } \\
\text { intersections? }\end{array}$ & & $\begin{array}{l}\text { Survey asked cyclists to } \\
\text { indicate which paths they } \\
\text { choose, and which routes } \\
\text { they'd prefer to actually take. }\end{array}$ \\
\hline $\begin{array}{l}\text { 4a. Does the shared space } \\
\text { design influence bicyclist } \\
\text { path and/or choice? }\end{array}$ & $\begin{array}{l}\text { Video observations were } \\
\text { used to show any } \\
\text { differences in how cyclists } \\
\text { ride through intersections }\end{array}$ & $\begin{array}{l}\text { Survey questions asked } \\
\text { cyclists who ride through } \\
\text { comparison intersections if } \\
\text { they avoid the shared space } \\
\text { intersections. }\end{array}$ \\
\hline $\begin{array}{l}\text { 4b. Which cyclists avoid } \\
\text { these shared space } \\
\text { intersections? }\end{array}$ & & $\begin{array}{l}\text { The survey had demographic } \\
\text { questions to indicate which } \\
\text { cyclists, if any, chose to avoid } \\
\text { the shared space intersections. }\end{array}$ \\
\hline
\end{tabular}


Prior research on pedestrians (Moody, \& Melia, 2013) found that respondents had generally negative perceptions regarding the Elwick Square intersection and felt less safe. This research hypothesized that cyclists who ride through the three shared space intersections (including Elwick Square) would also report feeling less safe compared to those who do not ride through the shared space intersections. However, the freedom of movement these spaces supposedly encourage in users may counter the feelings of insecurity that users report or have less impact than expected and create greater path variation compared to the control sites. This study's observations and surveys tried to tease out some of these influences.

Bicyclists, as discussed previously, have different transportation needs than motorists and pedestrians, yet also have the flexibility to operate similarly to a motorist or as a pedestrian. A cyclist can act as a pedestrian and ride on pedestrian-specific infrastructure. A cyclist can also act as a motorist and ride on driver-specific infrastructure. As a form of infrastructure which is touted to serve all user groups democratically, shared space designs supposedly create a positive riding environment for cyclists. I hypothesized, however, that there would be no significant differences in the paths cyclists chose through the shared space intersections when compared to the control intersections. No significant difference would show that shared space intersections might not have the liberating impact for vulnerable users that theory predicts. I believe the safety concerns and/or riding habits cyclists have when riding with motorized traffic influence their path choices more than the freedoms 
encouraged by shared space designs.

The survey of cyclists riding through both intersections was expected to reveal differences in either the demographics and/or the riding experience of the cyclists passing through the shared space intersections compared to the controls. I hypothesized that cyclists with less riding experience will choose, when possible, to avoid the ambiguity of the shared space intersections. In addition, I expected some variation in the different path and route choices made by different demographic groups. I hypothesized that the path variation differences will be greater in experienced/fearless cyclists compared to less experience/more nervous cyclists, and that some less experienced cyclists may choose to avoid the shared space intersections entirely.

The study sites represented a range in shared space complexity as well as use intensity. I hypothesized that there will be greater path variation in the more complex sites as compared to the simpler sites; however, that path variation may not carry over into the busier, yet complex, sites.

To summarize, this research addresses the following hypotheses:

1. $\mathrm{H}_{0}$ There will be no significant differences in the paths cyclists ride through the shared space intersections as compared to the control intersections.

$\mathrm{H}_{1} \quad$ There will be significant differences in the paths cyclists ride through the shared spaces intersections as compared to the control intersections.

2. $\mathrm{H}_{0} \quad$ Cyclists with less riding experience will choose, when possible, to avoid shared space intersections. 
$\mathrm{H}_{1} \quad$ Less experienced cyclists will not report avoiding the shared space intersections when possible.

3. $\mathrm{H}_{0} \quad$ There will be variation in the different path choices made by different demographic groups.

$\mathrm{H}_{1} \quad$ There will be no apparent path differences between different demographic groups.

4. $\mathrm{H}_{0} \quad$ Path variation differences will be greater between experienced/fearless cyclists compared to less experience/more nervous cyclists

$\mathrm{H}_{1} \quad$ There will be greater path variation or deviation observed between experienced or fearless versus less experienced more fearful cyclists.

5. $\mathrm{H}_{0} \quad$ There will be greater path variation in the more complex sites as compared to the simpler sites

$\mathrm{H}_{1} \quad$ There will be similar path variation in the whole range of site complexities.

\section{Study sites}

This research study was conducted in England. Shared space began in the Netherlands in the 1980s and has been disseminating across Europe since then; currently the majority of shared space projects are in the Netherlands and England. To date, there are no pure examples of shared space in the United States that meet the shared space definition and criteria. The literature regularly identifies, and discusses, several sites as showcase projects. Given various logistical, financial, and cultural/language issues, I focused only on existing shared space projects in England, specifically the showcase projects in Poynton, Ashford (Elwick Square), and Coventry. 


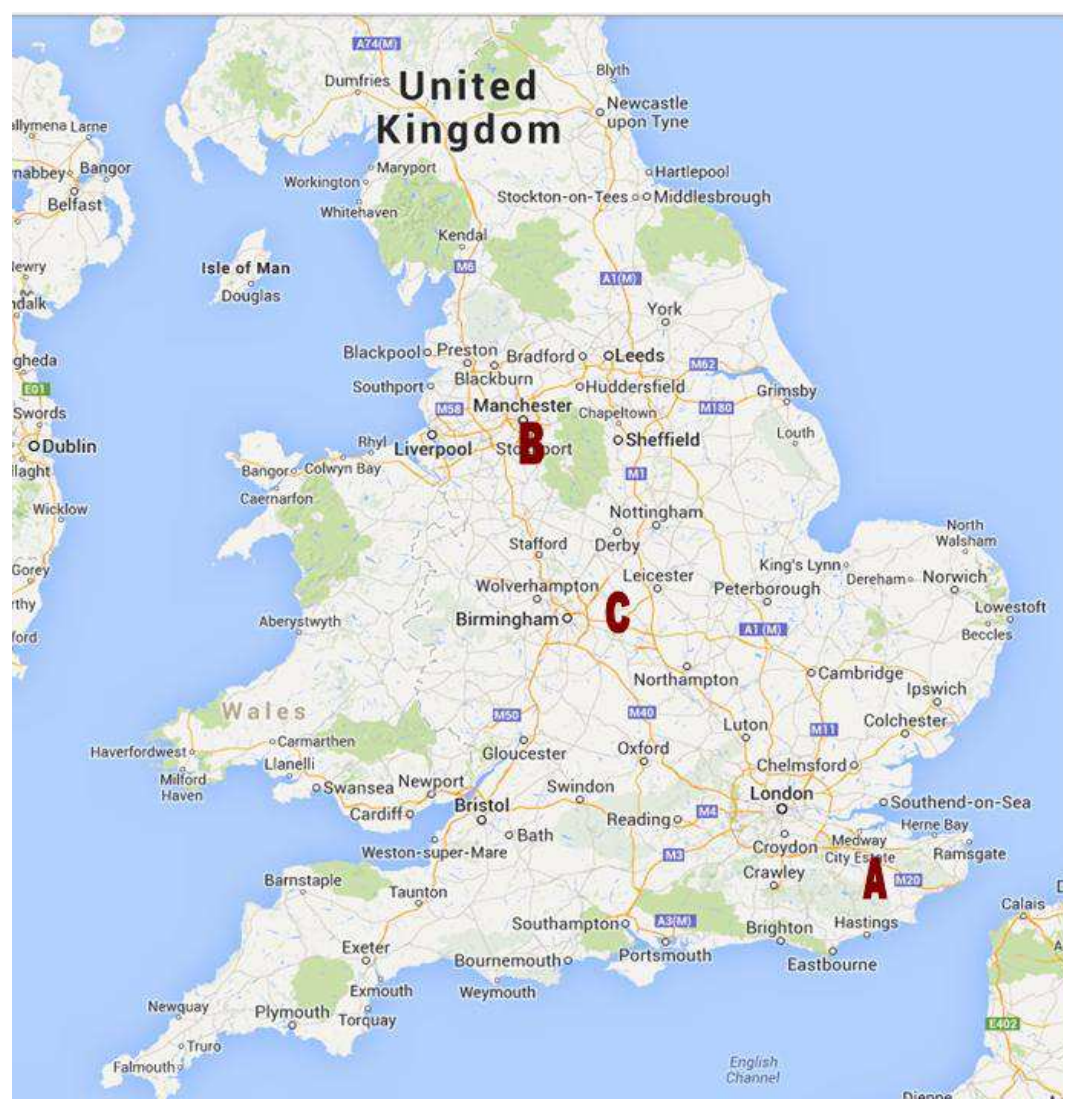

Figure 3: Study sites A: Ashford; B: Poynton; C: Coventry

I only selected intersections for this research; no straightaways were included in this project.

The primary reason is that the majority of cyclist collisions occur in intersections (Carter et al. 2007, Räsänen et al. 1998, Reynolds et al. 2009, Chaurand et al. 2012, Johnson et al. 2010). The site matrix (Appendix C) compares all 6 sites and their elements, modes present, and date of construction (where relevant). The selected shared space study sites, discussed in greater detail below, were chosen to represent a range of design detail and complexity as well as intensity of use.

Given the relative newness (and novelty) of shared space projects, there were very few 
projects available for actual observation. The selected projects were sites that typified or included many of the guiding principles of shared space as previously discussed as well as had a large number of cyclists who regularly rode through the sites. I selected the shared study sites following recommendations from experts in the field (Shared Space Institute/Pieter de Haan, Ben Hamilton-Baillie, and Sustrans/Finlay McNab) as well as the general literature that discussed various shared space projects. After settling on the three shared space study sites, I chose the three control sites after consultation with local bicycle shops, Google maps (bicycle layer), MapMyRide.com, cycle-route.com, everytrail.com and Strava Heat Maps (labs.strava.com/heatmap). I used these resources to identify intersections with a substantial number of cyclists. Each site's accompanying control site was selected to be as similar in surrounding uses as well as intensity. Given the limitations regarding both money and time, I chose control sites within reasonable distance from the shared sites so I could access them by either walking or transit. 


\section{Elwick Square, Ashford}

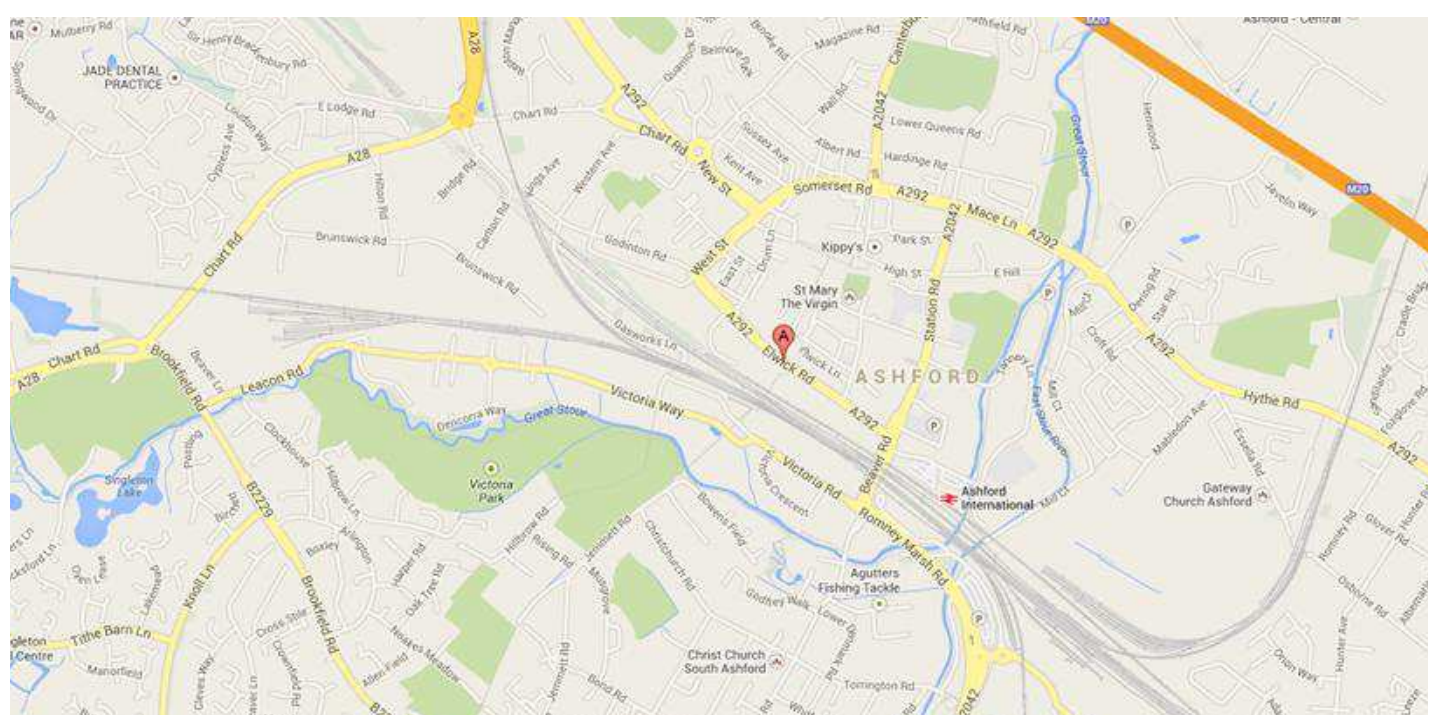

Figure 4: Elwick Square location

The first study site that met my shared space criteria was Elwick Square; in Ashton, Kent. I chose this project in Ashford as the most plaza-like of all the intersections. It was also the only shared site that had bicycle-specific infrastructure feeding directly into it. Elwick Square had also been previously studied by Moody, S., \& Melia, S. (2013), Hammond (2013), and the DfT (2010). These studies focused on pedestrians, not bicyclists.

Ashford International rail station was southeast of the site, a short walk from the site, and a shared use path that crossed the tracks led straight to the intersection. The surrounding uses are commercial but there is also a large area of vacant land adjacent to the site and rail line. The northwest corner, and location of closest bicycle rack, is a department store and entrance to the adjoining shopping mall. Heading north up Bank Street, past the department store, is a road leading to the town's central shopping district. 


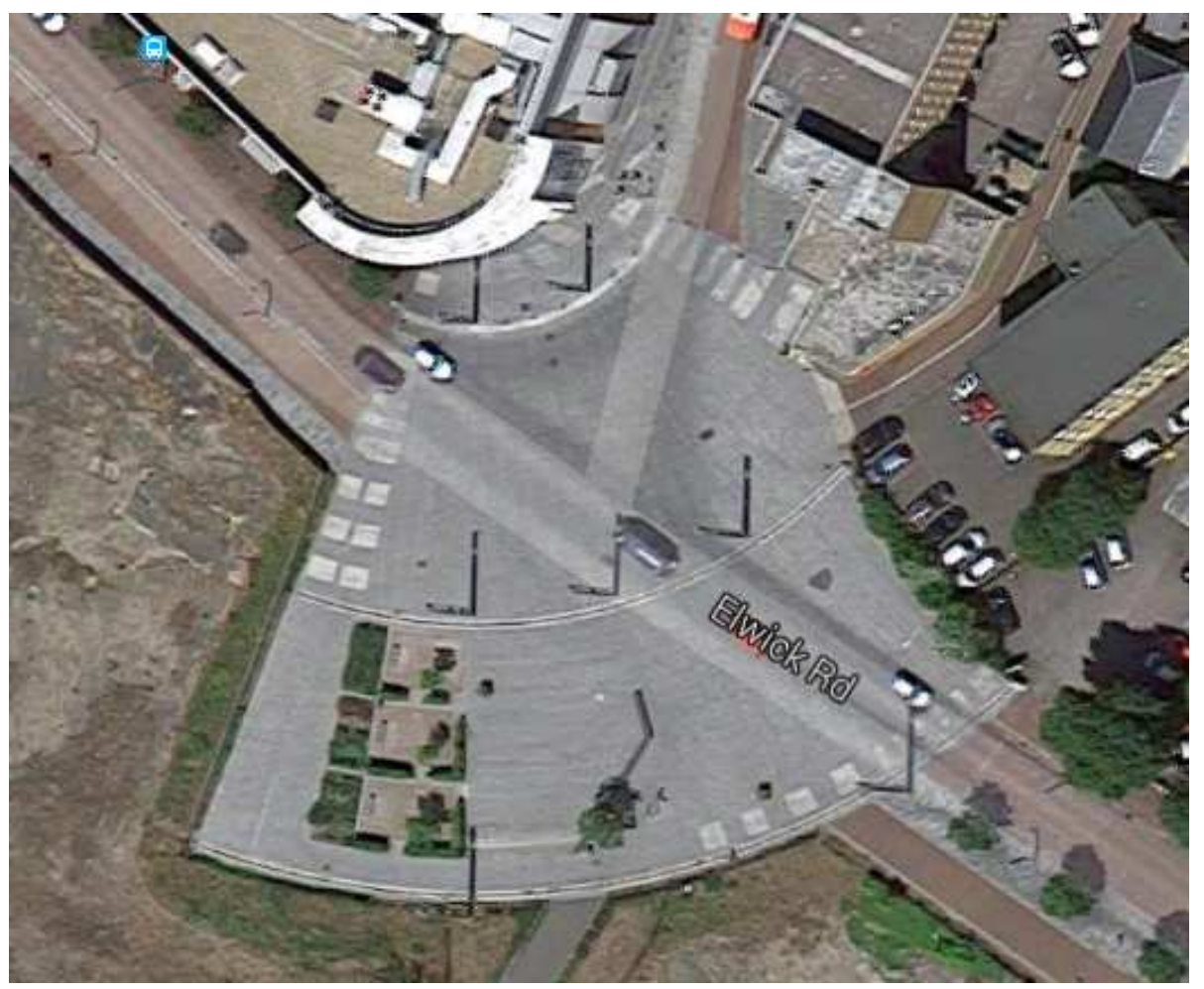

Figure 5: Elwick Square aerial (google.com 2015) 


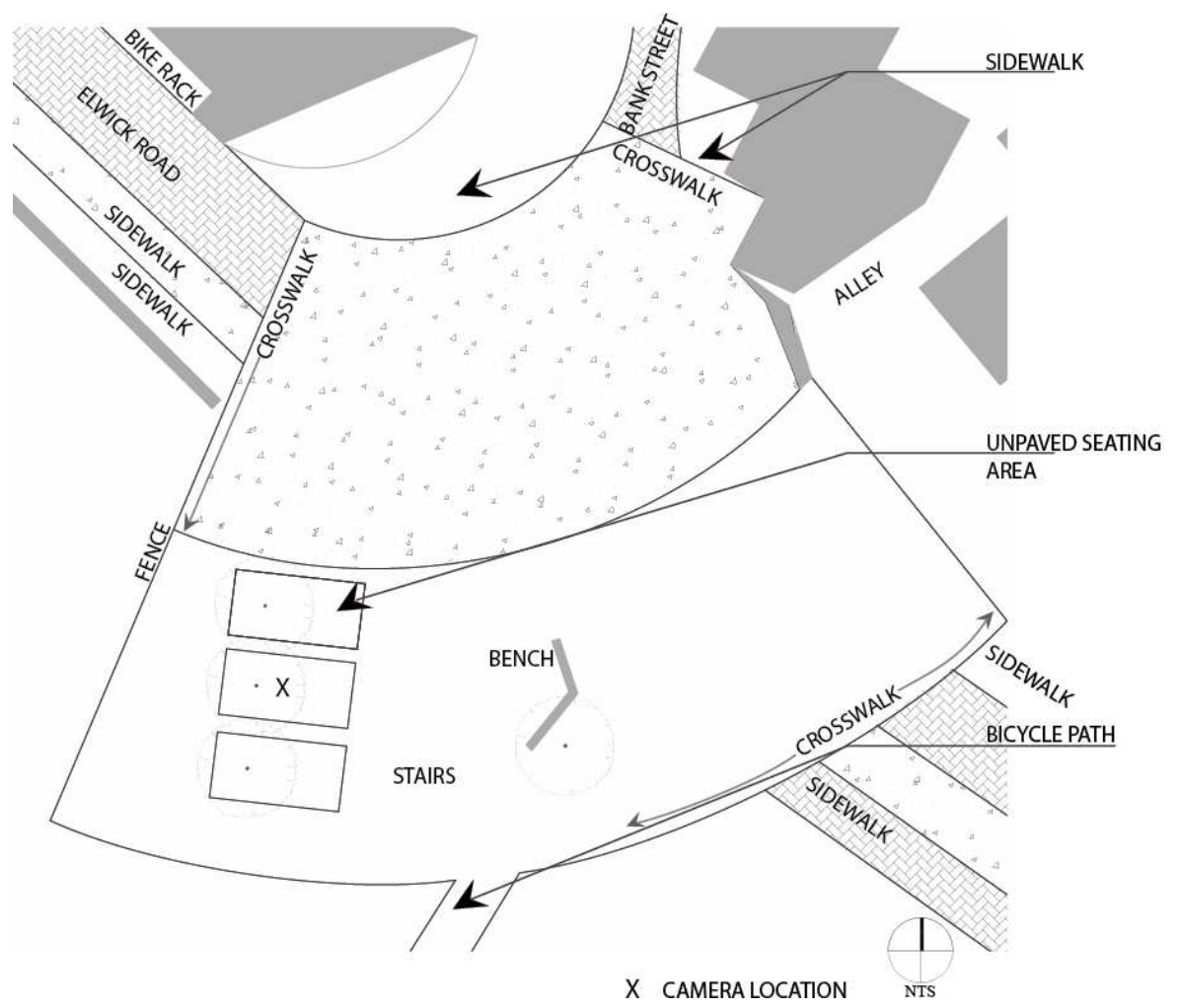

Figure 6: Elements within intersection

Figure 7 is a photo of Elwick Square taken in front of the bike path looking north towards the department store and commercial access street. It shows the grade changes as well as the bench that served as an inflection point for many riders. 


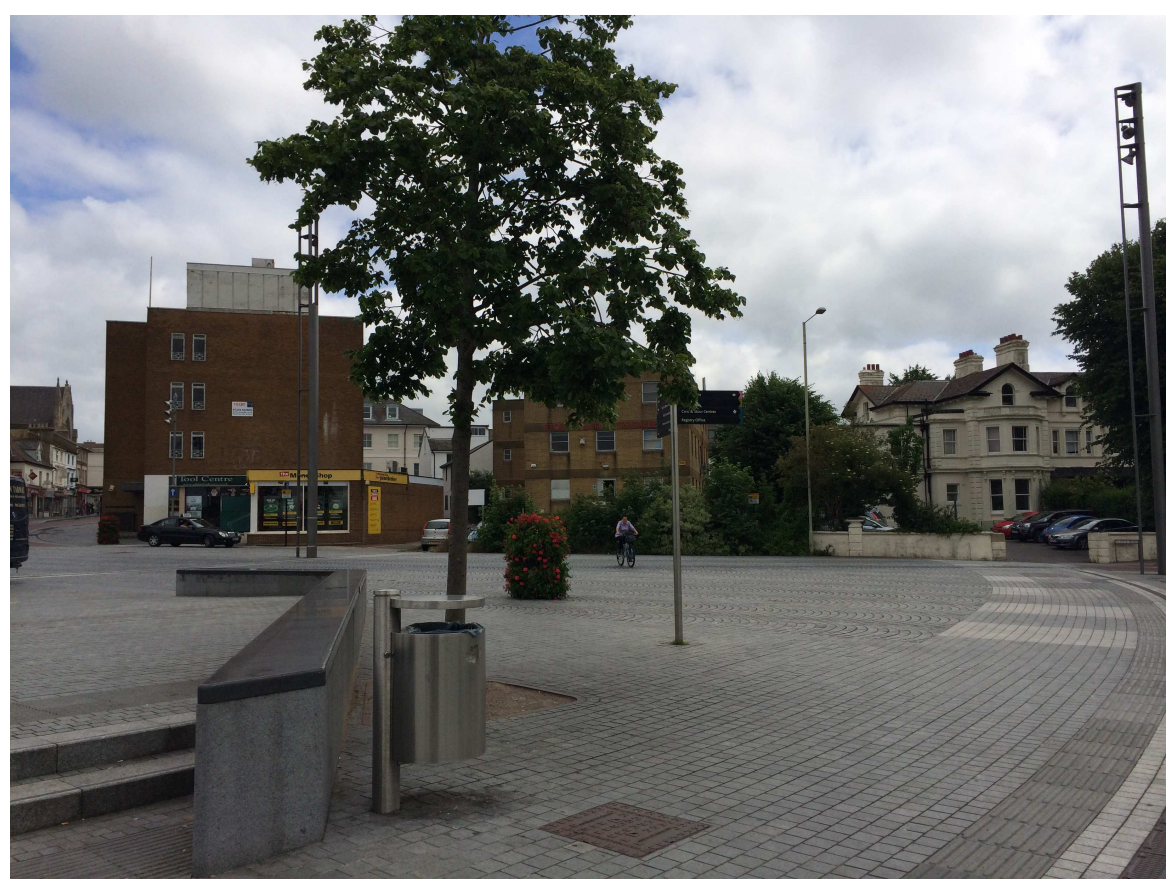

Figure 7: Elwick Square (note the stairs and scattered elements throughout the site.)

Figure 8 shows a crosswalk incorporated into the textured paving. It also shows the clearly defined sidewalk with its bollards. This was the only part of the intersection with bollards. 


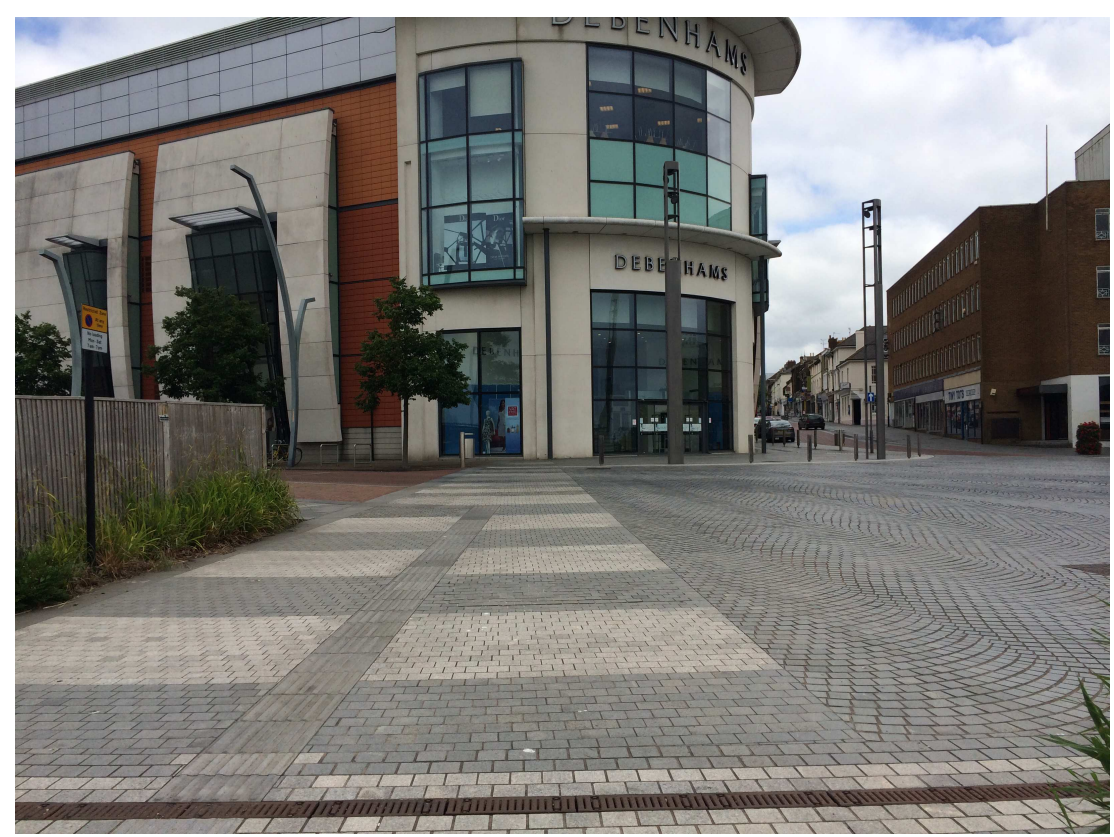

Figure 8: Elwick Square showing the marked crosswalk, sidewalk, bollards, and light posts

Figure 9 is another picture of the Elwick Square intersection that shows driving on both sides of the light posts. The photo shows where drivers often parked around the Square as well. 


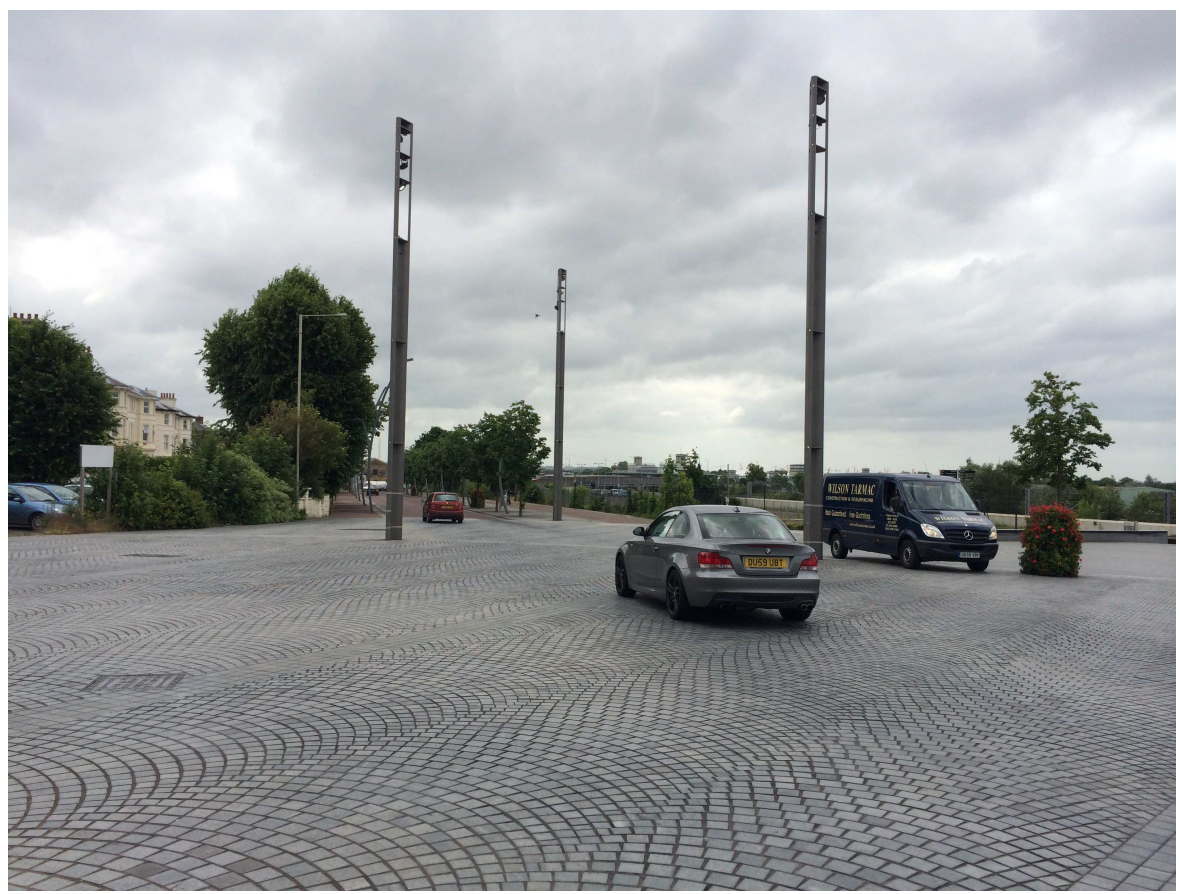

Figure 9: Elwick Square with the light posts, planters, and textured paving

Figure 10 shows the roadway leading to Elwick Square, and how the curb starts after the marked crosswalk. Interestingly, the sidewalk is wide and half concrete, half brick. This road leads to the train station and neighborhoods. 


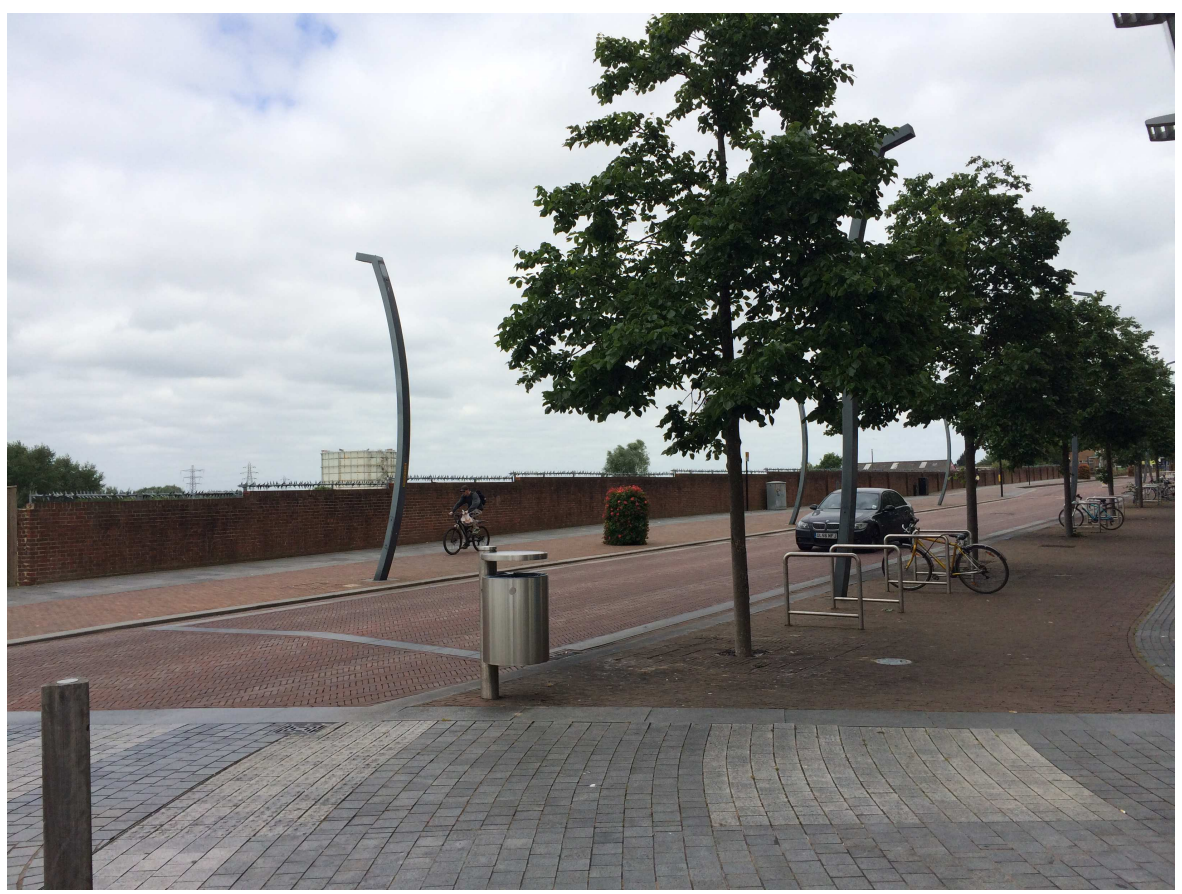

Figure 10: Elwick Road leading into Elwick Square

Wye (Ashford control intersection)

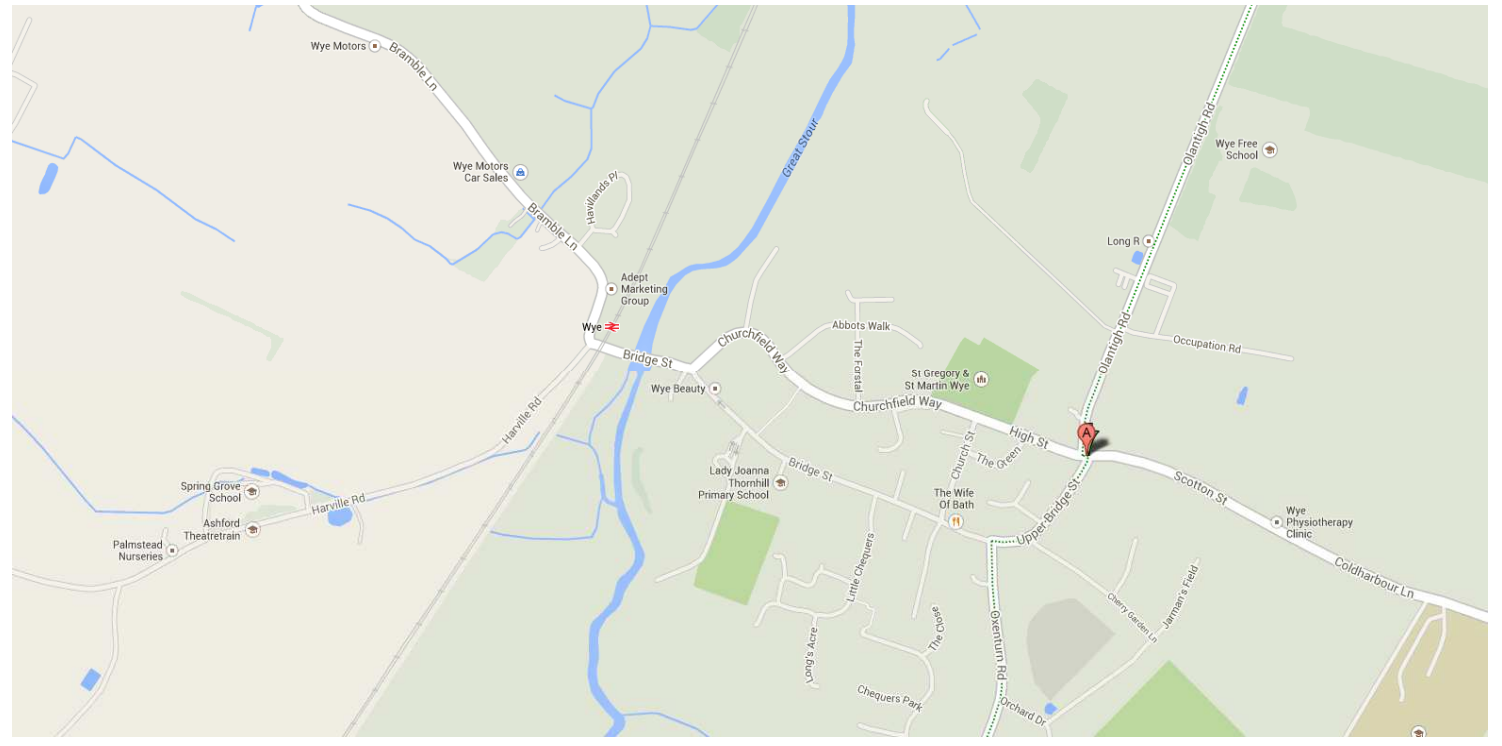

Figure 11: Wye, Ashford control location 


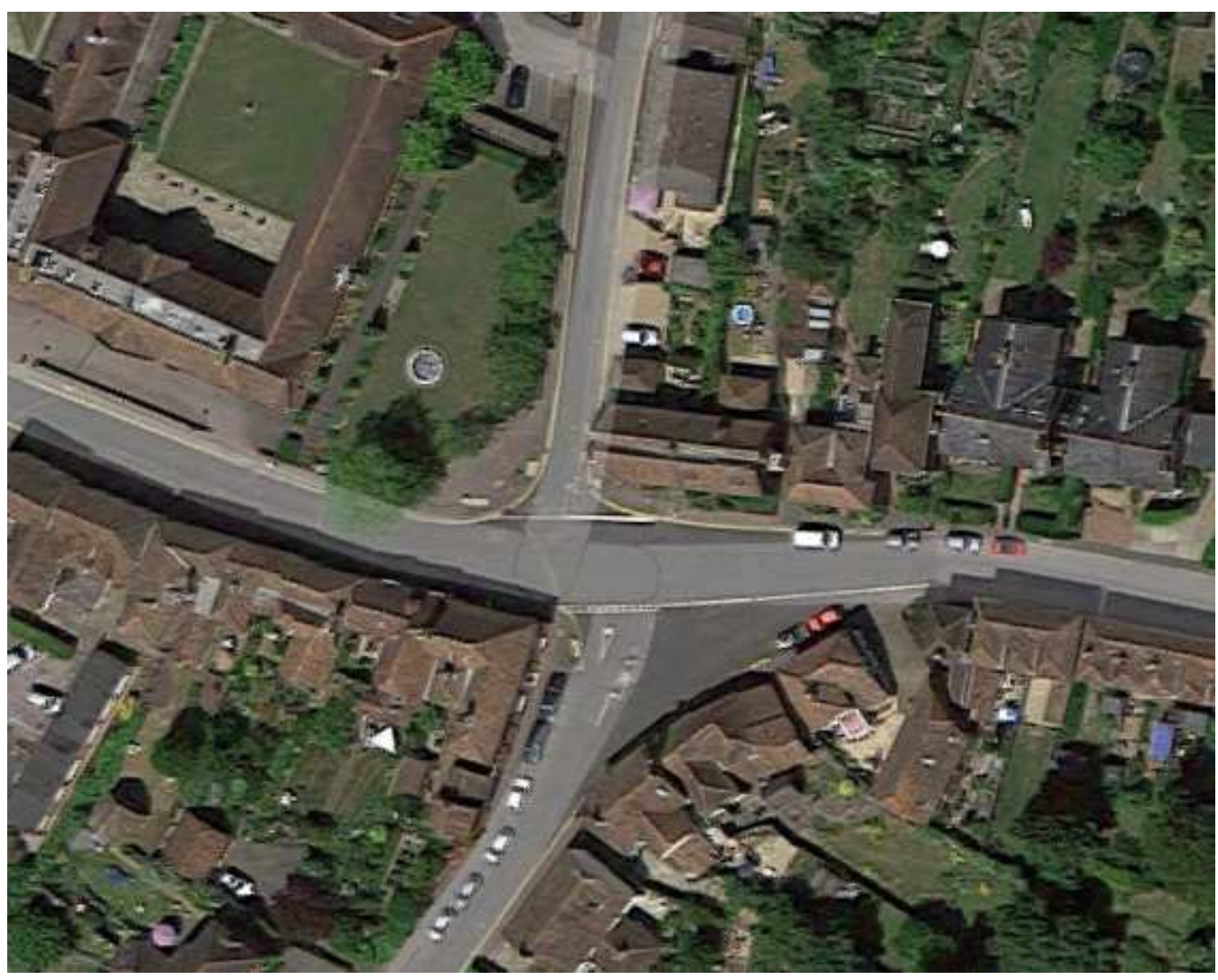

Figure 12: Wye aerial (google.com 2015) 


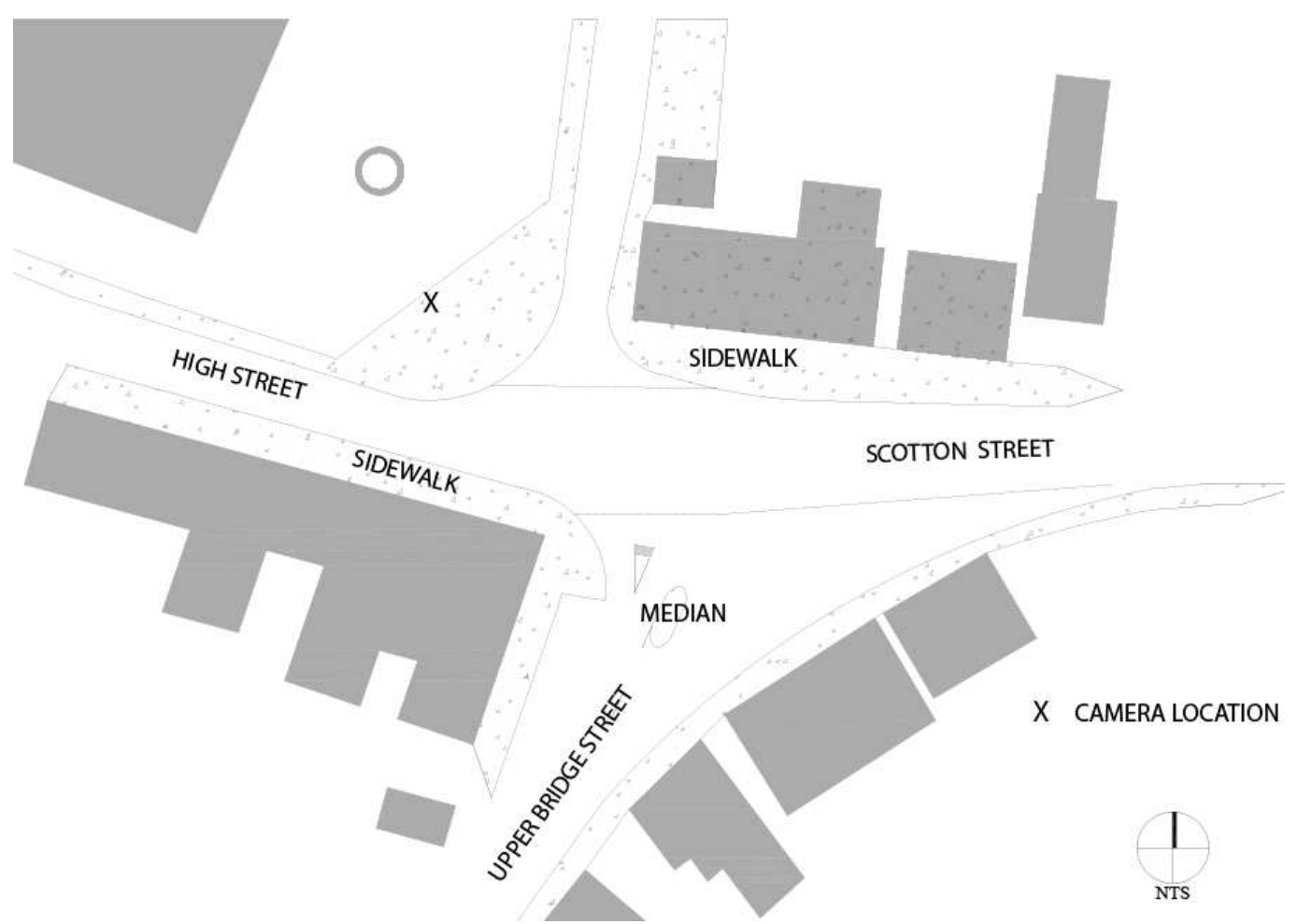

Figure 13: Elements within the Wye intersection

A short bus or train ride from Ashford, Wye is a quiet town with a population of approximately 2,300. The paired comparison site chosen in this town is at the intersection of Upper Bridge Street and Scotton Street in Wye, Kent. This site was chosen because it is a road in one of the national cycle networks. (See Appendix $C$ for site matrix.)

Figure 13 (above) and the following photos (Figures 16 and 17) show the various elements within the Wye control intersection. It was a relatively large, open, and irregularly shaped intersection bordered by narrow sidewalks immediately adjacent to row houses. The southern side of the intersection also had a small island with curb cuts. When looking for bicyclist crosswalk use where there were no painted crosswalks, curb cuts around the 
intersection and the median were used as a proxy for crosswalks. This intersection is just down the street from the village church, the primary bus stop, and its small commercial section. I set up my video camera on a broad stretch of pavement bordering a recentlyclosed branch of an agricultural college.

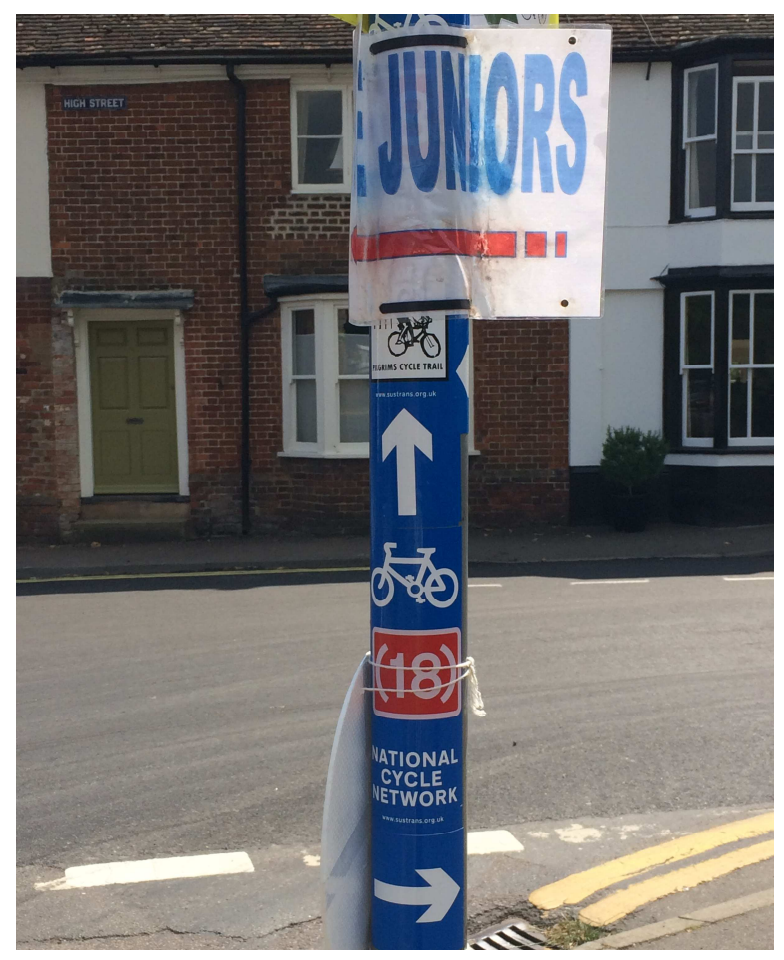

Figure 14: Wye signpost indicating national cycle route 


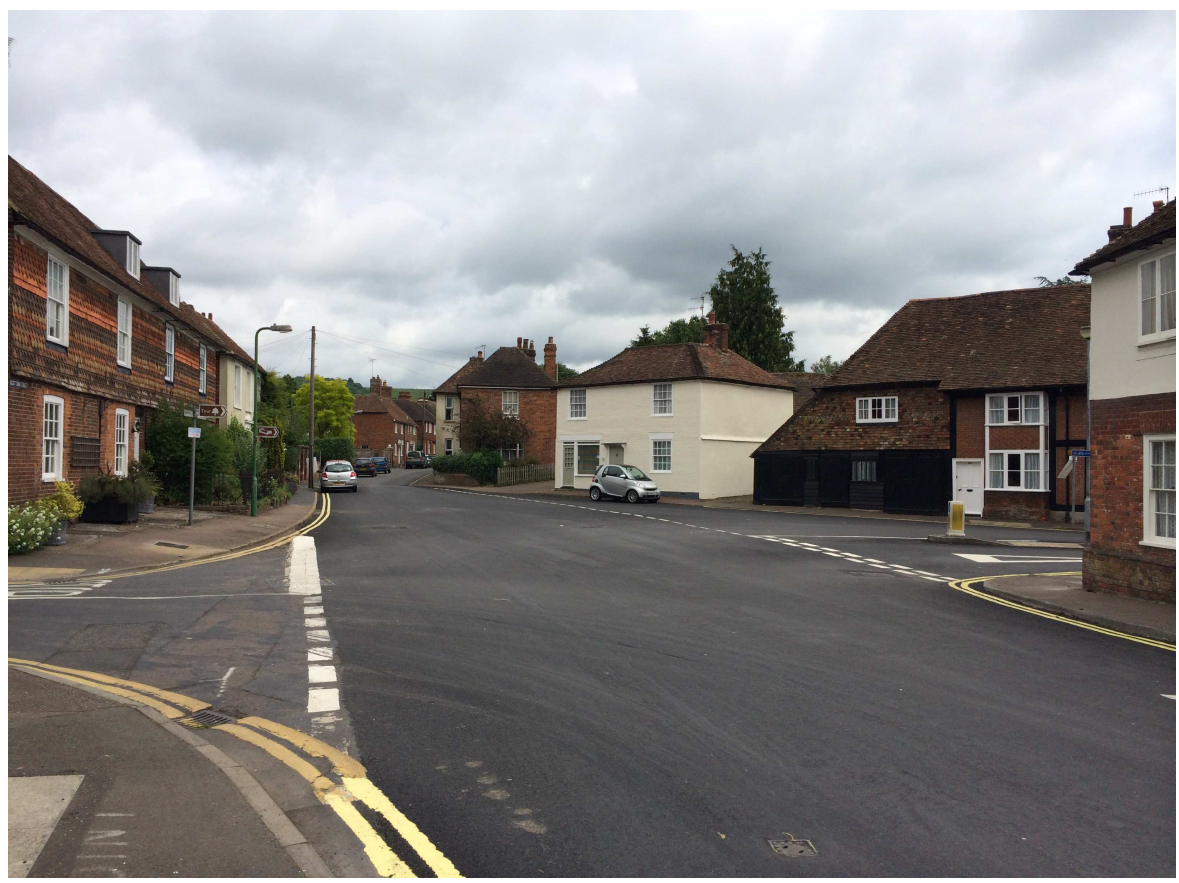

Figure 15: View of Wye intersection facing east

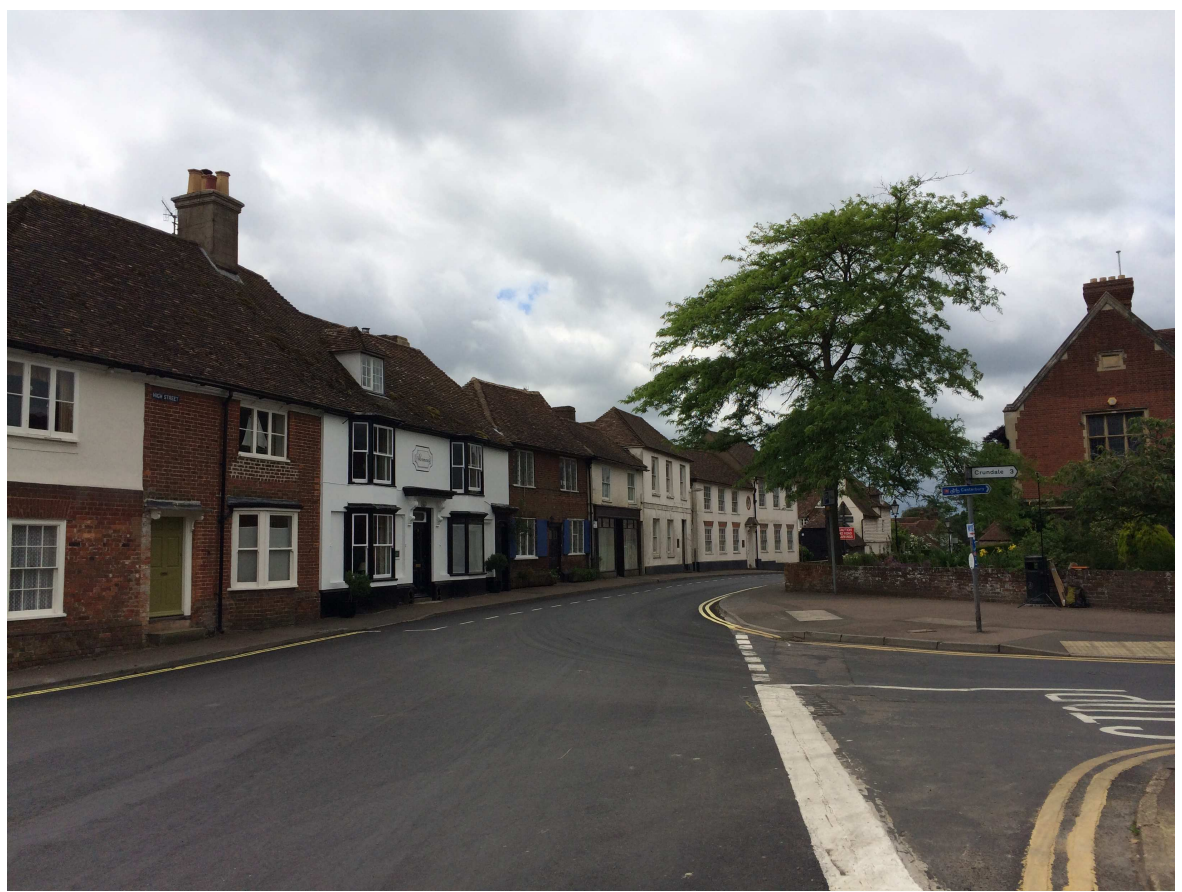

Figure 16: View of Wye intersection facing west (camera set up on right side of intersection) 


\section{Coventry, West Midlands}

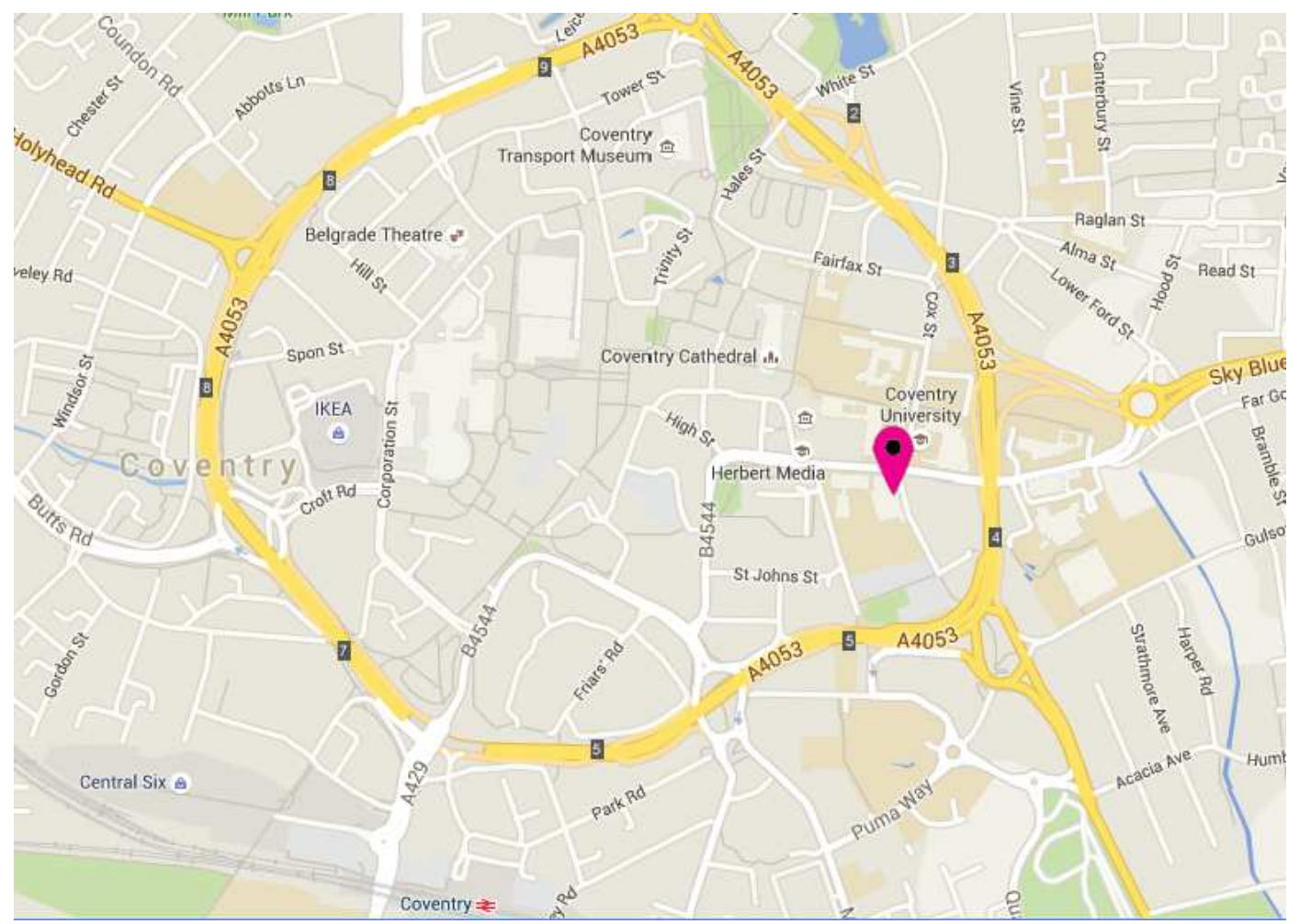

Figure 17: Coventry shared space location (google.com, 2015) 


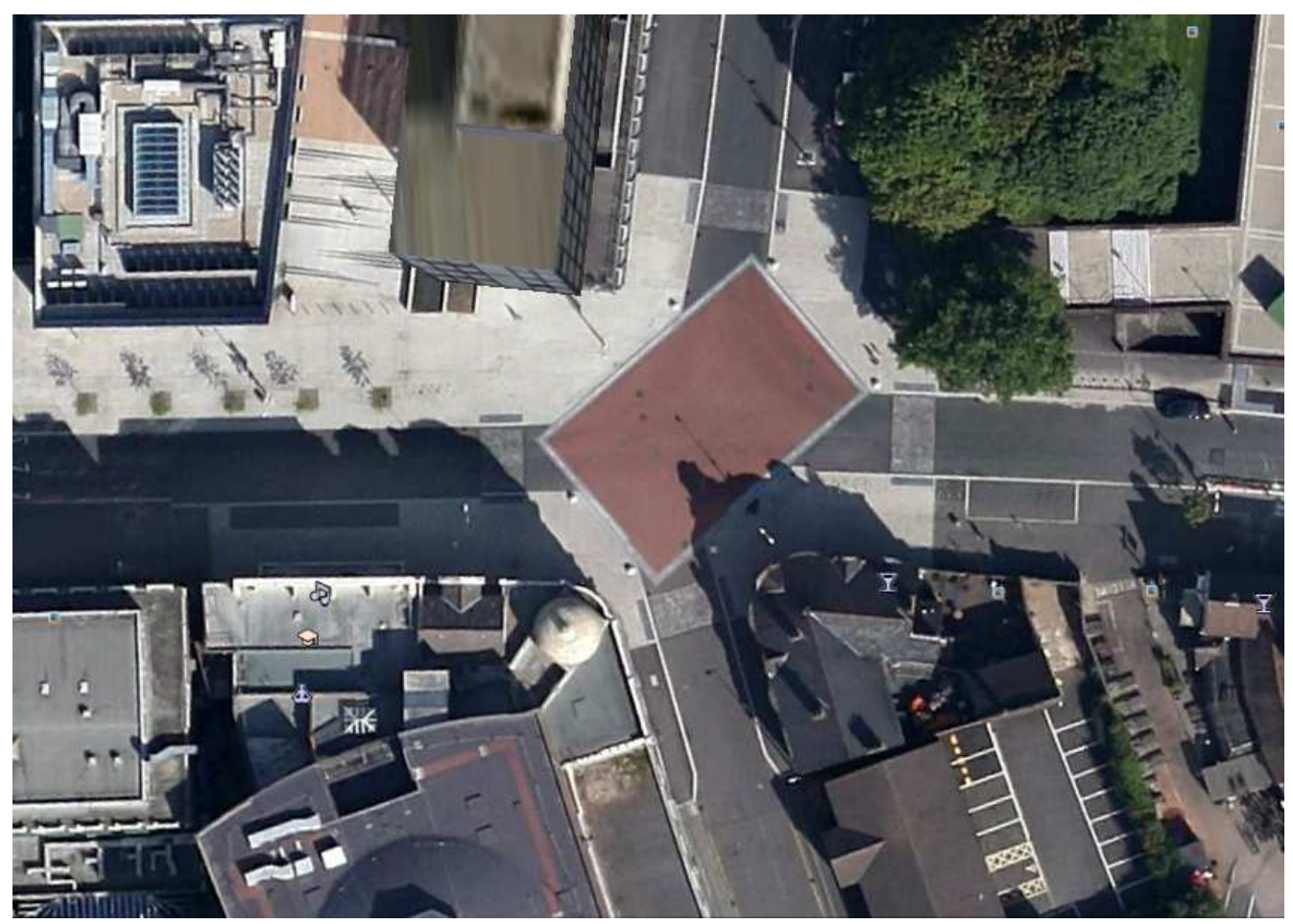

Figure 18: Aerial view of Coventry intersection (google.com, 2015) 

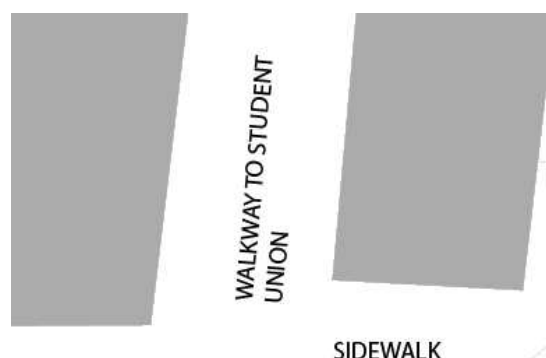

SIDEWALK

BR

BR

SIDEWALK

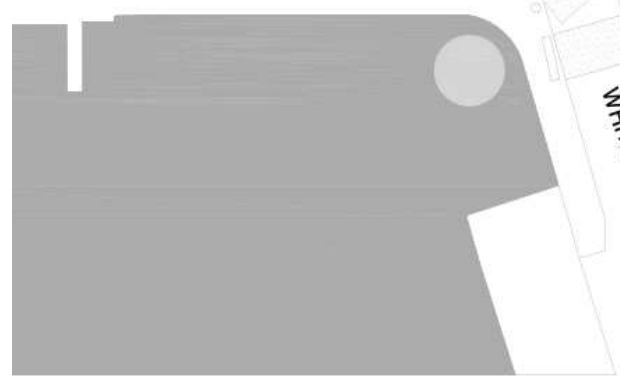

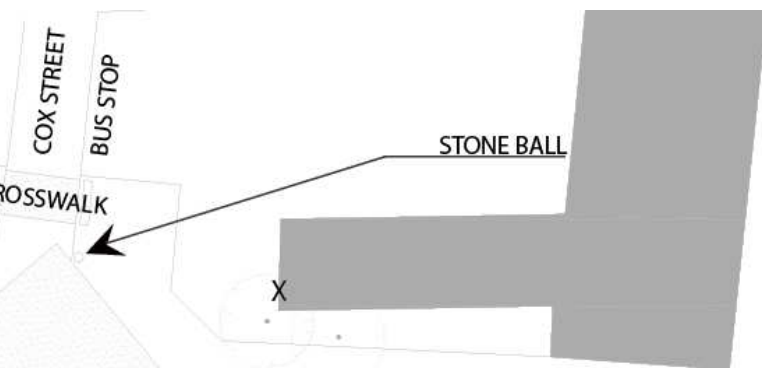

$\mathrm{BR}$

BR

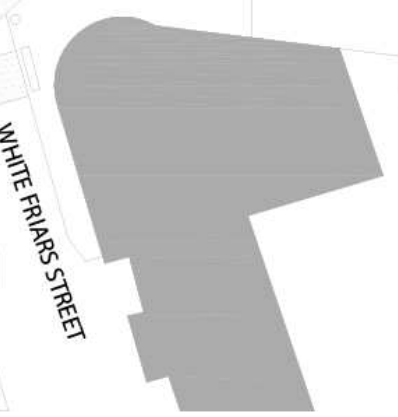

BR BIKERACK

$X$ CAMERA LOCATION

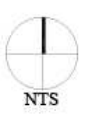

Figure 19: Elements in Coventry shared intersection

The city of Coventry has a population of 317,000 and its surrounding metropolitan area roughly 500,000. Close to Birmingham, Coventry used to be a hub for first, bicycle manufacturing, and then motor vehicle manufacturing (Rover, and Jaguar). This was the most urban of my study locations; I only looked at sites within the city's ring road (see Figure 19).

There are multiple shared space intersections within Coventry's city center, and I chose one at the intersection of Cox Street and Gosford Street for this project. The Student Union was around the corner and two pubs were across the street from my observation point. There were three bus stops around the intersection. This was the simplest shared space intersection 
of the ones selected. (See Appendix C for site matrix.) It was a relatively small intersection with large, round stone bollards placed in several points around the perimeter. Instead of textured pavement it was colored asphalt. Similar to my other shared sites, there were still sidewalks and minimal (less than one inch) curbs. Crosswalks were marked as well. Adjacent to Coventry University, with its 27,000 students, it had a heavy pedestrian presence as well as the most bicycle racks of any of the study sites.

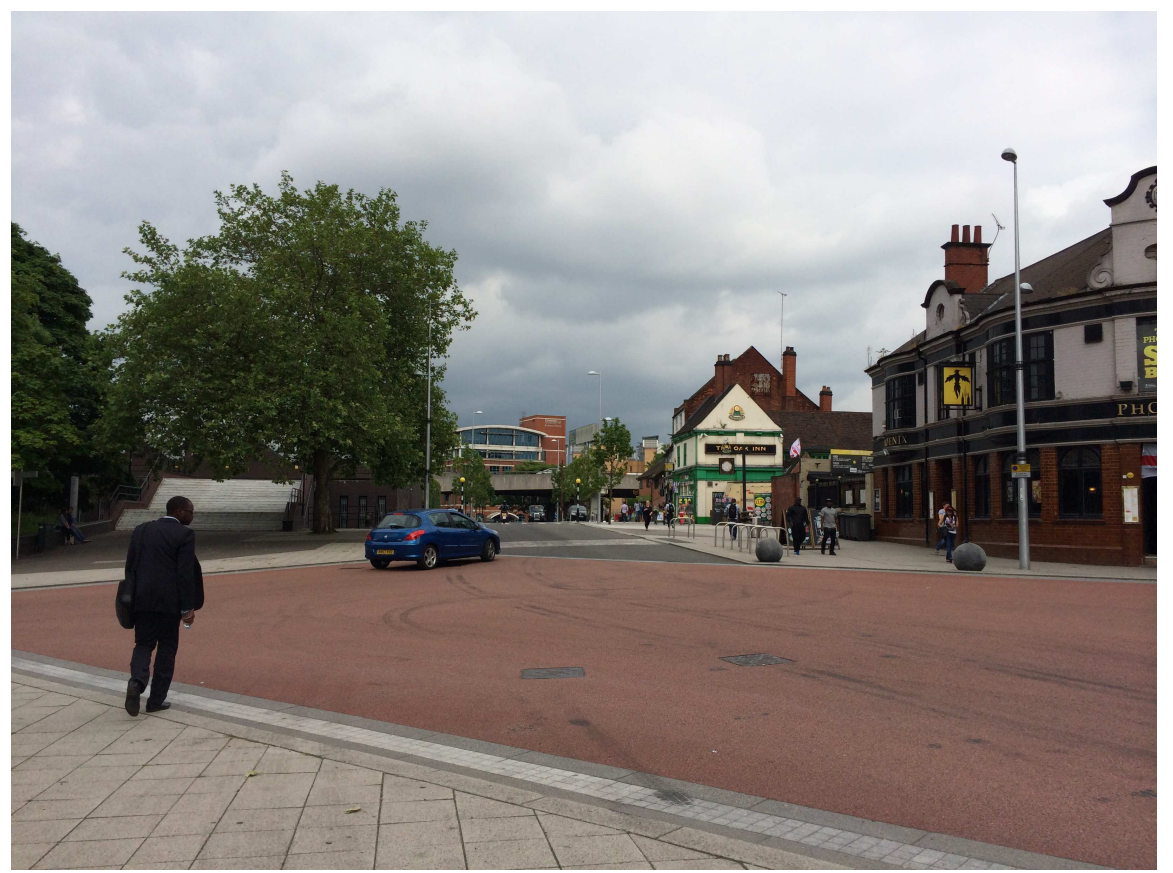

Figure 20: Coventry shared intersection 


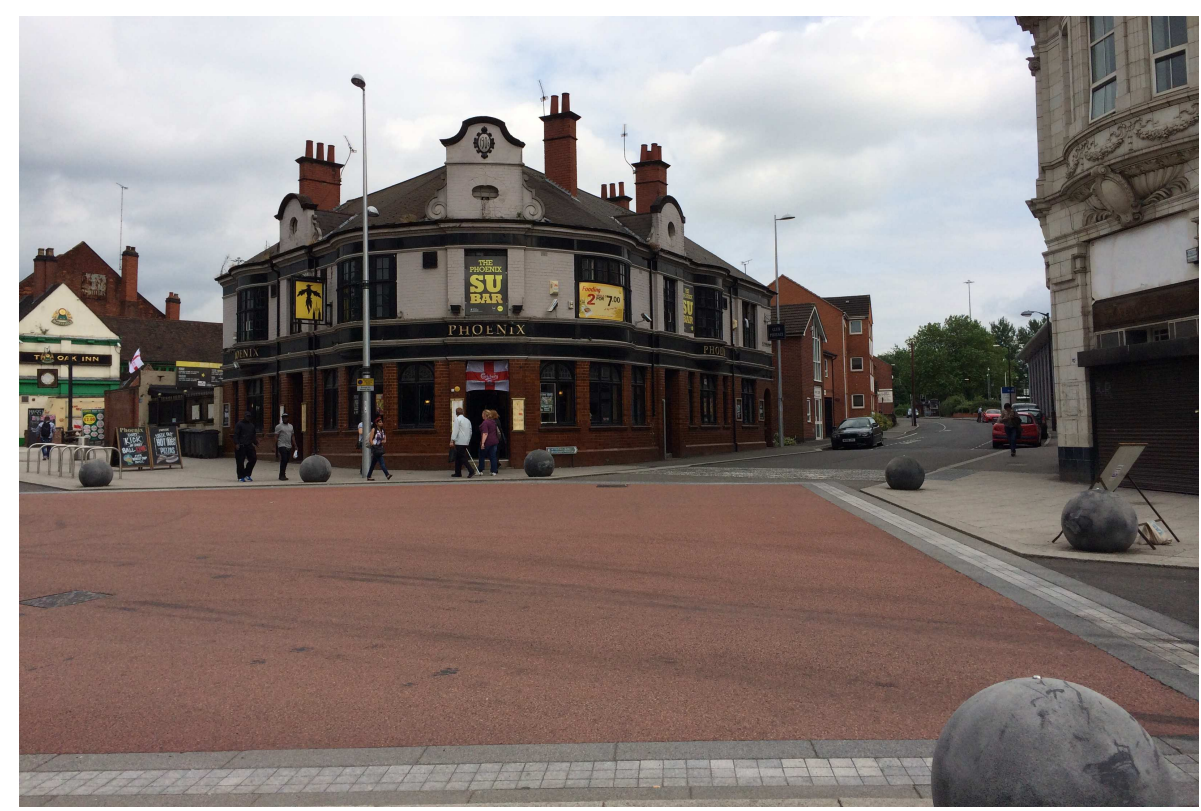

Figure 21: Coventry shared intersection

\section{Coventry control, West Midlands}

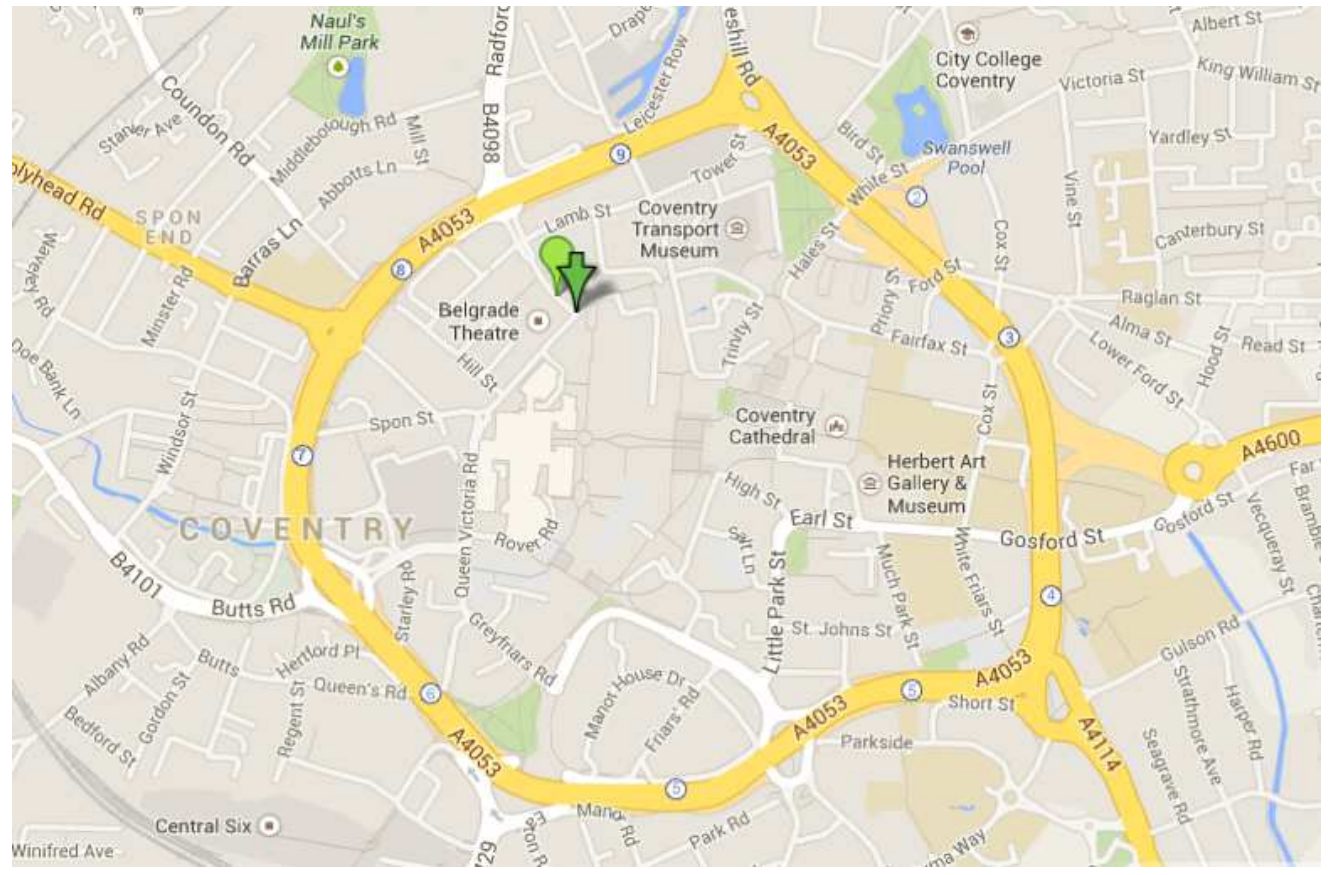

Figure 22: Coventry control location 


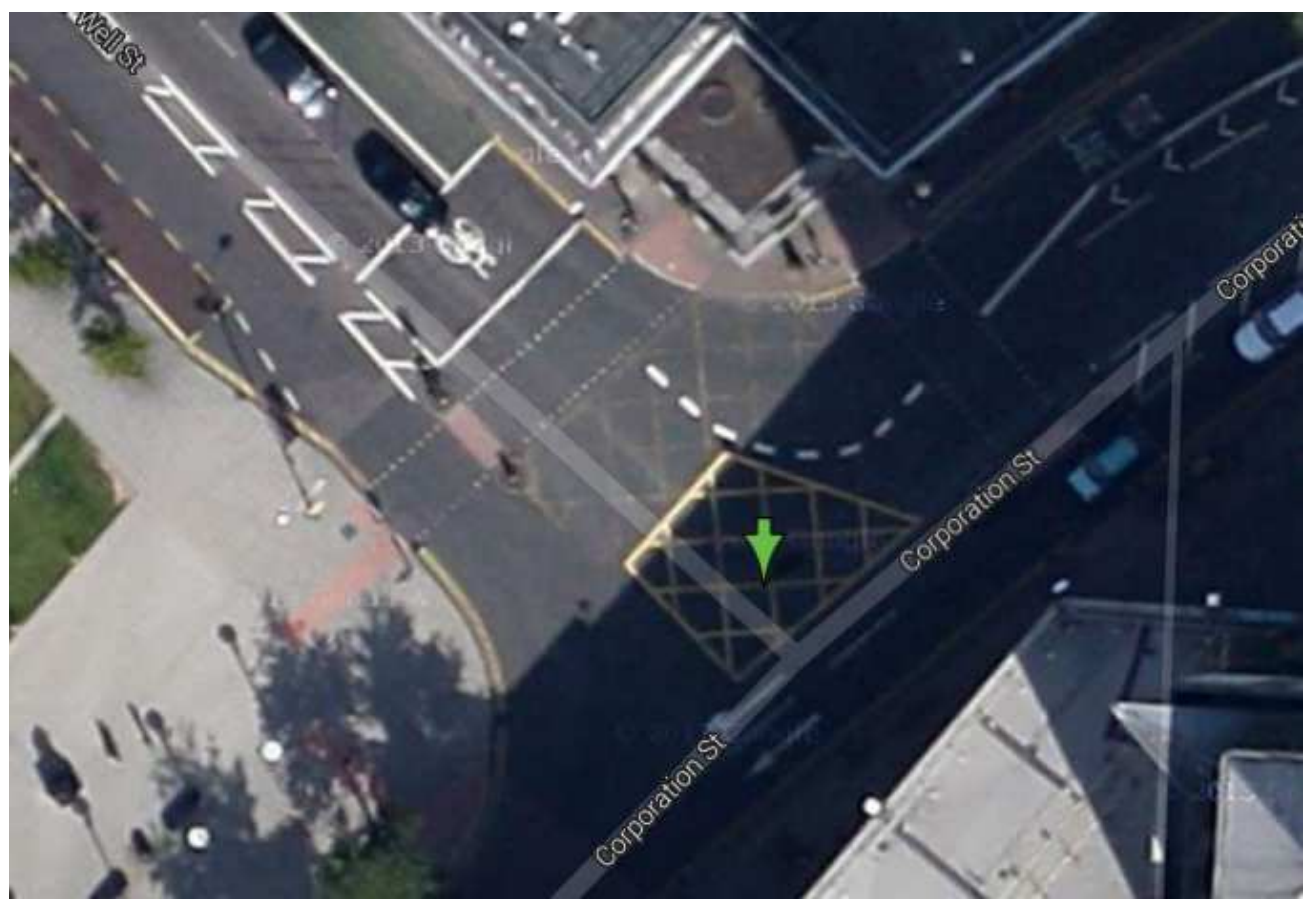

Figure 23: Coventry control aerial image (google.com 2015) 


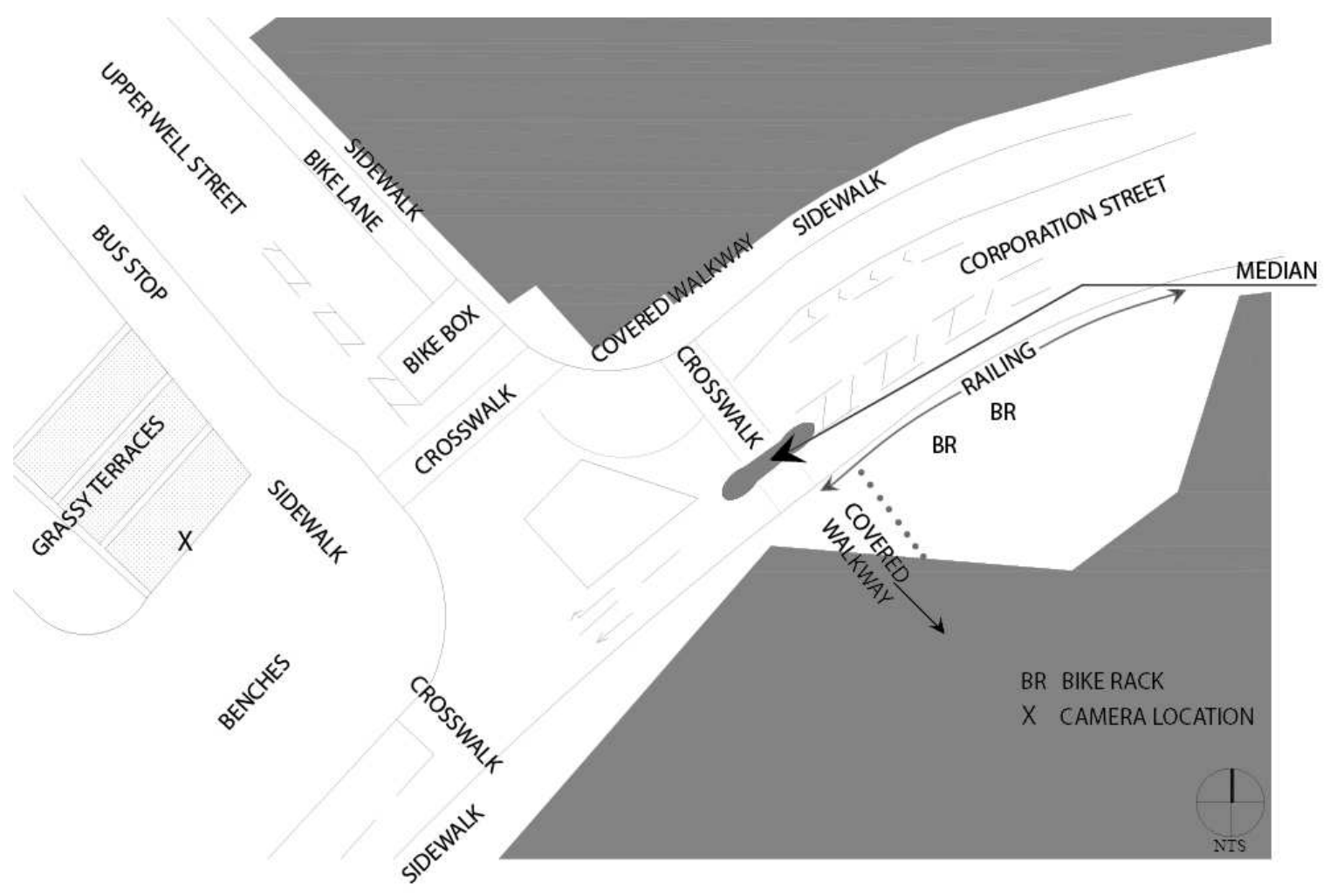

Figure 24: Elements in the Coventry control intersection

The paired comparison site chosen for Coventry was at the intersection of Corporation Street and Upper Well Street. This very busy intersection is in a commercial area, on several bus lines, and has a street designated as bicycle friendly feeding into it. Martin Wilkinson of the City of Coventry specifically suggested this site because it is slated for shared space treatment in 2015/16. 


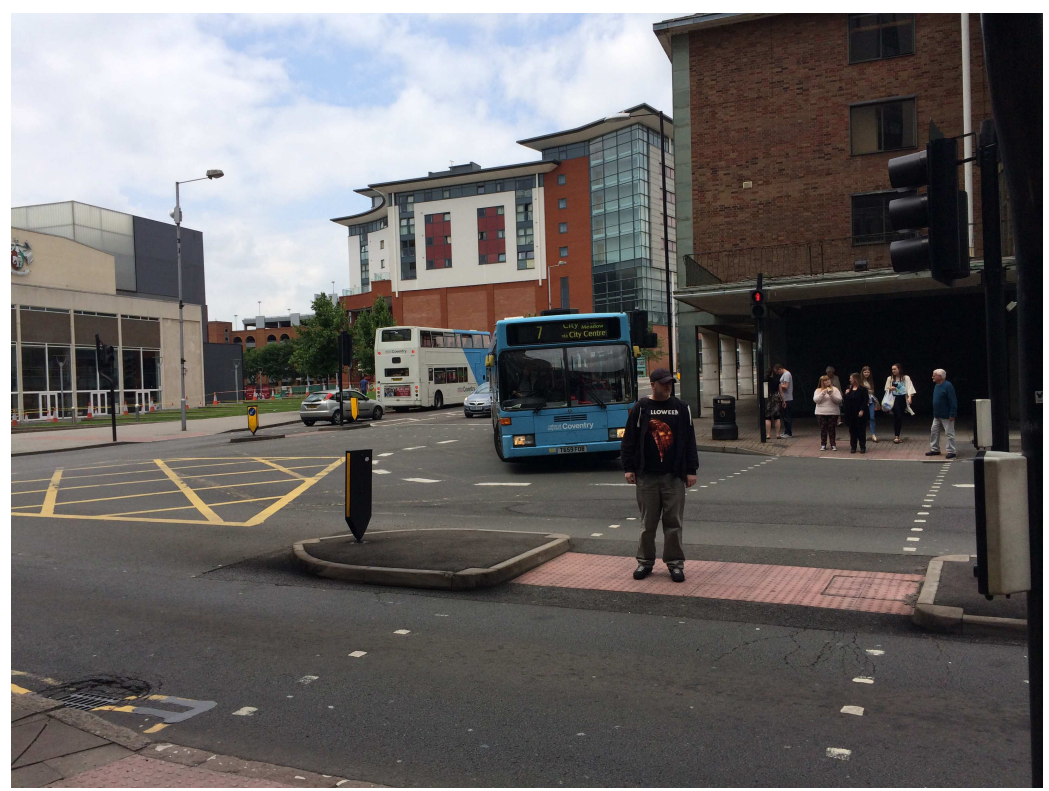

Figure 25: View of Coventry control intersection

The video camera was set up on the plaza to the left of the above photograph adjacent to the Belgrade Theatre. It is a heavily used transit and commercial area. There is a covered pedestrian walkway (Smithford Way) cutting through the building behind where this photograph was taken which led to the Coventry Retail Market, the City Arcade, and other pedestrian shopping areas. Obviously, for riders to access this walkway, they had to ride on the sidewalk. On the left of this road were also a painted bicycle lane and an unpainted bike box; there was not one on the other side of the street. The building on the left side of the road, Coventry Evening Telegraph, was empty and will be included in the upcoming redevelopment of this intersection. (See Appendix $C$ for site matrix.) The site itself is a busy, traditionally marked and signalized intersection with turn signals and pedestrian crossing signals. It has marked crosswalks, standard curbs and curb cuts. This site had the most transit use (double decker buses) of any of my study sites. 


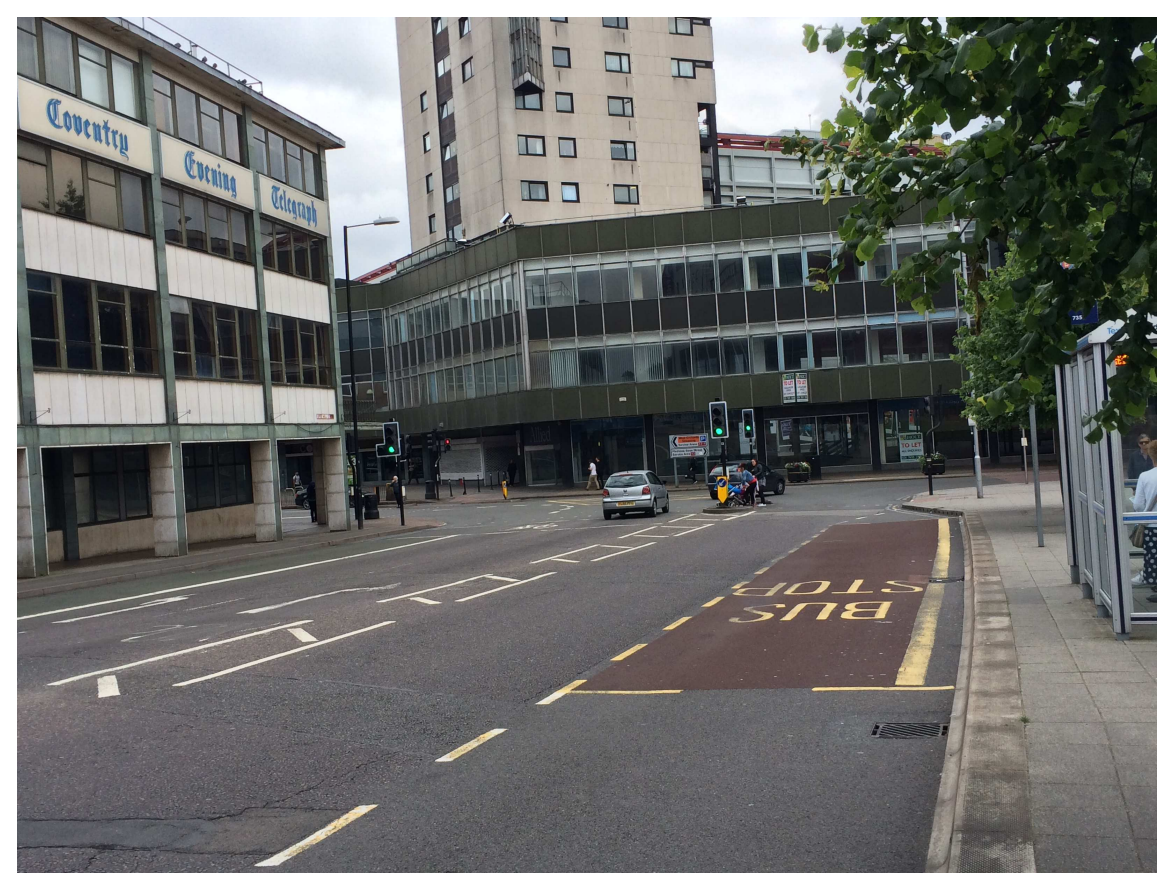

Figure 26: View of road with bike lane leading to Coventry control intersection

\section{Poynton, Cheshire East}

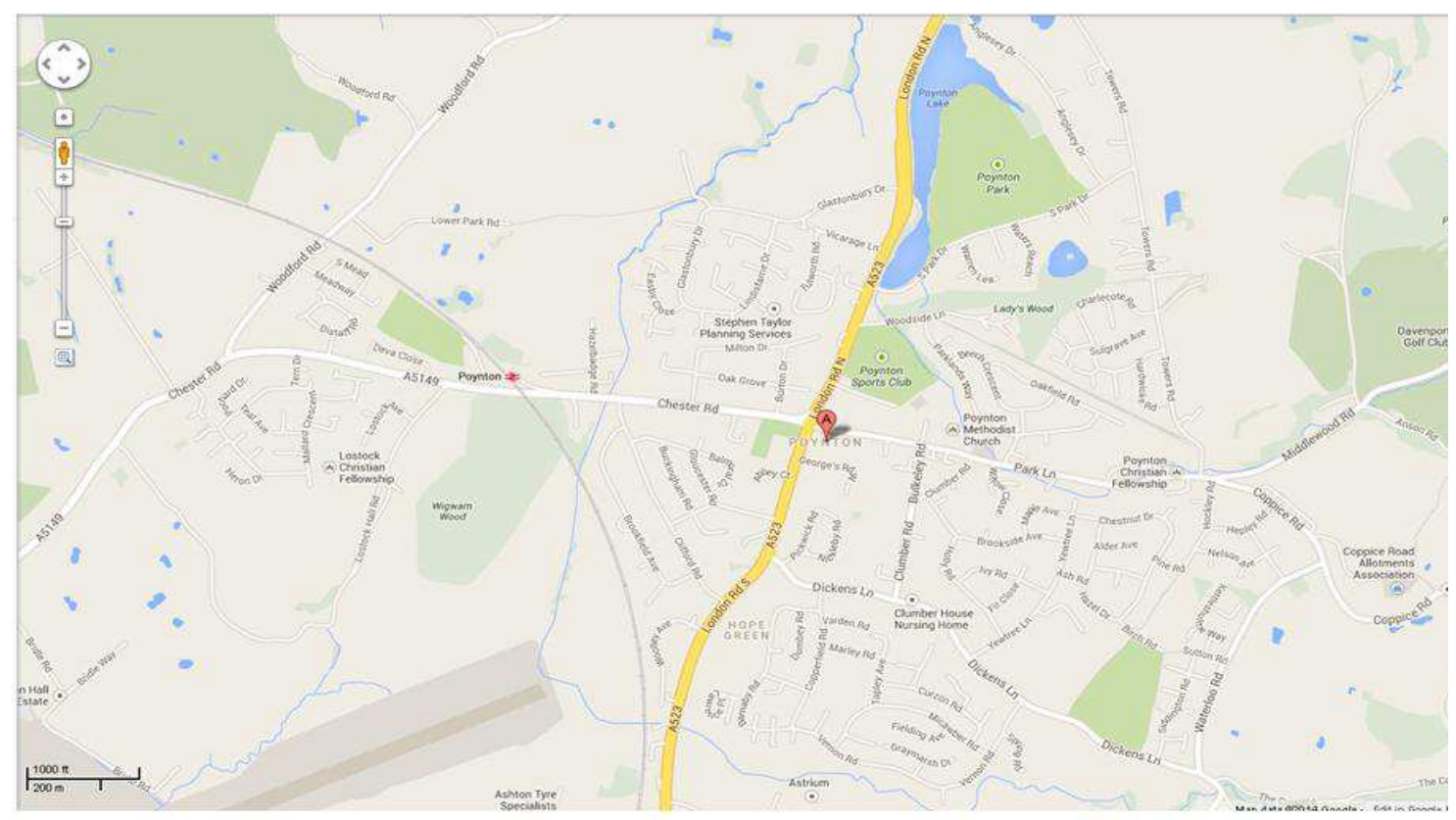

Figure 27: Poynton shared space location 


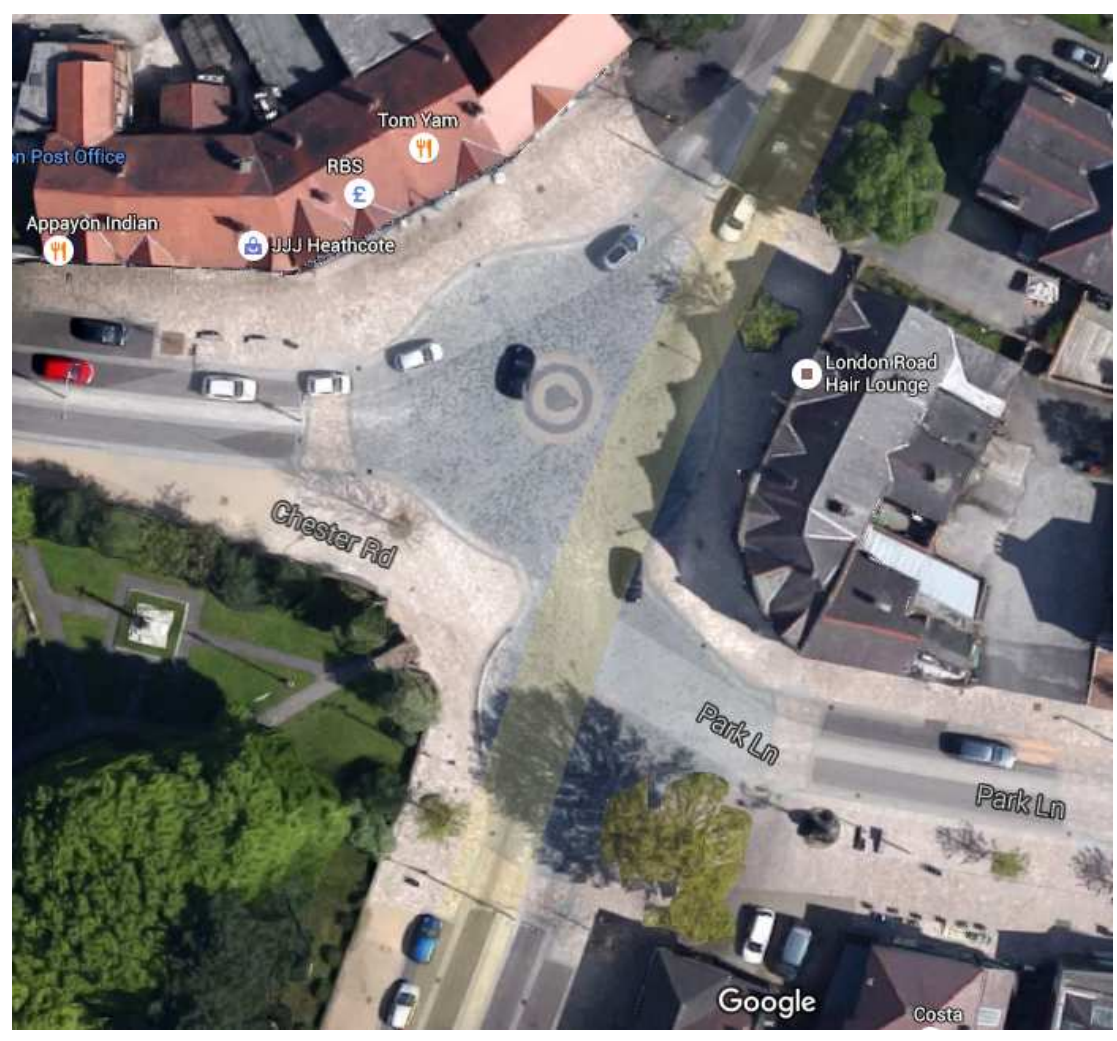

Figure 28: Poynton shared aerial image (google.com 2015) 


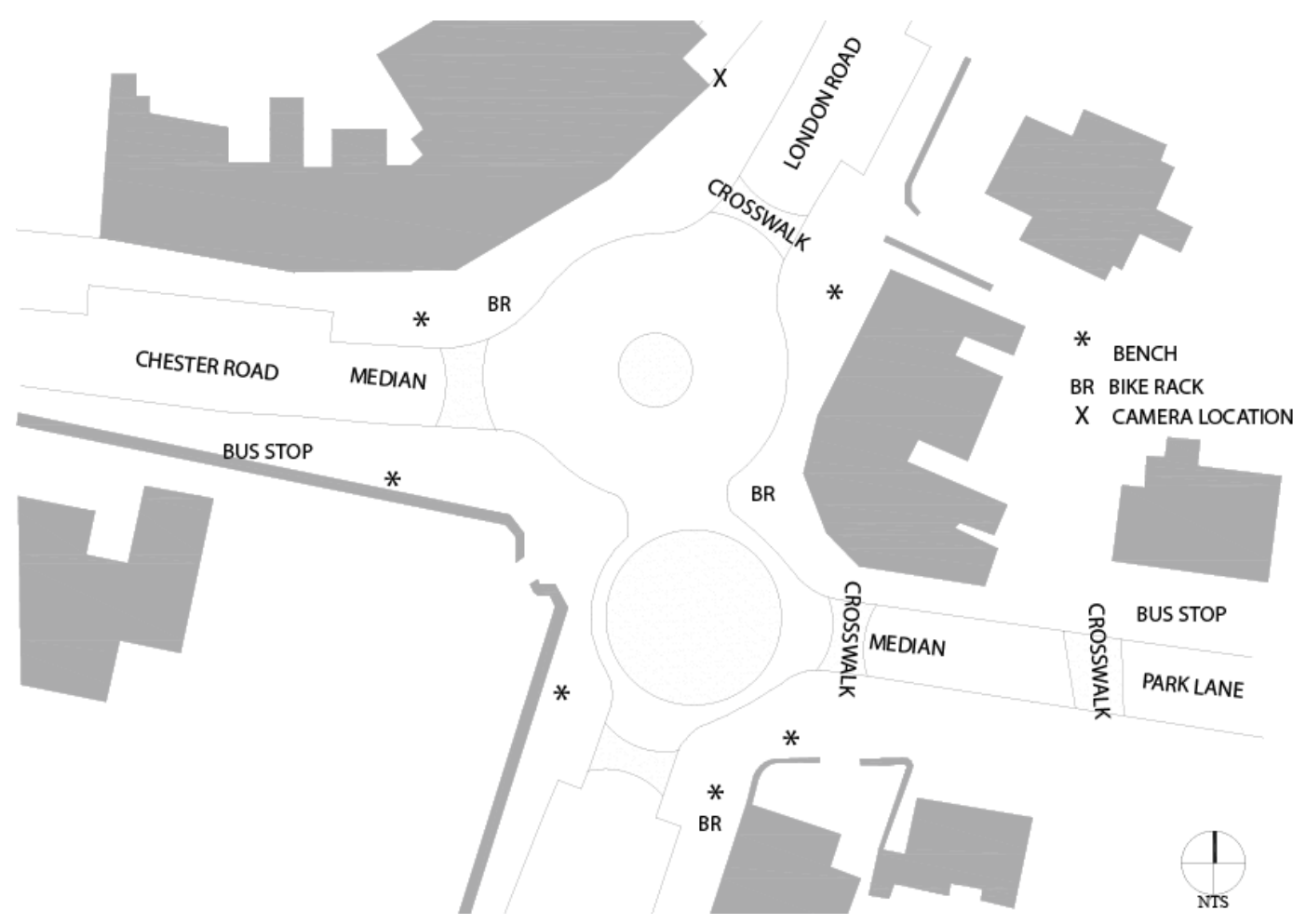

Figure 28: Elements in the Poynton intersection

Poynton, a village southeast of Manchester, has a population of approximately 14,260. The train station was halfway between the shared and control sites in this town. This shared space intersection is the town's central intersection and is a very well-publicized, showcase project in England. With its heavy commercial truck traffic, this is also the busiest intersection of all six selected for this study. Planning, and discussion with the designer Ben Hamilton-Baillie, indicated that there would be less bicycle traffic along the North-South "London Road" but more travelling East-West. I also chose this site for its complicated geometric layout, which had the potential to most influence a cyclist's path choices as compared to simpler designs. This intersection of the A523 (London Road) and the A5149 (Chester Road) has multiple businesses as well as a large church. The commuter rail station 
is .5 miles away on Chester Road.

The Poynton intersection was designed to be plaza-like with intricate, textured paving patterns laying out a double roundabout pattern in the roadway. There was also public seating and landscaping, as well as the removal of curbs, signs, signals, and lane striping. The shared space treatment continued east into the village's commercial section (See Appendix C for site matrix.). I set up my video observation point on the northwest end of the intersection, adjacent to a carpet shop and around the corner from the post office.

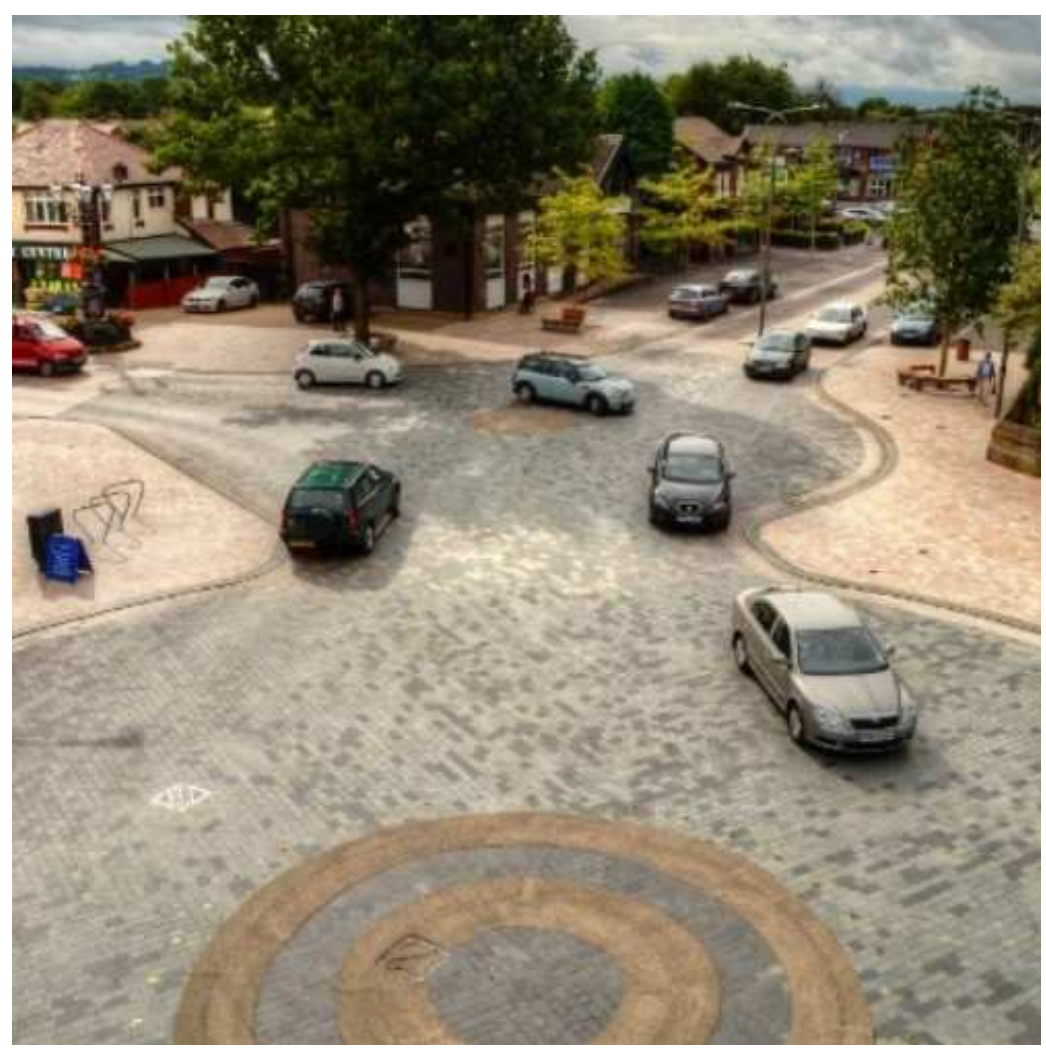

Figure 29: Poynton image (hamilton-baillie.com) 


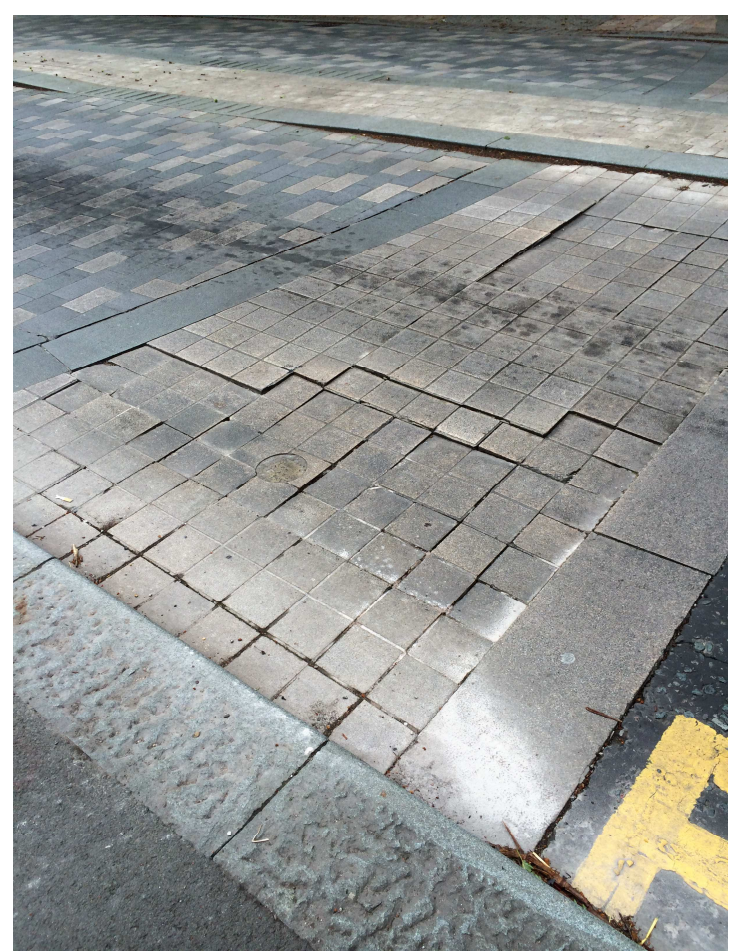

Figure 30: Poynton crosswalk and paving detail

The above photo is a detail of the road paving, curbs and crosswalk. (Note the deterioration of the paving. It is a new site but already needing repair due to the heavy truck traffic.) 


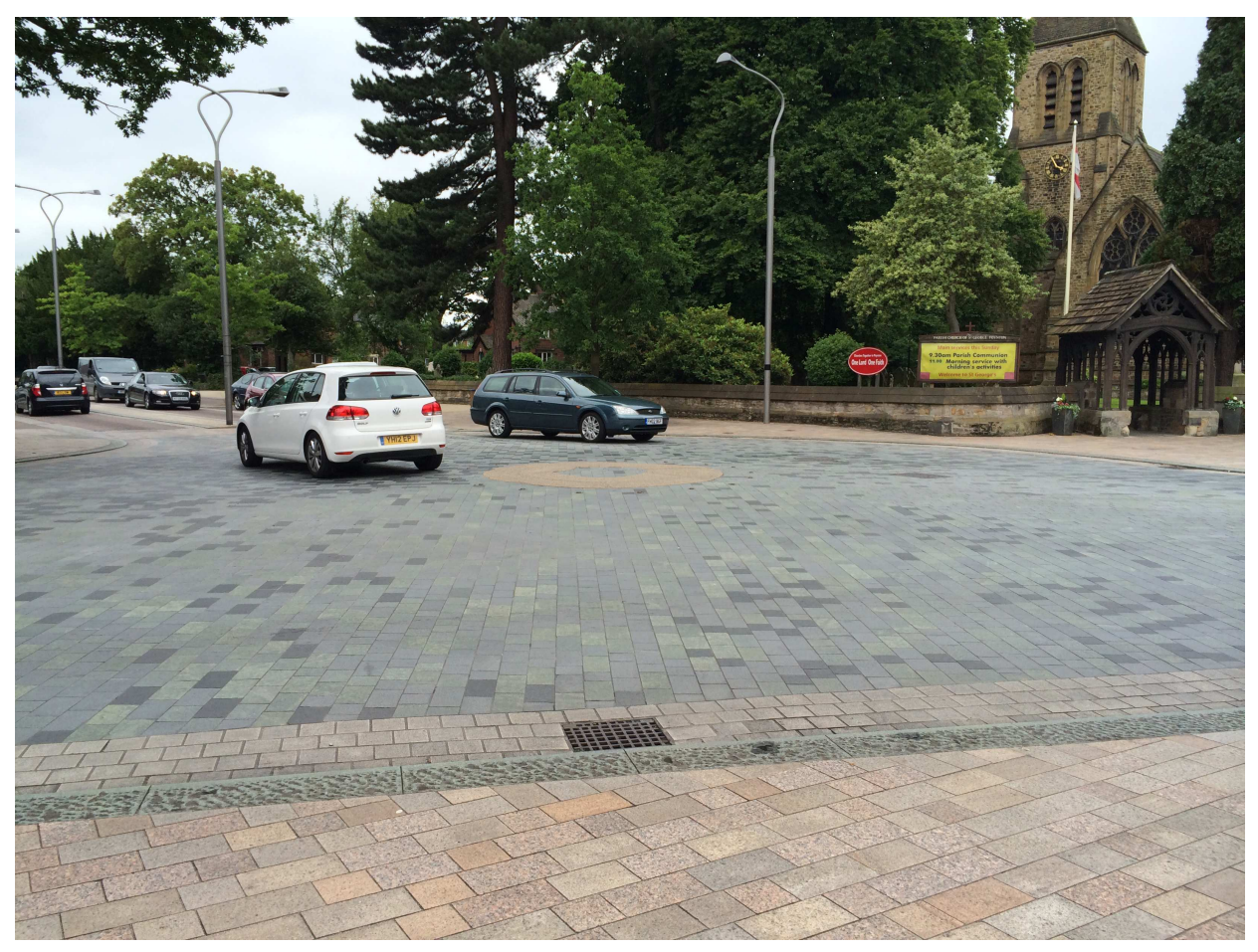

Figure 31: View of Poynton intersection facing southwest

The grey, textured curb edging is less than an inch high, and it was easily crossed and jumped by cyclists and pedestrians. The beige bricks (laid in the running bond pattern along the very low curb edging) were added after construction to keep cyclists from riding immediately adjacent to the curb edging. 


\section{Poynton control}

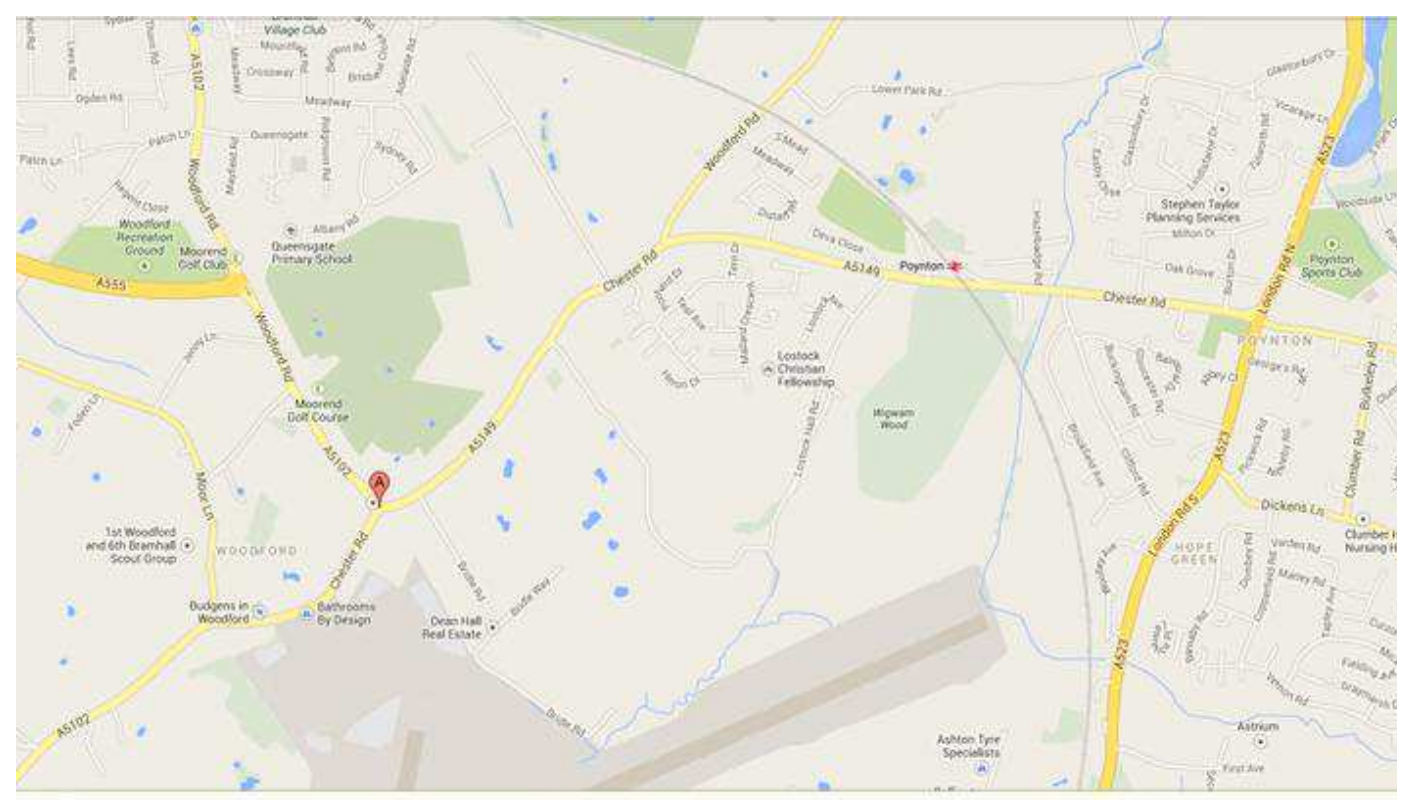

Figure 32: Poynton control location

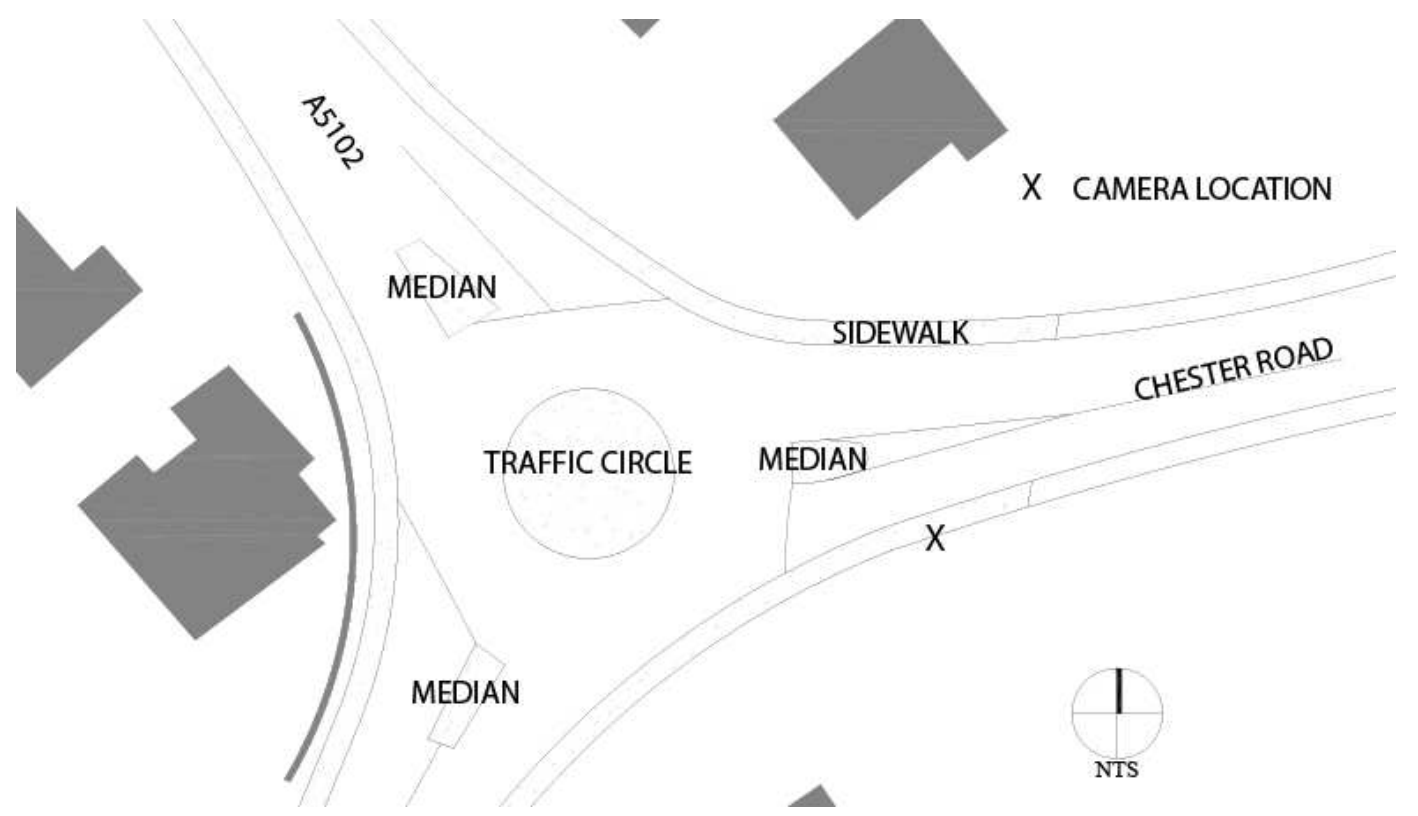

Figure 33: Elements in Poynton control intersection 


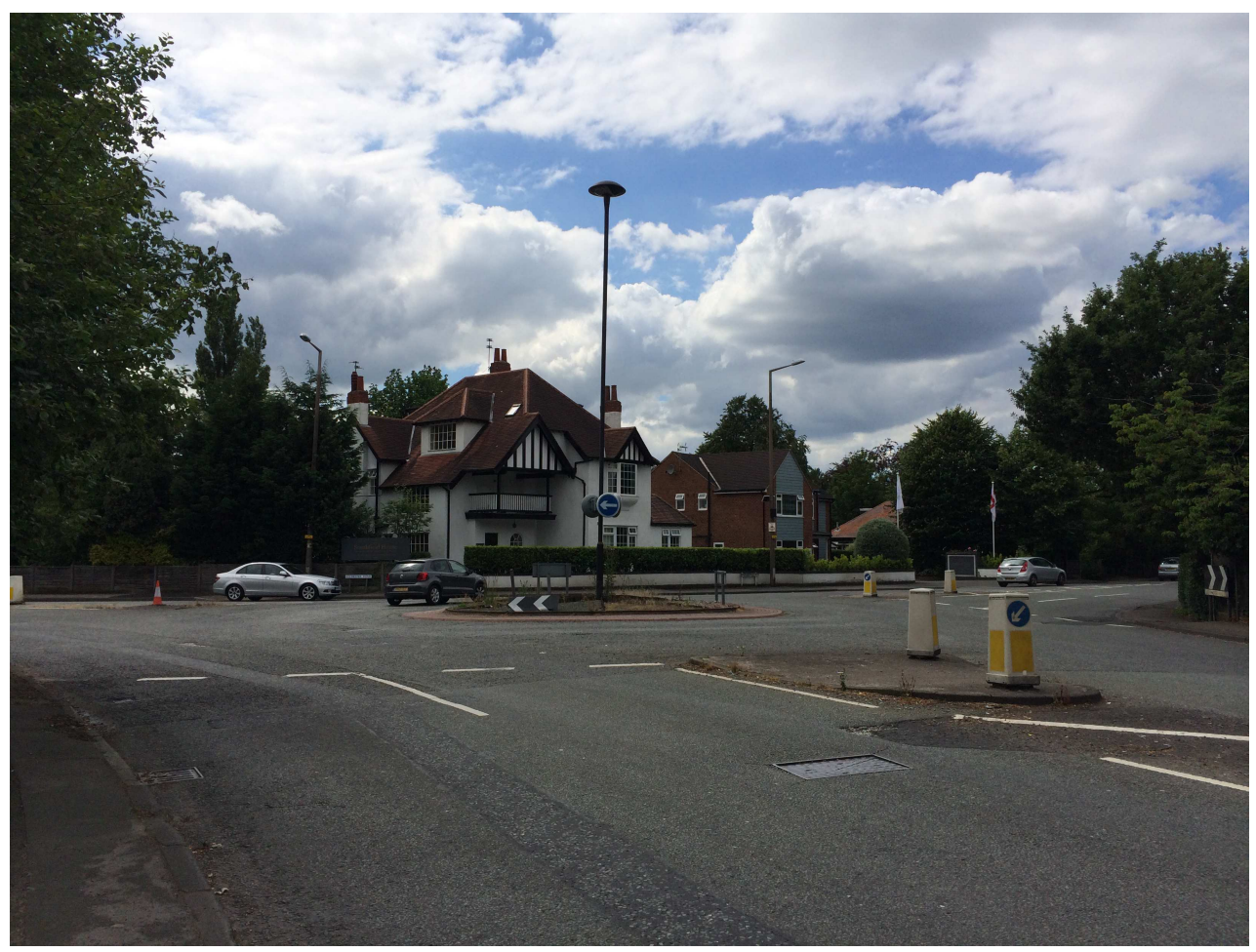

Figure 34: View of Poynton control intersection

A local bicycle shop, Rick Green Cycles, suggested the control site at the intersection at

Bramhall's A5149 (Chester Road) and A5102 (Woodford Road). Similar to the Wye site, this intersection is in a more residential area but is along a common cycling route. I confirmed the potential level of bicycle traffic via Strava's heat map website (labs.strava.com/heatmap), and observations confirmed that the bicycle traffic was primarily recreational. This site was just up the road from a small commercial area and very large plant nursery. It was west of the Poynton train station.

I set up the video camera on a wide section in the sidewalk on what appeared to be an abandoned driveway. The intersection had a medium level of traffic and was the only site 
with a physical roundabout. It was surrounded by narrow sidewalks, standard curbs and curb cuts, and several medians that also had curb cuts. Similar to Wye, these crosswalks were unmarked but I used the medians and curb cuts as proxy for the crosswalks themselves.

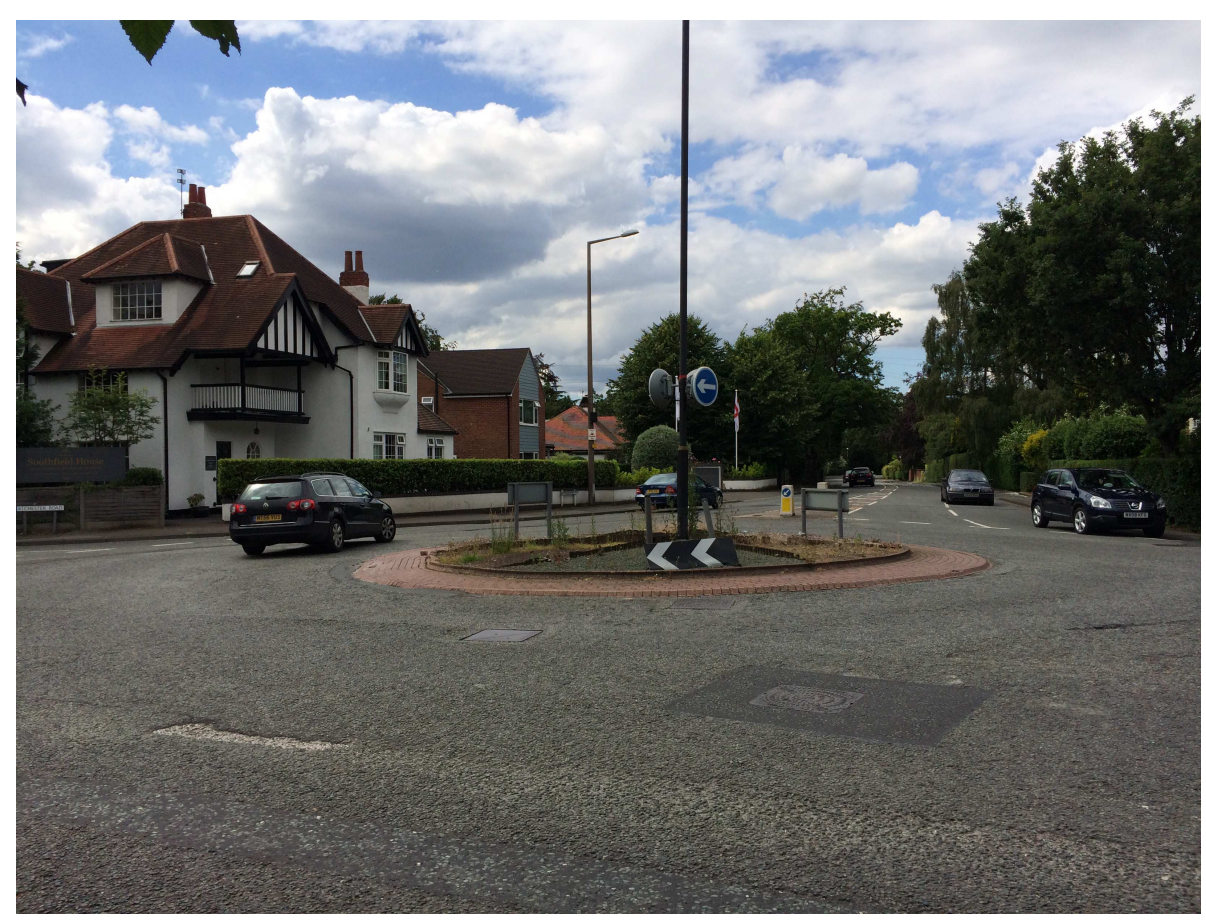

Figure 35: View of Poynton control intersection facing northwest

Table 3, below, summarizes and compares all of the inventoried elements for each site.

Table 3: Site matrix of all applicable elements

\begin{tabular}{|l|c|c|c|c|c|c|}
\hline & $\begin{array}{c}\text { Elwick } \\
\text { Square }\end{array}$ & Wye & Poynton & $\begin{array}{c}\text { Poynton } \\
\text { control }\end{array}$ & Coventry & $\begin{array}{c}\text { Coventry } \\
\text { control }\end{array}$ \\
\hline Year built & 2008 & $\mathrm{n} / \mathrm{a}$ & 2012 & $\mathrm{n} / \mathrm{a}$ & 2013 & $\mathrm{n} / \mathrm{a}$ \\
\hline Town population & 74,733 & & 14,433 & & 316,900 & \\
\hline Area & $\mathrm{unk}$ & & $\mathrm{unk}$ & & $98.64 \mathrm{~km} 2$ & \\
\hline $\begin{array}{l}\text { Traffic counts } \\
\text { (am/pm) }\end{array}$ & $834 / 864$ & $143 / 113$ & $1980 / 2185$ & $1846 / 1991$ & $504 / 727$ & $761 / 867$ \\
\hline Spatial type & & & & & & $\mathrm{X}$ \\
\hline Intersection & $\mathrm{X}$ & $\mathrm{X}$ & $\mathrm{X}$ & $\mathrm{X}$ & $\mathrm{X}$ & $\mathrm{X}$ \\
\hline Square & $\mathrm{X}$ & & & & & \\
\hline
\end{tabular}




\begin{tabular}{|c|c|c|c|c|c|c|}
\hline & & & & & & \\
\hline \multicolumn{7}{|l|}{ Modes present } \\
\hline Cars & $\mathrm{X}$ & $\mathrm{X}$ & $\mathrm{X}$ & $\mathrm{X}$ & $\mathrm{X}$ & $\mathrm{X}$ \\
\hline Bicycles & $\mathrm{X}$ & $\mathrm{X}$ & $\mathrm{X}$ & $\mathrm{X}$ & $\mathrm{X}$ & $\mathrm{X}$ \\
\hline Pedestrians & $\mathrm{X}$ & $\mathrm{X}$ & $\mathrm{X}$ & $\mathrm{X}$ & $\mathrm{X}$ & $\mathrm{X}$ \\
\hline Transit & $\mathrm{X}$ & $\mathrm{X}$ & $\mathrm{X}$ & $\mathrm{X}$ & $\mathrm{X}$ & $\mathrm{X}$ \\
\hline \multicolumn{7}{|l|}{$\begin{array}{l}\text { Marked } \\
\text { separation of } \\
\text { modes: }\end{array}$} \\
\hline Sidewalks & $\mathrm{X}$ & $\mathrm{X}$ & $\mathrm{X}$ & $\mathrm{X}$ & $\mathrm{X}$ & $\mathrm{X}$ \\
\hline Bike infra & & & & $\mathrm{X}$ & & $\mathrm{X}$ \\
\hline Traffic lanes & & $\mathrm{X}$ & & $\mathrm{X}$ & & $\mathrm{X}$ \\
\hline \multicolumn{7}{|l|}{ Other } \\
\hline \multicolumn{7}{|l|}{ Street clutter: } \\
\hline Traffic signs & & $\mathrm{X}$ & & $\mathrm{X}$ & & $\mathrm{X}$ \\
\hline Traffic lights & & & & & & $\mathrm{X}$ \\
\hline \multicolumn{7}{|l|}{ Other } \\
\hline \multicolumn{7}{|l|}{ Curbs present } \\
\hline Full & & $\mathrm{X}$ & & $\mathrm{X}$ & & $\mathrm{X}$ \\
\hline Low & & & & & $\mathrm{X}$ & \\
\hline None & $\mathrm{X}$ & & $\mathrm{X}$ & & & \\
\hline \multicolumn{7}{|l|}{$\begin{array}{l}\text { Surface } \\
\text { (hardscape) } \\
\text { contrast }\end{array}$} \\
\hline High & $\mathrm{X}$ & & $\mathrm{X}$ & & $\mathrm{X}$ & \\
\hline \multicolumn{7}{|l|}{ Medium } \\
\hline \multicolumn{7}{|l|}{ Low } \\
\hline Textured & $\mathrm{X}$ & & $\mathrm{X}$ & & & \\
\hline \multicolumn{7}{|l|}{$\begin{array}{l}\text { Public space } \\
\text { amenities }\end{array}$} \\
\hline Seating & $\mathrm{X}$ & & $\mathrm{X}$ & & & \\
\hline Street lamps & $\mathrm{X}$ & $\mathrm{X}$ & $\mathrm{X}$ & $\mathrm{X}$ & & $\mathrm{X}$ \\
\hline $\begin{array}{l}\text { Pedestrian scale } \\
\text { lighting }\end{array}$ & & & & & & $\mathrm{X}$ \\
\hline $\begin{array}{l}\text { Vegetation/landsc } \\
\text { ape }\end{array}$ & $\mathrm{X}$ & & $\mathrm{X}$ & & $\mathrm{X}$ & \\
\hline \multicolumn{7}{|l|}{ Art } \\
\hline \multicolumn{7}{|l|}{ Food/beverage } \\
\hline \multicolumn{7}{|l|}{ Other } \\
\hline Bollards & $\mathrm{X}$ & & & & $\mathrm{X}$ & $\mathrm{X}$ \\
\hline Guard rails & & & & & & $\mathrm{X}$ \\
\hline $\begin{array}{l}\text { Entry } \\
\text { monuments }\end{array}$ & & & $\mathrm{X}$ & & & \\
\hline \multicolumn{7}{|l|}{$\begin{array}{l}\text { Traffic calming } \\
\text { elements }\end{array}$} \\
\hline Geometric devices & $\mathrm{X}$ & & $\mathrm{X}$ & & $\mathrm{X}$ & \\
\hline Traffic circles & & & $\mathrm{X}$ & $\mathrm{X}$ & & \\
\hline Speed bumps & & & & & & \\
\hline
\end{tabular}




\begin{tabular}{|l|c|c|c|c|c|c|}
\hline Other & & & & & & \\
\hline Human scaled & $\mathrm{X}$ & & & & $\mathrm{X}$ & $\mathrm{X}$ \\
\hline $\begin{array}{l}\text { Marked } \\
\text { crosswalks }\end{array}$ & $\mathrm{X}$ & $1 / 2$ & $\mathrm{X}$ & $1 / 2$ & $\mathrm{X}$ & $\mathrm{X}$ \\
\hline
\end{tabular}

Note: Shared space matrix based on DfT (2011) Classification Questionnaire (p2.6)

\section{Units of analysis and variables}

This research uses both the terms path and route; I differentiate path and route by their scale. A path is defined at the intersection scale-it is the course that bike riders take when riding through an intersection. A route is defined on the larger, network scale-a route is the selection of roads, sidewalks, and shared use paths that cyclists select in their travels from $\mathrm{A}$ to $\mathrm{B}$.

Each intersection observed had elements such as sidewalks, crosswalks, and, in some cases, curbs (See Figures 5 to 35). Table 3 details how I categorized cyclist behaviors according to their interactions with various site elements.

Table 4: Definitions of variables coded

\begin{tabular}{ll}
\hline Variables & Descriptions \\
\hline Gender & Male, female, unable to determine (unknown) \\
& Whether or not the cyclist was wearing (not carrying) a helmet when \\
observed riding through intersection: yes, no, unable to determine \\
(unknown). \\
Helmet use
\end{tabular}


Crosswalk use is independent of sidewalk use.

Whether or not the cyclist used either a curb cut when leaving or accessing

Curb use

Walking companion

Walking leg

Origin-

Destination

Avoidance

behavior

Conflict/collision

Vehicle counts the sidewalk, or whether or not a cyclist was seen jumping on or off a curb when accessing a sidewalk: curb cut, curb jump

If the cyclist was observed riding alongside a companion who was walking

If the cyclist was observed dismounting his/her bicycle at some point across the intersection and walking for a portion of the path

The direction the cyclist was observed entering the intersection from combined with the direction the cyclist was observed leaving the intersection: OD

If a cyclist was observed making an obvious swerve or path deviation to avoid a vehicle, pedestrian, or other cyclist.

If a cyclist was observed having an obvious near miss or actual collision with a vehicle, pedestrian, or other cyclist.

Average morning and afternoon hourly vehicle counts were done for each site. Vehicles were divided into two size classification: large (bus size or larger) and smaller (cars, trucks, vans, etc.).

Each cyclist path, and the number of nodes that comprised those paths, were the primary units of analysis with nodes being the points along a line required to define a path. The number of nodes thus described the amount of deviation in a path and served as an evaluative unit of measure, which I created to compare cyclist paths across the same intersections. Each line therefore represents a single path ridden by a cyclist. For instance, Figure 37 shows the overlay of several observed cyclist paths across the Coventry shared intersection. The figure illustrates how the description and composition of those paths is comprised of lines and nodes. 


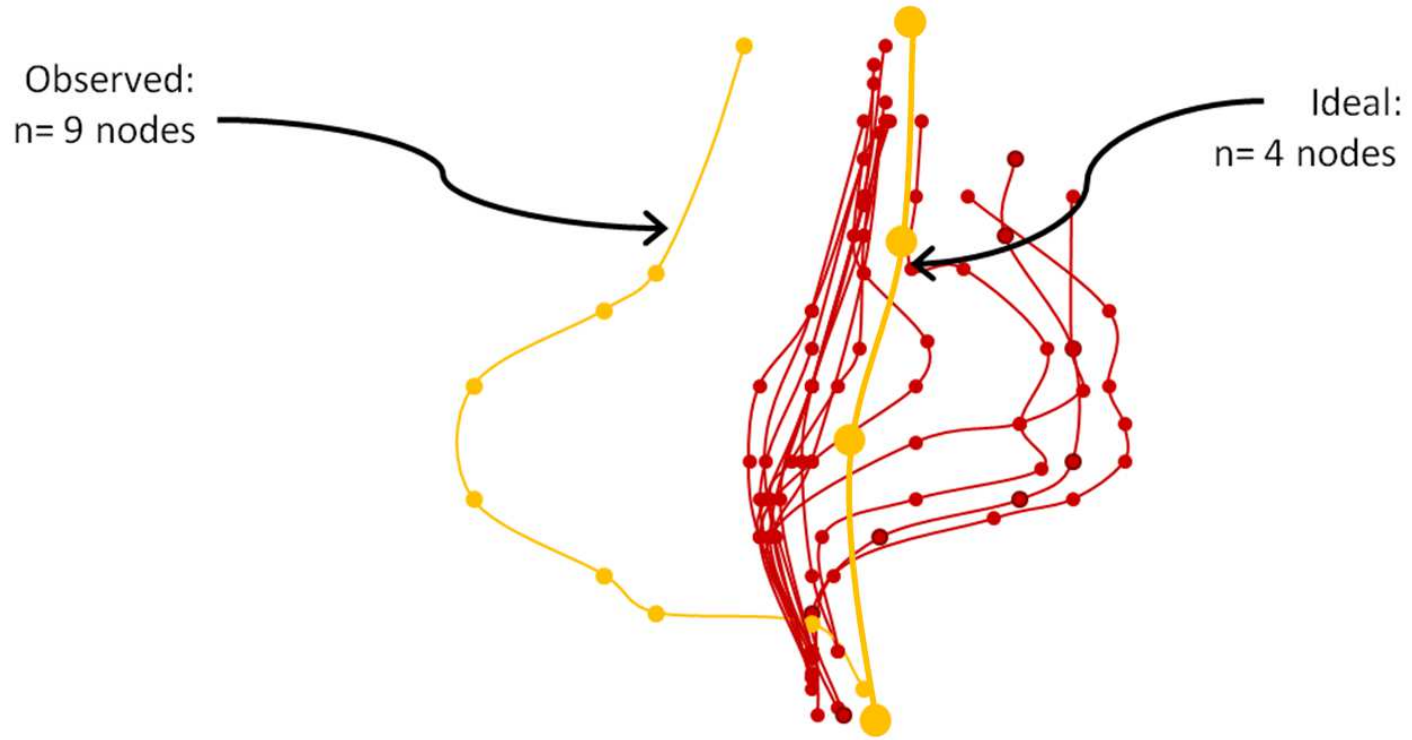

Figure 36: Example of path comprised of nodes and ideal paths

In order to compare each path with respect to other paths, I designated an ideal path for each possible direction through the intersection (see Figure 37). I created these ideal paths after observing each intersection. An ideal path was not the shortest path. It was the most realistic path; these were the paths that a confident cyclist might choose if there were no impediments. The ideal path value was subtracted from each observed path's value to calculate the node difference: Observed \# nodes - ideal \# nodes $=$ node difference. The node difference (nodediff) was the primary dependent variable for the path analysis.

One of the research questions was to try to understand why cyclists rode the paths they did and if there were any alternative paths they would prefer. I built on previous stated preference surveys. But, by trying to create questions regarding preferred paths through an 
intersection, I also created a new form of survey questions regarding path choice.

To achieve this, I created maps of each study site with a few possible paths a cyclist might ride. After observing each intersection, both control and shared, I identified at least two 'expected' paths for each leg of the intersection. The 'expected' path options were presented in the online survey when asking respondents to identify which routes they choose and which routes they would prefer to ride.

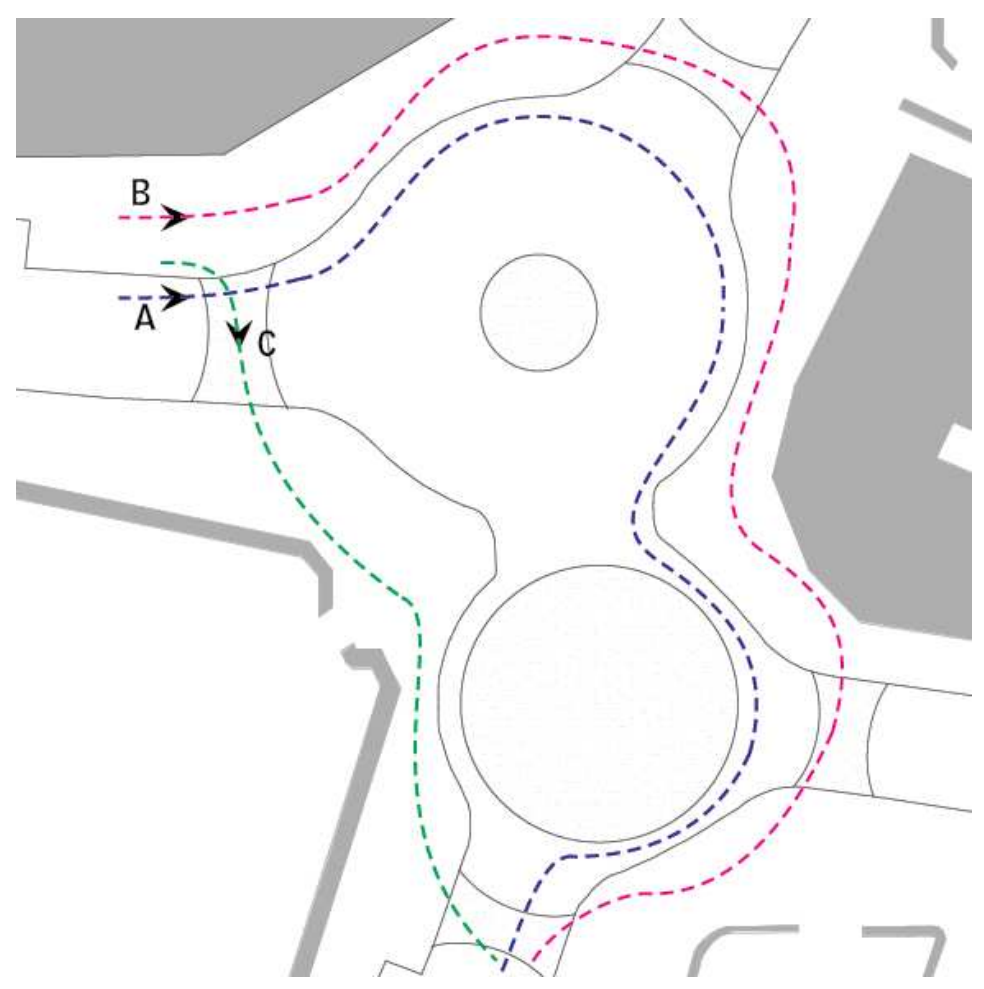

Figure 37: Example of survey question asking about path choice, Poynton

\section{Pilot study}

Both the online survey and video camera set up were both pre-tested in Portland, Oregon, before leaving for England. The general survey was pre-tested twice, using one set of 
respondents who were familiar with transportation research, and another set of respondents who were not transportation academics. Additionally, multiple people looked over the route choice illustrations for each site to verify that the chosen bicyclist path options were both understandable and reasonable.

The video camera/tripod set up was also pre-tested to ensure that 1) the video settings were sufficient to capture enough of the details of the cyclists riding through the intersections, and 2) that the 12 ' tripod was stable and sturdy enough to serve for the several weeks of travel and use.

The project was approved by Portland State University's Institutional Review Board as exempt — with the caveat that people would not be individually identifiable in the saved videos. There were several resolution options on the camera and I chose the one that best met all the requirements. Decreasing the resolution slightly impacted some of the variable measurements for individual riders. For instance, in some instances it was impossible to accurately determine a rider's gender, bicycle type, or even if he/she was wearing a helmet.

\section{Data collection procedures}

\section{Video Observations}

While planning this research, I attempted to obtain permission to mount video cameras to light poles at each intersection in each of the three municipalities because having the camera up would have captured the cyclists' routes more easily. Permission was difficult to attain, instead I stayed with the tripod and camera during all video observations. I set the tripod up 
on the sidewalks as close as possible to the intersection while still being able to capture the entire intersection with the video camera. Each of my tripod locations was in an area with pedestrians and bicyclists traveling on the sidewalks; I balanced capturing the entire intersection on video while still staying out users' way by setting up in wide places, adjacent to walls, and out of the line of travel. My tripod locations were removed enough that no users had to deviate their paths to avoid me. It is possible some users (both pedestrians and cyclists) may have changed their paths to see what I was doing, but if so, it was not obvious in the paths plotted.

GoPro's cameras are Bluetooth accessible, so I was able to set up the 12' tripod and see how much of the site was captured by the video camera via my tablet. This made it easy and efficient to move the camera around to make sure I captured all of the intersection. I observed each site a minimum of 3 days - two weekdays, and one weekend day, with observations taken roughly for 3 hours in the morning and 3 hours in the early evening. The ending of each session was determined when there was an observable decrease in bicycle traffic and several minutes went by before seeing another cyclist ride through the intersection. The weekend day was to see if there was a change in pattern for weekend riders, such as more families and children. I lost one day of observation to rain. I noted that Kaparias, et al. (2013) had observed 291 cyclists in their study of the London's Exhibition Road shared space project; therefore, given that some of the study sites were smaller towns, I planned additional days if the numbers of cyclists observed was lower than 200 per city. Two of the sites, Wye and Poynton control, turned out to be more recreational cyclist sites 
so I spent extra weekend time on those to capture as many riders as possible.

I also sampled a selection of videos to calculate average hourly vehicle count for all six study sites. Several twenty-minute videos from multiple days, both from morning and afternoon, were selected for each site. I counted each motor vehicle traveling through the study intersections and classified them as either large or small. An average hourly count was calculated as well as an average hourly share of large versus smaller vehicles per intersection.

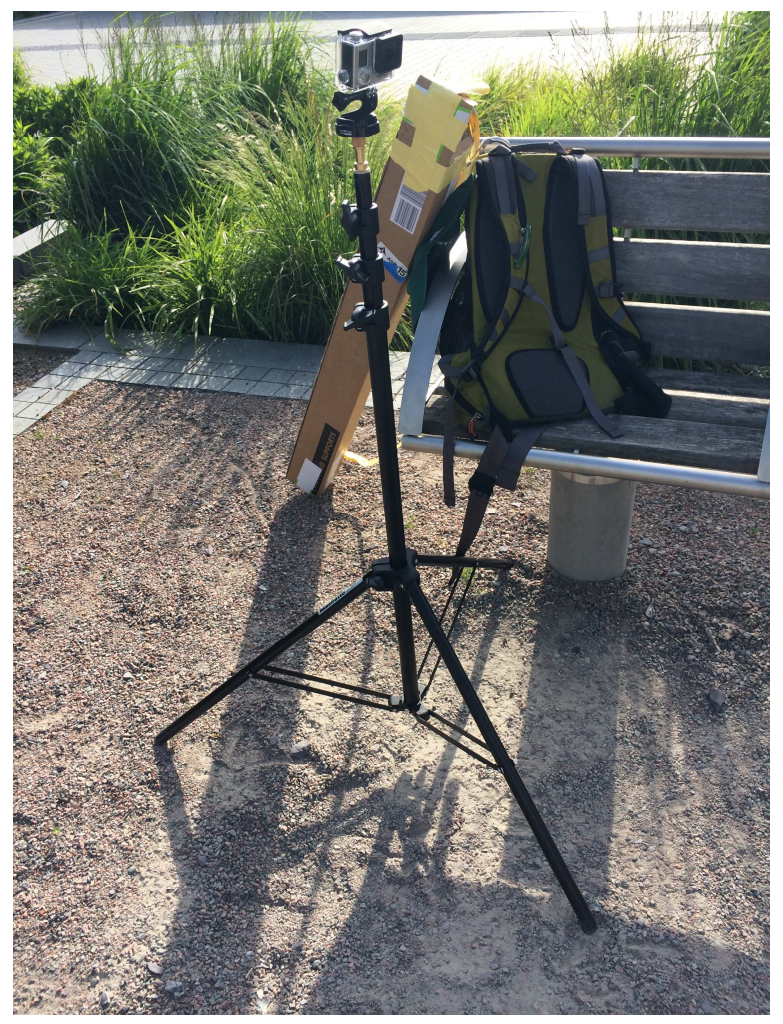

Figure 38: Video camera equipment, Elwick Square 


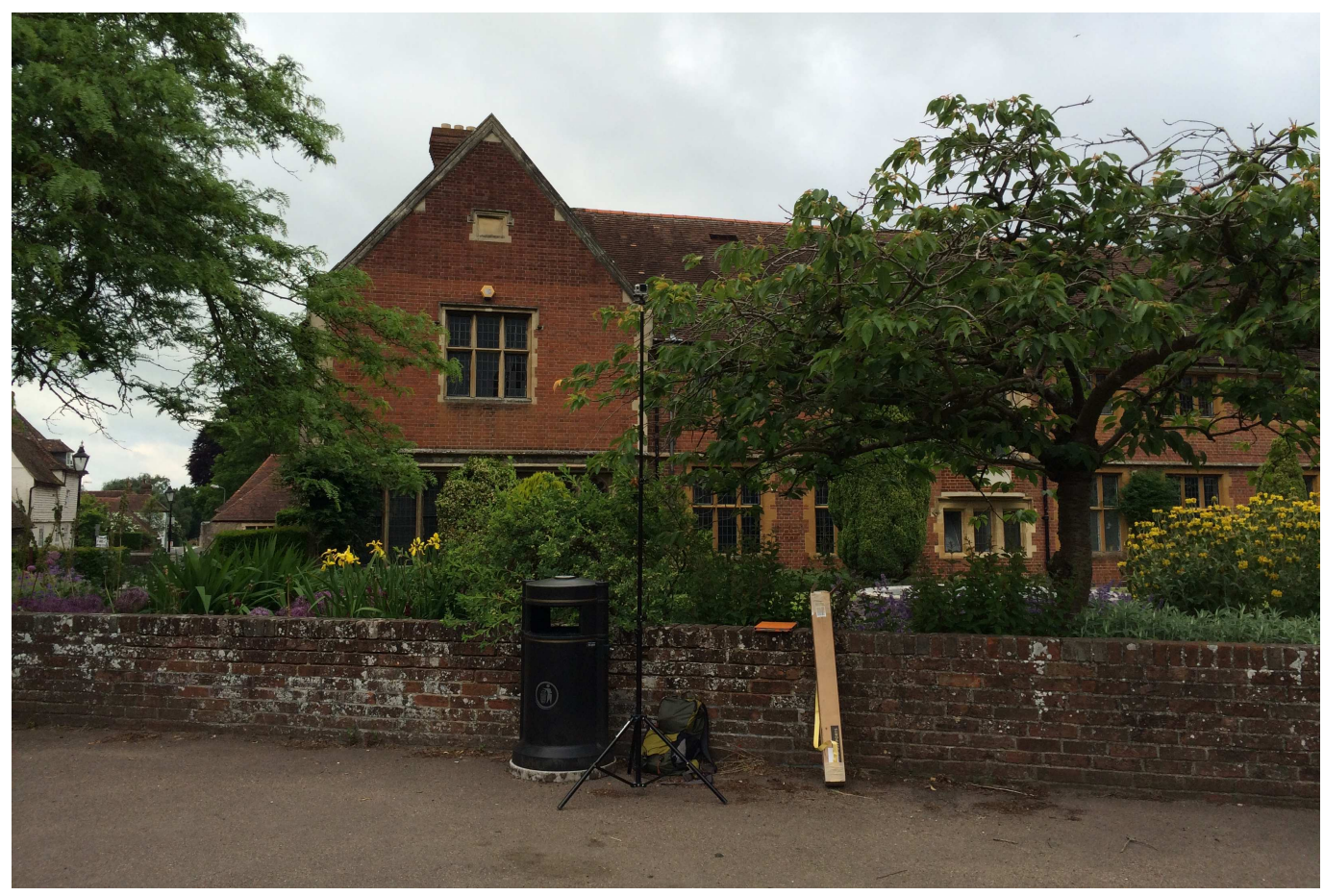

Figure 39: Video camera and tripod setup, Wye

\section{Online survey}

As noted in the literature review chapter, there was very little previous research looking at nonmotorized users' paths through shared space sites so I used several similar, pre-existing surveys in developing the online surveys. The Kaparias, et al. survey, in their work on London's Exhibition Road, included their 10-question survey instrument in their 2013 article. While the Kaparias, et al. cyclist perception work is most similar to my own, I was also interested in the paths users choose through the space, as well as their reasons. Therefore, I supplemented the Kaparias, et al. instrument with other questions from the 2007 NHL report on Laweiplein, the 2013 article by Moody, the 2008 Moller study on cycling and roundabouts, and various pedestrian audits. 
There were pluses and minuses to the decision to include an online survey. On the positive side, the cost of an online survey was much less than a mailed survey, and had format advantages that a paper survey lacks, such as drop down menus and automated skip patterns which can make the survey experience clearer for the respondent. Based on the literature as well as this project's goals and requirements, I included some stated preference questions to elicit if the shared space intersections influenced route choice, such as intersection avoidance.

On the negative side, an online survey may be intimidating or inaccessible for some users. The internet is now available to the majority of people in the United States as well as England. According to the UK's Office for National Statistics (ONS), 83\% of British households had internet access in $2013^{3}$. However, internet usage is much lower in older British age groups, with the age group 65 and older using the internet the least of all age groups. It was possible that some cyclists in Ashford, Poynton, or Coventry may not have had internet access or proficiency, and these users may have been missed.

The sampling population of this survey was cyclists in the English towns of Ashford, Poynton, and Coventry who ride through at least one of study sites. Pretesting the survey

${ }^{3}$ Statistical bulletin: Internet Access - Households and Individuals, 2013

http://www.ons.gov.uk/ons/rel/rdit2/internet-access---households-andindividuals/2013/stb-ia-2013.html 
indicated it took about 10-15 minutes to complete online; the language was also reviewed by two British English speakers to make sure the terms used in the survey made sense in the British setting (for instance, pavement instead of sidewalk, and junction instead of intersection). The survey also included the following categories: demographics, route options (through and to), experience riding, and intersection perceptions. (See Appendix B for the survey.)

I created a survey for each site using the on-line survey software, Qualtrics. In order to capture a range of cyclists, I initially planned to intercept cyclists at the shared space intersections and the control site intersections. Once on the ground, I decided against intercepting cyclists primarily because I would have needed additional time at each site to intercept because I could not do this while filming; time and money were limiting factors. As indicated in Table 4, I received additional help from several local groups in distributing the survey links to potential respondents. For instance, I sent the online survey out to several bicycle shops and cycling groups; a cycling group in the Kent area asked me to write up a brief description of the survey, including the links, and they published it in their monthly newsletter. The City of Coventry's planning department, the staff of which I had communicated with regarding video permission and then met with, sent out the survey links to their listserv, which included faculty and staff at the University. BBC Radio (Coventry) also heard about my research and interviewed me for one of their morning shows; they then posted the survey links on their Facebook page. The town of Poynton posted the research and survey description, and included it, and the survey links, on the town's website. 
Table 5: Online survey distribution methods by site

\begin{tabular}{llllll}
\hline $\begin{array}{l}\text { Wye } \\
\text { (control) }\end{array}$ & $\begin{array}{l}\text { Elwick } \\
\text { Square }\end{array}$ & $\begin{array}{l}\text { Coventry } \\
\text { (shared) }\end{array}$ & $\begin{array}{l}\text { Coventry } \\
\text { control }\end{array}$ & $\begin{array}{l}\text { Poynton } \\
\text { (shared) }\end{array}$ & $\begin{array}{l}\text { Poynton } \\
\text { control }\end{array}$ \\
\hline $\begin{array}{l}\text { Local bike } \\
\text { shop }\end{array}$ & $\begin{array}{l}\text { Local bike } \\
\text { shop }\end{array}$ & City listserv & City listserv & $\begin{array}{l}\text { Village } \\
\text { website }\end{array}$ & $\begin{array}{l}\text { Village } \\
\text { website }\end{array}$ \\
$\begin{array}{l}\text { Monthly } \\
\text { newsletter }\end{array}$ & $\begin{array}{l}\text { Monthly } \\
\text { newsletter }\end{array}$ & $\begin{array}{l}\text { BBC Radio } \\
\text { interview }\end{array}$ & $\begin{array}{l}\text { BBC Radio } \\
\text { interview }\end{array}$ & $\begin{array}{l}\text { Local bike } \\
\text { shop }\end{array}$ & $\begin{array}{l}\text { Local bike } \\
\text { shop }\end{array}$ \\
& & BBC Radio & BBC Radio & & \\
& Facebook & Facebook \\
page & page & \\
\end{tabular}

\section{Data processing and statistical analysis}

\section{Analysis overview}

Both the videos of the cyclist paths through each intersection as well as responses from the site-specific online surveys were analyzed.

The observational component of this project looked at the variation of movement from the observed and predicted paths for each of the study's 6 intersections as well as the amount of variation between the shared space intersections as compared to the control intersections. For instance, when comparing the paths chosen by cyclists through the control intersections, how much more path variation was, or was not, observed in the paths cyclists choose when crossing the shared space intersections?

\section{Video analysis}

Each site had at least 10 hours of video processed and analyzed. The video was filmed in HD using a GoPro camera mounted on a 12' tripod. I chose VLC media player for video 
playback because it is easy to manipulate the playback speed and video resolution. Given the scale of the analysis and the importance the sites themselves have on the analysis, it was important to present the bicycle paths in a manner as illustrative and as easy to read as possible. Each site previously had been drawn up to scale in AutoCAD with an overlaid, numbered, 8' by 8' grid along the $\mathrm{X}$ and $\mathrm{Y}$ axes. Using 11" by 17" sheets, each cyclist had his/her own data sheet, and the path each cyclist took was traced upon the site plan. The grid overlay allowed the points along each path to be labeled (x, y) so that each path then could be plotted on a graph. This work needed to be done by hand because there was no software yet available to meet my specific needs.

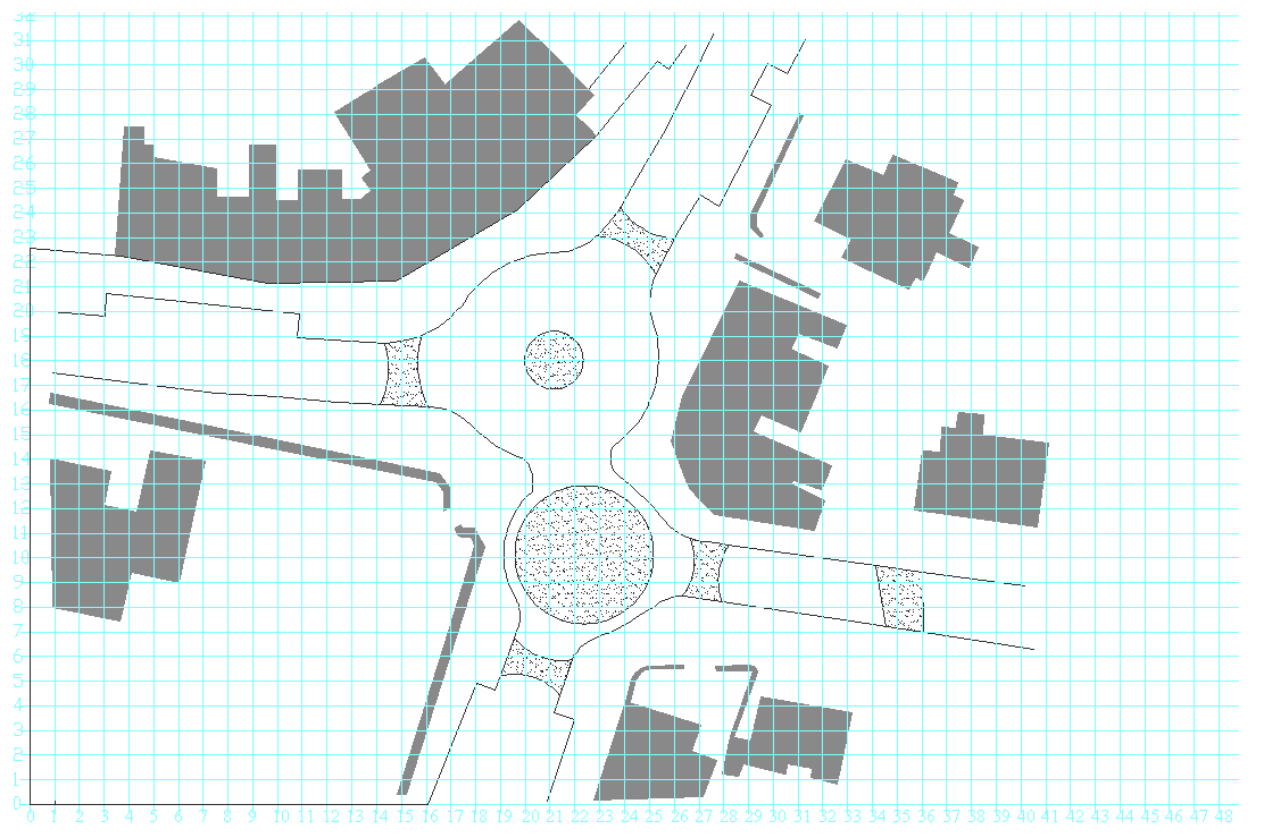

Figure 40: Data processing sheet, Poynton example

I plotted each cyclist path on the gridded overlay. In addition to the variables noted in Table 
3, I also noted the number of nodes for each observed path. As defined in Figure 37, I called these bends and deviations in the paths 'nodes'; the greater the number of nodes in a cyclist's path, the longer the path taken through the intersection will be. Given the observed OD (Table 3) each path had an 'ideal' path (Figure 37) to compare it to. The difference between this 'ideal' number of nodes and the observed number of nodes was calculated; this is the dependent variable 'node difference'.

\section{Survey analysis}

\section{Bias and error}

There are several errors that may arise when doing surveys: "coverage, sampling, nonresponse, and measurement" (Dillman et al. p16). The sources of error anticipated in this research include coverage error - the error found when not all potential respondents have an equal chance of being surveyed. This is possible when trying to do intercept surveys of the cyclists using the survey site but certain groups may choose not to ride through the intersection. The inclusion of a second intersection, which is not a shared space site, will hopefully catch those cyclists who may choose not to ride through the shared space intersection. However, the surveys will not catch cyclists who prefer, or cannot, ride through either of each city's sites. This is therefore a form of sampling bias because even an increase in the sample size will never capture these riders.

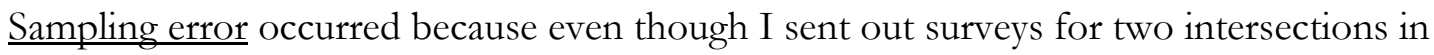
each town, there still must have been cyclists I missed either due to site selection (also 
sampling bias), or various online related factors. Obviously, it was impossible to survey the entire cycling population who ride through Ashford, Poynton, and Coventry, therefore, some sampling error was inevitable.

Nonresponse errors were inevitable. The surveys were sent out via various online resources, such as Coventry University listserv, the village of Poynton newsletter, and an Ashford regional cycling newsletter. An additional survey boost happened after BBC Radio Coventry interviewed me and posted the survey links on its Facebook page. Despite the various online delivery methods, there would have been many people who saw the relevant survey links but did not take, or complete, the online surveys. Some of these respondents may have been different from those who do not respond in ways relevant to the study.

Measurement errors occur when respondents' answers are inaccurate or imprecise. My survey, for instance, looked at how cyclists navigate through the selected intersections. Some respondents may have answered these questions imprecisely due to a variety of factors, including misunderstanding the questions as worded or confusing survey design. Measurement error can reduce the likelihood that there is a significant difference between the shared space sites and the control sites.

\section{Limitations}

This study had multiple limitations. With respect to the site selection, shared space projects are rare, at least outside of the Netherlands where they originated, and given the study's need to look at cyclists and intersections, the pool of applicable study sites was small. Multiple 
concerns contributed to the decision to look at shared space projects in England instead of the Netherlands including, but not limited to, language, bicycle culture, traffic laws, and personal finances.

As discussed previously, the quality of video observations was also limited both by camera resolution as well as camera siting. I used a 12' tall tripod which meant the video was filmed from a lower height so that the paths (and variables) were not always be as clear as they would have been if observed from higher up.

Unfortunately, software had not caught up with the need to track cyclist paths at this scale so that instead of employing a program that could identify, and track, individual cyclists as they rode through the intersections, I manually traced the paths on gridded site plans. Node difference is not a perfect measure. It shows the amount of deviation along the path the cyclist takes in comparison with the ideal paths I calculated for each OD leg. It does not always indicate, for instance, if the cyclist path is chosen to avoid the center of the site by riding along the sidewalk or that riding along a sidewalk and through crosswalks may actually result in a shorter, more efficient path. This is a weakness in the measurement-it is not very clear and still open to interpretation.

Online surveys have limitations as previously discussed; my time available on the ground in England prevented doing intercept surveys at the shared space and control intersections. Instead, I relied on community contacts to share the relevant surveys to possible respondents. 


\section{Summary}

My research looked at how people ride through several roadway spaces as well as how people perceive those spaces. When designing this research, it was clear that my research questions and hypotheses were best addressed by mixed methods research-video observations and online surveys.

My research questions and hypotheses regarding a cyclist's perceptions of shared or control intersections build on previous stated preference surveys. I used several questions shared space researchers have used but, by trying to create questions regarding preferred paths through an intersection, I created a new form of survey questions regarding path choice.

Because bicycle travel data typically are collected and analyzed at the route scale, and not at the intersection scale, I also had to create a new method and framework for collecting, processing, and analyzing the video observation data. Fortunately, technology provided me with a very small, lightweight, and high resolution video camera I could easily use and travel with.

The existence of these new types of spaces, as well as the growing interest in nonmotorized users and transportation safety, allowed me to design a type, and scale, of research not done on cyclists to date. There is now the interest (as well as the need) to analyze the detailed movements of bicycle riders to determine how the site and the related dependent and independent variables impact them 


\section{CHAPTER IV}

\section{OBSERVATIONAL RESULTS}

I observed a total of 1,748 cyclists traveling through the six study sites. The Results section looks the variables collected regarding the observed cyclist paths. First I will discuss the observed characteristic variables and the descriptive statistics as well as plots of cyclist path choices. Then I will consider the behavioral variables and the related descriptive statistics, and path plots. Finally, the observational results chapter will present each site's traffic volume data and then the analysis of the path and node differences for each site as well.

I classified the variables by rider characteristics and rider behaviors (see Table 3). The characteristics were independent variables such as gender or helmet use. The rider behavior variables included observable actions such as sidewalk use and walking.

I did not note factors such as clothing type (lycra or not), pedal type (clipless or platform), panniers or not, and so on. I also chose not to note whether or not a cyclist wore day-glo colored clothing. (Many cyclists did wear day-glo vests while riding, but I was unable to determine whether it was worn on the job and kept on while riding or if it was worn for bicycle safety reasons.) Even noting clothing type could not clarify if a cyclist was commuting or riding recreationally. For instance, some cyclists may commute wearing traditional bicycle racing attire, such as a lycra bicycle jersey and padded shorts, but others commute in work clothing. Therefore I could classify the skill or experience level of a cyclist 
due to the type of clothing worn, bicycle ridden, or even presence or absence of a helmet.

\section{Rider characteristics}

I describe each variable and the descriptive statistics calculated with respect to each study site individually, with all of the control sites pooled together, and with all of the shared sites pooled together, and when appropriate, all six of the study sites pooled together. As

discussed previously, not all variables were determinable by observation. I had to code some path variables as 'unknown' due to a variety of factors. For instance, some sites were too large to accurately identify a rider's gender from across the intersections, while others had building overhangs that cast obscuring shadows.

\section{Gender $^{4}$}

Figure 42 shows the breakdown by site and observed gender percentages. Of all observed riders, there was a large share $(58 \%)$ of cyclists whose genders were not clearly identifiable. I coded these cyclists 'unknown'. When considering the identifiable genders, the males in all cases dominated the gender split of bike riders observed. Wye, the quietest intersections, had the largest percentage of female riders at 24\%. Figure 42 appears in two versions; the first

\footnotetext{
${ }^{4}$ I reference 'cyclist' but I also mean 'paths'. Some cyclists were seen multiple times as they crossed through the intersections more than once but each path they rode was counted individually.
} 
one groups the sites together by area so that a shared site is clustered by its local control (such as Ashford with both Wye and Elwick Square). Figure 118 in Appendix $F^{5}$ groups the sites by study type.

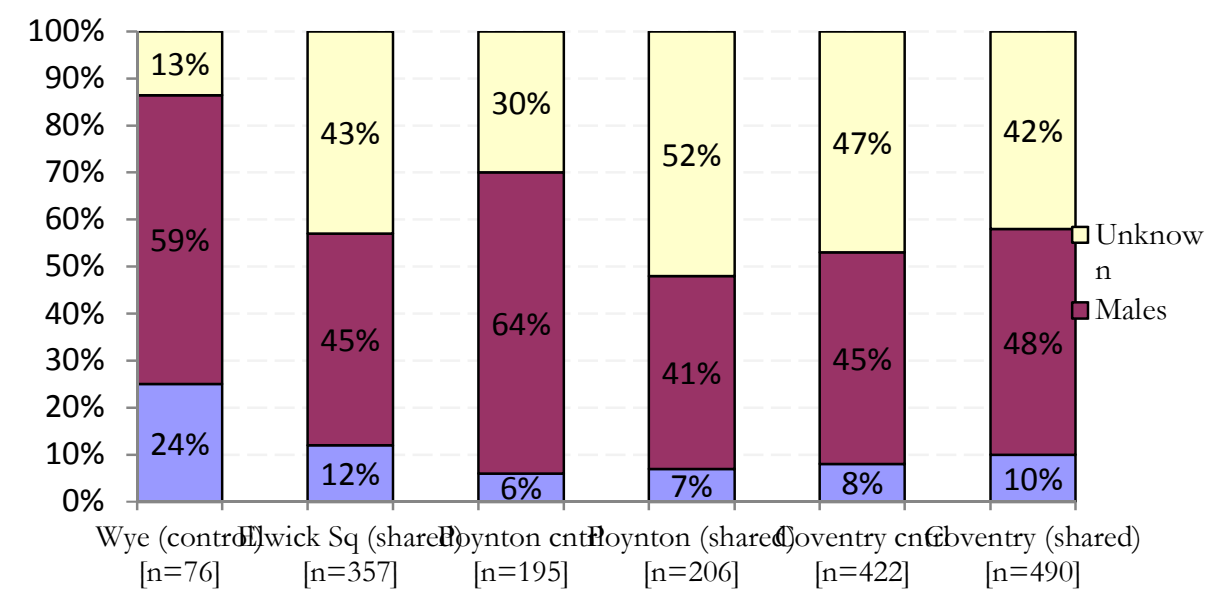

Note 6 : Wye $\mathrm{p}=0.819$, Elwick Square $\mathrm{p}=0.212$, Poynton control $\mathrm{p}=0.337$, Poynton shared $\mathrm{p}=0.156$, Coventry control $\mathrm{p}=0.213$, Coventry shared $\mathrm{p}=0.692$. All shared $\mathrm{p}=0.058$, all control $\mathrm{p}=0.285$.

Figure 41: Gender percentages by site

I found no significant relationships between gender and study sites. Removing unknown genders from this analysis, I conducted 1-way ANOVAs to compare the effects of gender

${ }^{5}$ When appropriate, a second copy of this chapter's bar graphs is included in Appendix F. The data in the Appendix figures are grouped according to site type, control versus shared, instead of by location. In some instances, trends are more apparent in the Appendix figures.

${ }^{6}$ Unknowns (9s) not included 
on the dependent variable of node difference and ran ANOVA tests for the data sets-- both individually and pooled (full data set, all control observations, and all shared observations). I found no significant variance of mean node differences for any of the sites—neither individually, nor pooled. These results indicate that there were no significant differences, by gender, in how males and females rode through the either the shared or the control study sites.

As will be discussed in the following sections, gender had multiple significant relationships with several other variables: helmet use, crosswalk use, bicycle type, and node difference.

\section{Helmet use}

Helmet data were categorized by presence, absence, and unknown. Of the 1748 observed cyclists, helmet use for 250 cyclists was unclear (Figure 43), therefore labeled as unknown for helmet use. Helmet use was irregularly distributed among the sites. Wye and Poynton Control had the highest percentages of helmet use among the control sites, $66 \%$ and $87 \%$, respectively. Poynton had the highest percentage of helmet use (54\%) and Elwick Square had the lowest share of helmet use (18\%) among the shared spaces. 


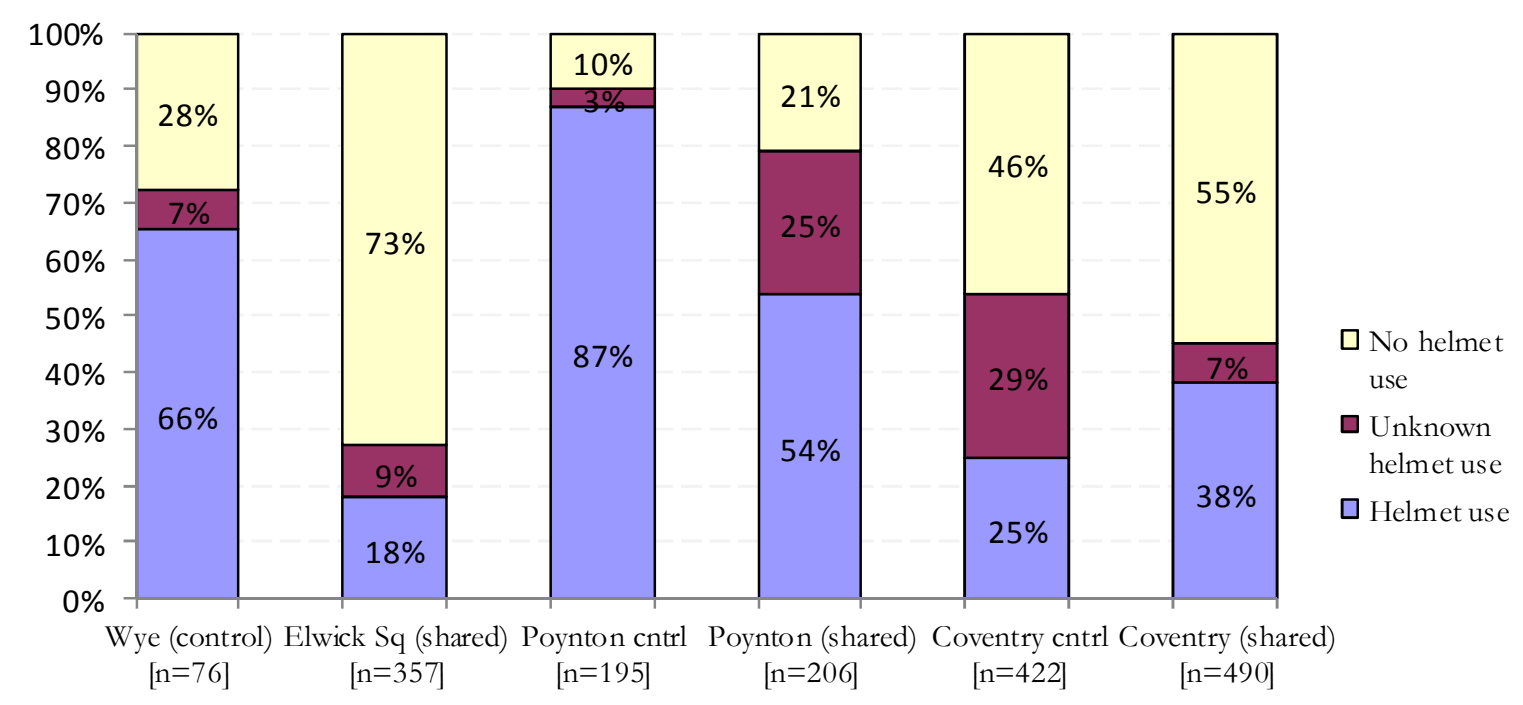

Figure 42: Helmet use by site

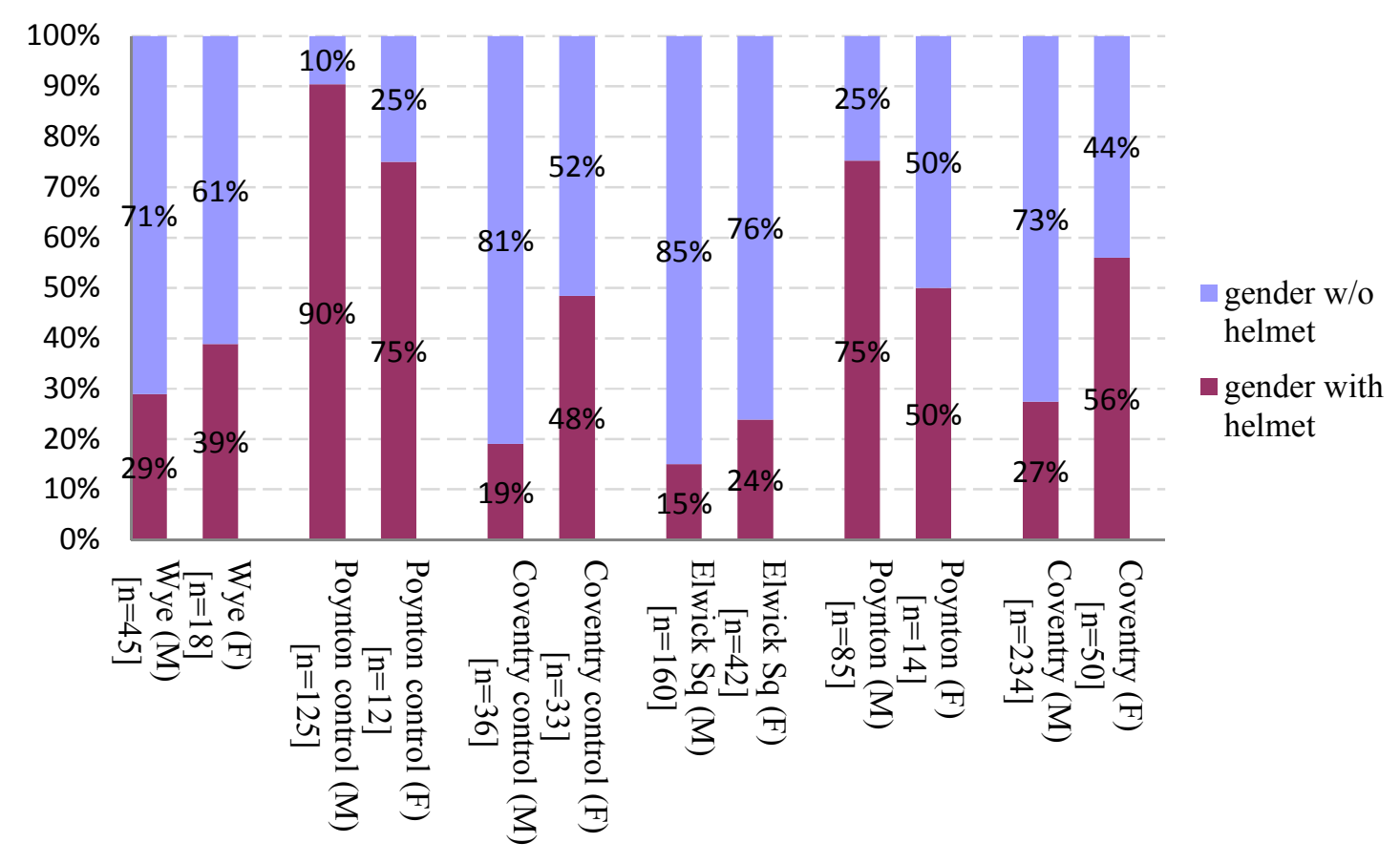

Figure 43: Percentage helmet use by gender 
When looking at all helmet use and rider gender (Figure 44), a higher share of males wore helmets than females (Figure 45) at only two sites: Poynton control and Poynton. At the other four sites, the percentage of women who wore helmets was higher than the percentage of males who wore helmets. This indicates that males were more likely to wear helmets at both of the Poynton sites.

When delving deeper into helmet use and other potentially associated variables, chi-square tests of the data sets showed significant associations (Table 5) between helmet use and the following variables:

Table 6: Chi-Square test results for Helmet use

\begin{tabular}{lll}
\hline \multicolumn{1}{c}{ Study sites } & \multicolumn{1}{c}{ Variables } & \multicolumn{1}{c}{$\begin{array}{c}\text { Significant Chi-Square } \\
\text { results }\end{array}$} \\
\hline \multirow{2}{*}{$\begin{array}{l}\text { Combined shared and } \\
\text { control data set }\end{array}$} & Helmet use and Gender & $\mathrm{c}^{2}=295.0, \mathrm{p}=.000$ \\
& Helmet use and Sidewalk & $\mathrm{c}^{2}=312.5, \mathrm{p}=.000$ \\
& Helmet use and Crosswalk & $\mathrm{c}^{2}=87.2, \mathrm{p}=.000$ \\
Shared data set & Helmet use and Gender & $\mathrm{c}^{2}=116.9, \mathrm{p}=.000$ \\
& Helmet use and Sidewalk & $\mathrm{c}^{2}=127.2, \mathrm{p}=.000$ \\
& Helmet use and Crosswalk & $\mathrm{c}^{2}=35.2, \mathrm{p}=.000$ \\
\hline
\end{tabular}

ANOVAs run per site with unknown helmet use showed significant variance in node differences for a few sites. However, once I filtered out those paths with unknown helmet use, only two of the shared sites, Poynton and Coventry, still showed a significant effect between helmet use and node difference (Table 6). The Coventry control site, as well as the pooled control site data set, also showed significant relationships between helmet use and 
node difference. This indicates that there is a relationship between riders who wear helmets and those who ride on sidewalks as well as through crosswalks.

Table 7: ANOVA results for Helmet use

\begin{tabular}{lll}
\hline \multicolumn{1}{c}{ Data set } & \multicolumn{1}{c}{ Variables } & \multicolumn{1}{c}{ Significant Chi-Square results } \\
\hline & Poynton & $\mathrm{F}(1,151)=5.258, \mathrm{p}=.023$ \\
$\begin{array}{l}\text { Nodediff and Helmet use } \\
\text { (excluding unknown) }\end{array}$ & Coventry & $\mathrm{F}(1,454)=11.946, \mathrm{p}=.001$ \\
& Coventry control & $\mathrm{F}(1,294)=7.345, \mathrm{p}=.007$ \\
& Control sites data set & $\mathrm{F}(1,552)=11.117, \mathrm{p}=.001$ \\
\hline
\end{tabular}

\section{Bicycle type}

Another rider characteristic I identified was the type of bicycles that cyclists rode through the study intersections. It was easier to identify bicycle type; of the almost 1,800 observations only 180 bicycles were unidentifiable. Initially, I coded several types of

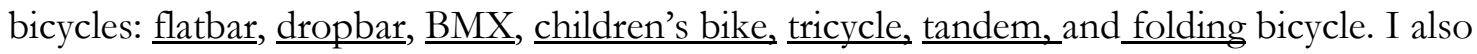
coded when I observed the riders carrying children (trailer, seat behind, seat in front). Given the lower numbers in some categories, I winnowed the categories down to three leaving just

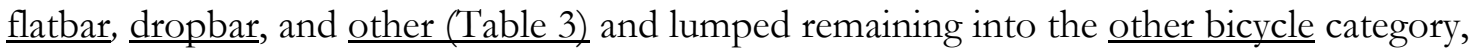
Flatbar bicycles (such as mountain bikes and hybrids) were the most popular bicycles ridden across all of the intersections, with the sole exception of Poynton Control ( $25 \%$ flatbar). Figure 46 shows that the percentage of dropbar bicycles was highest at Wye, Poynton, and Poynton control. These also were the same sites with the highest share of helmet use of all six study sites (Figure 43). 


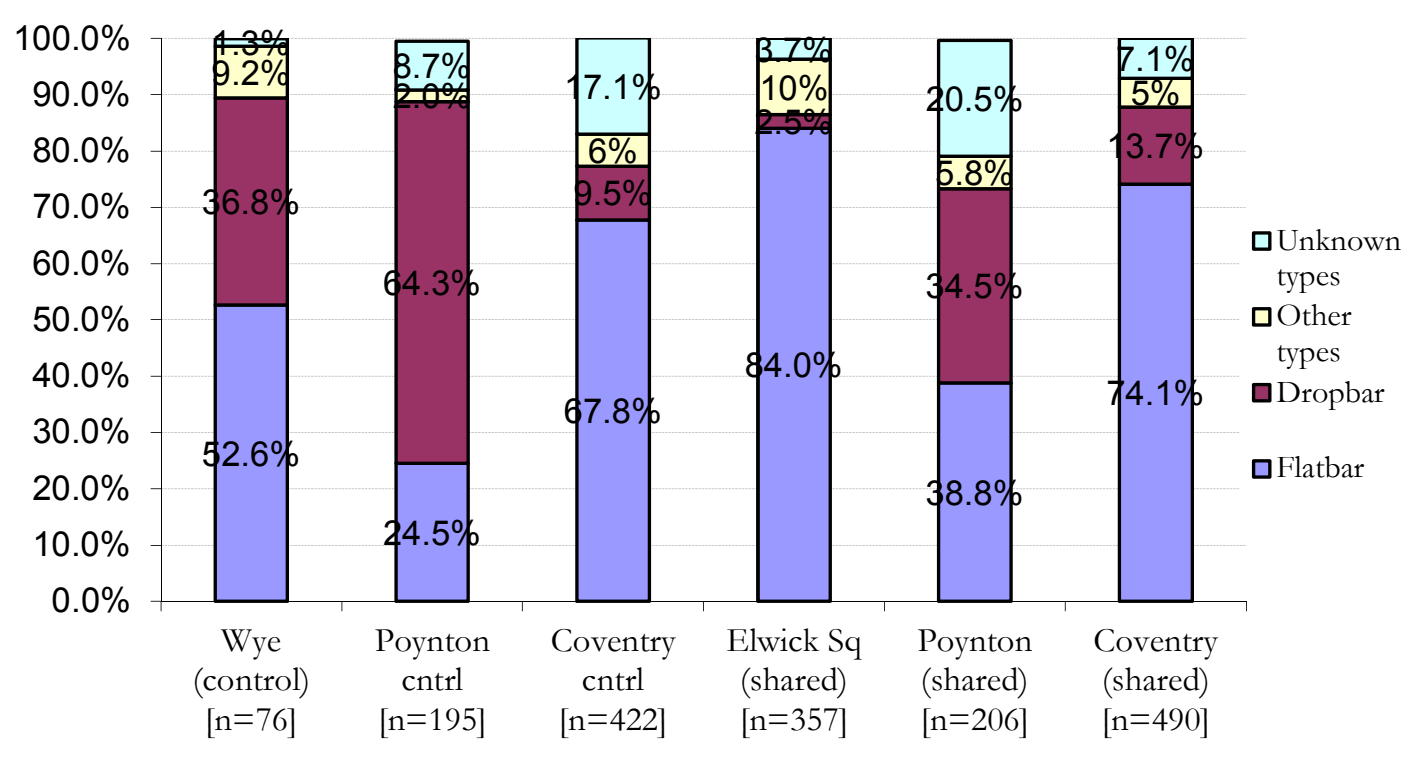

Figure 44: Bicycle type by site

\section{Rider behaviors}

As discussed in Chapter III, I divided the collected variables up by rider characteristics and behavior. The characteristics of a cyclist, whether they wore a helmet, what type of bike they rode, as well as their gender, are independent variables. However, the cyclists' reactions or behaviors while riding through the intersections was classified as behavioral and were dependent variables. As identified in Table 3, behavioral characteristics included sidewalk or crosswalk use, and number of nodes in their observed paths.

\section{Sidewalk and crosswalk use}

As defined earlier, none of the shared study sites were 'pure' shared sites. That is, they all had sidewalks and crosswalks along some portion of each intersection. All of the control 
sites had sidewalks and crosswalks as well. Figure 46 shows the percentage of observed cyclists who rode on or off a sidewalk for some portion of their path through the study sites. When looking at the physical sidewalk itself, the control intersections of Wye and Poynton had the narrowest sidewalks of the six sites; understandably, they also showed the least amount of sidewalk use. The other sites had wider sidewalks (see Chapter III for photos of each site), and I observed extensive sidewalk use at the rest of the sites ranging from $42 \%$ to a high of $88 \%$. Chi-square tests on the associations between the full dataset (all shared and control observations), the shared dataset (all shared site observations), and the control dataset (all control site observations) and sidewalk use showed significant associations for all three data sets indicating a relationship between all sites' pooled datasets (control sites, shared sites, and all sites) and sidewalk use.

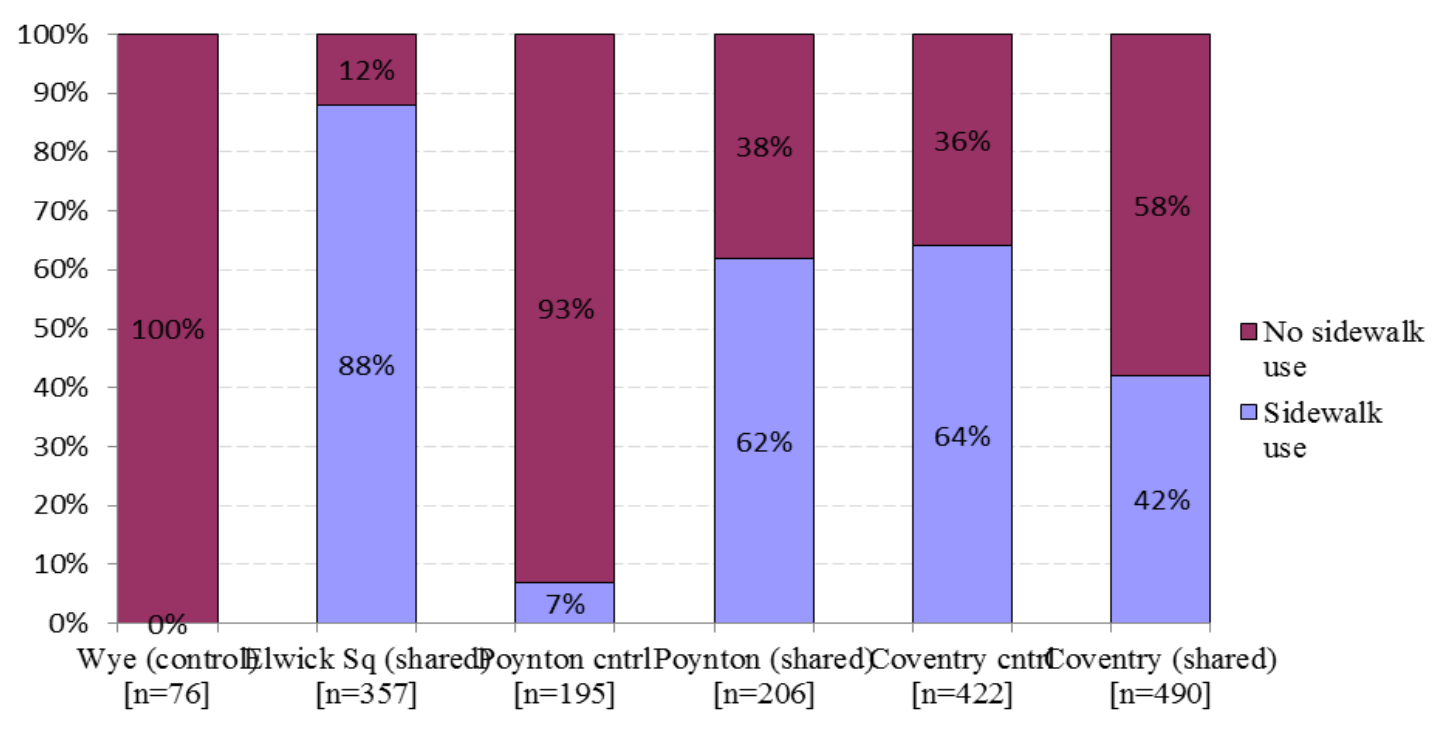

Note: full data set (shared and control pooled) $\left(\mathrm{c}^{2}=469.3, \mathrm{p}=.000\right)$; shared data set $\left(\mathrm{c}^{2}=178.0, \mathrm{p}=\right.$ $.000)$; and control data set $\left(\mathrm{c}^{2}=233.9, \mathrm{p}=.000\right)$.

Figure 45: Sidewalk use by site 
Narrowing the analysis down to individual site observations, I conducted an ANOVA to compare the variance between cyclist sidewalk use and node difference for each site's dataset as well as for the pooled datasets. Two of the shared sites, Poynton and Coventry, showed significant effects between sidewalk use and node difference (Table 7). But ANOVAs on the pooled shared sites showed no significant effects. The control sites, Poynton control and Coventry control, showed significant effects between sidewalk use and node difference (while Wye had no observed sidewalk use). The pooled control sites variance was also significant.

Table 8: Sidewalk use with respect to node difference

\begin{tabular}{|c|c|c|}
\hline Study site & Mean (SD) & Significant ANOVA results \\
\hline \multicolumn{3}{|l|}{ Poynton } \\
\hline Sidewalk & $3.52(3.32)$ & {$[\mathrm{F}(2,200)=10.217, \mathrm{p}=.002]$} \\
\hline No sidewalk & $4.97(2.81)$ & \\
\hline \multicolumn{3}{|l|}{ Coventry } \\
\hline Sidewalk & $2.73(2.78)$ & {$[\mathrm{F}(1,488)=12.635, \mathrm{p}=.000]$} \\
\hline No sidewalk & $2.05(1.4)$ & \\
\hline \multicolumn{3}{|l|}{ Poynton control } \\
\hline Sidewalk & $0.50(1.23)$ & {$[F(1,193)=10.447, p=.001]$} \\
\hline No sidewalk & $1.5(1.1)$ & \\
\hline \multicolumn{3}{|l|}{ Coventry control } \\
\hline Sidewalk & $1.7(2.21)$ & {$[\mathrm{F}(1,412)=26.021, \mathrm{p}=.000]$} \\
\hline No sidewalk & $.74(.99)$ & \\
\hline \multicolumn{3}{|l|}{ Pooled control } \\
\hline Sidewalk & $1.64(2.2)$ & {$[F(1,681)=10.442, p=.001]$} \\
\hline No sidewalk & $1.22(1.17)$ & \\
\hline
\end{tabular}


As discussed above regarding sidewalks, each site had crosswalks as well. I coded three behaviors with respect to crosswalk use (Table 3): crosswalk use, no crosswalk use, and veering toward a crosswalk. Figure 50 shows the share of each crosswalk behavior per study site. Crosswalk use was not counted when someone rode from one sidewalk to another via the curb cut and crosswalk. Crosswalk use was only counted when it performed independently of sidewalk use. A cyclist could still ride on the sidewalk and in a crosswalk during one path across the intersection but these behaviors would have occurred at separate instances during the path.

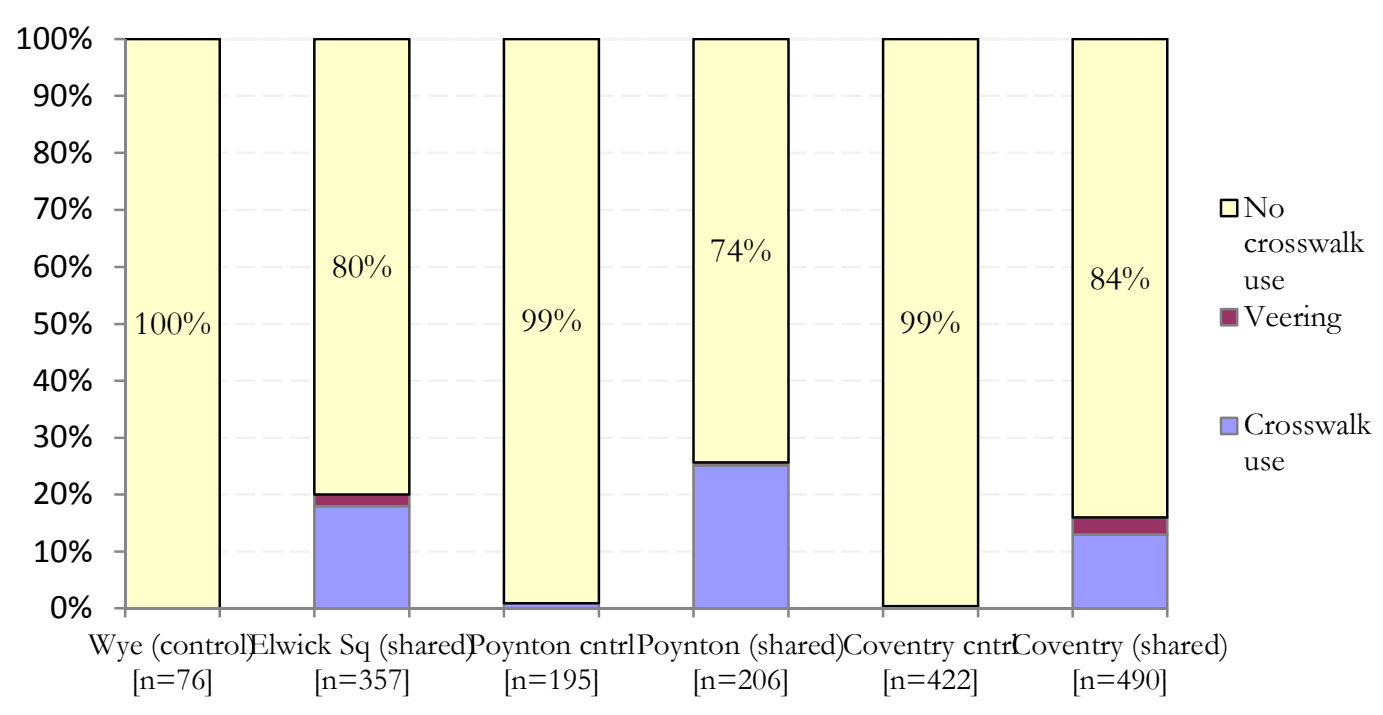

Note: shared dataset $\left(\mathrm{c}^{2}=17.15, \mathrm{p}=0.002\right)$

Figure 46: Crosswalk use by site

A chi-square test on the pooled shared data set showed an association between study site and crosswalk use. An analysis of variance showed the effect of crosswalk use and node 
differences for all the sites (except for Wye and Poynton control, both of which had little to no crosswalk use observed). Understandably, this is where the largest values for node differences were seen. When looking at the separate datasets, the Coventry control site's variance showed significant effect between crosswalk use and node difference while pooled control sites also showed significant effect (because the large number of crosswalk users in Coventry control itself as compared to the other control sites).

Table 9: Crosswalk use with respect to node difference

\begin{tabular}{|c|c|c|}
\hline Study site & Mean (SD) & Significant ANOVA results \\
\hline \multicolumn{3}{|l|}{ Pooled control } \\
\hline Crosswalk & $3.00(0.0)$ & \multirow{3}{*}[\mathrm{F}(2,680)=91.235,\mathrm{p}.000]{} \\
\hline No crosswalk & $1.00(1.4)$ & \\
\hline Veer & $2.89(1.8)$ & \\
\hline \multicolumn{3}{|l|}{ Coventry } \\
\hline Crosswalk & $5.38(2.3)$ & \multirow{3}{*}[F(2,487)=75.953,p=.000]{} \\
\hline No crosswalk & $1.89(1.7)$ & \\
\hline Veer & $4.52(2.5)$ & \\
\hline \multicolumn{3}{|l|}{ Coventry control } \\
\hline Crosswalk & $3.00(0.0)$ & \multirow{3}{*}[F(2,411)=106.09,p=.000]{} \\
\hline No crosswalk & $0.55(1.4)$ & \\
\hline Veer & $2.91(1.8)$ & \\
\hline
\end{tabular}

A pure shared space design does not have sidewalks or crosswalks—all of my study sites, as discussed in the Study Sites section, had crosswalks and sidewalks in some form. As with sidewalk use, the Wye and Poynton control sites saw essentially no crosswalk use. Coventry 
control and the three shared intersections all had many bike riders either use or veer toward the crosswalk while riding through the site. Poynton saw the largest percentage $(25 \%)$ of cyclists use the crosswalk in some manner. Despite the presence of the crosswalks, the vast majority of cyclists did not use them. For instance, $74 \%$ of Poynton cyclists did not use the crosswalk.

\section{Walking behavior}

One unexpected observation was the number of cyclists who were either accompanied by a walking companion $(n=24)$ or who walked a portion, or leg, of their path through the intersection $(\mathrm{n}=25)$. As Table 9 shows, the shared intersections saw a greater number of cyclists both with walking companions as well as with walking legs. As will be discussed later, the presence of both walking companions and walking legs through several of the study sites contributed to me designating Coventry control the primary comparative control intersection.

Table 10: Walking variables

\begin{tabular}{lllllll}
\hline Rider behaviors & $\begin{array}{l}\text { Wye } \\
(\text { control) }\end{array}$ & $\begin{array}{l}\text { Poynton } \\
\text { control }\end{array}$ & $\begin{array}{l}\text { Coventry } \\
\text { control }\end{array}$ & $\begin{array}{l}\text { Elwick } \\
\text { Square }\end{array}$ & Poynton & Coventry \\
\hline Walking companion & $0 \%$ & $0 \%$ & $1 \%$ & $2 \%$ & $3 \%$ & $2 \%$ \\
No companion & $100 \%$ & $100 \%$ & $99 \%$ & $98 \%$ & $97 \%$ & $98 \%$ \\
Total companion & $100 \%$ & $100 \%$ & $100 \%$ & $100 \%$ & $100 \%$ & $100 \%$ \\
$\mathbf{( \% )}$ & $\mathrm{n}=76$ & $\mathrm{n}=195$ & $\mathrm{n}=422$ & $\mathrm{n}=359$ & $\mathrm{n}=206$ & $\mathrm{n}=490$ \\
\hline
\end{tabular}




\begin{tabular}{lcccccc}
\hline Walking leg & $0 \%$ & $1 \%$ & $1 \%$ & $2 \%$ & $4 \%$ & $1 \%$ \\
No walking leg & $100 \%$ & $99 \%$ & $99 \%$ & $98 \%$ & $96 \%$ & $99 \%$ \\
Total walking legs & $100 \%$ & $100 \%$ & $100 \%$ & $100 \%$ & $100 \%$ & $100 \%$ \\
$\mathbf{( \% )}$ & $\mathrm{n}=76$ & $\mathrm{n}=195$ & $\mathrm{n}=422$ & $\mathrm{n}=359$ & $\mathrm{n}=206$ & $\mathrm{n}=490$ \\
\hline
\end{tabular}

Note for walking legs: $\left.\mathrm{c}^{2}=9.9, \mathrm{p}=.007\right)$. However, the observed numbers were so low I chose not to run any further tests on these data.

\section{Curb use}

Another unexpected observation was the fluidity with which many cyclists used the curbs in navigating the study sites. 13 cyclists jumped on or off a curb during their ride through the intersections, and 30 used curb cuts to either access the roadway or leave it (Table 10). For instance, in Coventry control, I observed 3\% of cyclists jumping on and off the curbs. The shared sites in Poynton and Coventry (and Coventry control) all had many cyclists jumping the curbs; several were observed both jumping a curb and using a curb cut on a single ride across the intersection. These behaviors were counted individually. Curb use in Elwick Square was not counted due to the arrangement of the plaza and the curbs. 
Table 11: Curb use variables

\begin{tabular}{lllllll}
\hline Rider behaviors & Wye & $\begin{array}{l}\text { Poynton } \\
\text { control }\end{array}$ & $\begin{array}{l}\text { Coventry } \\
\text { control }\end{array}$ & $\begin{array}{l}\text { Elwick } \\
\text { Square }\end{array}$ & Poynton & Coventry \\
\hline Curb cut & $0 \%$ & $0 \%$ & $7 \%$ & $\mathrm{n} / \mathrm{a}$ & $1 \%$ & $3 \%$ \\
Curb jump & $0 \%$ & $1 \%$ & $3 \%$ & $\mathrm{n} / \mathrm{a}$ & $7 \%$ & $13 \%$ \\
No curb & $100 \%$ & $99 \%$ & $90 \%$ & & $92 \%$ & $84 \%$ \\
Total & $100 \%$ & $100 \%$ & $100 \%$ & & $100 \%$ & $100 \%$ \\
& $\mathrm{n}=76$ & $\mathrm{n}=195$ & $\mathrm{n}=422$ & & $\mathrm{n}=206$ & $\mathrm{n}=490$ \\
\hline
\end{tabular}

Note: In the shared data set, an association between gender and curb use was found $\left(c^{2}=18.6, p=\right.$ .017). No other significant associations were found.

As explained in Chapter III (Methods), this measurement is a little different than the others. There were no curb cuts within the intersections that were not connected to crosswalks.

Wye, a control site, saw no curb use during my observations, and Poynton Control had only two observed instances.

\section{Traffic volumes}

I calculated average hourly morning and afternoon traffic volumes for each site. The Poynton intersections had the largest average hourly traffic volumes of the six study sites. The remaining four study sites all had approximately one-half to one-quarter of the hourly traffic as the Poynton sites. 


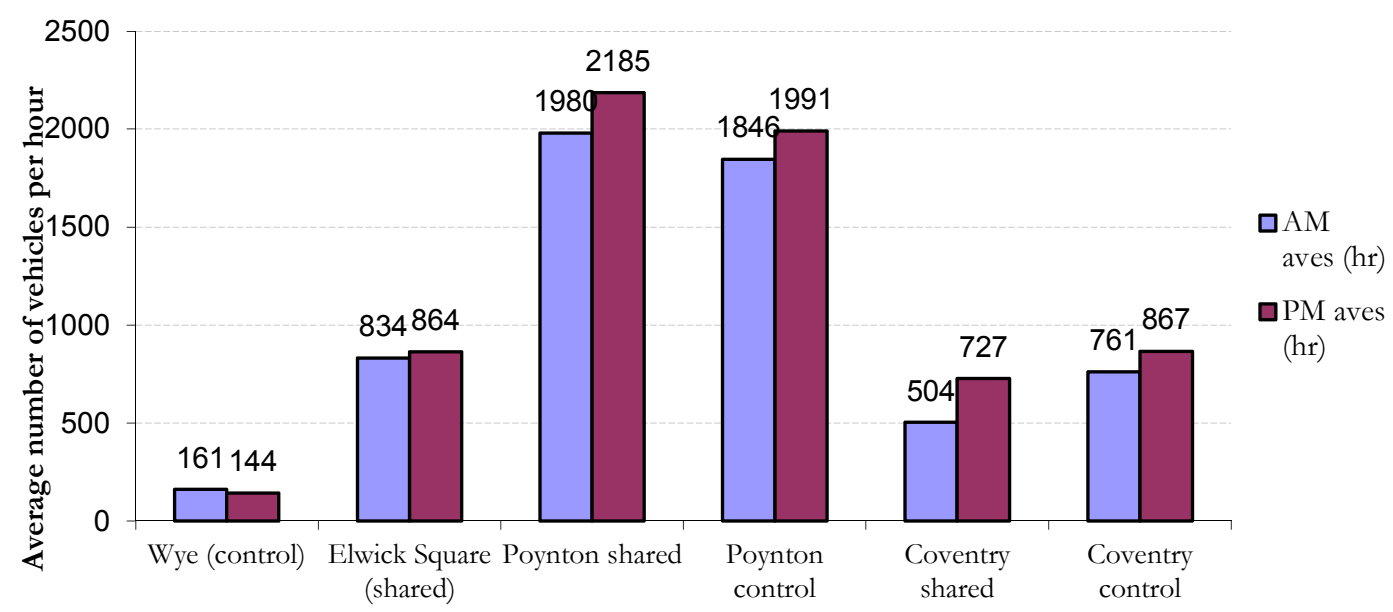

Figure 47: Average hourly number of vehicles

I also classified vehicles by size (Figure 49): large and smaller. Large vehicles were anything roughly the size of a transit bus (typically 30 -foot long or greater) or larger. Both of the Coventry sites had the greatest share of large vehicles while Wye had the smallest, with only two transit buses observed during the vehicle counting. 


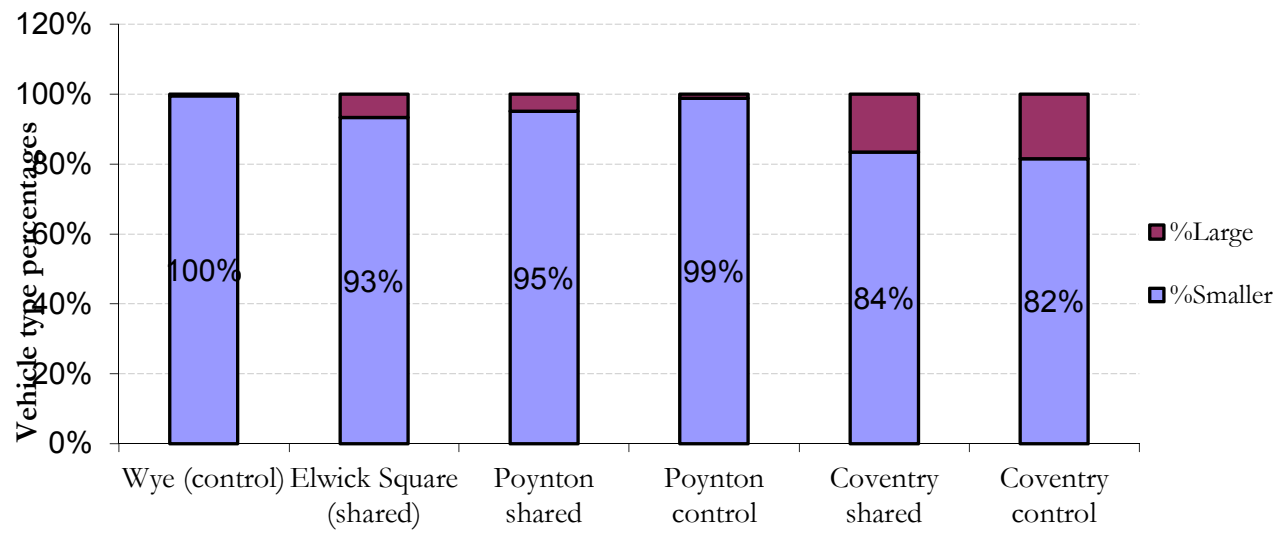

Figure 48: Vehicle sizes by percentage

Figures 50 to 55 present a selection of screen shots showing representative traffic volumes for each of the study sites. As can be seen in both Figure 48 and Figure 50, Wye was the quietest of all of the study sites. It also had the smallest observed shared of large vehicles.

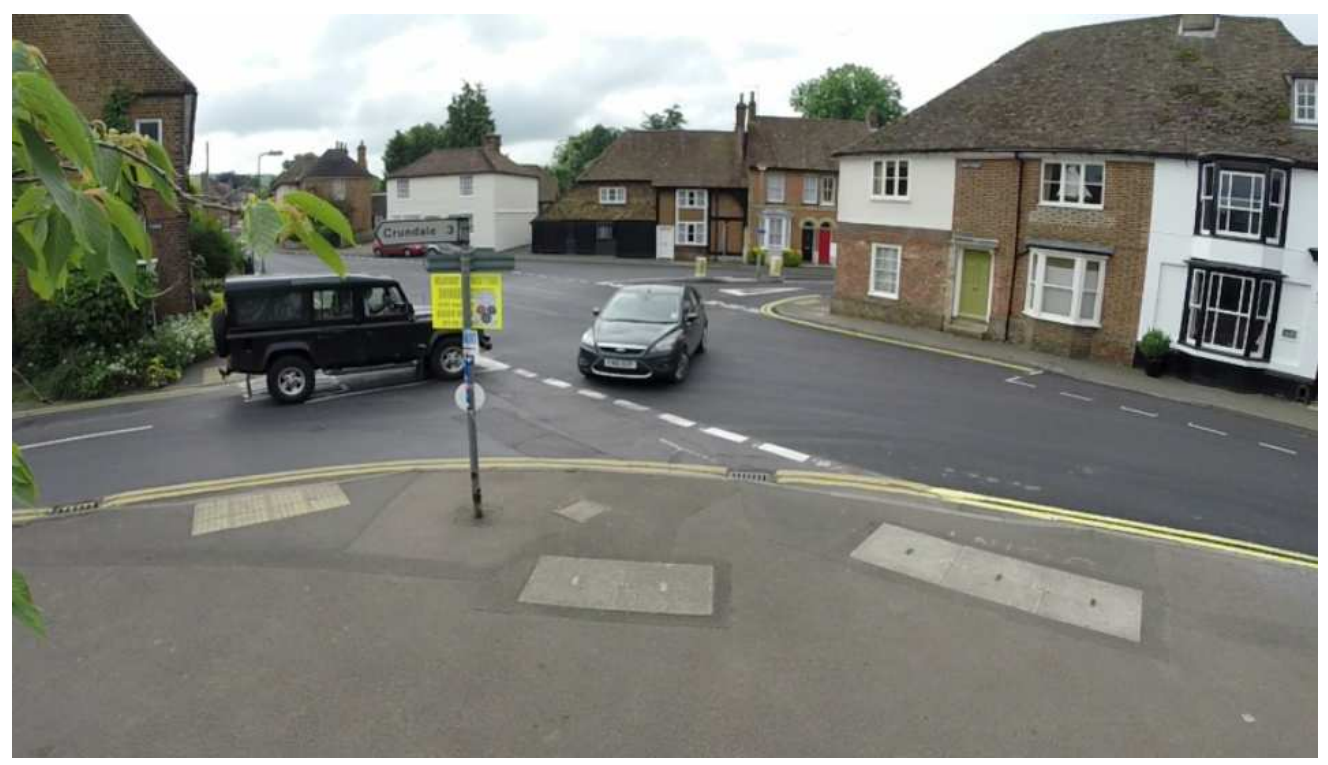

Figure 49: Wye--representative traffic volume 
Elwick Square was much busier than its accompanying control space, Wye. This shared space had similar levels of morning and afternoon traffic, and a little less than $10 \%$ was large vehicle.

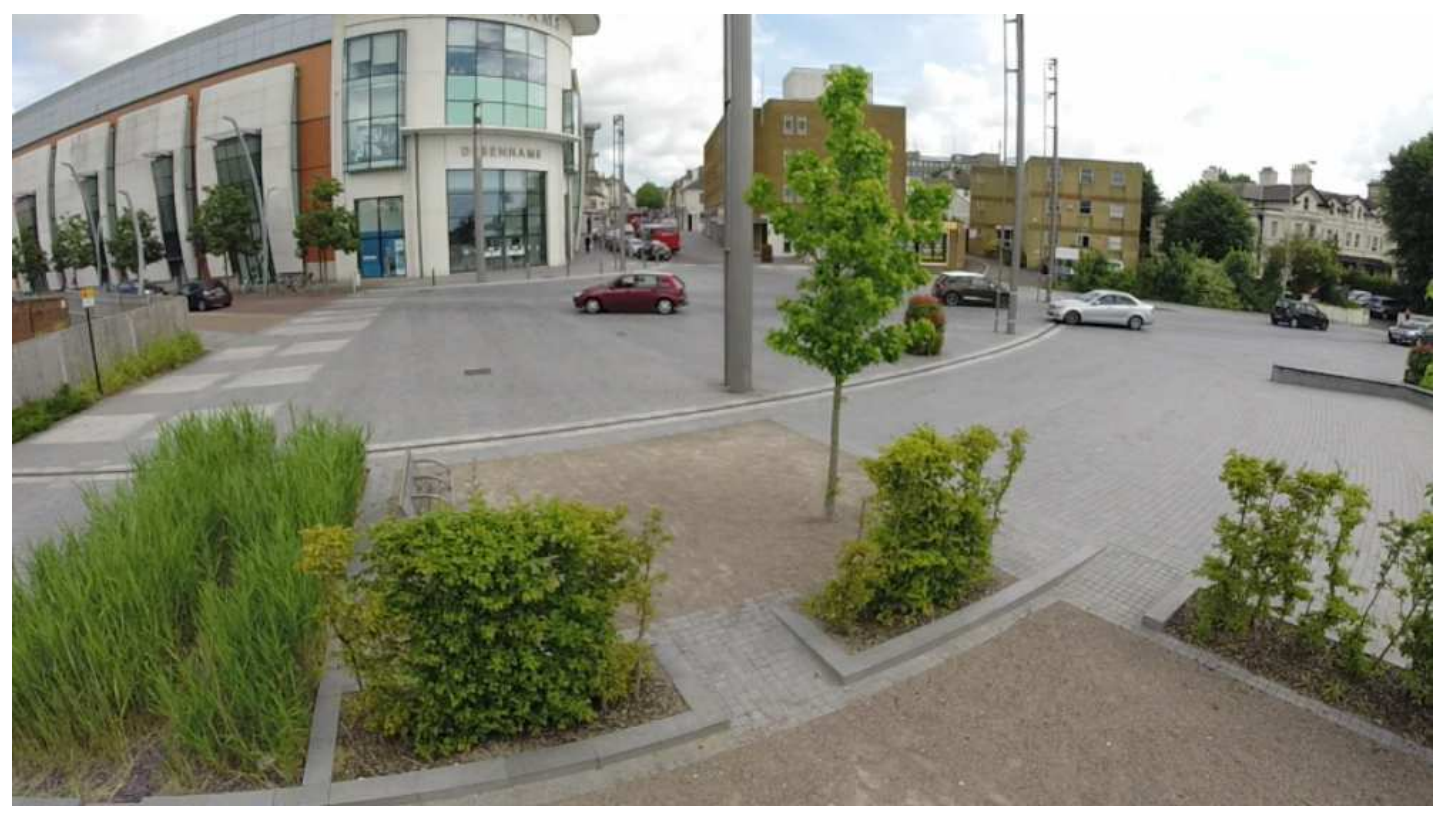

Figure 50: Elwick Square--representative traffic volume

The Coventry sites had the greatest percentages of observed large vehicles. The Coventry control intersection appeared busier than it actually was due to the greater share of larger vehicles, especially double-decker and articulated buses. 


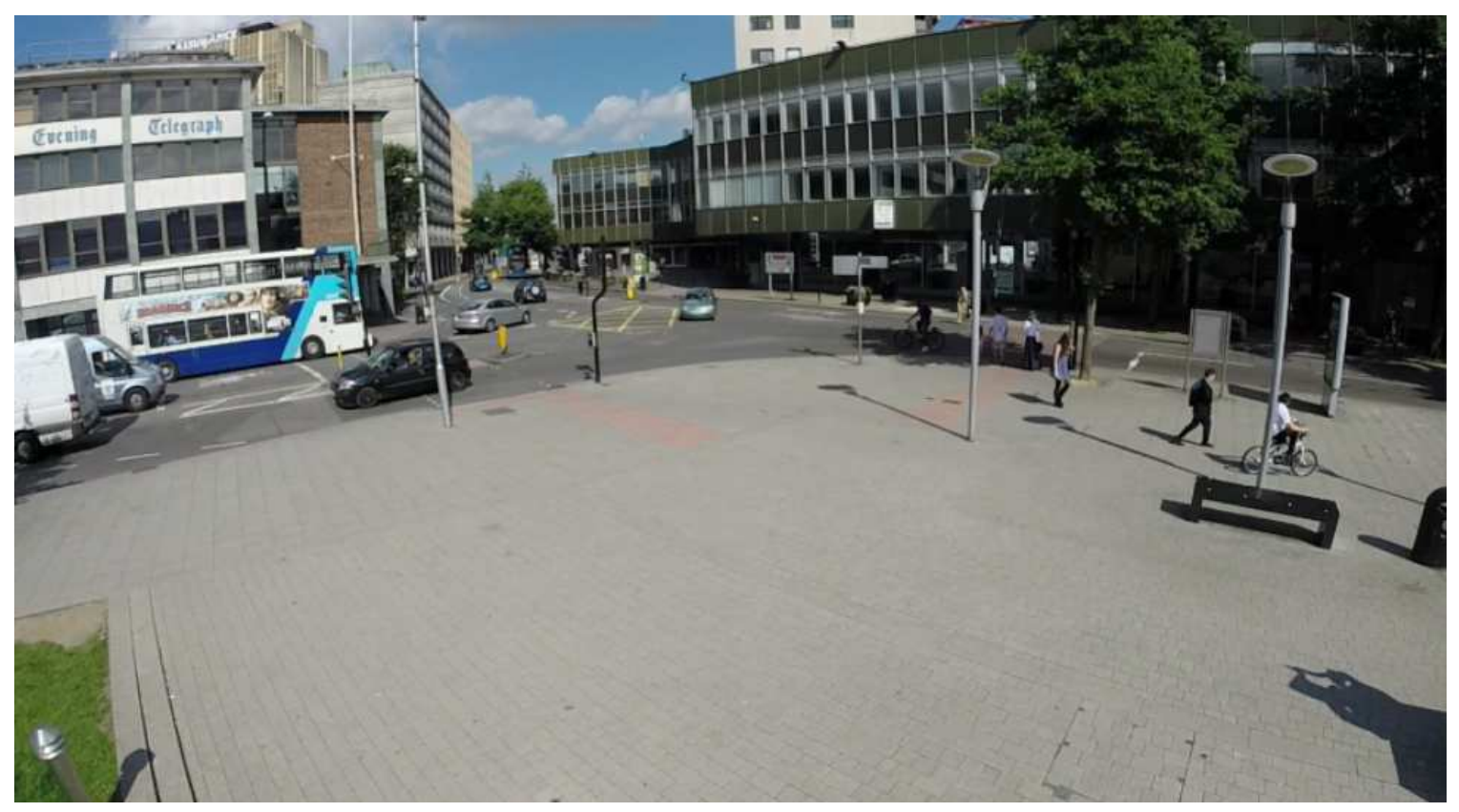

Figure 51: Coventry control--representative traffic volume

The Coventry shared intersection had somewhat lower traffic volumes than the control site but a similar share of large vehicles as the Coventry control intersection. Again, this was due primarily to the frequent bus service. 


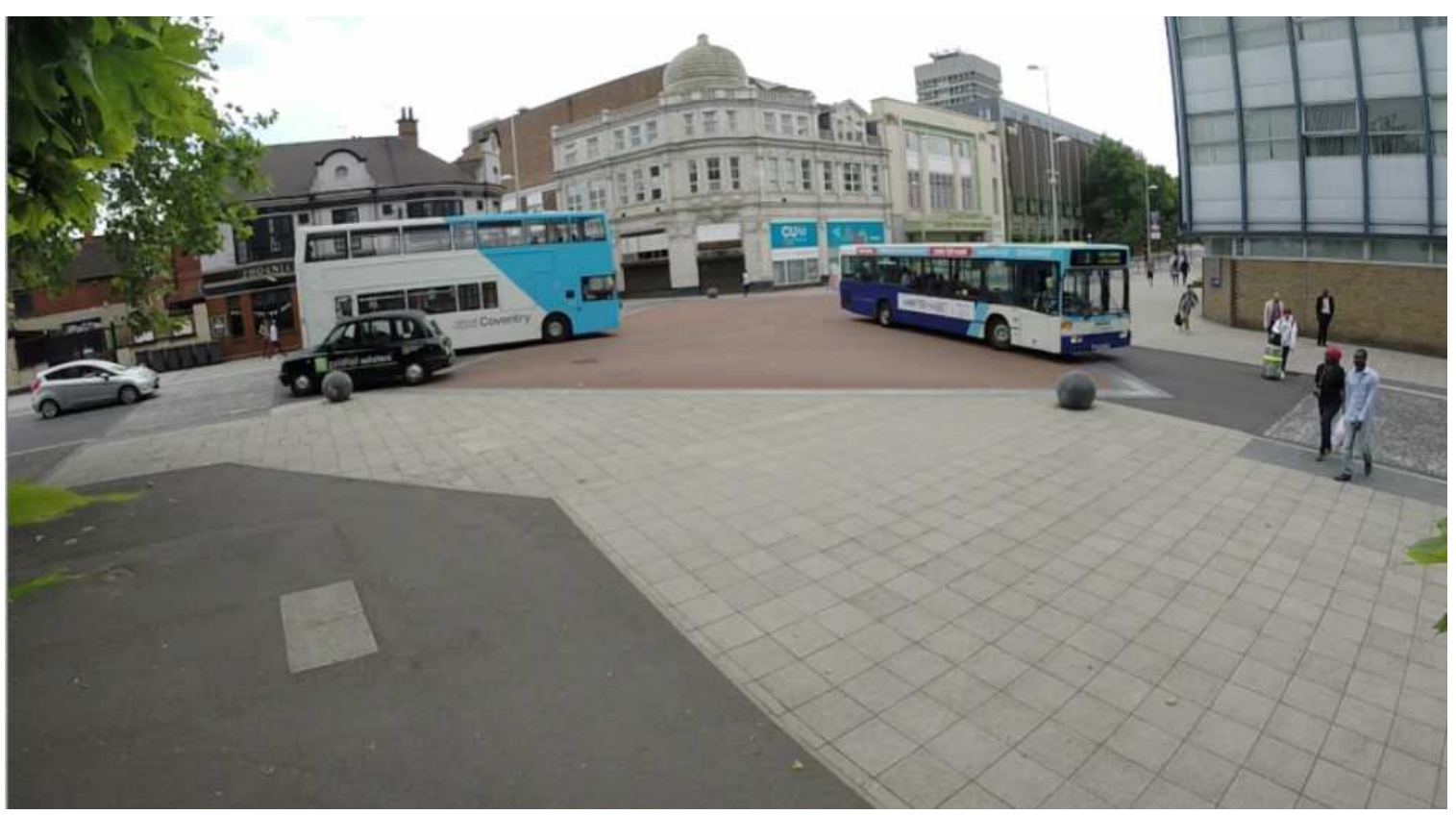

Figure 52: Coventry shared--representative traffic volume

Both Poynton intersections had the largest average hourly traffic counts of the six study sites. The Poynton (shared) site had the largest hourly traffic volume at more than 4000 vehicles/hour. The Poynton control intersection (Figure 53), despite not being on the busy London Road that runs through Poynton's (shared) (Figure 54) intersection, was similarly busy albeit with less large vehicle traffic. 


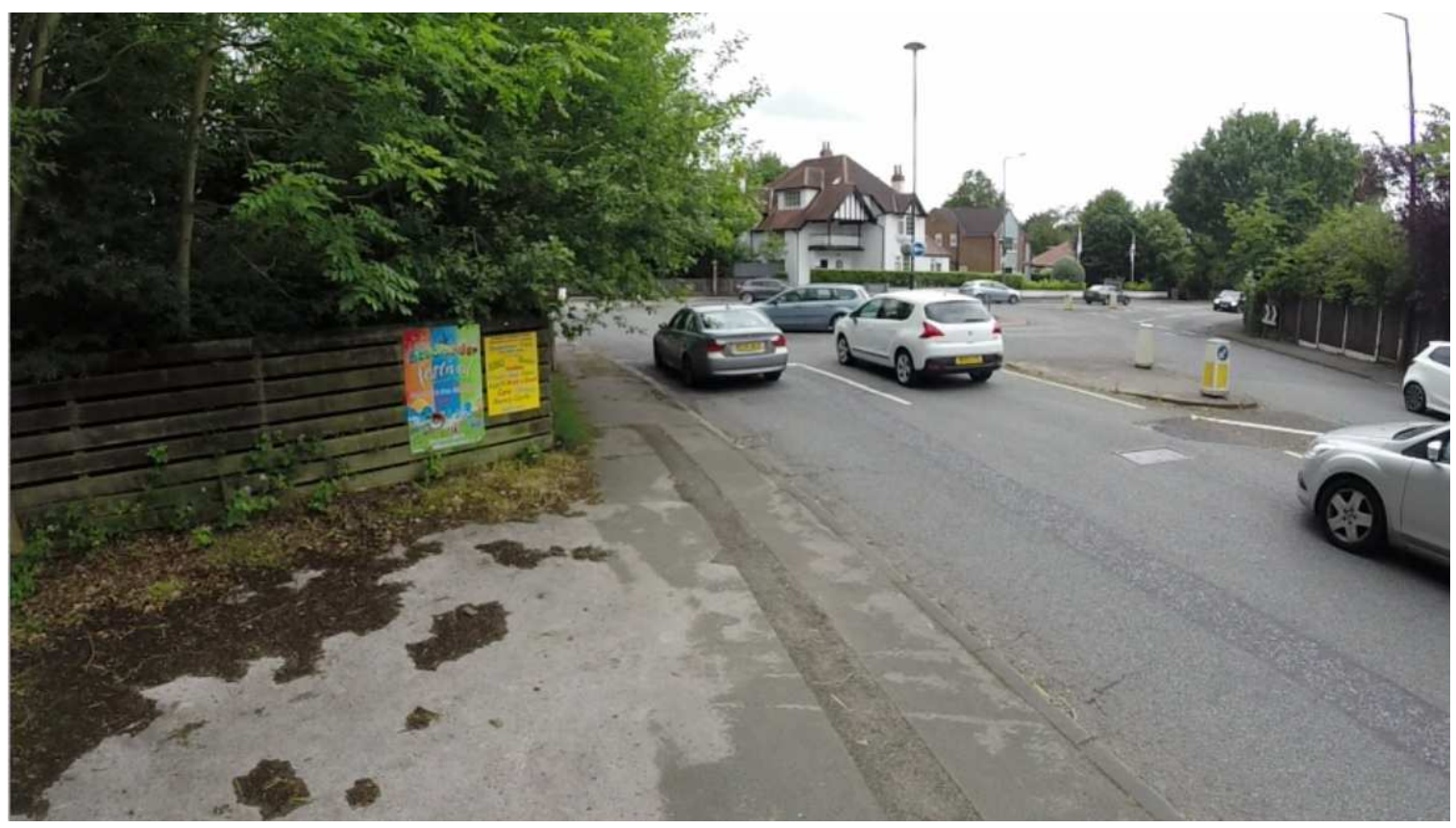

Figure 53: Poynton control--representative traffic volume

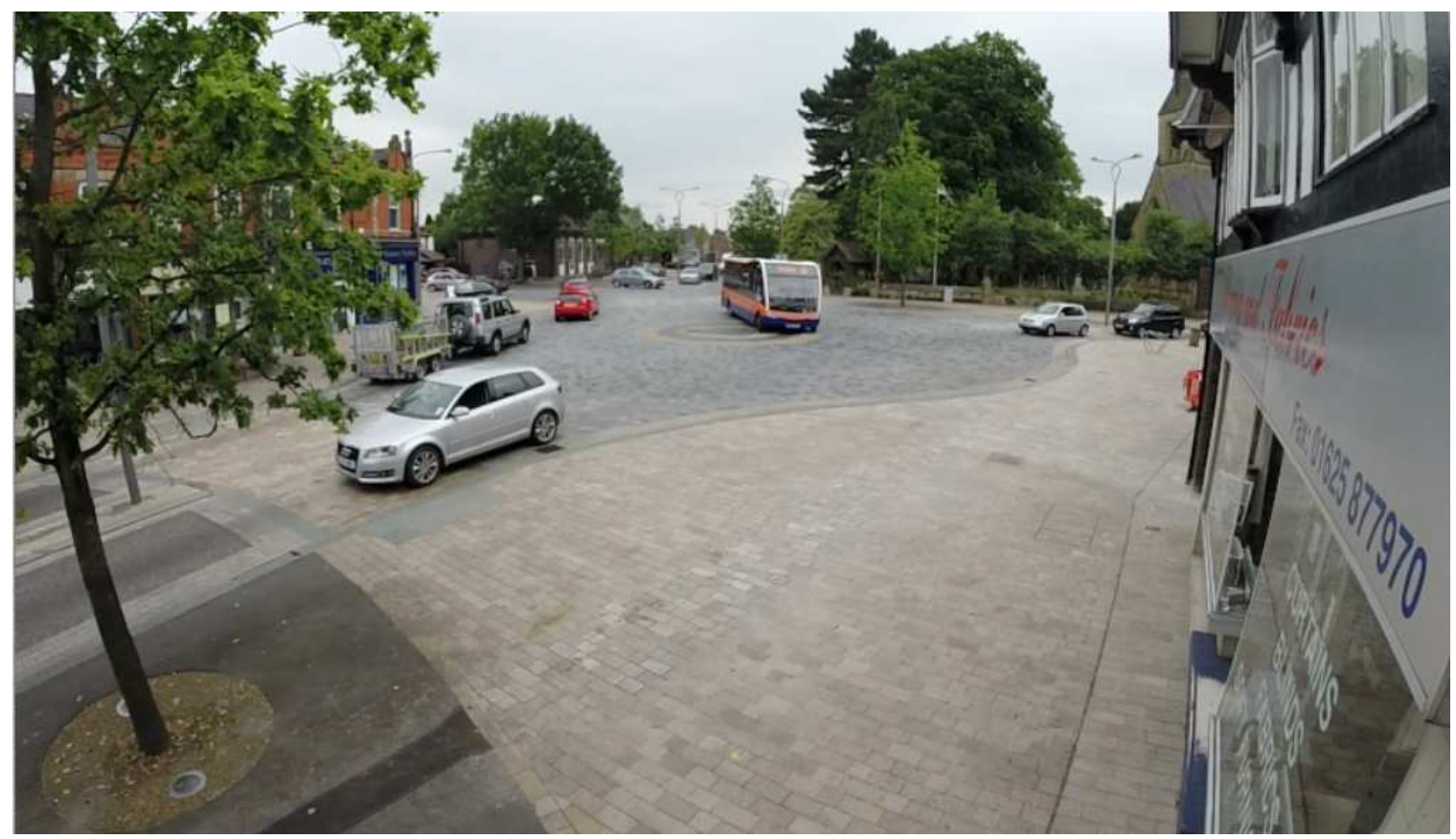

Figure 54: Poynton shared--representative traffic volume 


\section{Node Differences}

One of this study's primary research questions focused on analyzing the paths taken by cyclists through each of the study sites. The main dependent variable I used to evaluate this variability in paths chosen was the difference in the number of nodes that comprised each individual path. As discussed earlier in Chapter III, I hypothesized that a longer path may indicate a less confident bike rider; a cyclist who took a more circuitous path through a site was trying to avoid the middle, more exposed areas of the intersection. For instance, a cyclist who hugs a curb, or rides from crosswalk to crosswalk will show greater path deviation as compared to a cyclist who rides directly through the intersection. Note that some paths taken that incorporated the sidewalks and crosswalks were actually shorter [fewer nodes] than those taken through the middle of the intersection.)

Each intersection I observed had several different possible routes a cyclist could take which I differentiated by combining the origin (direction the cyclist first arrived from) with the destination (the direction the cyclist exited the intersection) (OD). For instance, Elwick Square had 18 possible routes a cyclist could take through the plaza, such as ENE (E to NE) and SWNE (SW to NE). As discussed in Chapter III, I calculated the difference between the number of nodes for each observed path and the ideal number of nodes for each origindestination path. I then calculated the mean node difference for each origin-destination path. Some routes had a negative mean node difference indicating that some paths ridden were more efficient than the ones I had designated as ideal. Appendix B lists each site's possible paths and the ideal number of nodes calculated per origin-destination. 
In the sites that had significant relationships between node difference and curb use, Coventry $[\mathrm{F}(3,486)=9.622, \mathrm{p}=.000]$ saw the largest $\mathrm{b}$ value between cyclists who used a curb cut and those who both used a curb cut and jumped a curb. The riders who rode both had an average of -2.98 fewer nodes along their path, indicating this behavior created a shorter path than just riding up or down a curb cut. Poynton's $[\mathrm{F}(3,199)=3.479, \mathrm{p}=.017]$ multiple comparison table indicated that cyclists who did not use the curb cut, when compared to those who jumped off a curb, rode paths with -2.7 fewer nodes_-also indicating, at this particular intersection, that no curb use created the shorter paths. The analysis of variance of the effects of curb use on node difference was significant for both pooled shared $[\mathrm{F}(4$, $1039)=8.324, \mathrm{p}=.000]$ and control $[\mathrm{F}(2,680)=10.162, \mathrm{p}=.000]$.

I calculated the mean node difference and standard deviation for each observed OD. The number of cyclists who rode through each origin-destination varied dramatically; therefore, in order to screen out the origin-destinations that were too low (Table 11) I ranked the OD observations by frequency of observation. Those that fell below ten observations (or six for Wye because of its lower number of observed cyclists) are shaded in grey (Table 11) and eliminated from the following bar graphs (Figures 54-64).

Table 12: Origin-Destination means (OD) and standard deviations

\begin{tabular}{|l|l|l|l|l|}
\hline Site & \multicolumn{1}{|c|}{ OD } & \multicolumn{1}{|c|}{$\begin{array}{c}\text { Mean node } \\
\text { difference }\end{array}$} & \multicolumn{1}{|c|}{$\mathrm{n}$} \\
\hline Wye (1) & EW & 2.07 & 0.83 & 14 \\
\hline & WS & 1.50 & 1.16 & 14 \\
\hline & WE & 2.13 & 1.36 & 8 \\
\hline & EN & 1.71 & 0.95 & 7 \\
\hline
\end{tabular}




\begin{tabular}{|c|c|c|c|c|}
\hline & NS & -0.14 & 0.90 & 7 \\
\hline & SN & 2.00 & 1.79 & 6 \\
\hline \multirow[t]{6}{*}{ * } & SE & 1.25 & 0.96 & 4 \\
\hline & SW & 0.00 & 0.00 & 4 \\
\hline & WN & 3.00 & 1.41 & 4 \\
\hline & $\mathrm{NE}$ & 0.67 & 0.58 & 3 \\
\hline & ES & 2.00 & 0.00 & 2 \\
\hline & NW & 3.00 & $(\mathrm{n}=1)$ & 1 \\
\hline \multirow[t]{9}{*}{ Elwick Square (2) } & NS & 4.13 & 1.90 & 67 \\
\hline & SENW & 2.72 & 1.20 & 54 \\
\hline & SN & 3.49 & 1.63 & 49 \\
\hline & NWSE & 2.47 & 0.69 & 47 \\
\hline & SNW & 0.04 & 1.90 & 24 \\
\hline & NWS & 0.57 & 3.81 & 23 \\
\hline & NES & 1.86 & 1.11 & 21 \\
\hline & NSE & 0.45 & 1.70 & 19 \\
\hline & SEN & 1.21 & 1.90 & 19 \\
\hline \multirow[t]{8}{*}{ * } & SNE & 2.11 & 1.27 & 9 \\
\hline & NNW & 0.83 & 0.98 & 6 \\
\hline & NWN & 1.50 & 0.55 & 6 \\
\hline & SENE & 1.50 & 0.71 & 2 \\
\hline & SSE & 1.00 & 1.41 & 2 \\
\hline & SENW & 5.00 & $(n=1)$ & 1 \\
\hline & NESE & 4.00 & $(\mathrm{n}=1)$ & 1 \\
\hline & NWNE & 5.00 & $(n=1)$ & 1 \\
\hline \multirow[t]{9}{*}{ Poynton (3) } & WE & 7.83 & 1.32 & 36 \\
\hline & $\mathrm{EW}$ & 5.82 & 1.76 & 28 \\
\hline & SWNE & 6.17 & 0.92 & 24 \\
\hline & NEE & 1.83 & 1.56 & 23 \\
\hline & $\mathrm{ESW}$ & 0.37 & 1.01 & 19 \\
\hline & NESW & 6.19 & 2.23 & 16 \\
\hline & NEW & 1.00 & 1.08 & 13 \\
\hline & SWW & 1.80 & 0.63 & 10 \\
\hline & WNE & 0.90 & 1.60 & 10 \\
\hline \multirow[t]{4}{*}{ * } & SWE & -0.33 & 1.41 & 9 \\
\hline & ENE & 2.14 & 3.29 & 7 \\
\hline & WSW & 4.14 & 1.86 & 7 \\
\hline & NENE & 5.00 & $(\mathrm{n}=1)$ & 1 \\
\hline \multirow[t]{2}{*}{ Poynton cntrl (4) } & SWE & 2.26 & 0.98 & 58 \\
\hline & ESW & 0.84 & 0.94 & 44 \\
\hline
\end{tabular}




\begin{tabular}{|c|c|c|c|c|}
\hline & ENW & 0.81 & 1.09 & 32 \\
\hline & SWNW & 1.65 & 0.88 & 23 \\
\hline & NWE & 0.90 & 1.14 & 20 \\
\hline & NWSW & 1.59 & 0.51 & 17 \\
\hline \multirow[t]{8}{*}{ Coventry (5) } & WE & 3.40 & 1.94 & 144 \\
\hline & $\mathrm{EW}$ & 2.84 & 1.52 & 133 \\
\hline & $\mathrm{NW}$ & 2.00 & 1.22 & 36 \\
\hline & EN & 1.49 & 1.17 & 35 \\
\hline & WN & -0.76 & 0.71 & 33 \\
\hline & $\mathrm{NE}$ & -0.59 & 1.99 & 27 \\
\hline & SN & -1.50 & 0.73 & 18 \\
\hline & NS & 4.80 & 1.86 & 15 \\
\hline \multirow[t]{9}{*}{ * } & SW & 0.22 & 1.20 & 9 \\
\hline & NWE & 2.88 & 1.64 & 8 \\
\hline & SE & 0.38 & 1.30 & 8 \\
\hline & ENW & 3.29 & 1.38 & 7 \\
\hline & WS & 1.14 & 0.90 & 7 \\
\hline & ES & 0.33 & 1.53 & 3 \\
\hline & NWS & 2.33 & 1.53 & 3 \\
\hline & SNW & 1.67 & 1.15 & 3 \\
\hline & NWN & 0.00 & $(\mathrm{n}=1)$ & 1 \\
\hline \multirow[t]{9}{*}{ Coventry cntrl (6) } & SWNE & 1.37 & 1.81 & 148 \\
\hline & NESW & 2.30 & 1.65 & 135 \\
\hline & NWNE & 1.56 & 1.72 & 27 \\
\hline & NWSW & -0.64 & 1.43 & 22 \\
\hline & SWNW & -1.63 & 1.21 & 19 \\
\hline & NENW & 0.59 & 2.03 & 17 \\
\hline & SESW & 1.17 & 1.78 & 16 \\
\hline & NWSE & 1.50 & 1.24 & 12 \\
\hline & SENW & -0.30 & 1.16 & 10 \\
\hline \multirow[t]{2}{*}{ * } & SWSE & 0.31 & 2.07 & 8 \\
\hline & NESE & 4.00 & $(\mathrm{n}=1)$ & 1 \\
\hline
\end{tabular}

Note: $*=$ 'threshold n'

Figure 56 shows the variation in overall site node difference via a box and whiskers plots for each site. The boxes illustrate the boundaries of the upper and lower 25\% (quartiles) of the 
median node difference per site. The whiskers indicate the spread of the upper and lower quartiles beyond each site's median node difference.

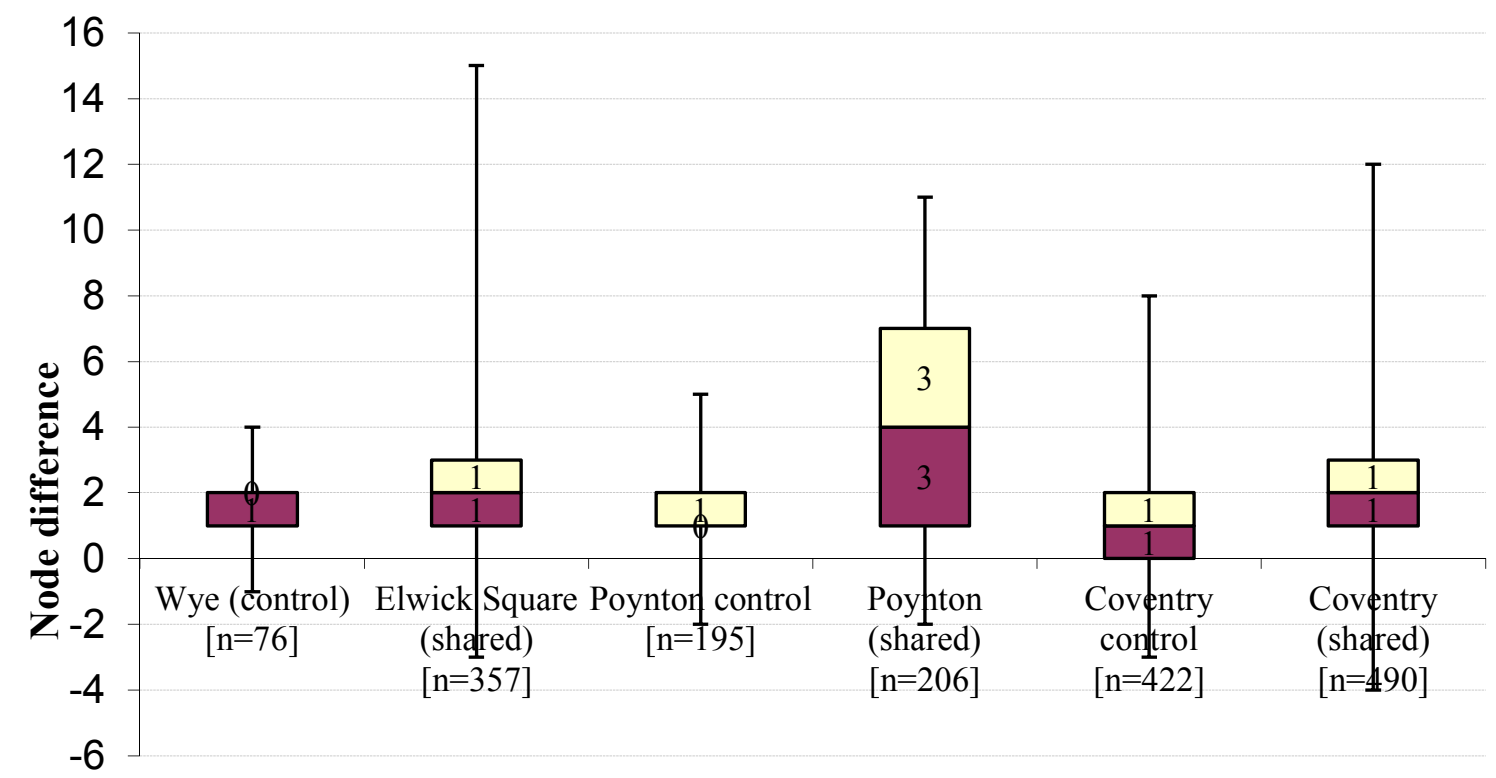

$\square$ distance from 1 st quartile to median $\square$ distance from median to 3 rd quartile

Figure 55: Variance in node difference by site

Figure 56 shows that the three shared sites and Coventry control all have the greatest variation in node difference compared to the control sites of Wye and Poynton control. Table 11 above also shows that the standard deviations for the shared sites have a larger range compared to the control sites of Wye and Poynton. For instance, Elwick Square's origin-destination standard deviations range from 0.55 to 3.81 whereas Wye's range from 0.58 to 1.79 . 
I calculated the coefficient of variation for each site as well. As shown by Figure 57, the paths observed in the four primary intersections all had paths that varied more than the two more recreational, control sites. The Coventry control intersection paths however varied the most of all six sites.

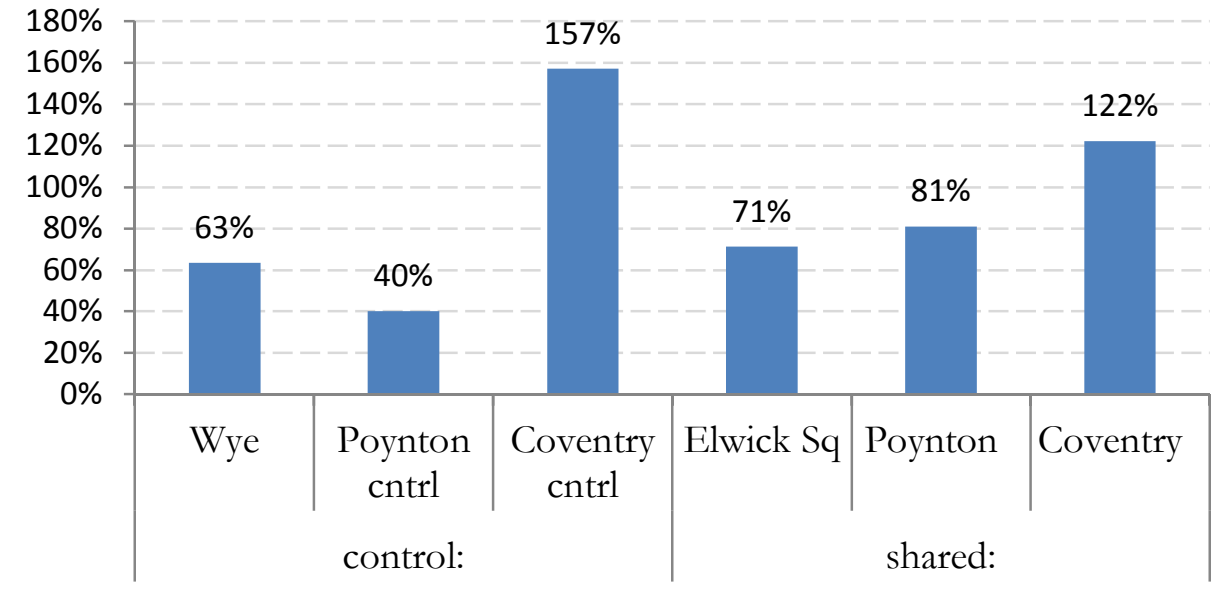

Figure 56: Coefficient of variation by site type

\section{Analysis of node difference by site}

This section will first generally discuss the regressions I ran for each site as well as the node difference calculations and comparative graphs and path plots. I will then present the individual site results with respect to calculated node differences and the stepwise regression models. 
Comparison of node differences and regression analyses

I ran linear regression models on the collected cyclist and path variables to determine if the values of any of the independent variables predicted the values of the node difference, the primary dependent variable. The independent variables run were site-specific origindestinations (OD), gender, helmet use, sidewalk use, and crosswalk use. The dependent variable was node difference. The four primary sites (three shared and one control) were run together and as well as individually. The following tables summarize the stepwise regression results for four sites: Elwick Square (shared), Coventry (shared), Coventry control, and Poynton (shared). Plots of the origin-destinations with significant betas follow each sitespecific table. Again, as with the tables, the path plots are grouped according to complementary ODs ${ }^{7}$.

The following bar graphs have been arranged in order with respect to their complementary origin-destinations. For instance, NS (north to south) and SN (south to north) reflect similar paths across the intersections in most cases and are located next to each other in the bar graphs. Again, as shown in Table 11, the ODs with a low number of observed paths were not included. Each bar graph is accompanied by a site plan with each direction labeled. Examination of the possible reasons for OD differences, such as with respect to intersection

\footnotetext{
${ }^{7}$ Enlarged versions of each plot are included in Appendix E
} 
elements, will be in the Chapter VI, the Discussion chapter.

\section{Elwick Square}

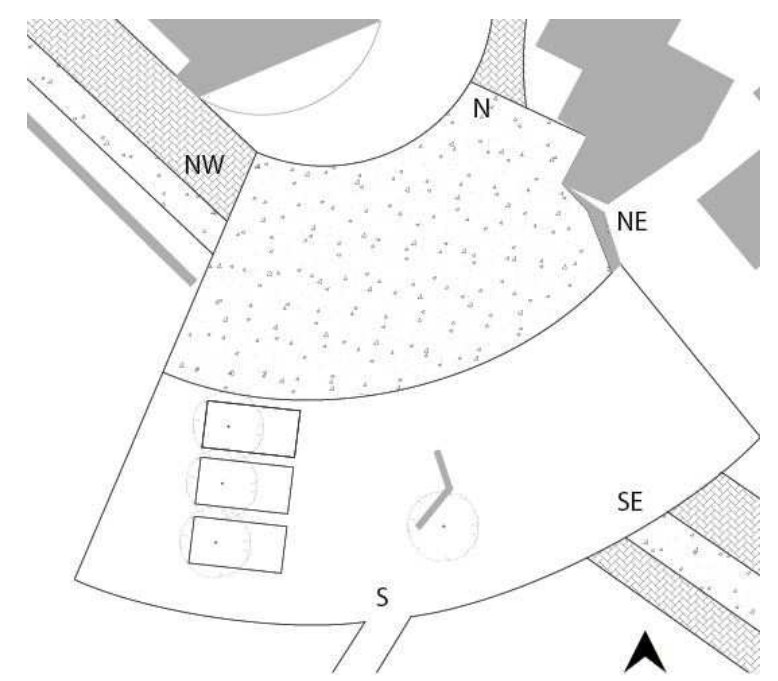

Figure 57: Labeled directions

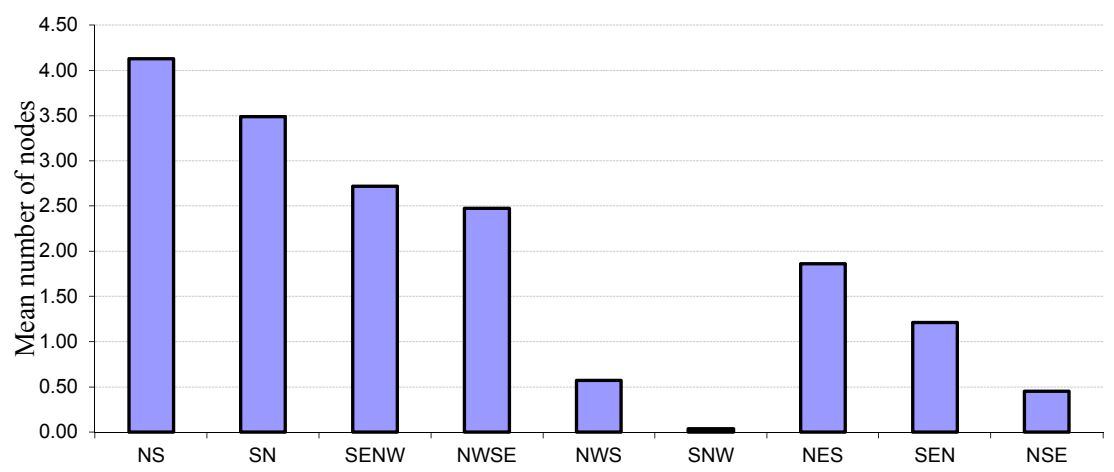

Figure 58: Elwick Square mean node difference per OD

A few origin-destinations legs at Elwick Square had large average node differences. Both NENW (northeast to northwest) and NWNE (northwest to northeast), which are the same 
leg but traveling in opposite directions, had the largest averages of 5. The origin-destinations of NS (north to south) and NESE (northeast to southeast) were 4 nodes or greater. On the other hand, the ODs of SNW (south to northwest) and NSE (north to southeast) were just slightly over the calculated ideal node meaning that the paths had the same number of nodes, or same amount of deviation, as the ideal path.

After doing stepwise linear regressions for the study sites, Elwick Square had significant $(\mathrm{p}<.05)$ betas for the following OD directions:

Table 13: Elwick Square OD stepwise regressions

\begin{tabular}{lll}
\hline Variables (n) & Beta & $\mathrm{p}$ \\
\hline NS (67) & 0.221 & 0.001 \\
NSE (19) & -0.329 & 0.000 \\
NWS (23) & -0.302 & 0.000 \\
SNW (24) & -0.162 & 0.008 \\
\hline
\end{tabular}

Note: $\mathrm{R}^{2}=0.314$, Adjusted R2 $=0.296$ 


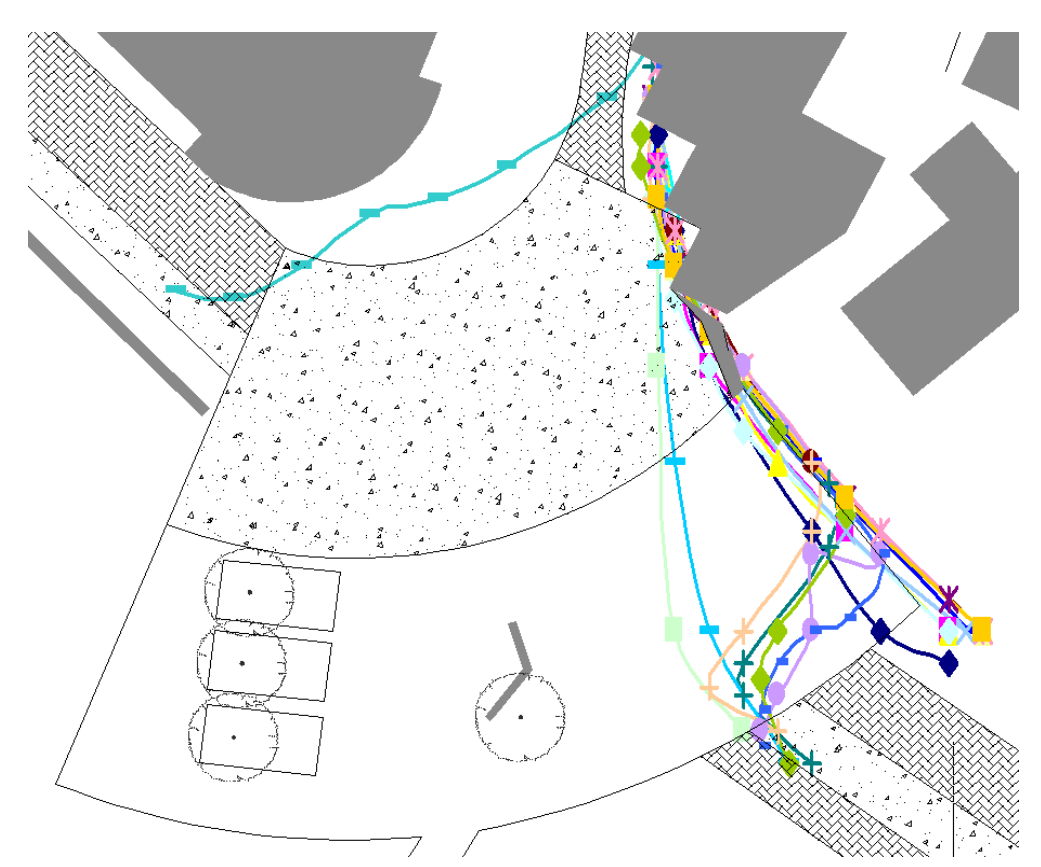

Figure 59: NSE $(\beta=-0.329, \mathrm{n}=19)$, mean nodediff $=0.45$

North to southeast has a low mean node difference indicating the paths observed were close to the ideal number of path nodes. This also shows that the observed riders varied little from each other in their path choices (see Figure 59). In other words, most of the observed cyclists riding this direction skirted the edge of the intersection to access the crosswalk while riding toward the train station. 


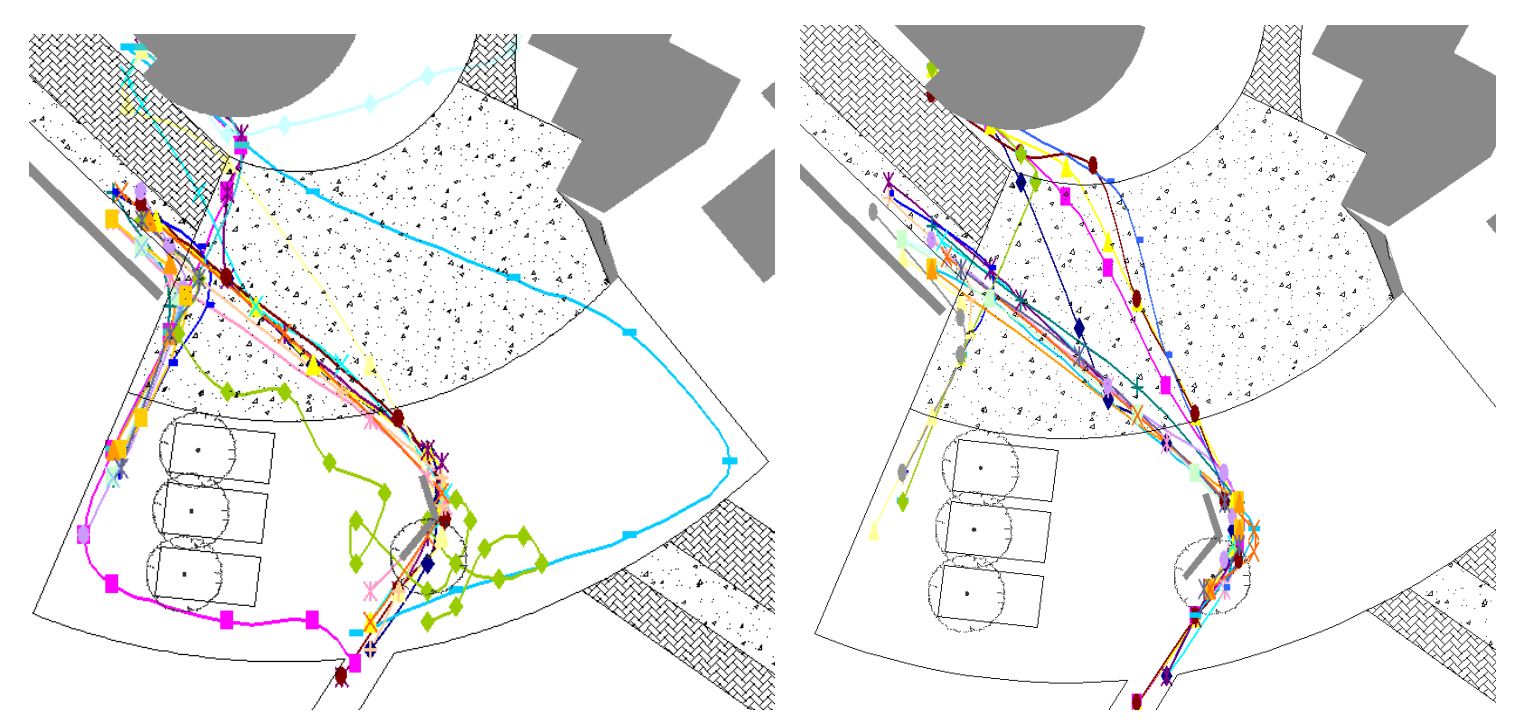

Figure 60: NWS $(\beta=-0.302, \mathrm{n}=23)$ (left) mean nodediff $=0.57$ and $\mathbf{S N W}(\beta=-0.162, \mathrm{n}=24)$ (right) mean nodediff $=0.04$

The northwest to south mean node difference was 0.57 nodes. With the exception of the BMX rider who made the loop-like path riding from northwest to south, most of the observed riders rode similar paths, which were also close to the ideal. The complementary direction, south to northwest, had an even smaller mean node difference of 0.04 . As can be seen in Figure 60, most of the cyclists rode very similar and direct paths pivoting around the seat wall as well as riding on the sidewalk. 


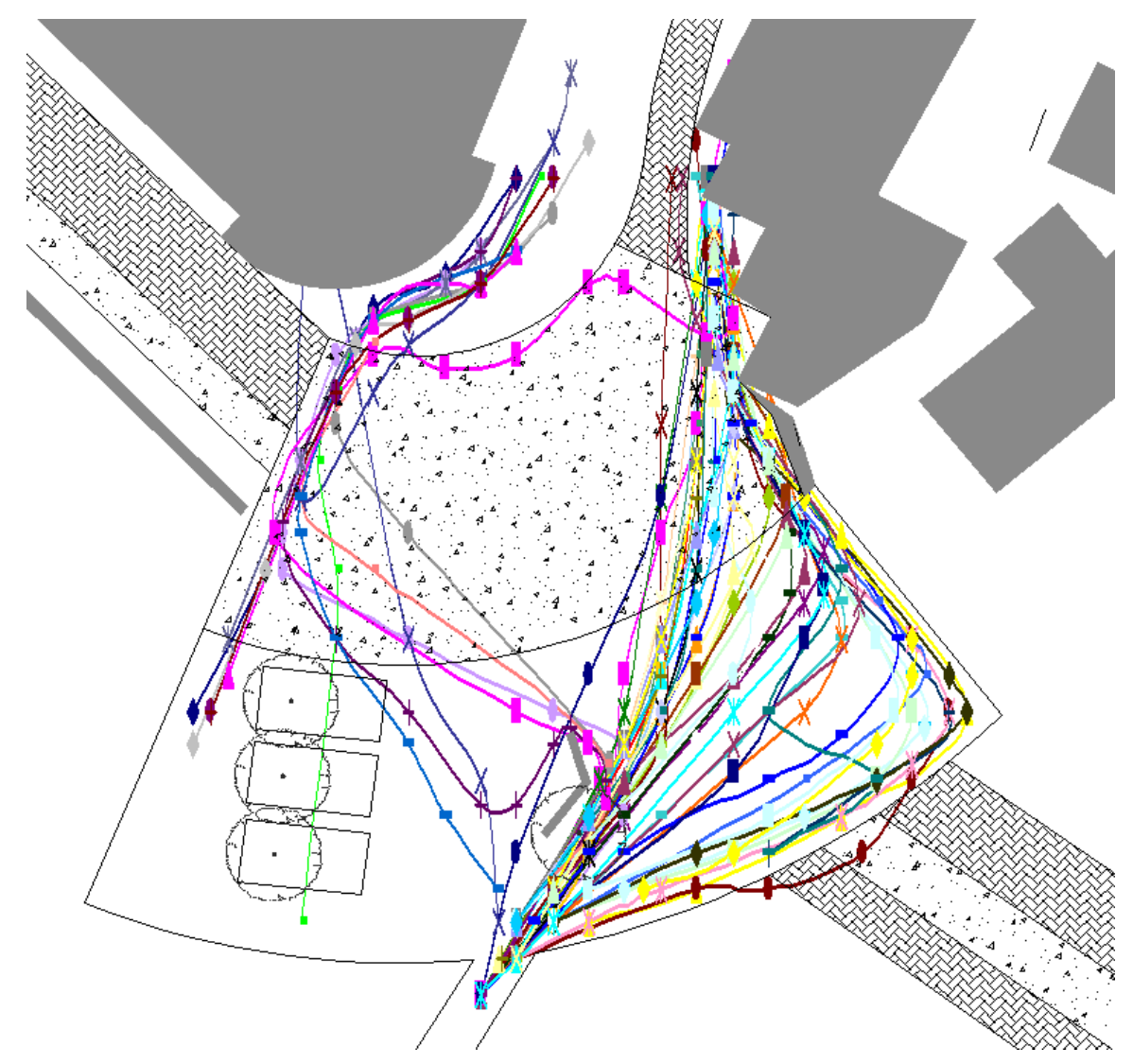

Figure 61: NS $(\beta=0.221, \mathrm{n}=67)$, mean nodediff $=4.13$

The observed cyclists riding from north to south had a large mean node difference of 4.13 nodes. This indicates that many of them deviated by several nodes from the ideal path. This can be seen in the spread where some cyclists ride straight through the intersections, and others skirt the edges to access the crosswalks on both sides of the shared site. 


\section{Poynton}

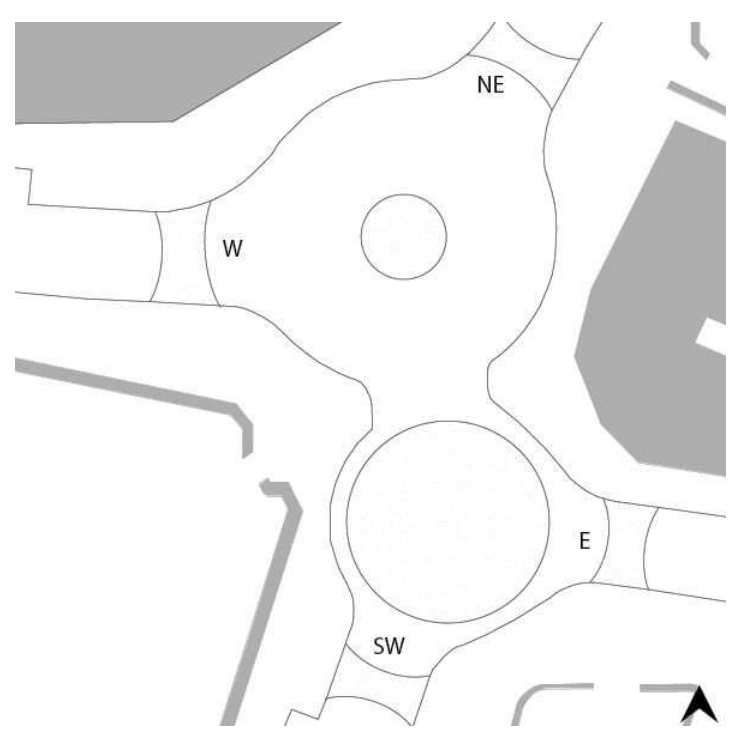

Figure 62: Labeled directions

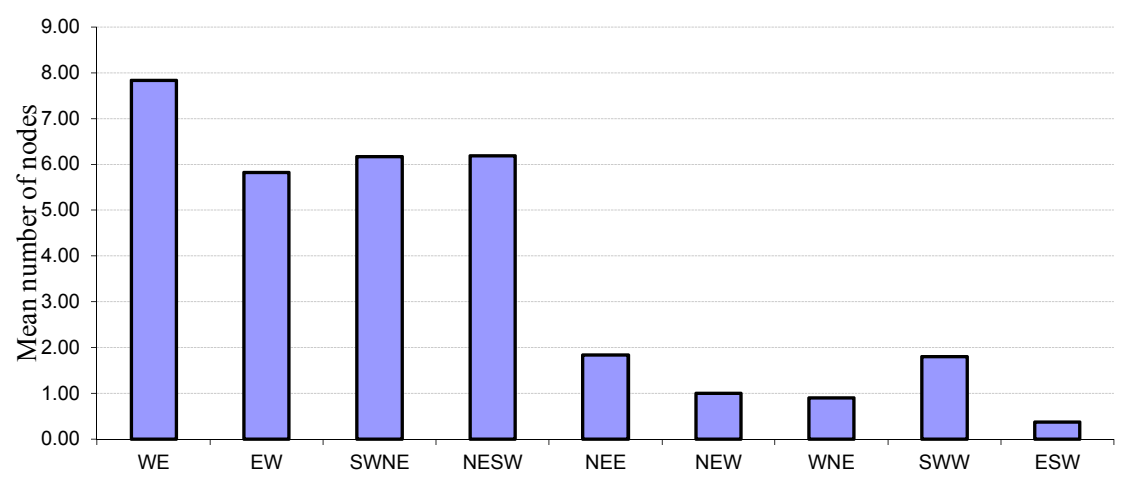

Figure 63: Poynton mean node difference per OD

Poynton had many origin-destinations legs with large average node differences. For instance, the WE (west to east) OD leg included almost eight nodes, while its opposite direction (EW, east to west) had an average less than six. The origin-destinations directions, 
NESW (northwest to southwest) and SWNE (southwest to northwest) had the same average of 6.17. These OD directions are for the same leg but traveling in different directions. This intersection also had some origin-destinations legs close to the ideal node number and one negative OD leg, SWE (southwest to east).

After doing stepwise linear regressions, the following OD directions had significant $(\mathrm{p}<.05)$ betas (the ODs of WSW and ENE are not included below because the N's are below the decided upon minimum):

Table 14: Poynton OD stepwise regressions

\begin{tabular}{lll}
\hline Variables (n) & Beta & $\mathrm{p}$ \\
\hline WE (36) & 0.853 & 0.000 \\
SWNE (24) & 0.678 & 0.000 \\
NESW (16) & 0.523 & 0.000 \\
EW (28) & 0.455 & 0.000 \\
WSW (7) & 0.220 & 0.000 \\
ENE (7) & 0.131 & 0.021 \\
Other bike (12) & -0.134 & 0.033 \\
\hline
\end{tabular}

Note: $\mathrm{R}^{2}=0.74$, Adjusted $\mathrm{R}^{2}=0.72$ 

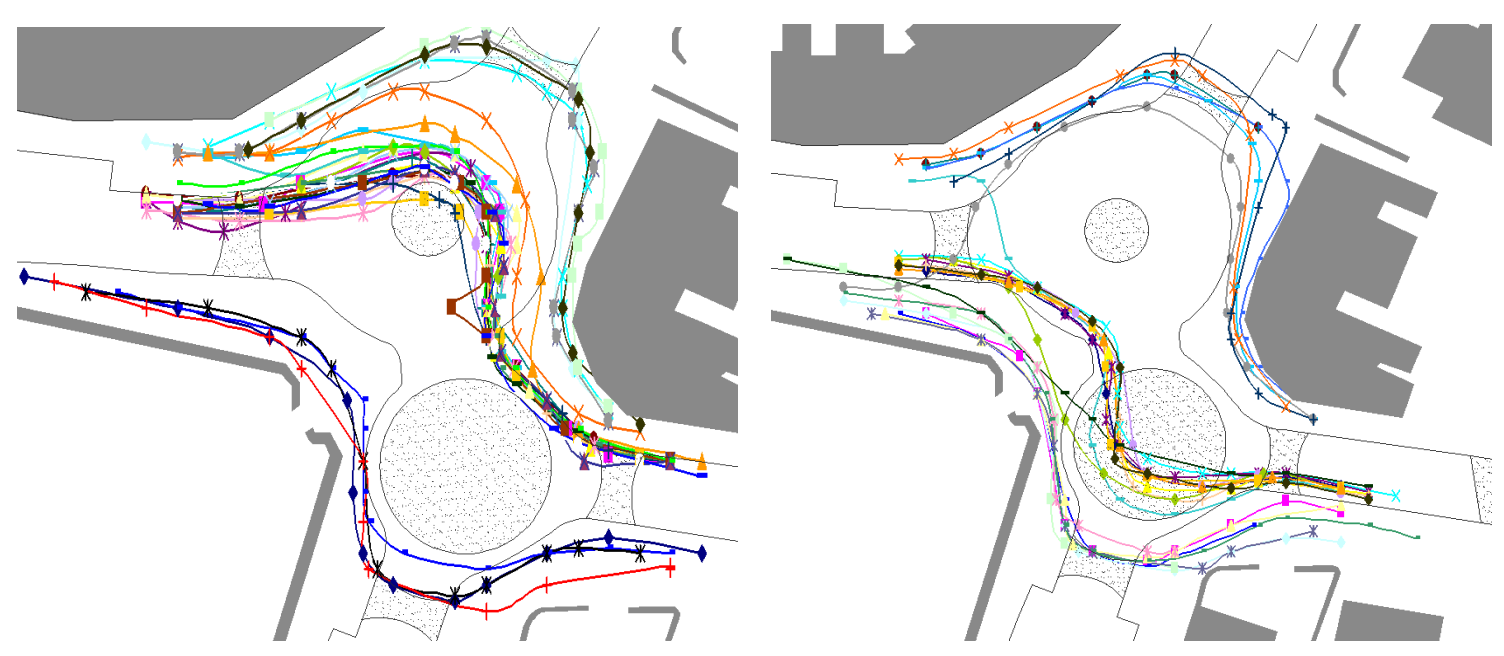

Figure 64: WE $(\beta=0.853, \mathrm{n}=36)$ mean nodediff $=7.83$ (left $)$ and $\mathbf{E W}(\beta=0.455, \mathrm{n}=28)$ mean nodediff $=5.82$ (right)

The complementary directions of west to east and east to west, pictured in Figure 64, show how the observed cyclists rode a couple of distinctly different paths. While many rode in a vehicular manner, many also skirted the site edges and rode on the sidewalks all the way up to the crosswalks on both sides of the intersection. Some of these paths therefore were much longer than the ideal path thus giving these ODs large mean node differences of 5.82 and 7.83 . 


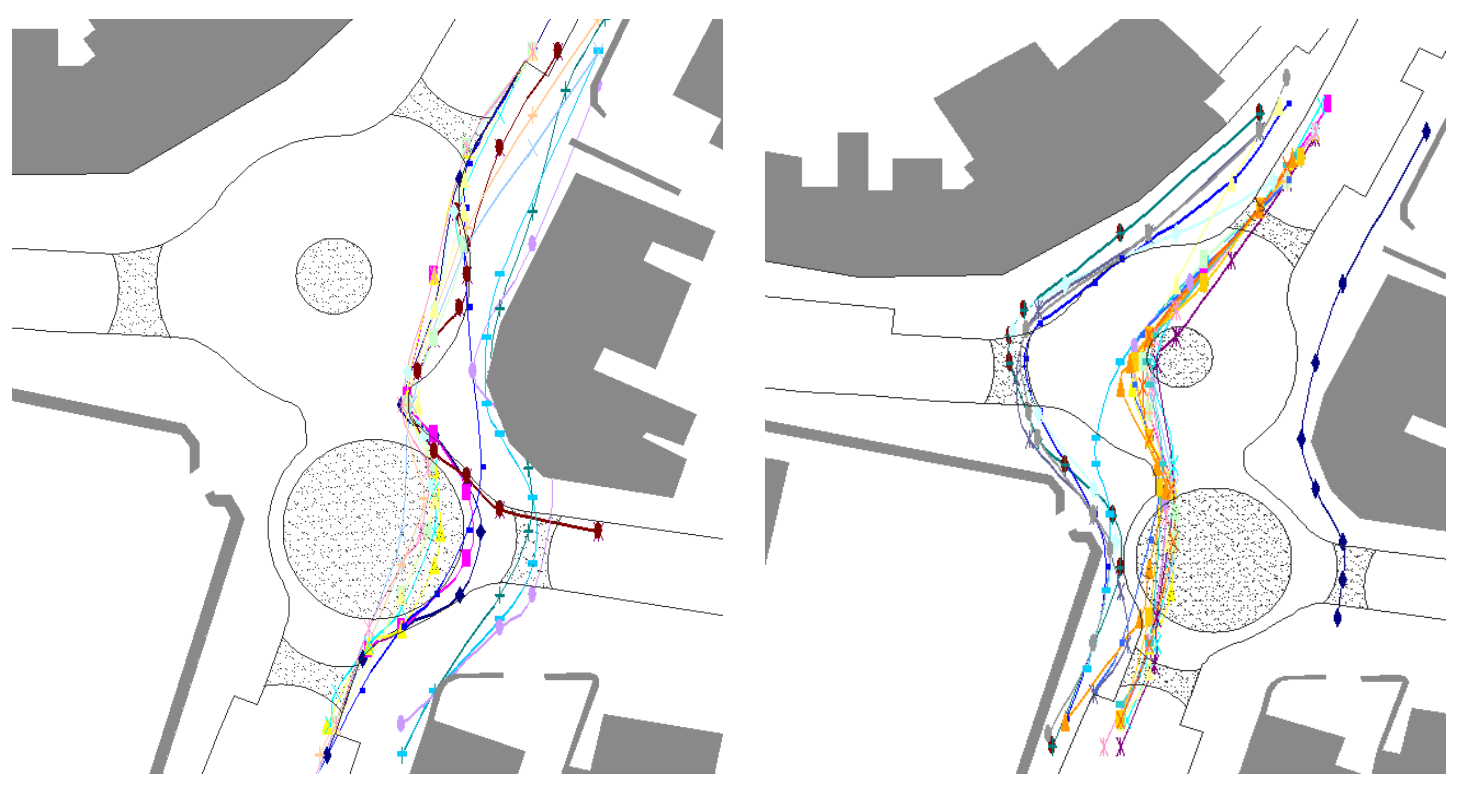

Figure 65: Poynton NESW $(\beta=0.37, \mathrm{n}=16)$ mean nodediff $=6.19$ (left) and SWNE $(\beta=0.678$, $\mathrm{n}=24)$ mean nodediff $=6.17$ (right)

Similar to Figure 64, the mean node differences for these complementary ODs were large but almost identical. The paths plotted in Figure 65 illustrate how many cyclists deviated their paths more than the ideal by skirting the edges and riding in crosswalks. 


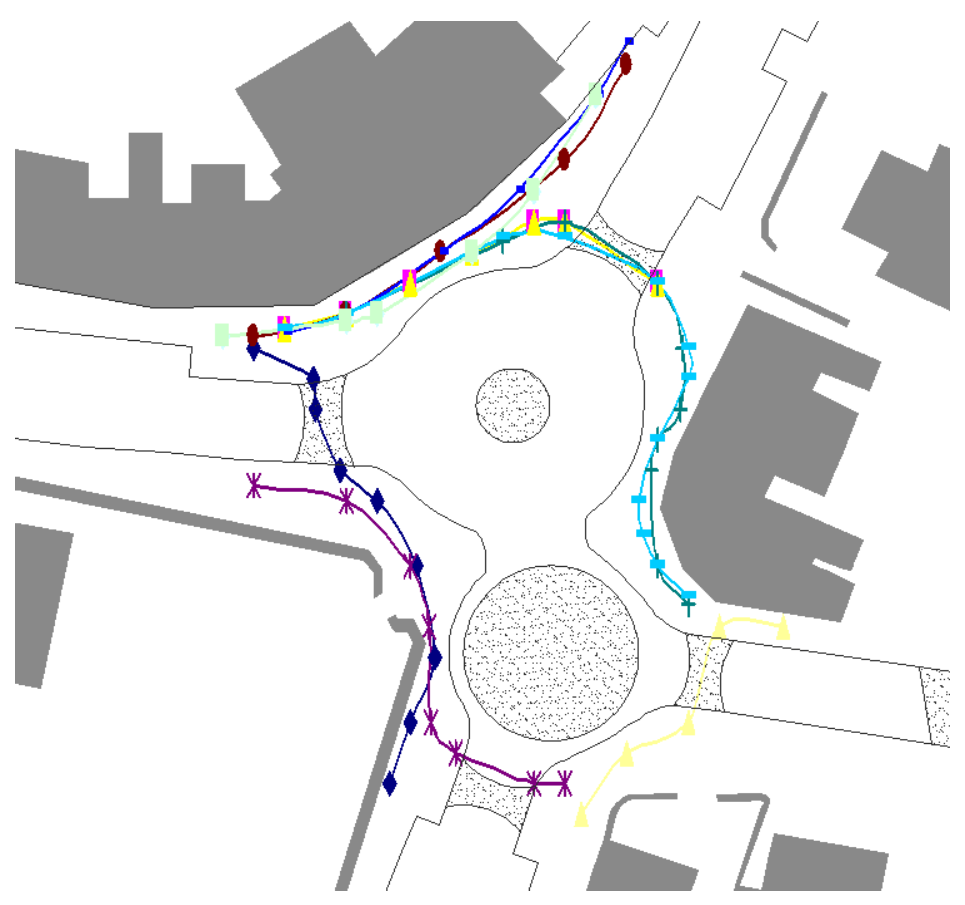

Figure 66: Other bike paths $(\beta=-0.134, \mathrm{n}=12)$

Figure 66 illustrates that cyclists who were coded as riding bicycles other than a flat bar or drop bar bicycle had a significant linear relationship between the cycle type and mean node difference. The plot shows that these riders all chose to skirt the outside of the intersection riding as far from motor vehicle traffic as possible. 


\section{Coventry}

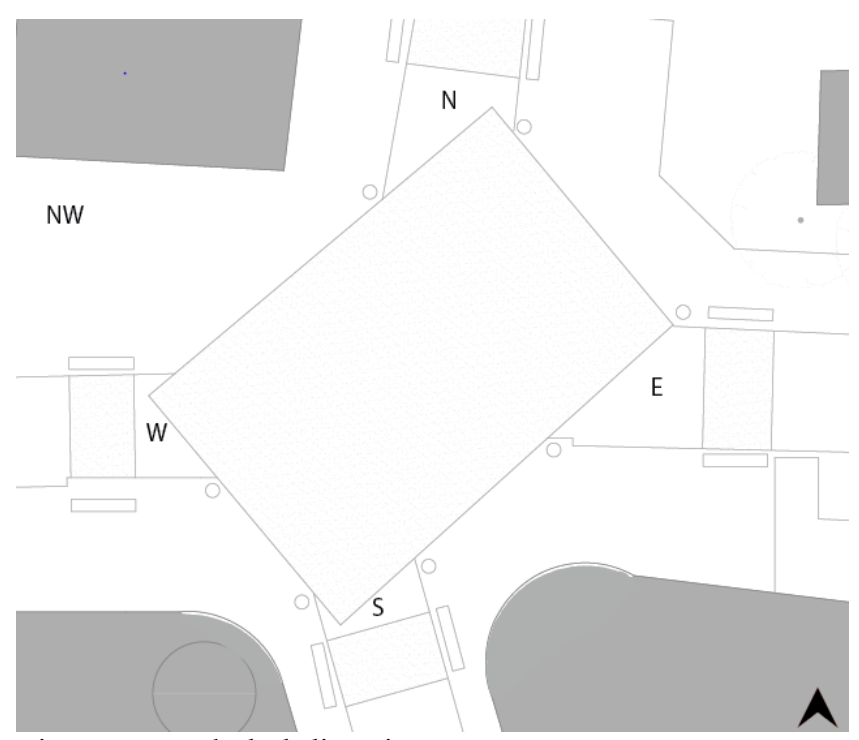

Figure 67: Labeled directions

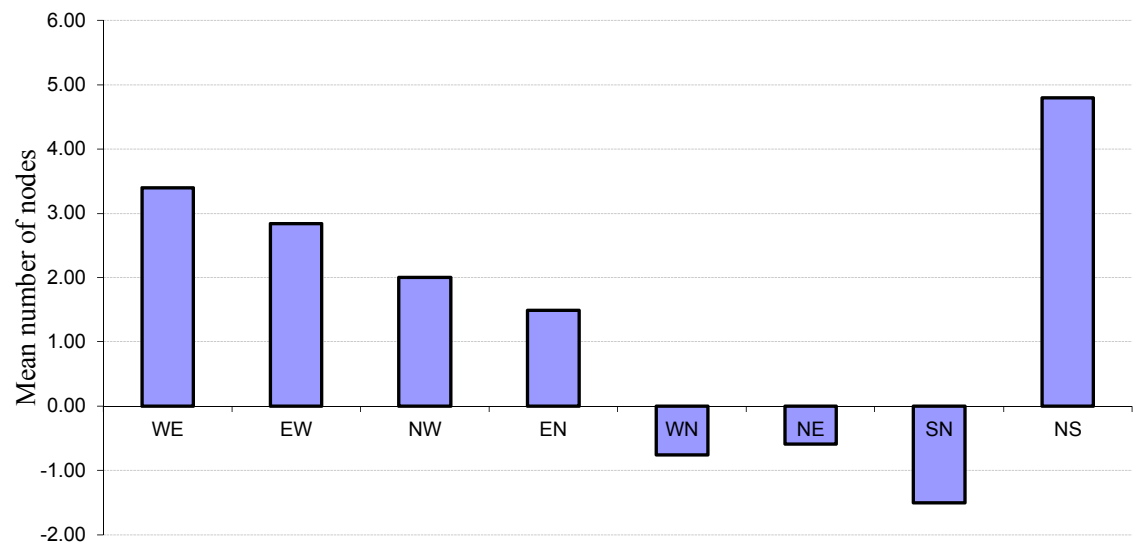

Figure 68: Coventry mean node difference per OD

Three origin-destinations had negative node differences meaning that the average paths taken through three of this site's ODs were more direct and/or efficient than the ideal paths 
I had interpolated. The Coventry origin-destinations node difference averages had one leg, NS (north to south), with a node difference of 4.80 and its opposite leg, SN, was -1.50 .

After running stepwise linear regressions, the following OD directions had significant $(\mathrm{p}<.05)$ betas (the ODs of SW and ES are not included below because the n's are below the decided upon minimum.):

Table 15: Coventry OD stepwise regressions

\begin{tabular}{lll}
\hline Variables (n) & Beta & $\mathrm{p}$ \\
\hline Sidewalk & 0.235 & 0.000 \\
NS (15) & 0.168 & 0.000 \\
WE (144) & 0.093 & 0.078 \\
Other bike (25) & -0.089 & 0.044 \\
SW (9) & -0.097 & 0.025 \\
ES (3) & -0.124 & 0.004 \\
NW (36) & -0.140 & 0.004 \\
EN (35) & -0.228 & 0.000 \\
WN (33) & -0.420 & 0.000 \\
NE (27) & -0.481 & 0.000 \\
\hline
\end{tabular}

Note: $\mathrm{R}^{2}=0.52$, Adjusted $\mathrm{R}^{2}=0.50$ 

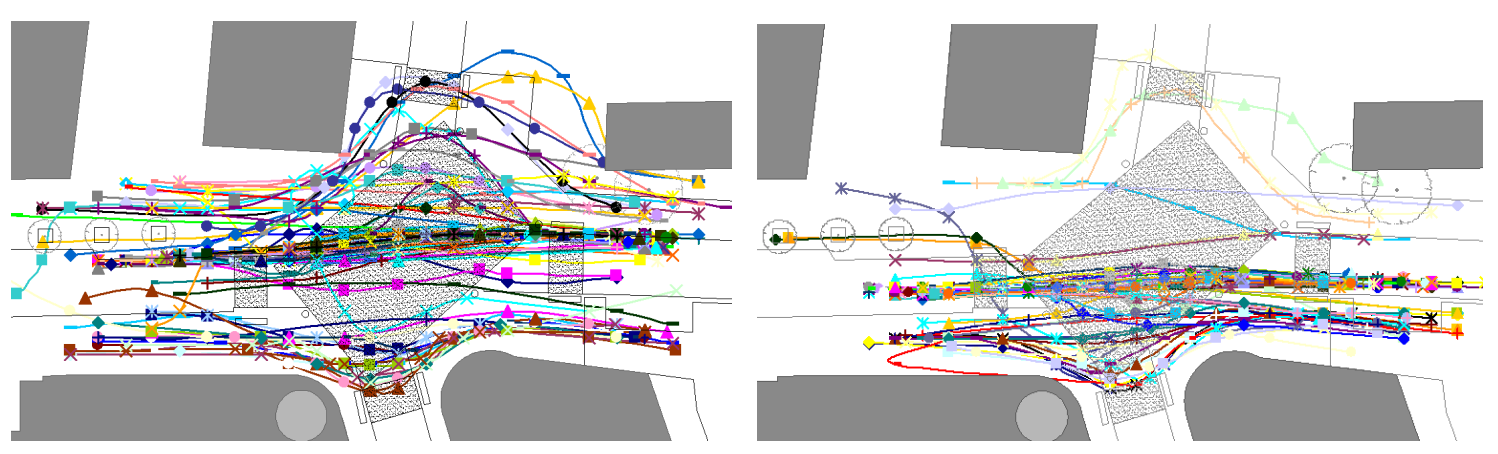

Figure 69: WE $(\beta=0.093, \mathrm{n}=144)$ mean nodediff $=3.40$ (left) and $\mathbf{E W}(\beta=0.363, \mathrm{n}=133)$ mean nodediff $=2.84$ (right)

Figure 69 with the complementary origin-destinations of west to east and east to west shows the spread of path choices. Both directions had somewhat longer paths on average than the ideal with west to east riders riding slightly longer paths than east to west. The plots show that the path choice was more widespread for these who rode west to east. Interestingly, those who ride east to west favored the southern crosswalk more whereas cyclists riding from west to east accessed the both the north and south crosswalks similarly. 


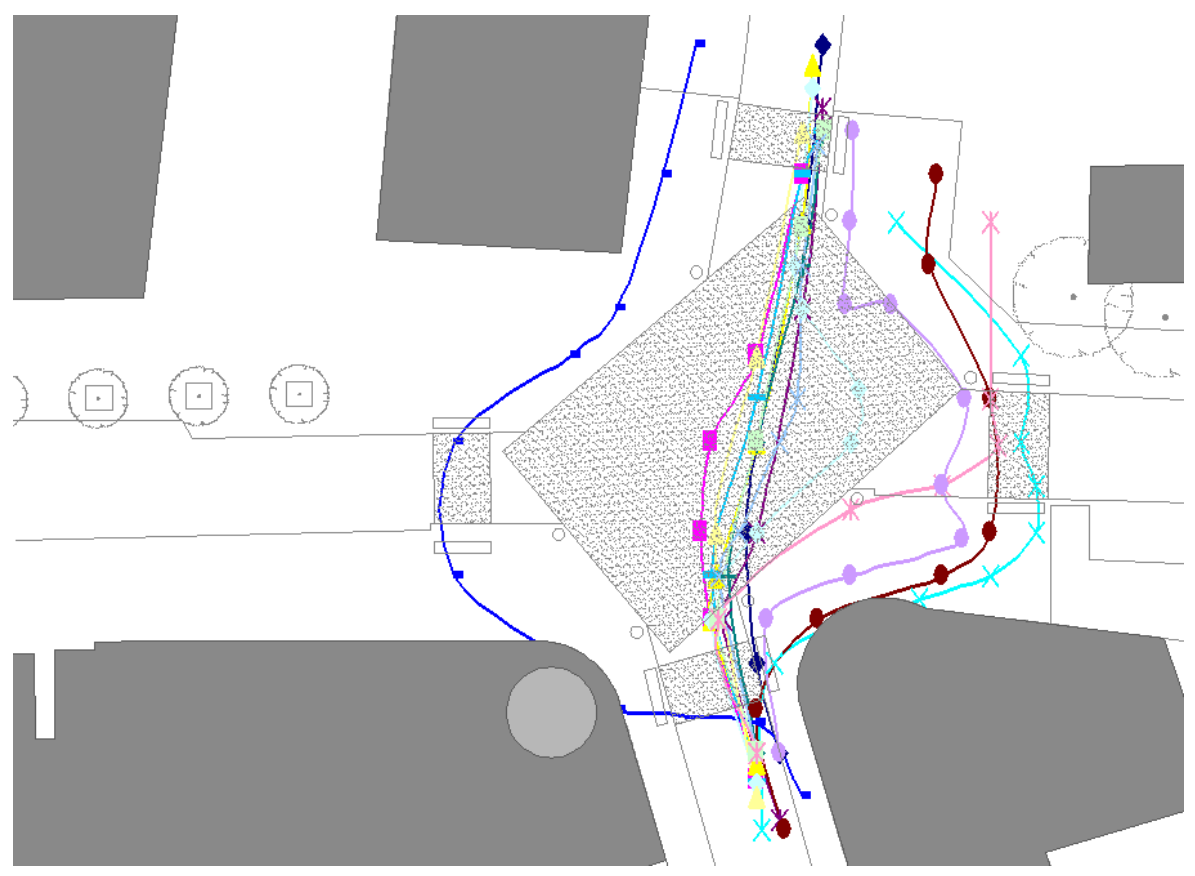

Figure 70: NS $(\beta=0.168, \mathrm{n}=15)$ mean nodediff $=4.80$

This direction of north to south had the largest mean node difference of all of the significant

ODs for this intersection. While several cyclists were observed riding mostly through the center of the site, Figure 70 shows how several were also observed skirting both edges and adding deviation, or nodes, to their paths. 


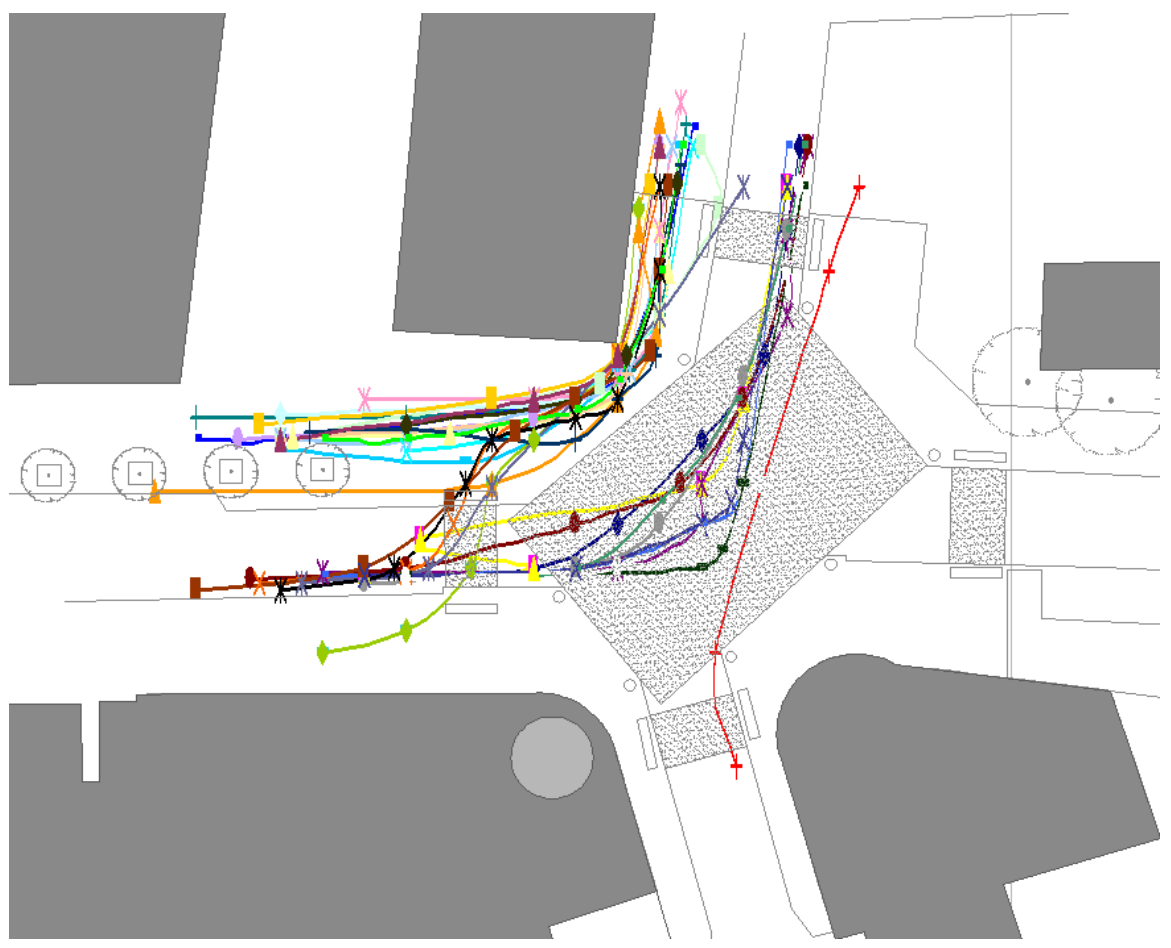

Figure 71: NW $(\beta=-0.140, \mathrm{n}=36)$ mean nodediff $=2.00$

As Figure 71 illustrates, many of the cyclists who rode from north to west chose to ride along the sidewalk and crosswalk before ending up on the road anyway.

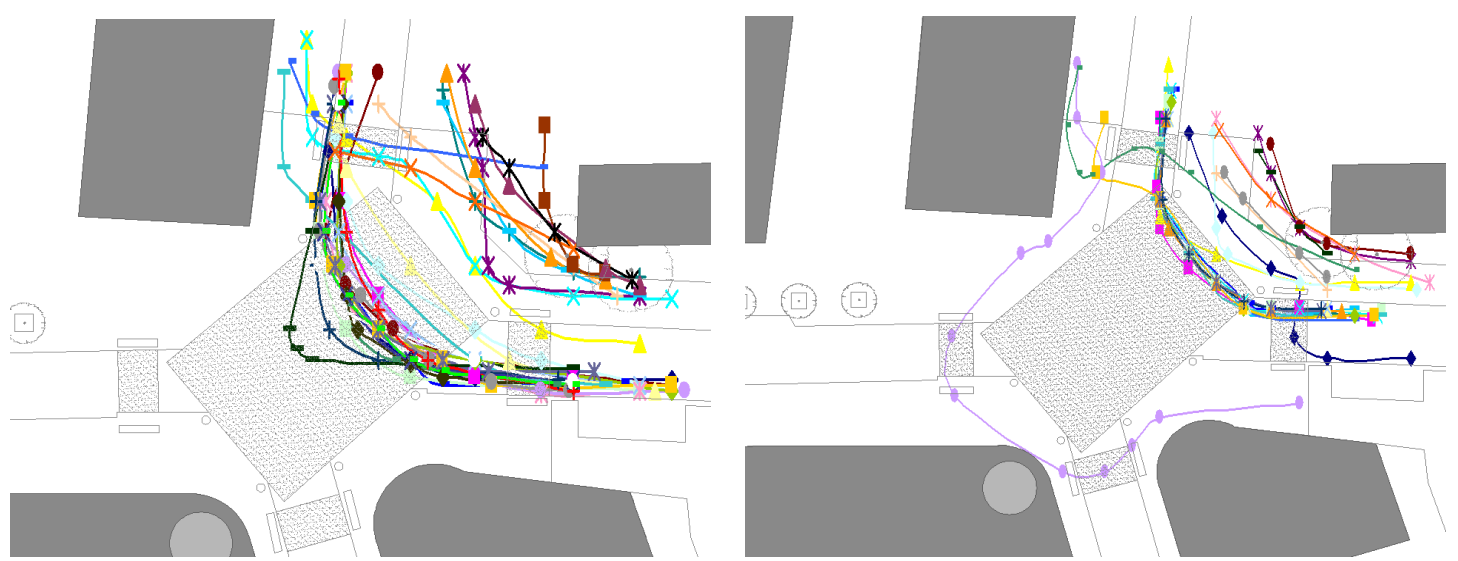

Figure 72: $\mathbf{E N}(\beta=-0.288, \mathrm{n}=35)$ mean nodediff $=1.49$ (left) and $\mathbf{N E}(\beta=-0.481, \mathrm{n}=27)$ mean nodediff $=-0.59$ (right) 
The paths plotted in Figure 72 show several riders avoided the vehicle portions of the intersection completely. However, this is one of those instances where the observed paths were shorter or more efficient than the ideal as illustrated by the mean node difference of 0.59 for north to east paths.

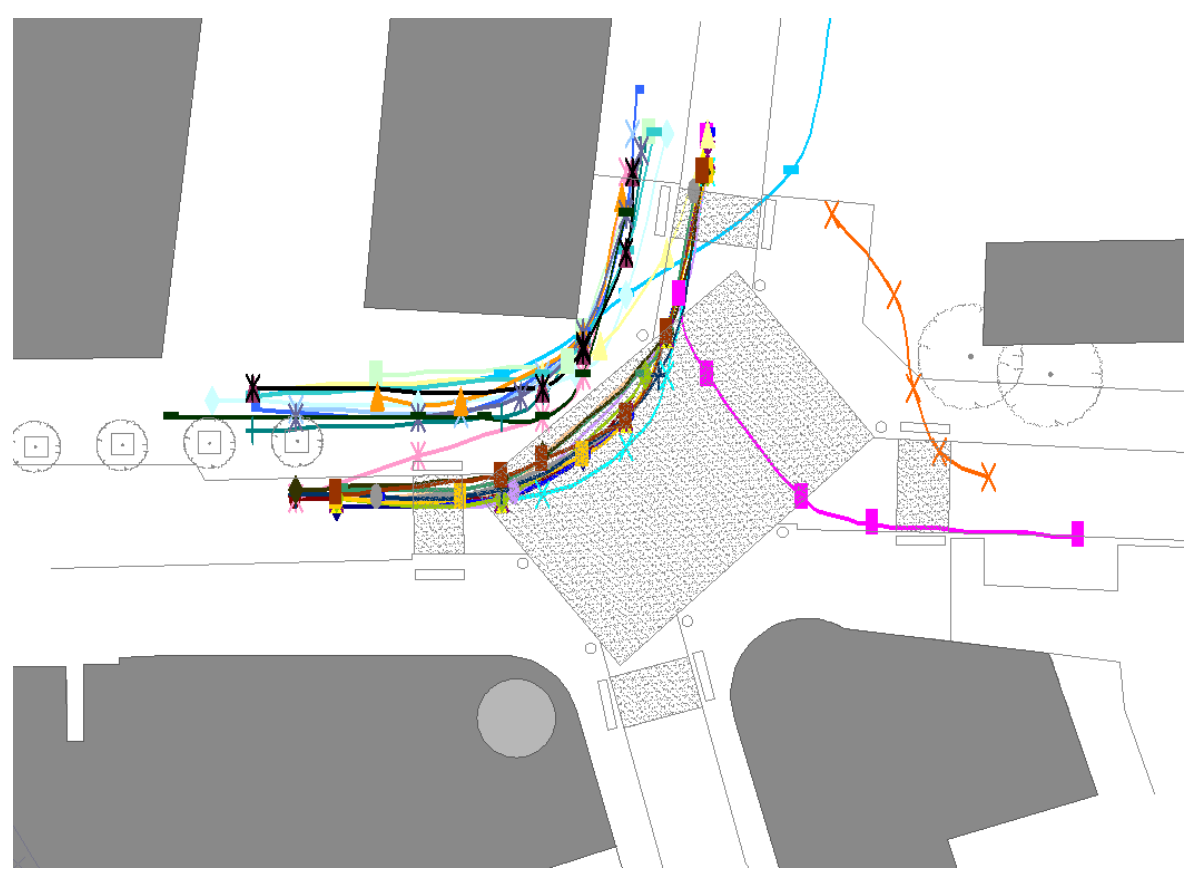

Figure 73: WN $(\beta=-0.420, \mathrm{n}=33)$ mean nodediff $=-0.76$

This OD also had a negative mean node difference. As the plot shows in Figure 73, roughly half of the observed cyclists skirted the edge of the intersection by riding on the sidewalk. This path was actually shorter than the ideal path therefore the nodediff is actually negative. 


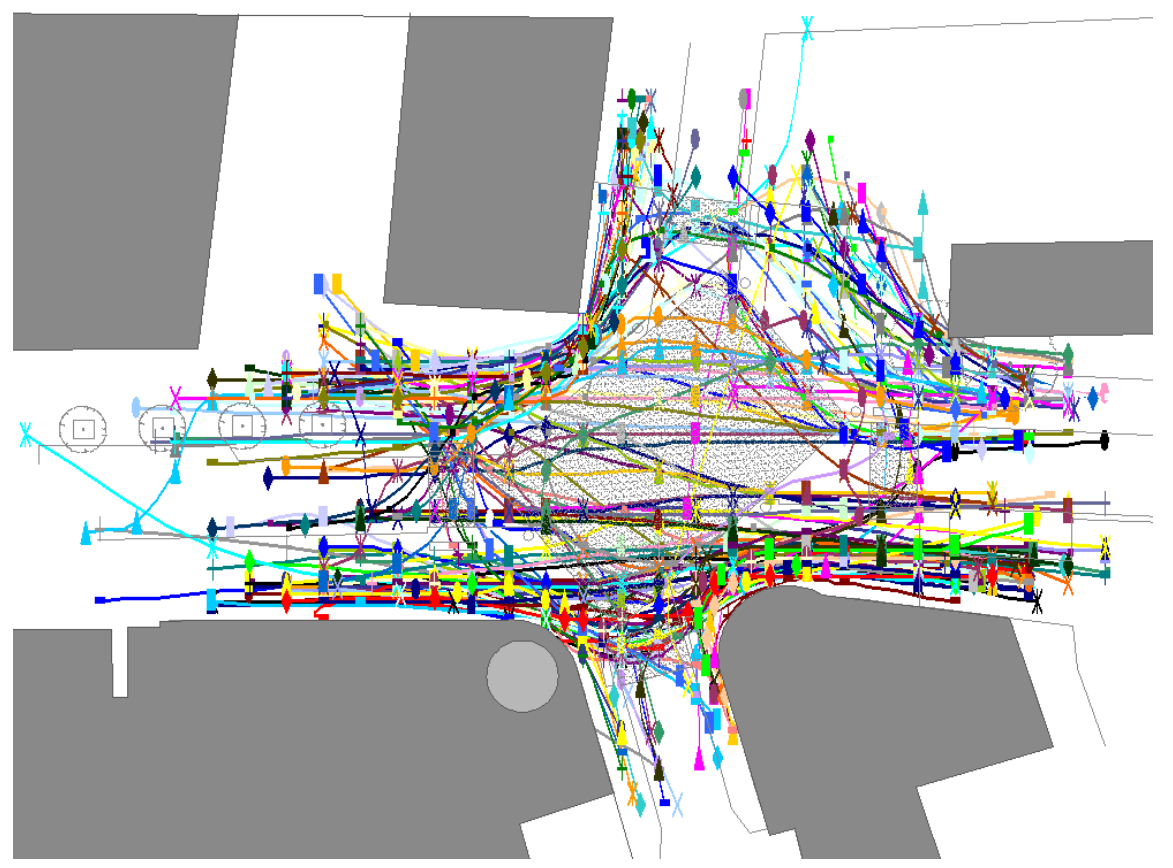

Figure 74: Sidewalk use $(\beta=0.235, \mathrm{n}=208)$

Figure 74 shows the 208 cyclists who rode through the Coventry shared intersection and rode at least a portion of their paths on the sidewalk. This illustrates that people used every available portion of the edges of the intersection when riding through this shared site. 


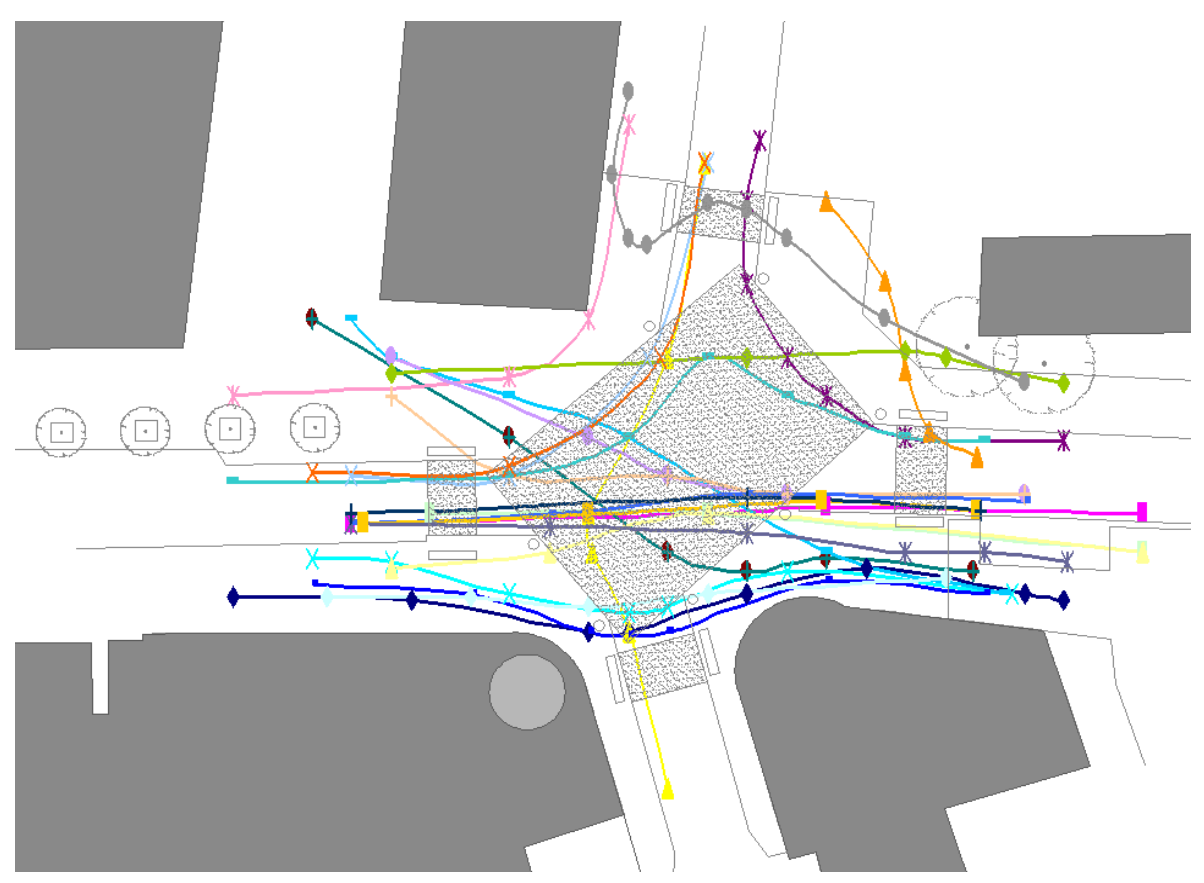

Figure 75: Other bikes $(\beta=-0.089, \mathrm{n}=25)$

Similar to Figure 66, this plot of cyclists on bicycles other than flat bar or drop bar illustrates that these riders had no specific way of riding through this site. They were seen riding directly through the center as the concept encourages; they were also seen veering toward crosswalks or ever riding out of their way to access the crosswalk. 


\section{Coventry Control}

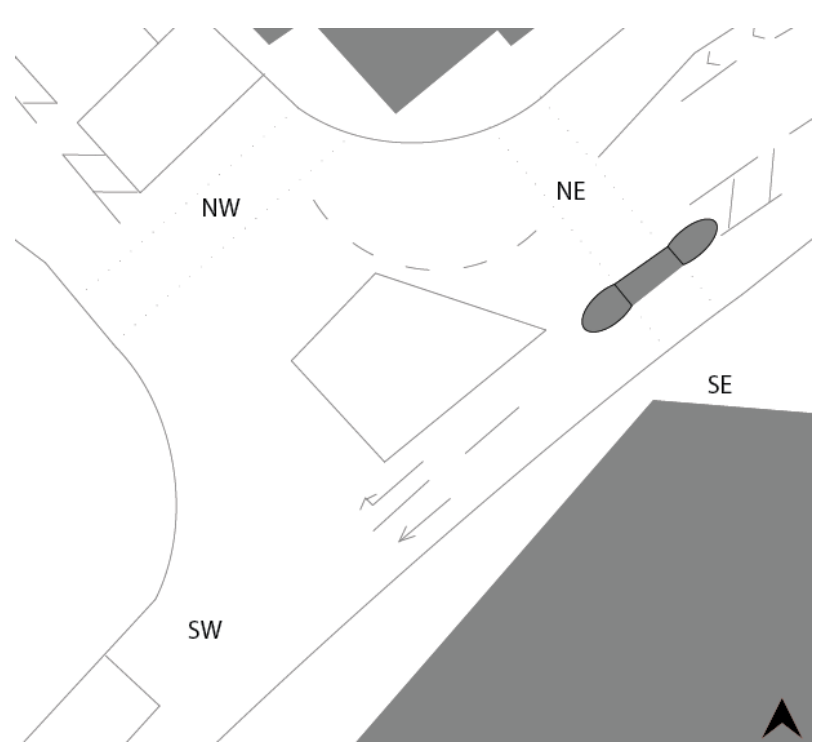

Figure 76: Labeled directions

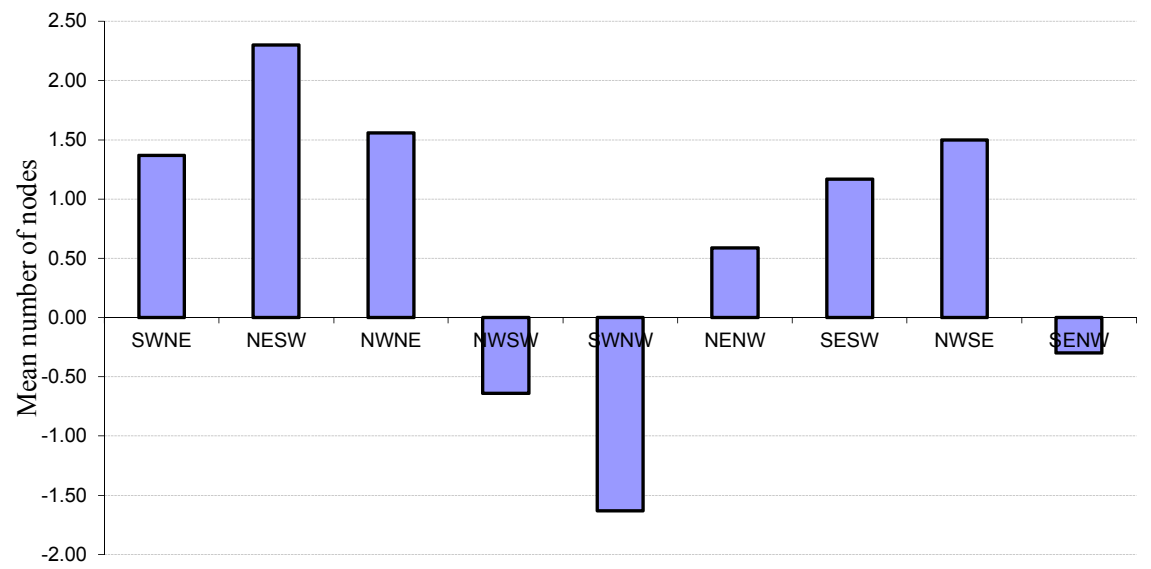

Figure 77: Coventry control mean node difference per OD

The SWNW (southwest to southeast) leg had an average of -1.63. The NESW OD leg had the largest average of 2.30. After running multiple linear regressions, the following OD 
directions had significant $(\mathrm{p}<.05)$ betas:

Table 16: Coventry control OD stepwise regressions

\begin{tabular}{lll}
\hline Variables (n) & Beta & $\mathrm{p}$ \\
\hline NWSW (22) & -0.374 & 0.000 \\
Sidewalk (268) & 0.378 & 0.000 \\
NESW (135) & 0.269 & 0.000 \\
SENW (19) & -0.136 & 0.011 \\
\hline
\end{tabular}

Note: $\mathrm{R}^{2}=0.43$, Adjusted $\mathrm{R}^{2}=0.42$

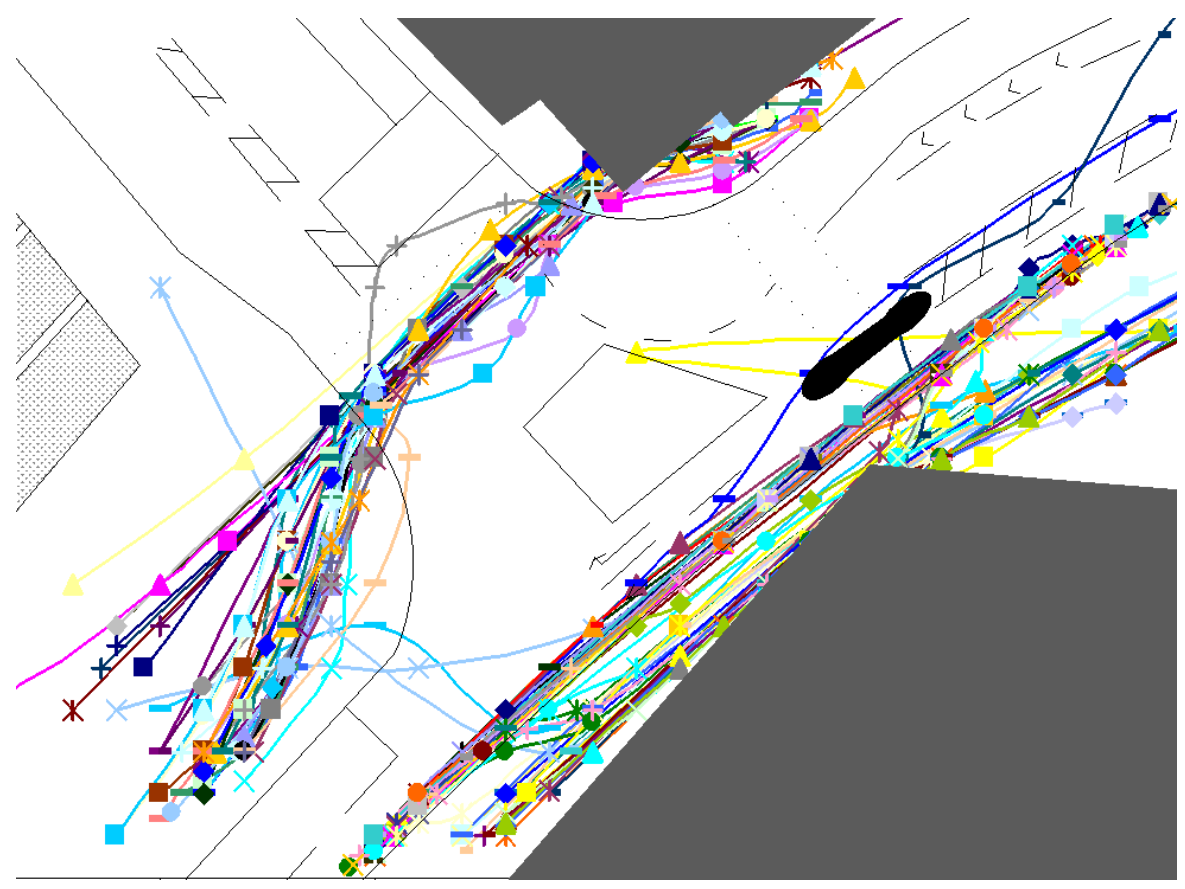

Figure 78: NESW $(\beta=0.279, \mathrm{n}=135)$ mean nodediff $=2.30$

The enlarged version of Figure 78 in Appendix E shows more clearly that the paths ridden on the southeast side of the intersection can actually be divided into two groups-road riding and sidewalk riding. On the northwest side of the intersection, there were also a large 
number of cyclists who chose to ride from sidewalk to sidewalk via the crosswalk. This diversity of path choices shows in the mean node difference of 2.3. The paths chosen were diverse but not too far off from the ideal path number of nodes.

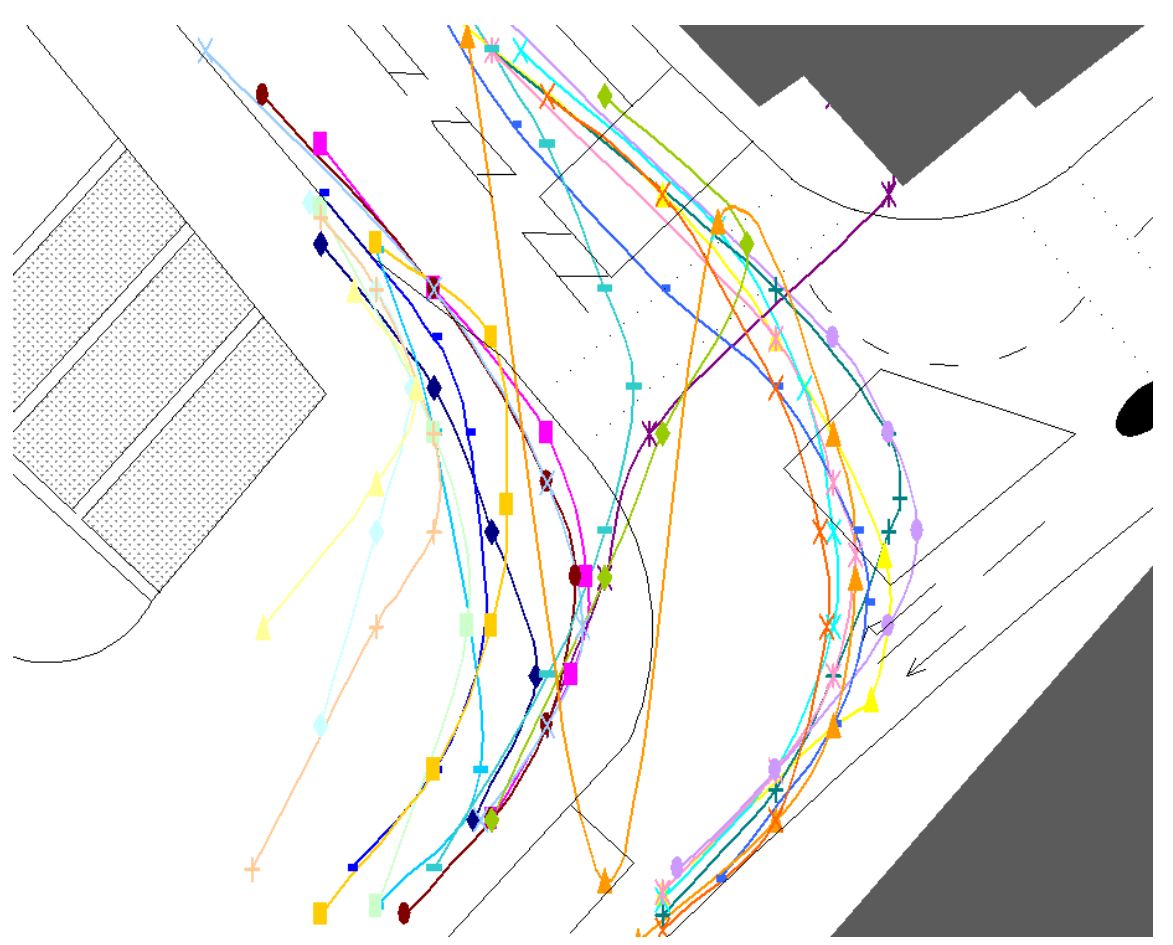

Figure 79: NWSW $(\beta=-0.251, \mathrm{n}=22)$ mean nodediff $=-0.64$

The cyclists I coded riding from northwest to southwest actually rode a shorter, more efficient path than the ideal I assigned to this OD by riding on the sidewalk, and cutting the corner. These path choices show why the mean nodediff was -0.64 , almost a full node shorter than the ideal. 


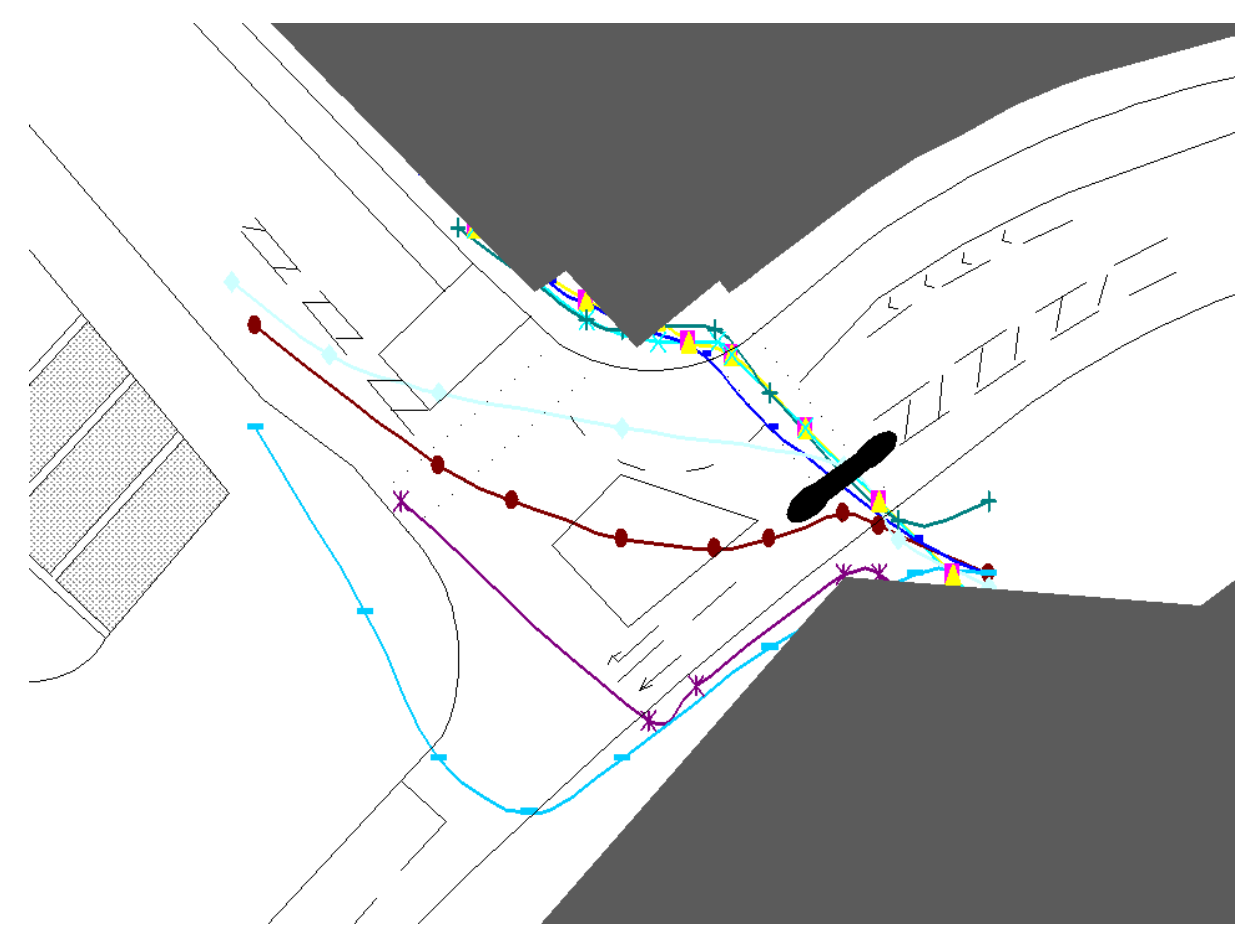

Figure 80: SENW $(\beta-0.136, n=19)$ mean nodediff $=-0.30$

Most of the cyclists who rode from southeast to northwest (Figure 80) rode through the crosswalks in their paths across the control intersection. It was impossible for cyclists to actually avoid the sidewalk for this OD because it originated from the pedestrian mall to the southeast. Again, the path choice straight through the crosswalk and back onto the sidewalk on the north side of the road was more efficient than the ideal path choice I designated for this OD.

Below I show the site results with respect to OD-specific node differences. I did not, however, run regression models for Wye and Poynton control. As will be discussed further in Chapter VI, I chose to focus on a single control intersection, Coventry control, due to its 
relative similarity and applicability to the shared study sites.

\section{Wye}
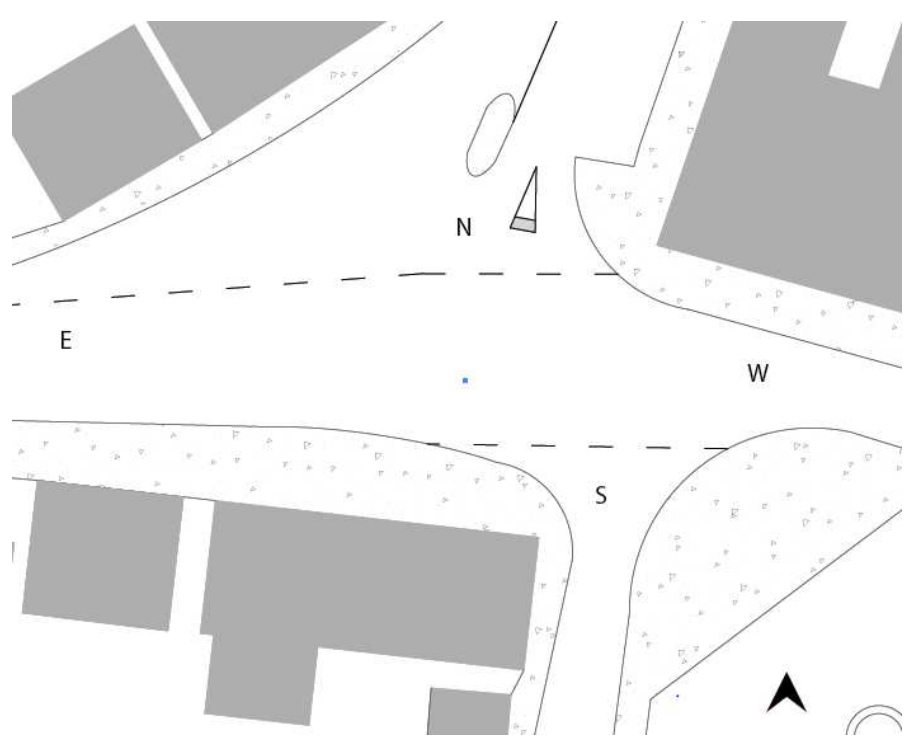

Figure 81: Labeled directions

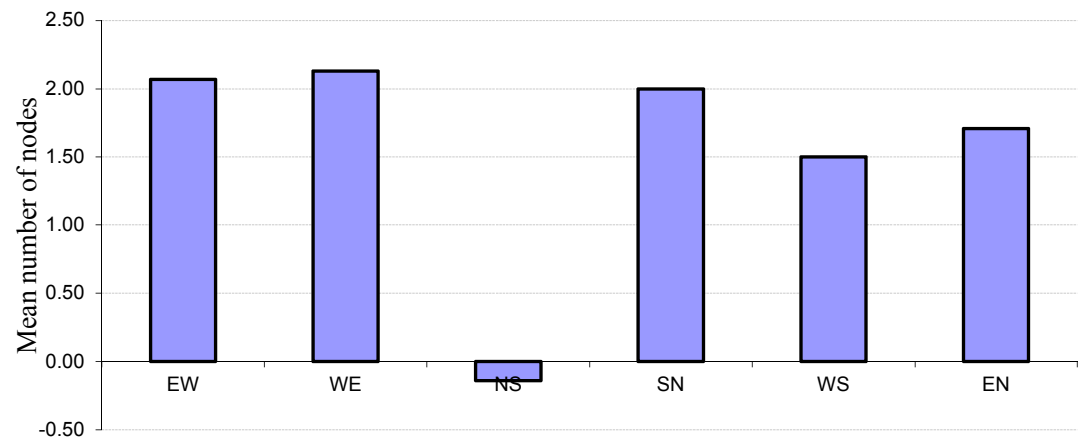

Figure 82: Wye mean node difference per OD

Wye's range of origin-destinations node difference averages was smaller than most of the other sites. Three of the sites were approximately two, and one OD had a negative leg, NS 
(north to south) of -0.14. Interestingly, its opposing leg, $\mathrm{SN}$, had a much larger average of 2.0.

\section{Poynton Control}

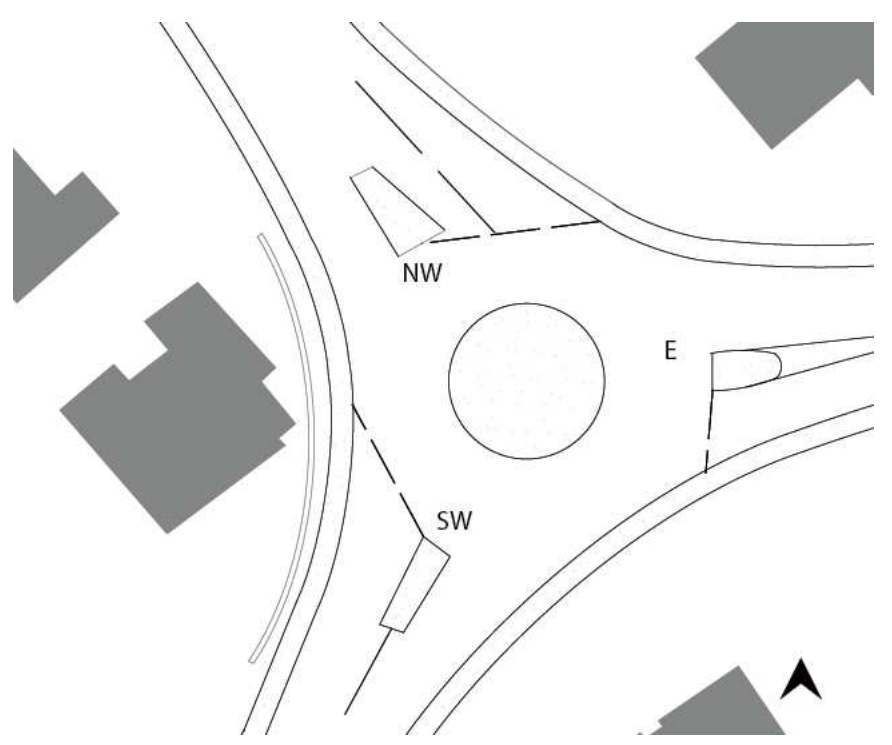

Figure 83: Labeled directions

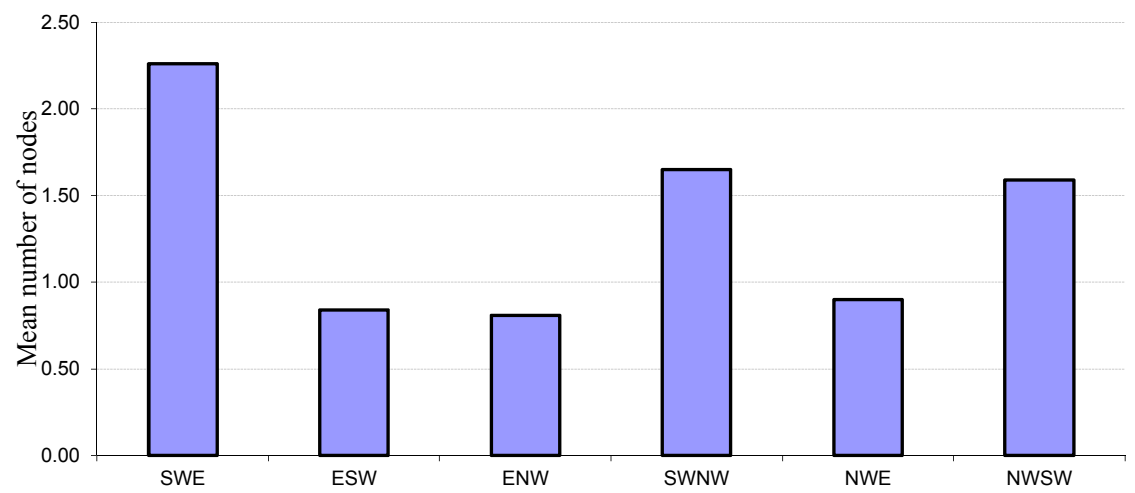

Figure 84: Poynton control mean node difference per OD 
This site had the smallest range of average node differences. While the origin-destinations leg, SWE (southwest to east) had the largest node difference of 2.26, its opposing leg, ESW was lower at 0.84 . This site had a physical traffic circle that impacted the length of turns. For instance, a left turn was shorter than a right turn because the rider than to physically go around the traffic circle.

\section{Summary of results}

There were several variables that showed significant associations with site type, a related variable, or both.

The Table 17, below, summarizes the relationships found between the observed variables and node difference and at which sites (or data sets) they were found to be significant.

- There were no significant differences found between genders at any of the locations.

- Riders who did not wear helmets made more deviations at two of the shared sites and one of the control sites, as well as the control sites combined.

- Riders with walking companions deviated more at one of the shared sites and less at one of the other shared sites. Two of the control sites had no observed walking companions.

- There were no significant differences between the path deviations cyclists made who walked a portion of their path across the intersections as compared to those who did 
not at any of the locations.

- Riders who rode on the sidewalks for a portion had significant path deviations at two of the three shared sites and two of the control sites, as well as the control sites combined. One site saw no sidewalk use.

- Riders who rode through crosswalks deviated more as compared to those who either veered or avoided crosswalks at all of the sites. One control site saw no significant difference.

- Riders who used curb cuts had less path deviation as compared to those who jumped off curbs or did not interact with curbs at all for each shared site as well as all the shared sites combined. Curb use was only observed at one control site and the associated deviations were significant there as well. 
Table 17: Summary of observed results

\begin{tabular}{|c|c|c|c|c|c|c|c|c|c|c|}
\hline & & & \multicolumn{4}{|c|}{ Shared site means (node difference) } & \multicolumn{4}{|c|}{ Control site means (node difference) } \\
\hline \multirow{5}{*}{ Rider characteristics } & & & $\begin{array}{l}\text { Elwick } \\
\text { Square }\end{array}$ & Poynton & Coventry & $\begin{array}{l}\text { All } \\
\text { shared }\end{array}$ & Wye & $\begin{array}{l}\text { Poynton } \\
\text { control }\end{array}$ & $\begin{array}{l}\text { Coventry } \\
\text { control }\end{array}$ & $\begin{array}{l}\text { All } \\
\text { control }\end{array}$ \\
\hline & \multirow[t]{2}{*}{ Gender* } & Male & 2.62 & 5.04 & 2.32 & 2.90 & 1.58 & 1.34 & 1.96 & 1.69 \\
\hline & & Female & 2.13 & 3.79 & 2.18 & 2.38 & 1.67 & 1.00 & 1.48 & 1.44 \\
\hline & \multirow[t]{2}{*}{ Helmet* } & Yes & 2.10 & 3.80 & 1.92 & 2.91 & 1.35 & 1.44 & 1.25 & 1.37 \\
\hline & & No & 2.53 & 5.04 & 2.60 & 2.66 & 1.90 & 1.25 & 1.89 & 1.84 \\
\hline \multirow[t]{14}{*}{ Rider behaviors } & \multirow[t]{2}{*}{$\begin{array}{l}\text { Walking } \\
\text { companion }\end{array}$} & Yes & 4.33 & 2.83 & 0.33 & 2.19 & $\mathrm{n} / \mathrm{a}$ & $\mathrm{n} / \mathrm{a}$ & 2.00 & 2.00 \\
\hline & & No & 2.37 & 4.11 & 2.37 & 2.71 & $\mathrm{n} / \mathrm{a}$ & $\mathrm{n} / \mathrm{a}$ & 1.34 & 1.39 \\
\hline & \multirow[t]{2}{*}{ Walking leg } & Yes & 2.43 & 5.44 & 3.33 & 4.00 & $\mathrm{n} / \mathrm{a}$ & 3.00 & 0.75 & 1.20 \\
\hline & & No & 2.41 & 4.01 & 2.33 & 2.67 & $\mathrm{n} / \mathrm{a}$ & 1.42 & 1.35 & 1.39 \\
\hline & \multirow[t]{2}{*}{ Sidewalk } & Yes & 2.41 & 3.52 & 2.73 & 2.73 & $\mathrm{n} / \mathrm{a}$ & 0.50 & 1.70 & 1.64 \\
\hline & & No & 2.39 & 4.97 & 2.05 & 2.65 & $\mathrm{n} / \mathrm{a}$ & 1.50 & 0.74 & 1.22 \\
\hline & \multirow[t]{3}{*}{ Crosswalk } & Yes & 4.33 & 7.00 & 5.38 & 5.15 & $\mathrm{n} / \mathrm{a}$ & $\mathrm{n} / \mathrm{a}$ & 3.00 & 3.00 \\
\hline & & Veer & 4.10 & 5.42 & 4.52 & 4.64 & $\mathrm{n} / \mathrm{a}$ & 1.50 & 2.91 & 2.89 \\
\hline & & No & 2.02 & 3.59 & 1.89 & 2.19 & $\mathrm{n} / \mathrm{a}$ & 1.42 & 0.55 & 1.00 \\
\hline & \multirow[t]{4}{*}{ Curb use } & $\begin{array}{l}\text { Curb } \\
\text { cut }\end{array}$ & $\mathrm{n} / \mathrm{a}$ & 2.33 & 1.47 & 1.61 & $\mathrm{n} / \mathrm{a}$ & $\mathrm{n} / \mathrm{a}$ & 2.52 & 2.52 \\
\hline & & $\begin{array}{l}\text { Jump } \\
\text { curb }\end{array}$ & $\mathrm{n} / \mathrm{a}$ & 6.57 & 3.30 & 3.88 & $\mathrm{n} / \mathrm{a}$ & 1.00 & 2.80 & 2.46 \\
\hline & & Both & $\mathrm{n} / \mathrm{a}$ & 5.00 & 4.44 & 4.55 & $\mathrm{n} / \mathrm{a}$ & $\mathrm{n} / \mathrm{a}$ & $\mathrm{n} / \mathrm{a}$ & $\mathrm{n} / \mathrm{a}$ \\
\hline & & No & $\mathrm{n} / \mathrm{a}$ & 3.90 & 2.17 & 2.71 & $\mathrm{n} / \mathrm{a}$ & 1.43 & 1.22 & 1.32 \\
\hline & \multicolumn{2}{|c|}{$\mathrm{n}$} & 357 & 206 & 490 & 1053 & 76 & 195 & 422 & 693 \\
\hline
\end{tabular}

Note: 1-way ANOVAs run with node difference as dependent variable. Independent variables are compared within each site (i.e. male node differences are compared to female node differences per site, and then per pooled set) 
Additionally, regression analyses found that each site had at least a few origin-destinations with significant mean node differences. In general, these significant ODs stood out due to the variety of paths that cyclists took while riding through the intersections. (See Appendix D for larger path illustrations.)

Elwick Square's NS (north-south) origin-destination (and its partner SN, south-north) cross the widest part of the intersection. The paths (Figure 67) spread out when crossing north to south much more than when crossing south to north (an origin-destination which was not significant). It appears that many cyclists have enough room to decide to move laterally and line up to cross the roadway area closer, or more in line with, the crosswalk. When traveling the opposite direction, there is not as much opportunity or space for the lateral movement. When looking at the directions NWS (northwest-south)and SNW (south-northwest), the bench in the center of the site (see Figure 7) serves as an ideal inflection or pivot point to line riders up to make a direct turn on and off of Elwick Road.

Poynton's WE (west-east) and EW (east-west) origin-destinations have the largest mean node differences of all the sites. It is not the largest site (Elwick Square is) so this is due to the site's complexity and possibly because riders find it very intimidating and/or confusing. Looking at Figure 68, the paths indicate three main choices; many cyclists ride on either side of the road to access the crosswalks on both sides, and many ride in the road more directly as well. This gives a very wide selection of paths as well as high number of nodes. The origin-destinations of SWNE and NESW show a similar pattern, with many cyclists riding 
on either side of the roadway to access the crosswalks.

Coventry's origin-destinations of NS and SN stand out due to their very different mean node differences. While the number of riders who rode the NS direction was relatively small, enough of them went significantly out of their way to ride through the crosswalks on either side of the intersection to make this OD stand out (Figure 72). (The SN origin-destination direction was negative, however, because in this case, riding on the sidewalk actually shortened and tightened up the cyclists' paths making it much shorter than my ideal path in the direction.) The NW origin-destination (Figure 73) is a good example of cyclists avoiding an intersection and using a curb cut to access the road once past the intersection.

The Coventry control intersection, similar to Poynton, has some ODs that had a wide variety of path choice. Cyclists riding the NESW OD (Figure 78) rode three primary ways: they rode on the sidewalk via the crosswalk on the north side of the intersection, they rode on the road close to the curb, or they rode on the sidewalk on the south side of the intersection. This site also has three ODs with negative mean node differences (NWSW, SWNW, and SENW). The majority of cyclists chose paths via the sidewalks and crosswalkboth elements that shortened the paths significantly.

\section{Contributions to shared space literature}

The above results indicate that the design, layout, size and (some) elements of a shared space do directly impact the path choices cyclists make. The shared space literature state that the inclusion of humanizing elements help make a site more welcoming and inclusive, but none 
of the literature had yet to look at how site elements and site layout impact the ways people ride their bicycles through shared space intersections (or non-shared for that matter). This research finds that the location of some elements, such as a concrete bench/seat wall can help direct people along a path as well as serve as a refuge or rest spot. Other elements, such as crosswalks and sidewalks, or an intersection shaped to allow more lateral movement, can provide space for cyclists to either ride far enough from vehicles as their comfort level requires or to allow them to circumvent a congested or trapped situation. Traffic volumes may play a role in a cyclist's path choices but the behaviors at both Coventry sites indicate that the size of the vehicles instead of just the numbers may also influence cyclists. 


\section{CHAPTER V}

\section{SURVEY RESULTS}

The survey results were less robust than I had hoped for. Despite help from each of the communities I was observing and surveying in, I had very low completion numbers. The general completed survey numbers were:

- Coventry: $n=21$

- Coventry control: $\mathrm{n}=11$

- Poynton: $\mathrm{n}=19$

- Poynton control: $\mathrm{n}=13$

I received no completed surveys for Elwick Square or Wye.

There were two surveys for this research—one for the shared space sites and one for the control sites. These surveys were very similar to each other but modified according to the intersection treatments (See Appendix D). For instance, question 12 asked about a respondent's experiences riding through the intersection prior to its redesign. This was a shared space-specific question and was not applicable for the control sites. Each survey was also modified to be site specific with labeled site plans, appropriate street names, and aerial photos.

The number of respondents for an online survey was very low so I suspect the surveys were 
either too long and/or too difficult. There were other factors that also probably contributed to the low response rate. For instance, it was more difficult to distribute the survey than previously anticipated. Given the short time I was in England, I did not hand out the survey cards in person. Instead, I communicated with several groups in each town and asked them to distribute the relevant surveys to their mailing lists (Table 3). Despite this multipronged approach, I only received 64 completed surveys. No one completed surveys for either Elwick Square or its control site, Wye.

The demographic and riding experience answers revealed that the respondents were mostly male and generally experienced cyclists (Table 16). The respondents' ages ranged from 19 to 72 years with the average respondent being 50 years old, most of the respondents rode multiple days a week, and regularly wore helmets; reported helmet use was higher than observed; Poynton control observed helmet use (87\%) was closest to the self-reported percentages. The respondents were both recreational and commuting cyclists. Most of the survey respondents were experienced cyclists who rode regularly and often year- round. These cyclists are likely more confident and probably have a different riding perspective than less confident and/or regular cyclists. 
Table 18: Survey respondent characteristics

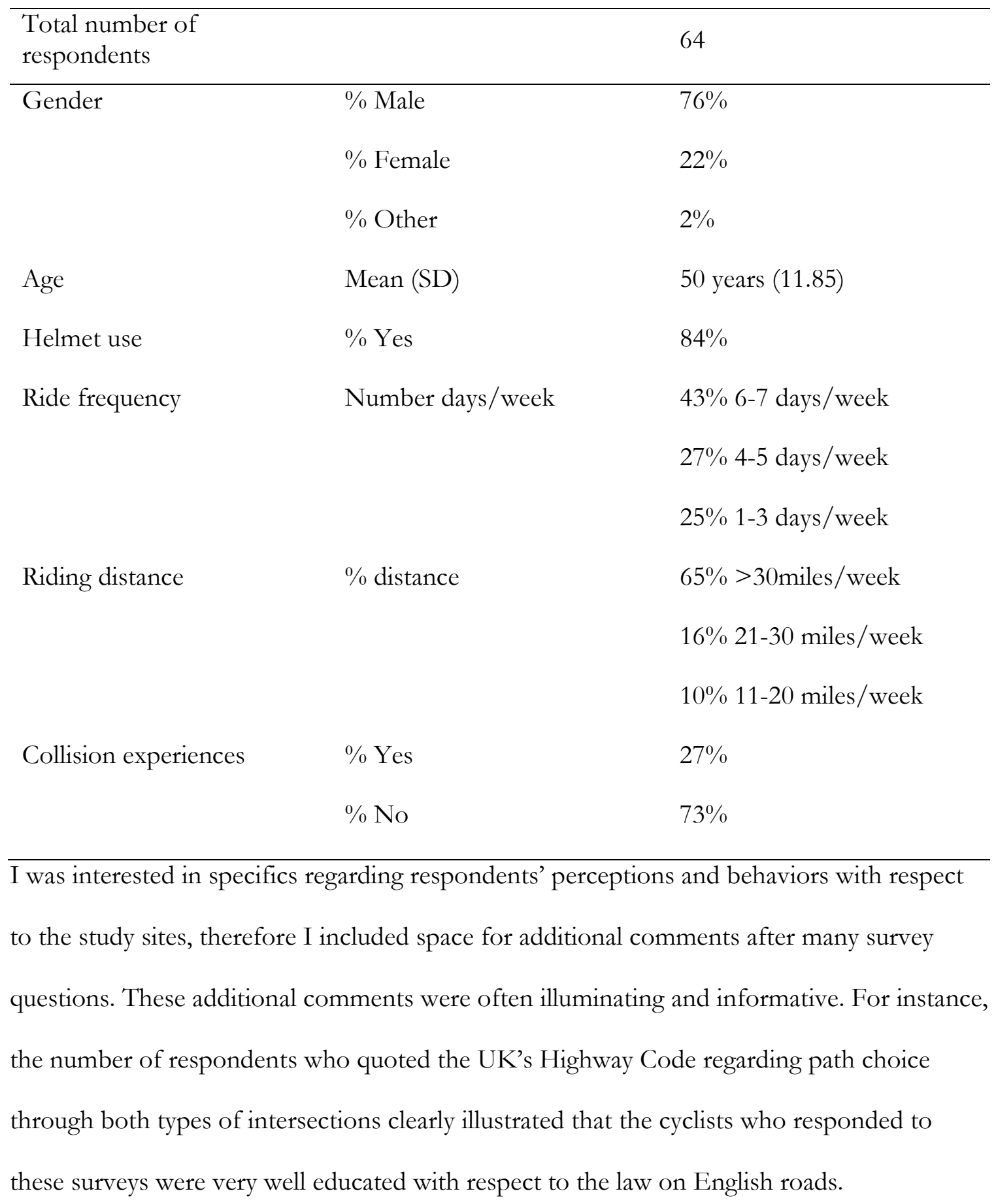


When asked about why respondents chose the paths through the intersections that they did, the general response for all four surveys, again referencing the Highway Code, was that there was no other path they would prefer to ride because the paths they already rode were the legal, correct choices. Comments regarding this included:

- "the legal way at a roundabout"

- "they are the conventional ways to progress"

- 'It's the correct route. Bicycles should use the carriageway in the absence of off-road lanes"

- 'It's against the law in the UK to ride on the Pavement. So cannot use your other lines. Beside there are other user on the Pavement."

One respondent did say, however, that:

- “Only legal way which is reasonably convenient. I note that illegal, footway cycling is often quicker \& more convenient.” (Coventry control)

Others stated that if they do have to ride on the sidewalk (pavement) for any reason, they get off their bicycles and walk. These comments further indicated that this was not a representative sample of the cyclists I actually observed riding through these sites; the survey respondents overwhelmingly stated it was illegal to ride on the sidewalks, but I observed up to $88 \%$ of riders (Elwick Square) doing just that.

Clarity in navigating the intersections revealed some control versus shared intersection 
differences. When asked how clear it was where to ride through the intersections, $90 \%$ of the Poynton control respondents felt it was clear or very clear where they should be riding whereas $58 \%$ of respondents felt as confident regarding the shared Poynton intersection. However, the responses regarding the Coventry control intersection were the same as the two shared intersections. The Poynton control intersection was a very straight forward, traditionally marked intersection with a roundabout. The Coventry control intersection was also traditionally marked but busier with transit and many more users of all modes. The expressed confusion is understandable for the shared intersections but the responses indicate that even a traditionally marked intersection can confuse cyclists.

When asked to provide any additional thoughts or comments about their path choices through the selected intersection, many wrote long comments. The respondents were well informed and showed insight regarding the study intersections, often explaining the traffic dynamics they have observed while riding through the study sites. For instance, one cyclist noted that the space allotted in the Coventry shared intersection seemed too tight for buses:

- "Please get rid of them. I take my life in my own hands each time I cross them. There is not even enought for the bus to take the corners. It has to swing over to the other side of the road when turning right or left. Putting not only cyclist but also other road users at more risk. The degsiner needs to be shot or made to ride bike 
through here. Hate it full stop." ${ }^{\prime \prime}$

While another respondent, also writing about the Coventry shared intersection and buses, said:

- "I find that buses are the most generous in giving way. Cars drivers are the most aggressive in sharing the junction space, and the most likely to be risky in their use of the space."

When discussing the Poynton shared space dynamics, one respondent wrote noted that the intersection appears too large for drivers to be able to observe cyclists:

- "There are two types of problem with this type of junction. Generally it is too big an area for motorists to scan to see cyclists. When it is busy there is no guarantee to the way a motorist will behave. Many have been queuing for 10 minutes and when they reach the junction they just go for it. That is particularly a problem coming out of Park Lanemotorists who are not local just do not see the second roundel. Also, the roads are major routes so much of the traffic does not know what a shard space scheme is and have no idea how to deal with it."

I also asked about how cyclists experienced priority (or the right to proceed) through the selected intersections; only the shared respondents answered that they felt they had more priority while riding through these intersections as compared to the control intersections. One respondent wrote:

${ }^{8}$ All quotes are verbatim 
- "This junction has re-arranged the priorities of users from vehicles to pedestrians and bikes. The uncommon nature of the layout and possibilities causes confusion with drivers who are uncomfortable with new road layouts. More pedestrians using the shared space as intended would 'teach' drivers to proceed with more consideration of other road users. Traffic east-west has improved, whilst North south users (normally through traffic to Stockport/ Manchester etc) are unwilling to admit the junction has benefitted the village" (Poynton).

Respondents were also asked for their opinions about the intersections themselves. When answering the shared space surveys (Coventry and Poynton), respondents were mixed in their perceptions. Some respondents disliked the shared designs saying, for example:

- "Remove it an put back the give way signs so every one know who has the right of way. Good job it painted RED so it won't show the BLOOD.” (Coventry)

- "The only thing that would make this safer is bike lanes that would give us a right of way and also widen the lane. Its gone from a wide road to a narrow road and cars dont know how to pass cyclists anymore. This layout is so different from other layouts in our area so it causes too much confusion. Looks dont make it safe!" (Poynton)

Others were more ambivalent:

- "Not sure. I thought it was intended to get everyone to slow down, give way and proceed with caution. When it first came out I spoke to a bus driver friend who suggested to treat it as having a zebra crossing at each entrance and a roundabout in the middle. Unfortunately this would lead to street clutter." (Coventry)

And a few respondents actually preferred the new shared designs: 
- "I love it; both as a pedestrian, cyclist and car driver. It keeps the traffic flowing, slows the traffic down making it safer for pedestrians and cyclists and makes it easier to cross the road" (Poynton)

- "I most frequently ride straight e-w or w-e and it feels bold and empowered. Other road users tend to notice me more at this junction" (Coventry).

Many respondents showed familiarity with the shared space concept:

- "These junctions are a great improvement over the old layouts. However, they should not be confused with 'shared space'. That concept is one where the whole junction / street is given over to public space, through which traffic may pass in a proportion of the area marked out by changes of surface and vertical features. This isn't attractive enough to be public space - in fact the design is rather crass - and the presence of kerbs around the 'carriageway' area signifies a distinct difference between footway and road pavement. I'd like to see a far more radical approach taken for future schemes." (Coventry shared)

\section{Summary of results}

The survey response rate was very low, and only four of the six sites had completed surveys; of those who did respond, the vast majority of survey respondents were male. These respondents mostly rode at least 30 miles and week, and almost all regularly wore helmets. Instead of the diverse group of cyclists I had hoped for, my respondents were a small, passionate, well-informed, and presumably confident sample of cyclists. It is also interesting to note that this sample was not unique to just one town but occurred in two different locations in the country. 


\section{CHAPTER VI}

\section{DISCUSSION}

According to the concept of shared space, road users should feel welcome, or free enough to walk through the intersection from any points instead of just through the crosswalks. A cyclist has the freedom of movement of a pedestrian while experiencing infrastructure at a different scale than a pedestrian. This suggests that cyclists should ride with more freedom through the sites as compared to non-shared sites.

I made several assumptions regarding cyclists and how they ride. First, some cyclists who are intimidated by the shared and control intersections will still ride through these intersections. Second, that each cyclist path I observed reflected that cyclist's perceptions of the intersection. And third, that each path observed counts individually. In other words, even if I observed the same rider multiple times each experience through the intersection is unique and stands alone.

I used video observations to approach the questions of how cyclists actually maneuvered through shared space intersections by seeing if cyclists avoided, or favored, certain sections of the intersections as compared to the control intersections. Looking at each site with cyclist variables analyzed and various OD legs plotted and overlaid upon the site plans, a few patterns began to emerge. 
Traffic volumes

One element that must be considered is the impact that surrounding traffic may have upon the riders and their paths through the study sites. While the concepts behind shared space strive to minimize the effects that motorized vehicles have, the observed behaviors indicate that motorized vehicles do still play a role in how cyclists navigate the shared (and control) study sites. If traffic volumes did not play a role in modifying or influencing a cyclist's path choices, then I would expect to see cyclists riding wherever they wanted. In other words, the paths observed would be widespread and presumably more direct and efficient (fewer nodes).

To summarize the observed hourly traffic volumes:

- Wye had the lowest average hourly traffic volumes of all of the sites

- Both Coventry sites had the greatest shares of observed large vehicles (primarily buses.)

- Both Poynton sites had the largest average number of vehicles per hour, with approximately double the traffic volume of both Elwick Square and Coventry control.

It is possible that cyclists are less impacted by motorized traffic while riding through the shared sites than the observed paths may indicate but instead are riding as they would through the control sites simply by habit. If this were happening, cyclist paths would look very similar in both types of intersections (which they do); it may take more time or a culture shift to modify the paths cyclists ride through the shared space sites to match more of what 
would be expected by the concept's principles. The online survey responses also intimated that a cultural or legal shift may be necessary before more experienced cyclists will ride as shared space designs try to encourage.

More specific discussion regarding traffic volume and other observed variables will follow in conjunction with variable specifics.

Characteristics and path choice

The first pattern to emerge was that two of the six study sites did not belong with the other four. After spending time on the ground and then processing the videos, it became clear that the Wye and Poynton control sites were too dissimilar from the third control site, Coventry control, and the three shared sites. Further analysis of variables such as helmet use (Figure 44), bicycle type (Figure 45), sidewalk and crosswalk use (Figures 46 and 47) clarified that these two control sites were primarily recreational and should be removed from further analysis because the other four sites had a wider range of cyclist types.

I observed that the more recreational a site (Wye and Poynton control), the greater the percentages of drop bar bicycles (Wye 37\%, Poynton control 64\%) and helmet use (Wye $66 \%$, Poynton control 87\%). For instance, I observed almost $90 \%$ of the bike riders wore helmets at the Poynton control intersection — this was also the site with the highest percentage of drop bar bicycles. Contrast this with Elwick Square, a shared site, where less than $20 \%$ of the cyclists were seen wearing helmets. In general, the shared sites had less helmet use than either of the two more recreational sites. While Poynton (shared) also had a 
large percentage of helmet-wearing cyclists, it also had a good mix of other bicycle riders, making it less recreational overall. Coventry control, the site most like the shared sites, had similar helmet use percentages to the shared sites. It is unclear why the cyclists in Ashford (Elwick Square) had the lowest rate of helmet use.

The analyses confirmed that initial impressions were correct; these sites and users were different than the other four sites. One site element that played a role in the patterns of use observed may be the narrowness of the sidewalks. Both sites had very narrow sidewalks that no one rode upon. They were also in quieter areas-but still very close to both commercial and residential areas.

I collected data on gender because I hypothesized that demographic differences would manifest in observable path choice variations. Again, I addressed this by asking, and watching, how cyclists actually maneuvered through these spaces. In England, as in the United States, the percentage of males who ride is greater than females who ride with roughly three times as many males riding as compared to females (NTS, 2013). I observed the smallest gender discrepancy at Wye (24\% observed riders were female), one of the more recreational sites (see Figure 42). At the rest of the sites (both shared and control), the percentage of female riders observed never exceeded 12\% (Elwick Square). These percentages are not comprehensive due to the previously discussed difficulty in identifying a rider's gender. After excluding the cyclists of unknown gender, a one-way ANOVA found no significant variance between gender and the number of nodes. In other words, neither 
gender was riding longer or shorter paths as compared to the other gender. This is an interesting finding and indicates that, for my study sites, both male and female riders rode through the intersections similarly.

I collected and analyzed bicycle type as an almost demographic proxy, curious to see if it might be related to skill or confidence and thus path choice. As of yet, though, there is no related research I have seen regarding confidence, or skill, and bicycle type. The predominant bicycle type of five of the six sites was the flat bar bicycle (Figure 45). There are many versions of a bicycle that may have a flat bar, and I did not differentiate between flat bar mountain bikes, hybrids, and single-speed/fixed gears. In general, a flat bar bicycle will put the rider in a more upright position which many bike riders find more comfortable. Drop bar bicycles, road bikes, are often perceived as being more 'race' bicycles and many people shy away from them for regular use because they can put the rider in a more forward, lower position. Additionally, many people want fatter tires on their bicycles and drop bar bicycles generally cannot accommodate wider tires. Only the Poynton control site had a larger percentage of drop bar bicycles than flat bar, reflecting its recreational status.

While the cyclists I observed predominantly rode flat bar bicycles, male riders rode a greater variety of bicycle types than female riders did. At every study site except one, the flat bar bicycles outnumbered the drop bar bikes. The female riders observed at the Poynton control site however, had a bike type split: 50\% flat bar and 50\% drop bar-while more than $70 \%$ of the males observed there rode drop bar bicycles. I did not ask about bicycle type in the 
online surveys.

Because both Poynton intersections also had the largest observed average hourly number of vehicles of the six study sites, bicycle choice may align somewhat with traffic volumes. The increased traffic as well as the more complicated intersection layout (for Poynton shared) may contribute to the larger numbers of drop bar bicycles. These bicycles are often seen as faster and for braver riders; increased traffic volumes can be more intimidating for more cautious cyclists.

\section{Behavior and path choice}

I saw people ride their bicycles many different ways. Many riders made path choices that seemed logical—whether via the roadway, sidewalk, or a combination. These paths were usually efficient and direct. Other cyclists surprised me by taking unexpected paths. This often involved a rider going out of his or her way and riding through more than one crosswalk to avoid the roadway all together. Figures 70 and 72 are just two examples that illustrate the diversity of path choices made to avoid as much of the intersection as possible. (Also see Appendix E for larger versions of path plans.)

Some behaviors were too rare and/or too difficult to catch to be analyzed effectively. For instance, I noted a few conflicts and avoidance behaviors (Appendix A), but likely missed many more of these incidents due to their subtlety and rarity. I observed only one collision (between a cyclist and a pedestrian running for a bus at the shared site) and one left hook (where the cyclist responded by slapping the side of the van at the control site). Both of 
these occurred in Coventry. There were other less significant incidents that I also noted where, for instance, a cyclist had to swerve to avoid a pedestrian or vehicle. I asked about collisions in the online surveys and none of the respondents said they had experienced collisions at any of the four study sites. My overall impression was that I observed fewer conflicts and avoidance behaviors in general for both shared and control intersections than I expected to.

As discussed previously, a 'pure' shared space project would have neither sidewalks nor crosswalks; however, my study sites (both shared and control) had these features. I had hypothesized (hypothesis 2) that less experienced cyclists would try to avoid the shared space intersections when possible. However, what I saw was probably much more sidewalk riding than just by reluctant bike riders. For the four primary sites, sidewalk use ranged from $42 \%$ to as high as $88 \%$. Due to the limited survey results, I cannot definitively state that certain demographic groups avoid, or prefer to avoid, these shared space intersections. (Especially because none of the survey respondents commented that they ever rode on the sidewalks, instead calling that choice an illegal behavior according to the Highway Code.) However, the percentages of cyclists I observed avoiding the centers of the intersections leads me to hypothesize that not just inexperienced cyclists are uncomfortable riding through these intersections. It must be noted, the apparent reluctance observed due to sidewalk and crosswalk riding was also very high in the Coventry control intersection.

My observations reinforced the idea that an advantage of the bicycle is its versatility and 
flexibility. At each of the four primary sites some sidewalk riding happened when riders wanted to avoid traffic, such as buses or large trucks, blocking the roadway. I saw many cyclists stopped behind large vehicles; often those riders chose to leave the roadway to ride on the sidewalk for a portion instead and avoid the congestion. The presence of a large sidewalk or additional plaza area expanded the rideable area--when the sidewalk (or plaza) space was available, a large percentage of people chose to ride on it.

Sidewalk riding can be a result of many contributing factors. It may be due to a cyclist's fear or concern of sharing the road space with motor vehicles. It may be a result of educationperhaps some of these riders have never been taught otherwise. But it can also be a rational decision that the most efficient way to ride through some of these intersections (due to factors such as traffic or site geometry) is to ride on the sidewalk.

Based on the analyses of the sidewalk hypotheses and accompanying research questions, I came to see a crosswalk as more than a sidewalk connector. I view crosswalks as pressure relief zones. The presence of motor vehicles exerts a type of pressure on cyclists, and in response to that vehicle pressure (presence) many cyclists choose to move away in whatever manner possible. For instance, I observed that many cyclists did not actually ride in the crosswalks but rode laterally towards the crosswalks, which I classified as veering. This veering appears to reflect the crosswalk as a safe haven of a sort and moved the riders laterally away from the traffic lane for a short distance. This increased the deviation in the cyclist's plotted path and showed up in the calculation of number of nodes and node 
difference.

The layout of the intersection may also contribute to crosswalk riding and crosswalk veering. For instance, Coventry had the largest number of veering bicycle riders, but this may also be due to its smaller overall, and slightly staggered layout. It may have been a more efficient path for cyclists to veer at this site than others. (Figure 69 shows a good selection of possible paths in one direction; I only classified a couple of those paths as veering but nonetheless many more riders than that did steer laterally more than would have been needed.)

The shared sites all had an open space, plaza-like treatment of the vehicle travel area. This openness allows the cyclists more space to move laterally than may be possible in more restrained intersections. It may be that even if the shared intersections did not have marked crosswalks, the possibility of lateral movement would invite many riders to veer similarly anyway.

The number of lateral moves I witnessed indicates that a good proportion of bicycle riders would simply prefer to ride as far from motor vehicles as possible, in both shared and control intersections. The theory behind shared space strives to design a more inviting space for all users, but if a large percentage is skirting the edges this indicates the spaces are not as inviting as they should be. Designing a space that is open yet comfortable for vulnerable users, while still confusing and complex enough to calm motor vehicle traffic, is a complex feat. 
I hypothesized (hypothesis 5) that more complex sites would see greater path variation compared to simpler sites. The definition of 'complex' can include the application of multiple techniques like geometric paving patterns and/or the incorporation of street furniture and landscaping in the site design; in other words, techniques to humanize the roadway and invite nonmotorized users in. Elwick Square had the most elements and the best-integrated elements of the sites (See Appendix C for the site matrix). When looking at some of the Elwick Square origin-destinations (Figure 67), I saw less lateral movement in some directions, which may be due to having integrated elements such as the seat wall and treed seating area within the site. The other two shared sites lacked the integrated elements such as seating and landscaping.

Traffic volumes were relatively low for the Coventry sites and Elwick Square, but these sites all saw a large amount of lateral path movement. While the actual vehicle numbers were relatively low (as compared to the Poynton study sites), the share of large vehicles was highest for the Coventry sites, and not negligible for Elwick Square. It may be that large vehicles such as buses intimidate cyclists enough to encourage more lateral movement.

I approached the hypothesis regarding complex sites and path variation by looking at identifiable variables in the context of each site. Each site had its own elements or features that may or may not have influenced the paths cyclists choose.

Elwick Square had the most human-scaled elements of the study sites (Figure 7). The concrete bench in the eastern portion of the site served multiple functions. This is illustrated 
in Figure 55, which shows how many riders traveling from the south to the northwest (SNW) used the bench as an inflection point. Several people also stopped here-I saw many riders stop here and rest a foot on the bench. They appeared to either be waiting for someone or just watching the people move around them. (This also served as a target for BMX riders.) Another influential point at Elwick Square was the seating area. The seating area had a few benches on dirt with small trees and dividing hedges. It was also bordered on one end by a few steps down toward the bike path. This area was frequently used by people throughout the day. Elwick Square also served as a meeting point. I saw multiple cars stop and park on the western edge between the sitting area and the driving area to pick up children who walked there from nearby schools.

The small and simple Coventry intersection was the most human-scaled intersection of the study sites but had no actual street furniture (Figure 20) (as compared to Elwick Square's elements). It also had fewer spots than Elwick Square to serve as pivot or inflection points. The stone bollards, which were placed near the "corners" of the intersection, did not greatly influence cyclists' paths; they were effective at keeping drivers from cutting the corners and driving on the sidewalks.

Poynton is England's best known shared space intersection. It is a very complicated site with intricate paving patterns. The only site furniture were a few benches on each side of the intersection (Figure 29) next to the roads, which saw very little use during my observations; the benches did not appear to directly hinder or impact any rider's paths but people could 
choose to ride on either side. They were not directly integrated into the site design and did not play much role in humanizing the site.

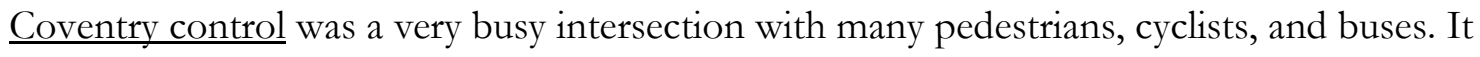
had the highest share of large vehicles per hour. Similar to Elwick Square, the plaza had some well-used seat walls and benches, which served sometimes to split the paths of riders. (The maintenance man servicing the water feature warned me to be careful while sitting there because this was an area with much theft and drug use. This was also the only site where I was harassed by anyone.) The plaza by the Theatre was the only section around the intersection with any street furniture or other human-scaled elements. The rest of the intersection lacked human-scaled elements with the exception of railing on the south side that served to channel pedestrians and presumably keep them out of the road. This was an intersection that saw a lot of crosswalk use as illustrated in Figure 78.

Nodes

The path a cyclist chose, and if he or she used the crosswalk, sidewalk, curb or not, impacted the shape and the length of that path. After spending days watching each intersection, I had a good idea what ideal paths through each intersection were. Those ideal paths served as the comparative tool in calculating the difference in the number of nodes each path took. The more deviations, or greater the node difference in an observed path, the less direct the path was. As Figures 58, 63, 68, 77, 83, and 85 show, some observed paths had negative differences indicating that along these origin-destinations many cyclists chose even more 
direct paths than I selected as ideal. Figure 47 showed that the shared intersections all had an overall, greater mean node difference than any of the control sites. This indicates that all of the shared sites had a greater path deviation, or longer paths ridden, than the control sites. Poynton and Elwick Square had the largest mean node differences of any of the other sites. However, the greatest path variation was found at the Coventry control intersection and not the shared intersections as calculated by the coefficient of variation (Figure 57). This could be due to the crosswalks many cyclists persistently rode through because when I designed ideal paths for each site, I did not include the crosswalks in any of them, especially not for the control sites.

The shared space concept suggests that all users will have "equal access" (Lutz, p4). If that were the case, I would be seeing paths with a lower number of nodes than I did. A high number of nodes when compared to the ideal number of nodes, node difference, shows that cyclists are traveling out of their way to avoid areas and/or vehicles. This indicates that these riders feel they do not have equal access or priority.

Did path choice vary depending on observable demographics?

When I planned this research, I included the standard demographics questions such as age and gender in the surveys. For those who did answer the surveys, $76 \%$ of the respondents were male. Given the low number of completed surveys, I modified this to be about 'observable' demographics instead-in other words, gender as well as I was able to code it via video observation. I found no indication that there was any statistical difference between 
the paths males and females chose in any of the shared space sites or the selected control site.

When looking at the full data set, I found a significant association between gender and crosswalk use. I also found associations between gender and sidewalk use at both Coventry and Coventry control-but not at any of the other sites individually. In addition, there was an association between gender and walking leg at shared sites but not at the control sites.

Despite only finding significant associations at two of the sites, the following paired comparisons of gender paths at each of the other sites show some of the general path tendencies, as well as illustrating the large differences in number of riders of each gender.

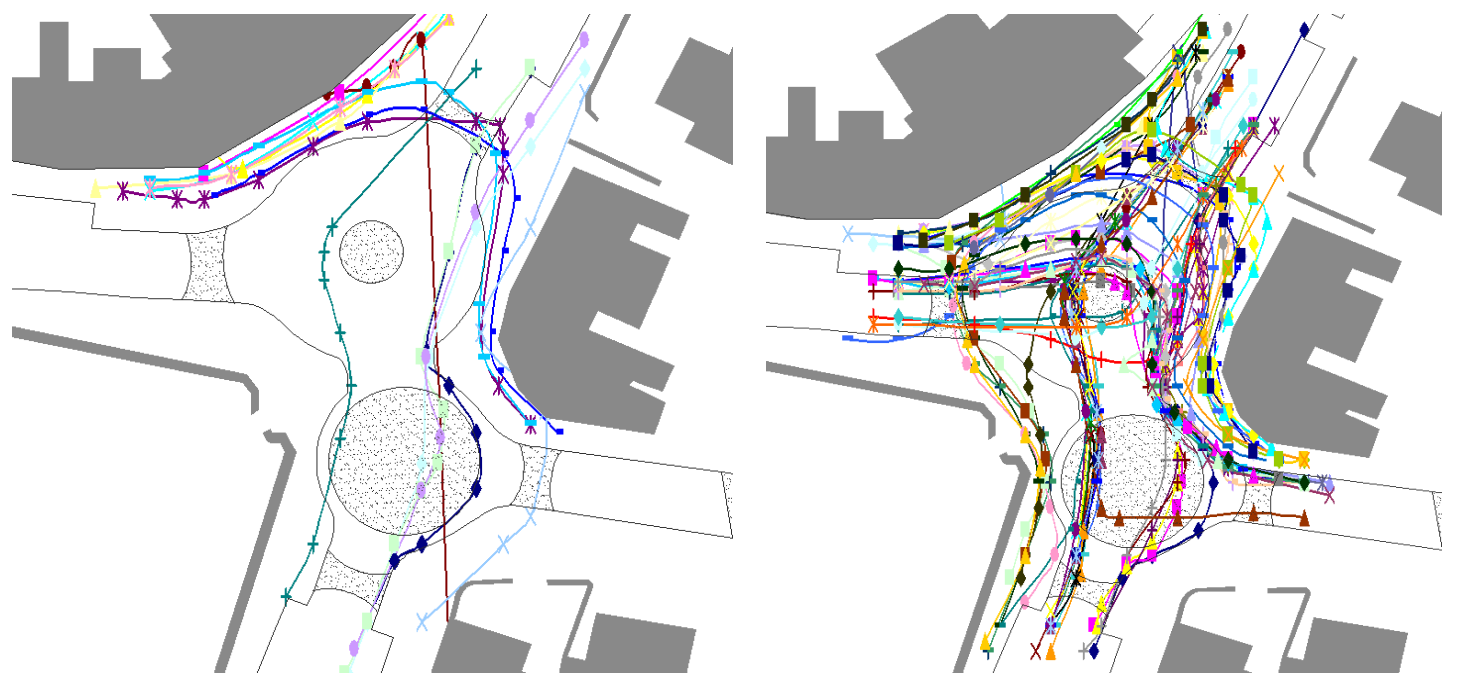

Figure 85: Poynton female paths (left) and male paths (right) 


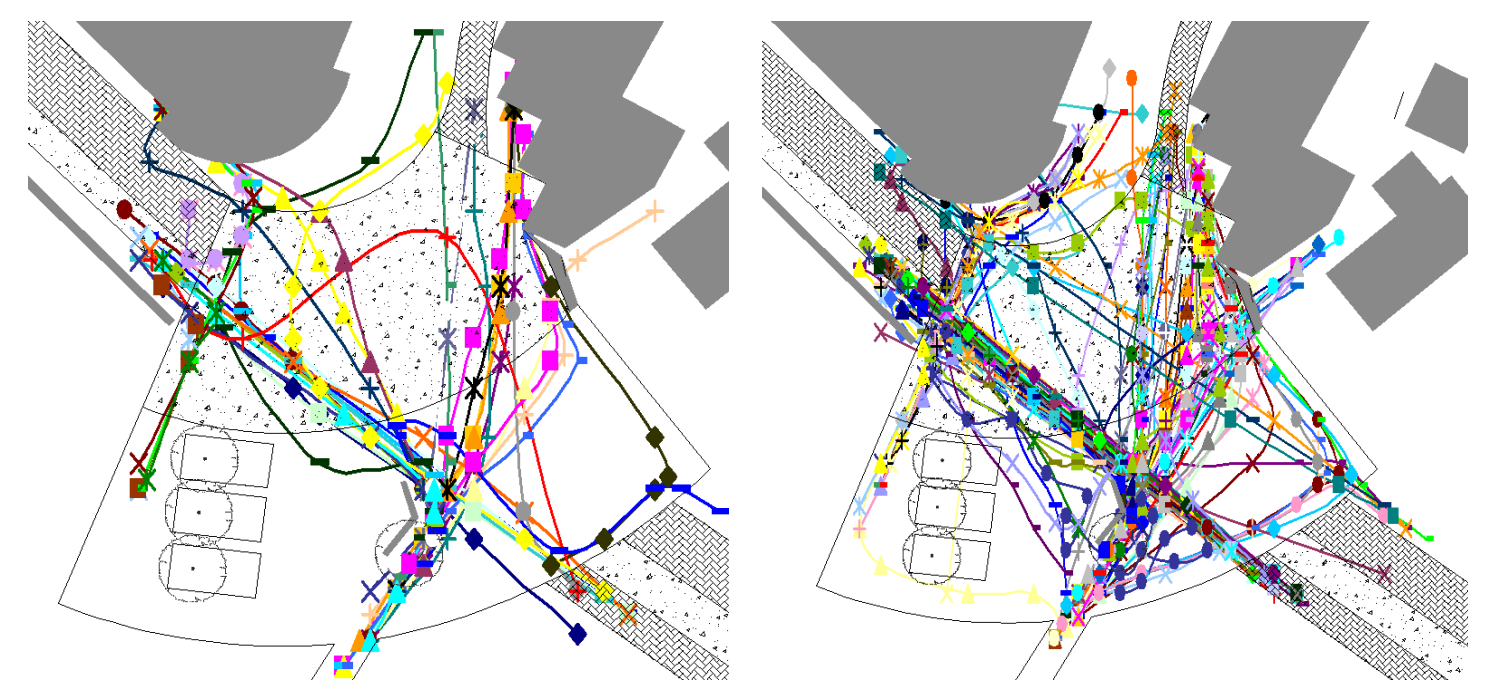

Figure 86: Elwick Square female paths (left) and male paths (right)

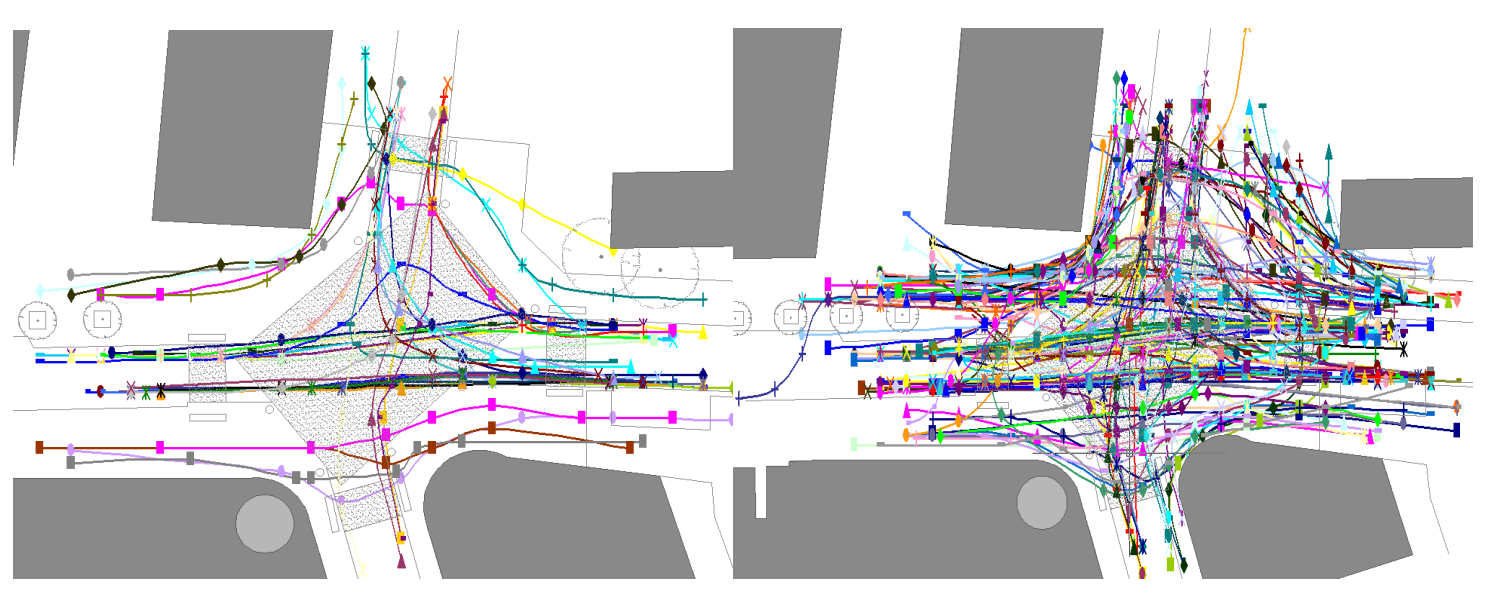

Figure 87: Coventry female paths (left) and male paths (right) 

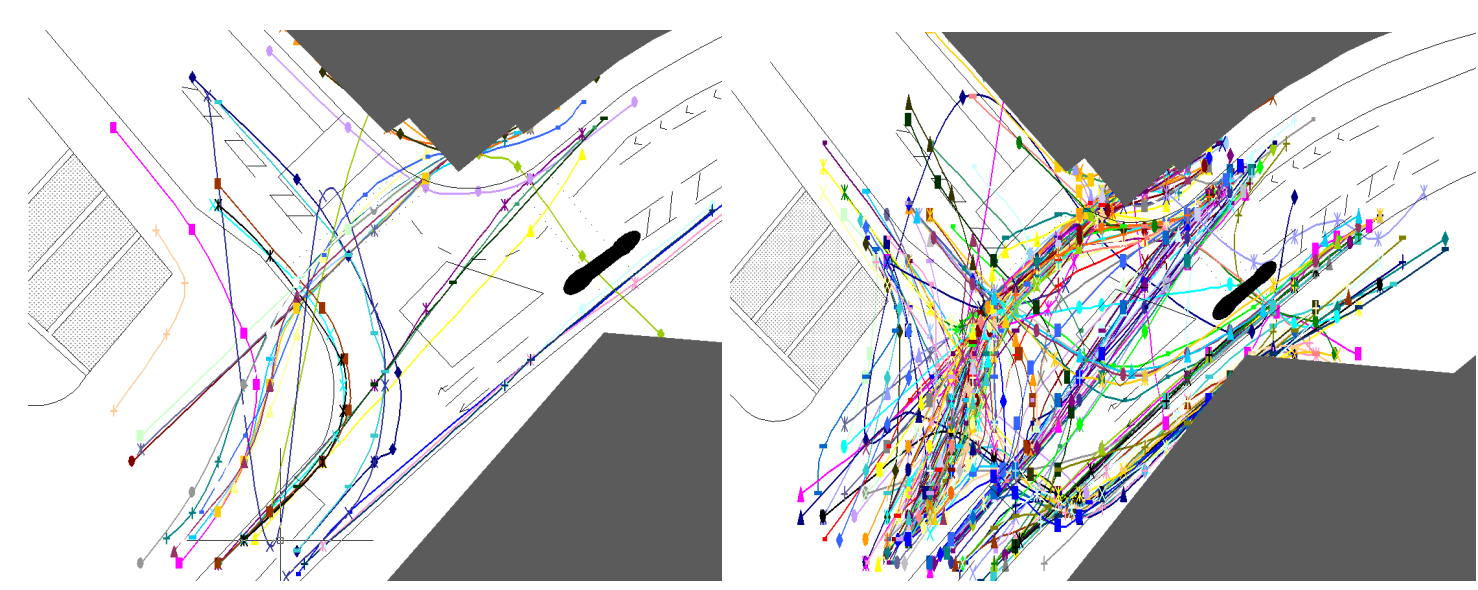

Figure 88: Coventry control female (left) and male paths (right)

Survey discussion

Instead of a diverse group of cyclists completing the surveys, the respondents were a small, passionate, well informed, and presumably confident sample of cyclists. It is interesting to note that this sample was not unique to just one town but occurred in two different locations in the country. Sadly none of the Ashford (Wye and Elwick Square) surveys were completed.

The limited response rate for the surveys reduces their applicability to my video observation analysis. I had hypothesized that first, cyclists would report feeling less safe in the shared spaces as compared to the control sites, second that less experienced cyclists would try to avoid the shared intersections when possible, and third that less experienced cyclists would make different path choices through the shared and control intersections when compared to the more experienced cyclists. Several research questions were designed around the online surveys (Table 23) because video observation alone could not give me the underlying 
motivation or concerns about these intersections. I cannot tell if a rider is confident or not when I watch them ride so I had hoped to have a diverse group of respondents answer the surveys. I did not have any less experienced cyclists answer the surveys.

However, the assortment of comments does indicate, despite most respondents being experienced riders, that the perceptions of the shared sites varied from dislike and fear to appreciation. One respondent even wished the shared space design was more radical (Coventry shared). More than one respondent commented that these intersections were fine for a confident rider but that less confident ones would find them intimidating.

When striving to understand path variation and how a cyclist is influenced by the road design, I could glean only a little from the completed surveys. Many respondents stated they would never ride on the sidewalks (pavements) because that was illegal. I took from this that the physical design of the intersection did not actually matter to this sample of survey respondents — these cyclists would ride according to the Highway Code (that is, like a vehicle) no matter what.

What I found most interesting about the survey results was how informed the respondents were. Several gave very good definitions of shared space and its underlying purposes, as well as referencing the country's Highway Code. It was also remarkable how adamant the majority of the respondents were in their refusal to ride anywhere other than the traffic lane. These two stances are not necessarily contradictory. Instead, it may indicate that even though this sample of cyclists understands what shared space means and is supposed to 
achieve, they will continue to ride in a vehicular manner. However, any change to the Highway Code may free up where these respondents feel they are allowed to ride. It also showed me that any educational outreach the communities are doing to inform the towns and cities about these new designs is working. The message is getting out and these cyclists, at least, understand what they are riding through.

Discussion summary

To review, I developed several hypotheses at the beginning of this research:

1. $\mathrm{H}_{0}$ There will be no significant differences in the paths cyclists ride through the shared space intersections as compared to the control intersections.

2. $\mathrm{H}_{0} \quad$ Cyclists with less riding experience will choose, when possible, to avoid shared space intersections.

3. $\mathrm{H}_{0} \quad$ There will be variation in the different path choices made by different demographic groups.

4. $\mathrm{H}_{0} \quad$ Path variation differences will be greater between experienced/fearless cyclists compared to less experience/more nervous cyclists

5. $\mathrm{H}_{0} \quad$ There will be greater path variation in the more complex sites as compared to the simpler sites

Hypotheses 2 and 4 remain unaddressed due to the low response rate of the online surveys.

These relied exclusively on the surveys; given the lack of less experienced riders who completed the surveys, I have no way of telling what that group of riders think or do when presented with a shared space to ride across. If I look only at the survey responses, I would 
see only experienced cyclists. These respondents were well-informed with respect to England's road laws as well as the purposes behind shared space designs; their responses illustrated that some cyclists will ride a specific way no matter the situation or level of concern.

After eliminating two of the control sites, the remaining control site was very similar to the shared sites. When looking at the primary significant differences, all four sites saw a large percentage of sidewalk use. All four also saw significant amounts of crosswalk use. Calculation of the coefficient of variation showed that the Coventry control site had the highest $\mathrm{CV}$. Therefore, I find that there were in general, no significant differences in between the paths ridden through the three shared sites and the single, selected control site. There were also no differences in the paths ridden according to a cyclist's observed gender.

The shared sites ranged in complexity with Poynton being the most complex and complicated. (The Coventry control site was also complicated due to its conventional transportation infrastructure and the amount of large (bus) vehicle traffic.) The paths observed through the Poynton (shared) site had the largest mean node differences of all of the sites. This was due to the site's complexity, and possibly due to the amount of vehicle traffic, including the presence of large, commercial trucks. Therefore, path variation was greater in the more complex sites. 


\section{CHAPTER VII}

\section{CONCLUSIONS}

The first section in this chapter will discuss implications for future theory as well as possible future research. The second section will then discuss the implications for practice on implementing shared space designs that are more welcoming to bicycle riders. .

This research looked at the understudied user group of bicyclists and their behaviors in the relatively new design concept of shared space. One of the tenets behind the concept of shared space is that these now calmed and ambiguous spaces are more democratic and therefore more open to all modes instead of dominated by drivers of motor vehicles. Another principle is that these naked streets increase the perception of risk. The purpose behind this increased feeling of risk is to slow drivers enough to open the spaces up to all users — motorized and nonmotorized. Can an increased perception of risk be balanced with the need to create inclusive and inviting safe spaces for vulnerable users? How does that increased perception of risk impact how bicycle riders perceive and ride through these spaces? This research shows that the answers to those questions are complicated and sitespecific.

Implications for theory and future research

I began this research with multiple hypotheses regarding cyclists and shared space 
intersections, more specifically regarding path choice, path preference, and path variation.

One of the reasons I chose to do this research was to provide more data on this design concept with the hope that similar projects might be built, where appropriate, in the United States. In order for shared space to be more acceptable to most American municipalities and transportation departments, more research must be done. This research will have to also be done in the United States with its different driving culture as compared to Europe or the United Kingdom. The lack of actual designs on the ground in the United States prompted me to choose to do this research in England because it was most similar, culture-wise, to the United States. It is still a different country, though, with different driving and legal cultures.

It is an on-going cycle: doing this research in the United States will be difficult due to the scarcity of actual projects on the ground, but few will install these spaces without more research. Fortunately, a few shared space projects are in planning or construction stages in the United States at this time. For instance, Chicago is constructing a new shared space, the Argyle Streetscape Project, but site drawings indicate the design does not include the intersection. Therefore, projects such as these will likely be conservative while we build up more experience, research, and exposure. One option may involve implementing and studying short-term demonstration projects, although a short timeline may be self-limiting. Another option involves studying intersections that have enough similar elements to shared space projects that some parallels may be drawn.

One of the drawbacks of my study sites, as previously discussed, was that none of my shared 
sites could be considered 'pure' shared space intersections because they all had adjacent sidewalk sections and marked crosswalks. Given that, future research should look at what cyclists would do in the absence of marked crosswalks and/or sidewalks in similar intersections. Would people still ride in those areas, or do similar lateral shifts in their paths to avoid motor vehicles? Would the absence of these elements indicate to all users that they may ride or walk anywhere? Future research should also study if drivers respond differently to a lack of pedestrian infrastructure in an ambiguous site; for instance, is yielding behavior better or worse when there are no crosswalks in shared spaces? (Note, again, that these intersection designs, and therefore my results, are based on English laws and roadway culture.)

I would also like to see more research about the placing of site furniture and landscaping. Evaluating how cyclists use these elements in positioning themselves in the intersections would give us more insight as to which types and forms are most effective and where to place them to best help nonmotorized users. This also ties in with a site's complexity. Is there are way to design a site that is complex for the drivers but does not unduly burden the nonmotorized users by making them ride or walk further than they should have to?

I speculate that many less confident and/or less experienced riders do not (or cannot) avoid these intersections as evidenced by the large shares of cyclists I observed skirting the edges and riding on the sidewalks and through the crosswalks. This is one reason I regret the low number of survey responses. Those who did respond were predominantly male as well as experienced cyclists and I missed responses from the less confident riders. Another 
approach I would take in future research is to set up something more interactive, such as a series of focus groups, with people who ride of all experience and comfort levels. With more time, future research should also involve more intercept surveys of cyclists who have just ridden through shared spaces. This would have to be far enough off of the site to not impact the path choices the intercepted riders make, but with the benefit that the decision and experiences of that intersection would be fresh in the rider's mind.

I remain very interested in avoidance and conflict behavior. These are difficult to study, but I believe looking at these interactions more closely in shared space intersections would be valuable. Crashes themselves are generally rare occurrences, but 'close calls' and other nervewracking encounters are more frequent. It is these experiences, or the expectation of these encounters, which may influence the paths many people ride.

The creation of the node as an evaluative variable was useful in comparing the nuances of the observed paths over a variety of sites and has potential in further research on cyclist behaviors. For instance, this variable can be used in other smaller scale bicycle travel research to drill down into the specific movements cyclists make while riding through a space. Its weakness is the subjectivity when defining where along a line to place a node but with consistency it can be a good comparative tool. Including this measure in future bicycle research will help fine tune the variable as well as further explore its weaknesses and strengths. 


\section{Implications for practice}

The concept of increasing the perception of risk for users makes sense for drivers. However, when considering nonmotorized users, including cyclists, this appears to backfire. The shares of cyclists who were observed skirting the edges of the intersections and going out of their way to ride in the crosswalks, indicated that many of these riders are not comfortable or confident enough to use the full space as it is designed. This is a weakness in the concept of shared space.

There is a difference between simply removing motor vehicle-specific elements, such as traffic signals and lane markings, and integrating elements to humanize a site. The selection and placement of street furniture and other humanizing elements may also help cyclists navigate these intersections. The humanization of a site can help nonmotorized users feel more welcome in the space, and it can give them elements to help ground their experience and path choices. Additionally, elements that are well integrated into the site's design can be used, for instance, as places where cyclists will wait for vehicle traffic to clear enough that they are comfortable enough to cross, or as a spot to aim for when crossing the more open spaces. Therefore, site elements need to be placed in locations that tie in with the possible paths users will take through the site. Elements should serve as virtual pivot or inflection points or as virtual barriers which can help an exposed user feel more comfortable.

Lateral space should be included into shared space designs to accommodate all confidence and skill levels of cyclists. Tighter spaces will be more crowded by both pedestrians and 
cyclists avoiding motor vehicles (as in control sites with emphasis on crosswalks and sidewalks) which may lead to an increase in both conflict and avoidance events.

Education of all modes should actively be done for an extended period of time. Outreach includes updating relevant traffic laws to encourage cyclists and pedestrians to feel legally allowed to use these spaces as the design concepts indicate.

Prior research has already demonstrated that shared space is an effective form of traffic calming. Despite these results indicating that the shared space design concept may not be as miraculous for vulnerable users as some literature touts, this continues to be the case. While these intersections may not have lived up to their idealized potential with respect to bicycle riders, these intersections have still been effectively calmed in general. Shared space remains a relevant tool in the traffic calming or urban design toolbox. Some thoughtful modifications in design and layout, and possibly certain road laws, may help make these spaces more comfortable for a wider range of bicycle riders. 


\section{REFERENCES}

Appleyard, D. (1980). Livable Streets: Protected Neighborhoods? ANNALS of the American Academy of Political and Social Science, 451, 106-117. doi:10.1177/000271628045100111

Bartle, C., Avineri, E., \& Chatterjee, K. (2013). Online information-sharing: A qualitative analysis of community, trust and social influence amongst commuter cyclists in the UK. Transportation Research Part F: Traffic Psychology and Behaviour, 16, 60-72. doi:10.1016/j.trf.2012.08.013

Biddulph, M. (2012). Street Design and Street Use: Comparing Traffic Calmed and Home Zone Streets. Journal of Urban Design, 17(2), 213-232. doi:10.1080/13574809.2012.666206

Chaurand, N., \& Delhomme, P. (n.d.). Cyclists and drivers in road interactions: A comparison of perceived crash risk. Accident Analysis \& Prevention. doi:10.1016/j.aap.2012.09.005

Dill, J., \& Gliebe, J. P. (2008). Understanding and measuring bicycling behavior: A focus on travel time and route choice (No. OTREC-RR-08-03).

Dill, J., Monsere, C. M., \& McNeil, N. (2012). Evaluation of bike boxes at signalized intersections. Accident Analysis \& Prevention, 44(1), 126-134. doi:10.1016/j.aap.2010.10.030

Dillman, D. A., Smyth, Christian, L. M., \& Dillman, D. A. (2009). Internet, mail, and mixedmode surveys: the tailored design method. Hoboken, N.J.: Wiley \& Sons.

Edquist, J., \& Corben, B. (2012). Potential application of shared space principles in urban road design: effects on safety and amenity. Retrieved from trid.trb.org/view.aspx?id=1143781

Forsyth, A., \& Krizek, K. (2011). Urban Design: Is there a Distinctive View from the Bicycle? Journal of Urban Design, 16(4), 531-549. doi:10.1080/13574809.2011.586239

Garrard, J., Rose, G., \& Lo, S. K. (2008). Promoting transportation cycling for women: The role of bicycle infrastructure. Preventive Medicine, 46(1), 55-59.

doi:10.1016/j.ypmed.2007.07.010 
Gerlach (2008), [german] Sinn und Unsinn von Shared Space -Zur Versachlichung einer populären Gestaltungsphilosophie; Teil 1

Gillies (2009) Is there road there to share? Shared space in an Australian context. Thesis

Hamilton-Baillie, B., Jones, P., Improving traffic behaviour and safety through urban design, Civil Engineering 158:39-47.

Hamilton-Baillie, B., Shared Spaces: Reconciling people, places and traffic, in: Built Environment, pp. 161-181.

Hamilton-Baillie, B., Towards shared space, in: Urban Design International, pp. 130-138.

Hammond, V., \& Musselwhite, C. (2013). The Attitudes, Perceptions and Concerns of Pedestrians and Vulnerable Road Users to Shared Space: A Case Study from the UK. Journal of Urban Design, 18(1), 78-97. doi:10.1080/13574809.2012.739549

Heinz, H. (2010). Shared Space or Saved Space? (p. 13). Presented at the 4th International Symposium on Highway Geometric Design, Valencia, Spain.

Johnson, M., Charlton, J., Oxley, J., \& Newstead, S. (2010). Naturalistic Cycling Study: Identifying Risk Factors for On-Road Commuter Cyclists. Annals of Advances in Automotive Medicine / Annual Scientific Conference, 54, 275.

Kaparias, I., Bell, M., Greensted, J., Cheng, S., Miri, A., Taylor, C., \& Mount, B. (2010). Development and Implementation of a Vehicle-Pedestrian Conflict Analysis Method. Transportation Research Record: Journal of the Transportation Research Board, 2198(-1), 75-82. doi:10.3141/2198-09

Kaparias, I., Bell, M. G., Chan, C., Biagioli, T., Kennedy, J., \& Mount, B. (2011). Investigating the willingness of drivers to share space with pedestrians. Presented at the Transportation Research Board Annual Meeting.

Kaparias, I., Bell, M. G., Miri, A., Chan, C., \& Mount, B. (2012). Analysing the perceptions of pedestrians and drivers to shared space. Transportation Research Part F: Traffic Psychology and Behaviour, 15, 297-310.

Kaparias, I., Bell, M. G., Singh, A., Dong, W., Sastrawinata, A., Wang, X., \& Mount, B. (2013). Analysing the perceptions and behaviours of cyclists in street environments with elements of shared space. In USTG. Oxford.

Krizek, K. J., El-Geneidy, A., \& Thompson, K. (2007). A detailed analysis of how an urban trail system affects cyclists' travel. Transportation, 34, 611-624. 
Lawson, A. R., Pakrashi, V., Ghosh, B., \& Szeto, W. Y. (2013). Perception of safety of cyclists in Dublin City. Accident Analysis \& Prevention, 50, 499-511.

doi:10.1016/j.aap.2012.05.029

Luca, O., Gaman, F., \& Singureanu, O.-G. (2012). Coping with congestion: Shared spaces. Theoretical and Empirical Researches in Urban Management, 8(3), 53-62.

Lutz, S. (n.d.-a). Shared Space: Final evaluation and results. Shared Space Institute.

Lutz, S. (n.d.-b). Shared Space--From Project to Process. Retrieved from http://www.sharedspace.eu/en/publications/downloads/doc_details/18-sharedspace-from-project-to-process

Lutz, S. (n.d.-c). Shared Space--Room for Everyone. Retrieved from http://www.sharedspace.eu/en/publications/downloads/doc_details/15-sharedspace-room-for-everyone

Macdonald, E. (2011). Streets and the public realm: emerging designs. In Companion to Urban Design ((1st ed.)., pp. 419-431).

Menghini, G., Carrasco, N., Schüssler, N., \& Axhausen, K. W. (2010). Route choice of cyclists in Zurich. Transportation Research Part A: Policy and Practice, 44(9), 754-765. doi:10.1016/j.tra.2010.07.008

Methorst, R., \& Gerlach, J. (2007). Shared Space: Safe or Dangerous? Presented at the Walk21, Toronto.

Møller, M., \& Hels, T. (2008). Cyclists' perception of risk in roundabouts. Accident Analysis \& Prevention, 40(3), 1055-1062. doi:10.1016/j.aap.2007.10.013

Moody, S., \& Melia, S. (2013). Shared space: Research, policy and problems. In Proceedings of the Institution of Civil Engineers - Transport.

Noodelijke Hogeschool Leeuwarden. (2007). The Laweiplein: Evaluation of the reconstruction into a square with a roundabout (p. 57).

Norgate, S. H. (2012). Accessibility of urban spaces for visually impaired pedestrians. Proceedings of the ICE - Municipal Engineer, 165(4), 231-237. doi:10.1680/muen.12.00019

Osberg, J. S., Stiles, S. C., \& Asare, O. K. (1998). Bicycle safety behavior in Paris and Boston. Accident Analysis \& Prevention, 30(5), 679-687. doi:10.1016/S0001-4575(97)00097-3 
Parkin, J., \& Smithies, N. (2012). Accounting for the Needs of Blind and Visually Impaired People in Public Realm Design. Journal of Urban Design, 17(1), 135-149. doi:10.1080/13574809.2012.646139

Pel, B. (2012). System innovation as Synchronization; innovation attempts in the Dutch traffic management field (dissertation). Erasmus University Rotterdam, Rotterdam.

Quimby, A., \& Castle, J. (2006). A Review of Simplified Streetscape Schemes (Published Project Report No. PPR292) (p. 66). Transport for London, Street Management Division.

Reid, S., Kocak, N., \& Hunt, L. (2010). DfT Shared Space Project Stage 1: Appraisal of Shared Space. MVA Consultancy.

Ronsdal, A. (2010). Citizen participation in planning of shared space. Universitetet for Miljøog biovitenskap, Norway.

Sakshaug, L., Laureshyn, A., Svensson, Å., \& Hydén, C. (2010). Cyclists in roundaboutsDifferent design solutions. Accident Analysis \& Prevention, 42(4), 1338-1351. doi:10.1016/j.aap.2010.02.015

Schlabbach, K. (2012). Shared Space. Presented at the Managing Operational Performance...Exceeding Expectations. 2012 ITE Technical Conference and Exhibit. Retrieved from http://trid.trb.org/view.aspx?id=1149985

Schönauer, R., Stubenschrott, M., Huang, W., Rudloff, C., \& Fellendorf, M. (2012). Modeling Concepts for Mixed Traffic. Transportation Research Record: Journal of the Transportation Research Board, 2316(-1), 114-121. doi:10.3141/2316-13

Sisiopiku, V. ., \& Akin, D. (2003). Pedestrian behaviors at and perceptions towards various pedestrian facilities: an examination based on observation and survey data. Transportation Research Part F: Traffic Psychology and Behaviour, 6(4), 249-274. doi:10.1016/j.trf.2003.06.001

Stinson, M., \& Bhat, C. (2003). Commuter Bicyclist Route Choice: Analysis Using a Stated Preference Survey. Transportation Research Record: Journal of the Transportation Research Board, 1828(-1), 107-115. doi:10.3141/1828-13

Stinson, M., \& Bhat, C. (2004). Frequency of Bicycle Commuting: Internet-Based Survey Analysis. Transportation Research Record: Journal of the Transportation Research Board, 1878(-1), 122-130. doi:10.3141/1878-15

Tilahun, N. Y., Levinson, D. M., \& Krizek, K. J. (2007). Trails, lanes, or traffic: Valuing 
bicycle facilities with an adaptive stated preference survey. Transportation Research Part A: Policy and Practice, 41(4), 287-301. doi:10.1016/j.tra.2006.09.007

Wood, J. M., Lacherez, P. F., Marszalek, R. P., \& King, M. J. (2009). Drivers' and cyclists' experiences of sharing the road: Incidents, attitudes and perceptions of visibility. Accident Analysis \& Prevention, 41(4), 772-776. doi:10.1016/j.aap.2009.03.014

Zhuang, X., \& Wu, C. (2012). The safety margin and perceived safety of pedestrians at unmarked roadway. Transportation Research Part F: Traffic Psychology and Behaviour, 15(2), 119-131. doi:10.1016/j.trf.2011.11.005

Zook, J. B., Lu, Y., Glanz, K., \& Zimring, C. (2012). Design and Pedestrianism in a Smart Growth Development. Environment and Behavior, 44(2), 216-234. doi:10.1177/0013916511402060 


\section{APPENDICES}

Appendix A: Overall variables by site

\begin{tabular}{|c|c|c|c|c|c|c|c|c|}
\hline Variables & & $\begin{array}{l}\text { Total } \\
(n=1746)\end{array}$ & $\begin{array}{l}\text { Wye } \\
(n=76)\end{array}$ & $\begin{array}{l}\text { Poynton } \\
\text { control } \\
(n=195)\end{array}$ & $\begin{array}{l}\text { Coventry } \\
\text { control } \\
(n=422)\end{array}$ & $\begin{array}{l}\text { Elwick } \\
\text { Square } \\
(n=357)\end{array}$ & $\begin{array}{l}\text { Poynton } \\
(n=206)\end{array}$ & $\begin{array}{l}\text { Coventry } \\
(n=490)\end{array}$ \\
\hline \multicolumn{9}{|l|}{$\begin{array}{l}\text { Helmet } \\
\text { use }\end{array}$} \\
\hline & Yes & 684 & 50 & 169 & 106 & 63 & 111 & 185 \\
\hline & $\mathrm{No}$ & 814 & 21 & 20 & 195 & 263 & 44 & 271 \\
\hline & Unk & 250 & 5 & 6 & 121 & 33 & 51 & 34 \\
\hline \multicolumn{9}{|l|}{ Gender } \\
\hline & Male & 838 & 45 & 125 & 189 & 160 & 85 & 234 \\
\hline & Female & 169 & 18 & 12 & 33 & 42 & 14 & 50 \\
\hline & Unk & 738 & 13 & 58 & 200 & 155 & 106 & 206 \\
\hline \multicolumn{9}{|l|}{ Bike type } \\
\hline & $\begin{array}{l}\text { Flat } \\
\text { bar }\end{array}$ & 1115 & 40 & 48 & 285 & 300 & 80 & 362 \\
\hline & $\begin{array}{l}\text { Drop } \\
\text { bar }\end{array}$ & 341 & 28 & 126 & 40 & 9 & 71 & 67 \\
\hline & Other & 290 & 8 & 21 & 97 & 48 & 55 & 61 \\
\hline \multicolumn{9}{|l|}{$\begin{array}{l}\text { Sidewalk } \\
\text { use }\end{array}$} \\
\hline & Yes & 931 & 0 & 14 & 268 & 313 & 128 & 208 \\
\hline & No & 815 & 76 & 181 & 154 & 44 & 78 & 282 \\
\hline \multicolumn{9}{|l|}{$\begin{array}{l}\text { Crosswalk } \\
\text { use }\end{array}$} \\
\hline & Yes & 324 & 0 & 2 & 139 & 65 & 52 & 66 \\
\hline & Veer & 22 & 0 & 0 & 2 & 6 & 1 & 13 \\
\hline & No & 1400 & 76 & 193 & 281 & 286 & 153 & 411 \\
\hline \multicolumn{9}{|l|}{ Curb use } \\
\hline & $\begin{array}{l}\text { Curb } \\
\text { cut }\end{array}$ & 48 & 0 & 0 & 30 & 0 & 3 & 15 \\
\hline
\end{tabular}




\begin{tabular}{|l|l|l|l|l|l|l|l|l|}
\hline & jump & 90 & 0 & 2 & 11 & 0 & 14 & 63 \\
\hline Avoidance & & 36 & 3 & 0 & 14 & 1 & 0 & 18 \\
\hline Conflict & & 9 & 1 & 0 & 1 & 2 & 0 & 5 \\
\hline Walk leg & & & & & & & & \\
\hline $\begin{array}{l}\text { Walk } \\
\text { comp }\end{array}$ & 24 & 0 & 0 & 4 & 6 & 6 & 8 \\
\hline
\end{tabular}


Appendix B: Ideal number of nodes by OD

\begin{tabular}{|l|c|}
\hline Poynton ODs & Ideal \# \\
\hline ESW & 5 \\
\hline EW & 4 \\
\hline ENE & 7 \\
\hline SWNE & 3 \\
\hline SWW & 6 \\
\hline SWE & 6 \\
\hline NESW & 4 \\
\hline NEE & 6 \\
\hline NEW & 5 \\
\hline WSW & 6 \\
\hline WE & 3 \\
\hline WNE & 5 \\
\hline
\end{tabular}

\begin{tabular}{|l|c|}
\hline $\begin{array}{c}\text { Poynton } \\
\text { control ODs }\end{array}$ & Ideal \# \\
\hline ESW & 4 \\
\hline ENW & 6 \\
\hline SWNW & 4 \\
\hline SWE & 4 \\
\hline NWSW & 5 \\
\hline NEW & 4 \\
\hline
\end{tabular}

\begin{tabular}{|l|c|}
\hline \multicolumn{1}{|c|}{ Wye ODs } & Ideal \# \\
\hline EN & 4 \\
\hline WS & 5 \\
\hline WE & 4 \\
\hline
\end{tabular}




\begin{tabular}{|l|c|}
\hline SN & 7 \\
\hline EW & 4 \\
\hline NE & 7 \\
\hline SW & 6 \\
\hline WN & 7 \\
\hline ES & 6 \\
\hline SE & 6 \\
\hline NW & 5 \\
\hline
\end{tabular}

\begin{tabular}{|l|c|}
\hline Coventry ODs & Ideal \# \\
\hline WE & 2 \\
\hline SN & 3 \\
\hline NS & 2 \\
\hline EW & 2 \\
\hline NWE & 4 \\
\hline NWN & 5 \\
\hline WN & 6 \\
\hline WS & 4 \\
\hline SE & 6 \\
\hline ENW & 4 \\
\hline EN & 6 \\
\hline ES & 4 \\
\hline NWS & 4 \\
\hline NW & 6 \\
\hline NE & 5 \\
\hline SW & 5 \\
\hline SNW & \\
\hline
\end{tabular}

\begin{tabular}{|l|l|}
\hline Elwick Sq & Ideal \# \\
\hline
\end{tabular}




\begin{tabular}{|l|c|}
\hline \multicolumn{1}{|c|}{ ODs } & 6 \\
\hline NNW & 6 \\
\hline NSE & 5 \\
\hline SENE & 2 \\
\hline SENW & 2 \\
\hline NWSE & 6 \\
\hline SEN & 5 \\
\hline NWN & 4 \\
\hline NWNE & 6 \\
\hline NWS & 5 \\
\hline NESE & 5 \\
\hline NENW & 6 \\
\hline SES & 6 \\
\hline NWS & 6 \\
\hline SNW & 6 \\
\hline SSE & \\
\hline
\end{tabular}

\begin{tabular}{|l|c|}
\hline \multicolumn{1}{|c|}{$\begin{array}{c}\text { Coventry } \\
\text { control ODs }\end{array}$} & Ideal \# \\
\hline NENW & 6 \\
\hline NWSE & 5 \\
\hline NESW & 3 \\
\hline SWNW & 5 \\
\hline SWNE & 5 \\
\hline SENW & 8 \\
\hline NWNE & 5 \\
\hline NWSW & 7 \\
\hline SWSE & 7 \\
\hline SESW & 5 \\
\hline NESE & 5 \\
\hline
\end{tabular}


Appendix C: Survey questions

There were 6 different surveys_-one for each site. The shared space surveys were all the same, with the exception of maps and street names, and the control surveys were the same, with the same exceptions as the shared space surveys. The surveys were online via Qualtrics.

\section{Informed Consent Form}

\section{Introduction}

You are invited to participate in a research study titled "Shared Space and Bicyclists". This study is being conducted by Allison Duncan, a graduate student at Portland State University in the United States for graduate research. This study is collecting information about how cyclists ride through various intersection types as well as their perceptions of those intersections. You are being asked to take part in this study because you are a cyclist who rides through at least one of the intersections being studied.

\section{Procedures}

You will be shown some maps of a local intersection that you ride through and asked to complete a short survey about that intersection, your experiences riding through it, and your thoughts about it. The survey consists of XX questions and will take approximately 15 minutes or less. This questionnaire will be conducted with an online Qualtrics-created survey. 


\section{Risks/Discomforts}

Risks are minimal for involvement in this study. It is possible that some of the questions may upset you if they bring up some unpleasant memories. Additionally, although we do not expect any harm to come upon any participants due to electronic malfunction of the computer, it is possible though extremely rare and uncommon. You may end this survey at any time with no consequence if you are uncomfortable.

\section{Benefits}

There are no direct benefits for participants. However, it is hoped that through your participation, researchers will learn more about which intersection designs are best for bicycling. The results of this research will be made available to your city.

\section{Confidentiality}

All of your responses to this survey will remain anonymous and cannot be linked to you in any way. No identifying information about you will be collected at any point during the study, and your survey will be identified only with a random number. Once you submit your completed survey, there will be no way to withdraw your responses from the study because the survey contains no identifying information. The responses collected will be stored in the Qualtrics-secure database until it has been deleted by the primary investigator.

\section{Participation}

Participation in this study is entirely voluntary at all times. You can choose not to participate 
at all or to leave the study at any time. Regardless of your decision, there will be no effect on your relationship with the researcher or any other consequences.

\section{Questions about the Research}

If you have questions regarding this study, you may contact me, Allison Duncan, at 00-1xxx-xxx-xxxx, abduncan@pdx.edu.

\section{Questions about your Rights as a Research Participant}

If you have questions you do not feel comfortable asking the researcher, you may contact

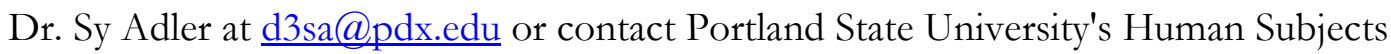
Research Review Committee at 00-1-503-725-2227, hsrrc@pdx.edu.

By completing and submitting this survey, you are indicating your consent to participate in this study.

The questions in this section will help us understand your thoughts about the intersection at $\mathrm{xxx} \& \mathrm{xxx}$.

1. How frequently do you cycle through the intersection at $\operatorname{xxx} \& \mathrm{xxx}$ ?

$6-7$ days a week

4-5 days a week

1-3 days a week

1-3 days a month

Less than one day a month 
2. Do you feel that you cycle slower through this intersection than other intersections you ride through? Yes No

3. This intersection has no curbs or painted lane lines. How clear is it to you where you may cycle through this intersection? (ss intersection)

Very clear

Clear

Somewhat confusing

Very confusing

Comments...

4. This intersection has no bike lanes. How clear is it to you where you may cycle through this intersection? (non-ss intersection, adapt as necessary.)

Very clear

Clear

Somewhat confusing

Very confusing

Comments...

7. As a cyclist, would you like to have more intersections on your routes like the one at $\mathrm{xxx}$ \& $\mathrm{xxx}$ ?

\section{Yes Not sure No}

Comments...

8. Do you worry about sharing the road space with motor vehicles at this intersection?

Do you worry about sharing the road space with pedestrians at this intersection?

Do you worry about sharing the road space with other bicyclists at this intersection? 
Do you worry about sharing the road space with heavy duty vehicles (buses, lorries, etc.) at this intersection?
Always
Often
Sometimes
Rarely
Never
Comments...

10. Do you feel this intersection is a place where you may stop and socialise or 'hang out'/spend time?

Yes, I am comfortable stopping to spend time here I am somewhat comfortable stopping to spend time here I am somewhat uncomfortable stopping to spend time here I am not comfortable at all stopping to spend time here There is no available place to socialise or spend time Comments...

11. As a cyclist, would you make any changes to the layout of this intersection?

\section{Yes No}

Please elaborate....

12a. As a cyclist, did you ever ride through this intersection prior to its redesign? (skip for non-ss intersection)

\section{Yes No}

If yes, please go ahead to $12 \mathrm{~b}$, if not, skip to 13.

12b. Did you feel safer in the original intersection prior to its redesign? 
Yes, much safer

Yes, somewhat safer

No difference

No, somewhat less safe

No, much less safe

Comments...

13. As a cyclist, do you feel you have more, less, or equal priority over other vehicles when riding through this intersection?

More priority

Equal amount of priority

Less priority

9. In this type of city setting, would you prefer traditional traffic light crossings and

pavements at the intersection? (skip for non-ss intersection)

Yes No

Comments...

The next section will ask about the paths you take when riding through this intersection. (Site plan inserted here)

1a. There are X\# paths drawn in the above maps of the intersection. Please choose the labeled lines which most represent the paths you most commonly take when riding through this intersection on your bicycle. (pull down A to ...) [Note-there were 4 maps per intersection, 24 total] 
For your ride through this intersection, why do you choose this path? (select all that apply)

\section{Fun}

Quickest

Avoiding pedestrians

Avoiding motor vehicles

Avoiding other bicycles

Maximizing route directness

Minimizing route congestion

Minimizing distance

Safety

Most straightforward and easy

Aesthetics

Smooth pavement

Convenience/comfort

Other.........................

1b. Is there a different path through this intersection you'd prefer to take when riding through the intersection?

If Yes, please choose the path which most closely represents the path you'd prefer to take.

(pull down A to ...)

1c. Why would you prefer this path? (select all that apply)

Fun

Quickest

Avoiding pedestrians

Avoiding motor vehicles

Avoiding other bicycles 


\author{
Maximizing route directness \\ Minimizing route congestion \\ Minimizing distance \\ Safety \\ Most straightforward and easy \\ Aesthetics \\ Smooth pavement \\ Convenience/comfort
}

Other.........................

2. Does your preferred path through this intersection alter depending on how much motor vehicle traffic there is?

Does your preferred path through this intersection alter depending on how much bicycle traffic there is?

Does your preferred path through this intersection alter depending on how much pedestrian traffic there is?

Yes, major changes to my route

Yes, minor changes to my route

No changes to my route

3. What are your reasons for choosing your path through this intersection? (select all that apply)

Fun

Quickest

Avoiding pedestrians 
Avoiding motor vehicles

Avoiding other bicycles

Maximizing route directness

Minimizing route congestion

Minimizing distance

Safety

Most straightforward and easy

Aesthetics

Smooth pavement

Convenience/comfort

Other........................

5. How often do you come across this intersection as a pedestrian?

6 -7 days a week

4-5 days a week

1-3 days a week

1-3 days a month

Less than one day a month

Never

6. How often do you come across this intersection as a motorist?

$6-7$ days a week

4-5 days a week

1-3 days a week

1-3 days a month

Less than one day a month

Never 
This section will be about your thoughts and experiences regarding safety and this intersection.

1. How big do you think the risk of a collision is with a motor vehicle while you are riding through this intersection?

How big do you think the risk of a collision is with a pedestrian while you are riding through this intersection?

How big do you think the risk of a collision is with another bicyclist while you are riding through this intersection?

Very large

Large

Medium

Small

Very small

2. What would in your opinion make this intersection safer for cyclists?

If there were fewer cars

If there were more cyclists

If there was more space for cyclists

If there was less space for cyclists

If there was more space for vehicle traffic

If there was slower vehicle traffic

If this intersection was converted into a signalized intersection

Other.......................

3. Have you, as a cyclist, been involved in a collision in this intersection? 
Yes No

If yes, were you involved in a collision with a

Motor vehicle

Bicycle

Pedestrian

Stationary object

Other

4. Have you, as a cyclist, been close to getting involved in a collision at this intersection?

Yes $\quad$ No

5. In general, do you think this intersection is dangerous for cyclists?

Yes, very much

Yes, to some extent

No, not much

No, not at all

6. Do you have any other comments about this intersection?

\section{Please tell us a little about your bicycling experience}

1. How often do you ride your bicycle?

$6-7$ days a week

4-5 days a week

1-3 days a week

1-3 days a month

Less than one day a month

2. Approximately how many kilometers do you usually cycle a week? 
$0-5 \mathrm{~km}$

$6-10 \mathrm{~km}$

$11-20 \mathrm{~km}$

$>20 \mathrm{~km}$

3. Which of these statements best describes your bicycling travel habits? Please choose only one answer.

I rarely ride my bicycle for any purpose

I only bicycle for recreation or exercise, and not to get to places, such as work, shopping, errands, etc.

I bicycle occasionally for transportation (e.g. to get to work, school, shopping, errands, etc.)

I bicycle regularly for transportation (e.g. to get to work, school, shopping, errands, etc.), but it's not my main mode

My bicycle is my main mode of transportation during good weather. I drive or take transit more when the weather is bad.

My bicycle is my main mode of transportation year-round.

Other (please describe) ....................

4. Do you wear a bicycle helmet when you cycle? Yes Sometimes No

\section{Demographics}

1. In what year were you born? ...........

2. What is your gender? Male Female Other

3. Do you currently have a valid driver's license? Yes No

4. Are you currently enrolled in school?

Yes, part time

Yes, full time 
No

5. What is your current employment status? (please select one)

Not employed, looking for work

Not employed, not looking for work

Employed full time (includes self-employed)

Employed part time (includes self-employed)

Retired, but working at least part time

Retired and not working

Disable, unable to work

Other

6. If you are employed, is your primary place of work outside the home?

Yes No Not applicable

7. How many years of school have you completed?

Some high school or less [Secondary school]

High school diploma or GED [Secondary school]

[GCSE or similar]

[A Levels or similar]

Some university

Trade/vocational school

Associate degree

Three-year university degree or more

Other (please specify) $\ldots \ldots \ldots \ldots \ldots \ldots \ldots$

\section{Questions specific for Control intersections}

1a. Have you ever ridden through the intersection at $\mathrm{xxx} \& \mathrm{xxx}$ ? [insert map]

Yes No (skip to 1c.) 
1b. If yes, how frequently do you ride through the intersection at $\mathrm{xxx} \& \mathrm{xxx}$ ?

$6-7$ days a week

4-5 days a week

1-3 days a week

1-3 days a month

Less than one day a month

1c. If no, for what reasons do you not ride through the intersection at $\mathrm{xxx} \& \mathrm{xxx}$ ? (select all that apply)

It is not on any of my routes

I feel unsafe riding through that intersection

I think the intersection is too busy

I think there are too many motor vehicles at that intersection

I am confused about how to navigate that intersection

Vehicle speeds are too fast

Vehicle speeds are too slow

That intersection is too congested

The pavement is too rough

Poor street lighting

Poor drainage/pooling water

Other...............

2. What factors make you feel unsafe riding through that intersection? (select all that apply)

I do not feel unsafe riding through this intersection

Too many cars and trucks

Too many buses

Too many pedestrians 
Too many bicyclists

Traffic speed is too fast

Traffic speed is too slow

Too few motor vehicles

Too few bicyclists

Too few pedestrians

Too many parked cars

Rough or poor pavement condition

Poor drainage/pooling water

Poor street lighting

Personal security concerns

Other...................

Do you feel that you can focus on other users, such as motor vehicles, while in this intersection? 
Appendix D: Enlarged path plans

\section{Elwick Square}

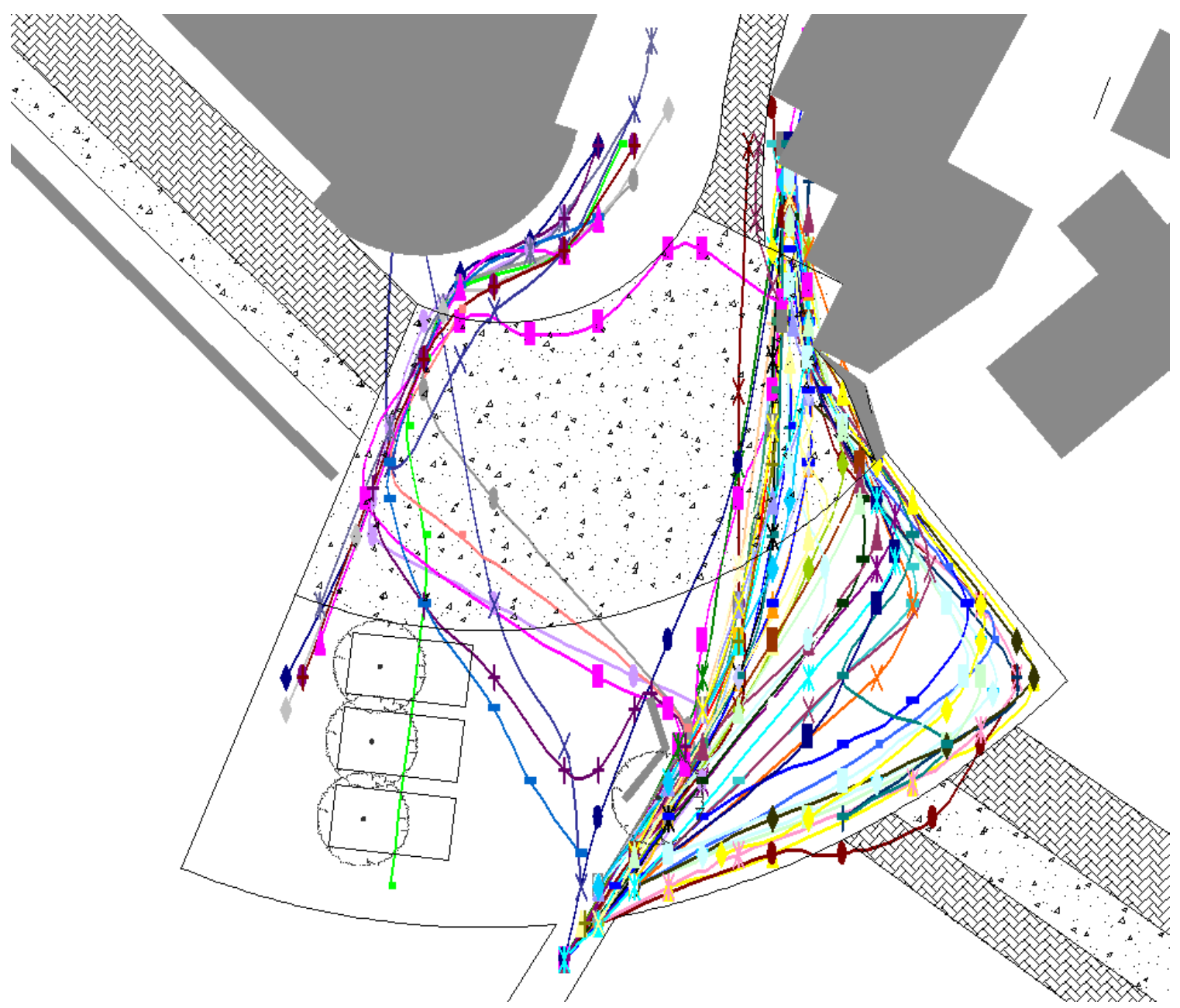

Figure 89: Elwick North to South ODs 


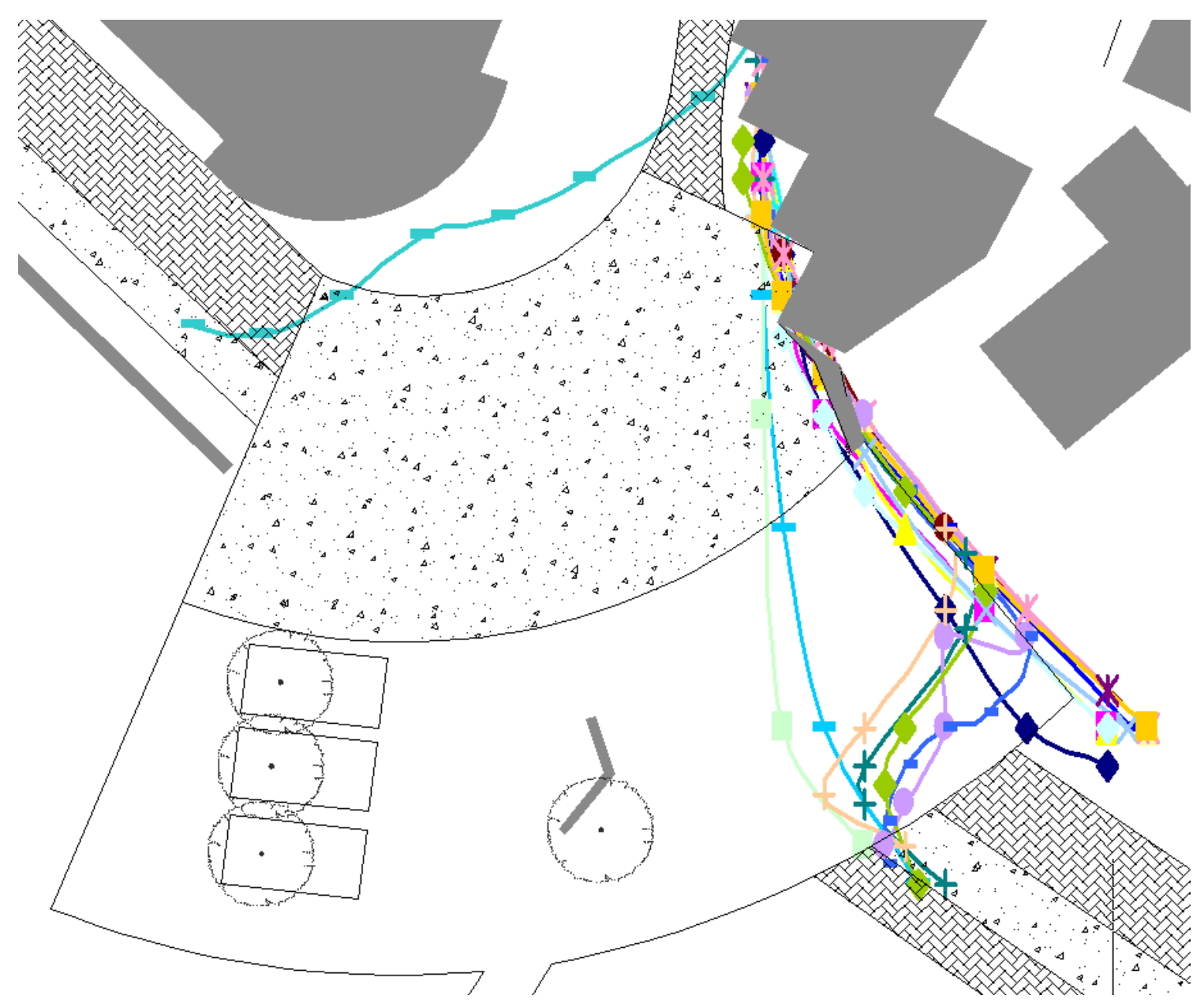

Figure 90: Elwick Square north to southeast OD 


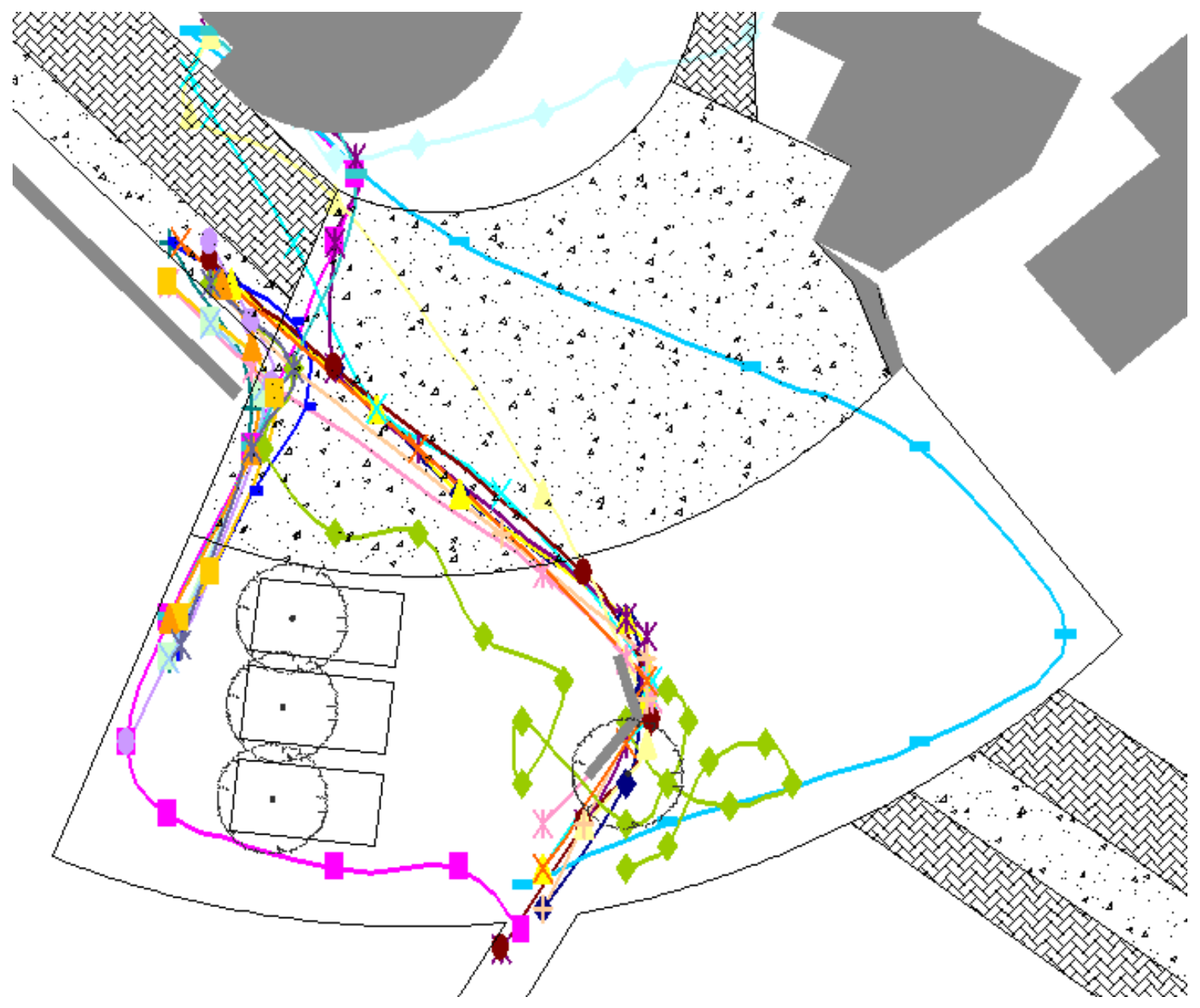

Figure 91: Elwick Square northwest to south 


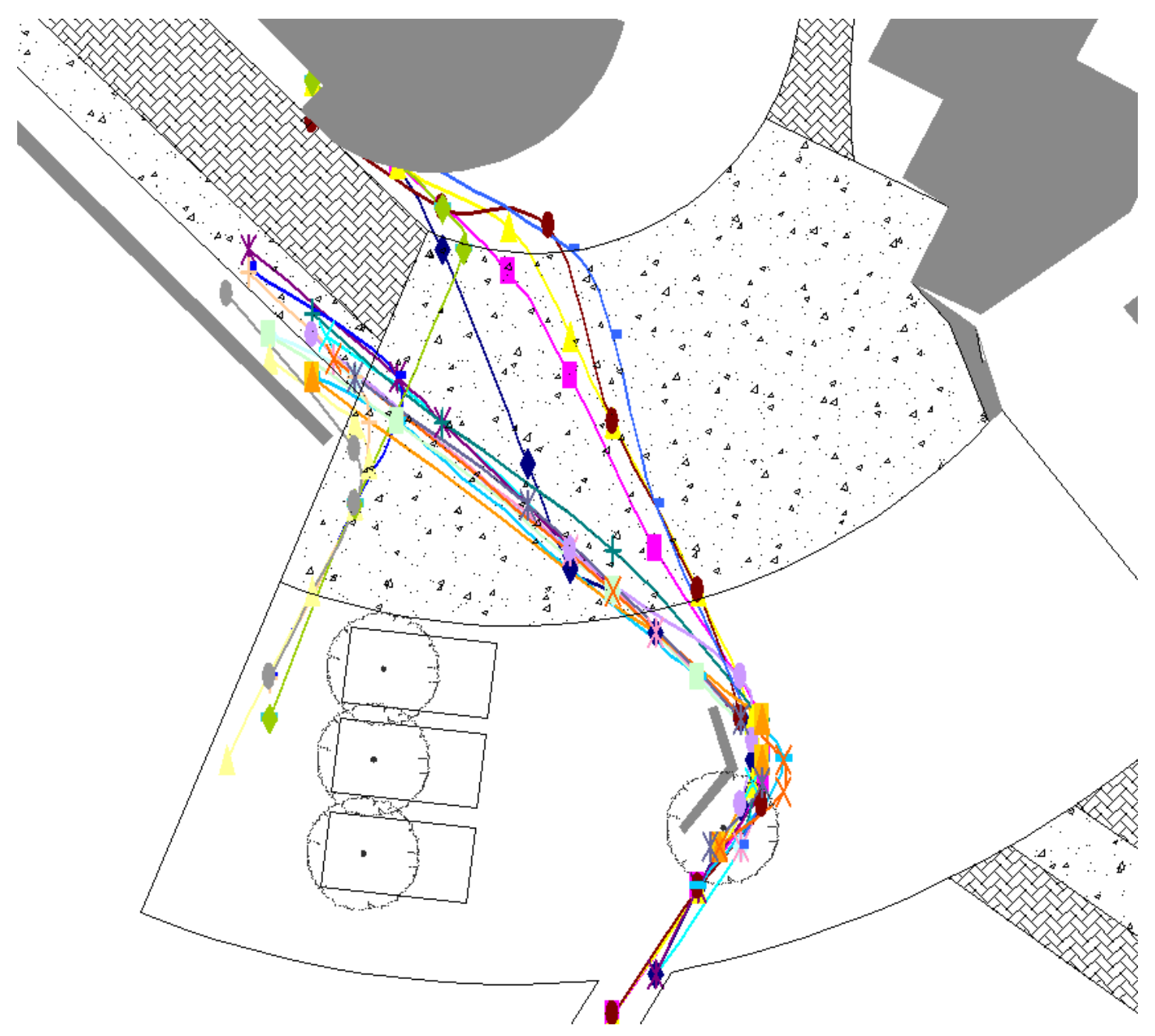

Figure 92: Elwick Square south to northwest 


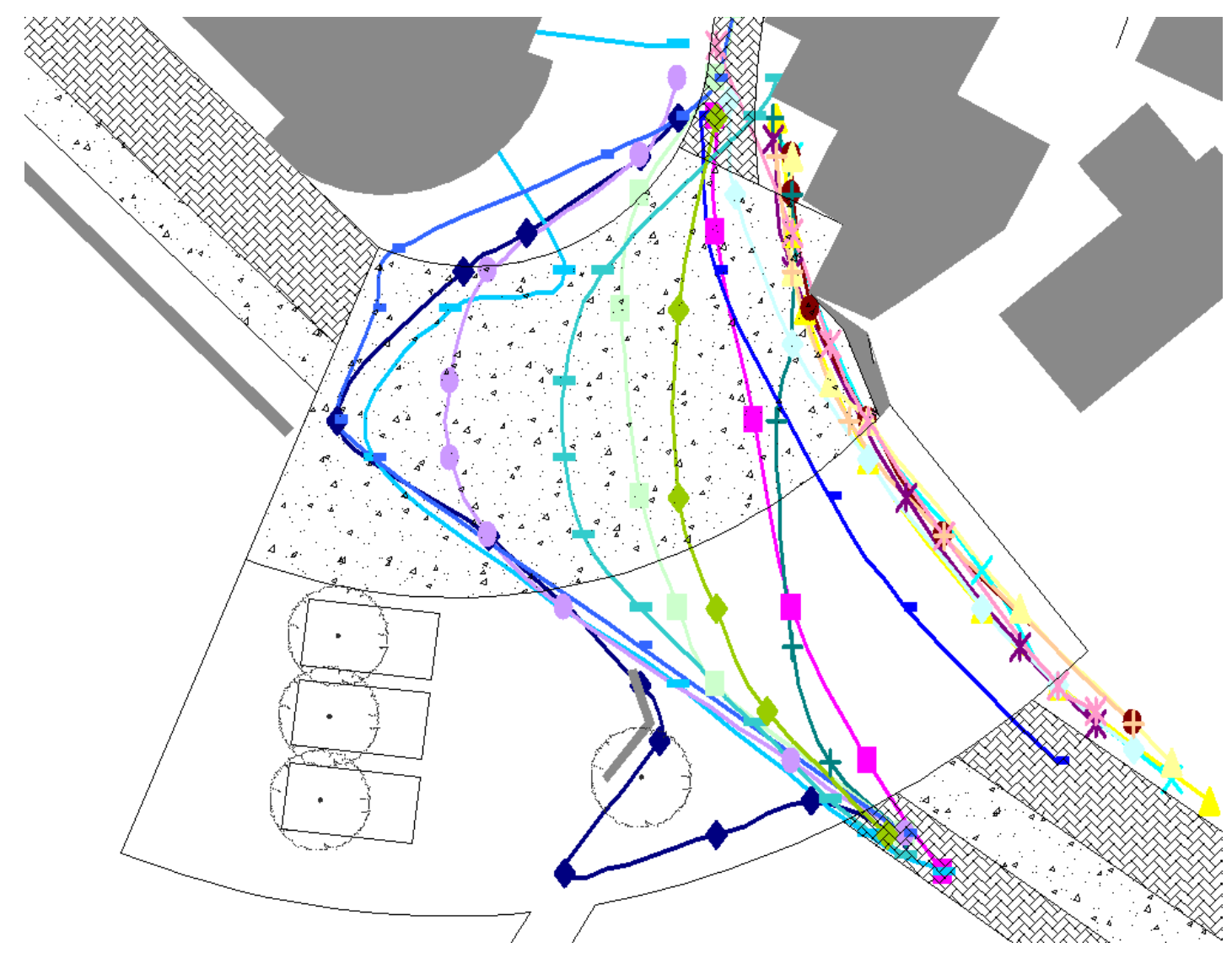

Figure 93: Elwick Square southeast to north 


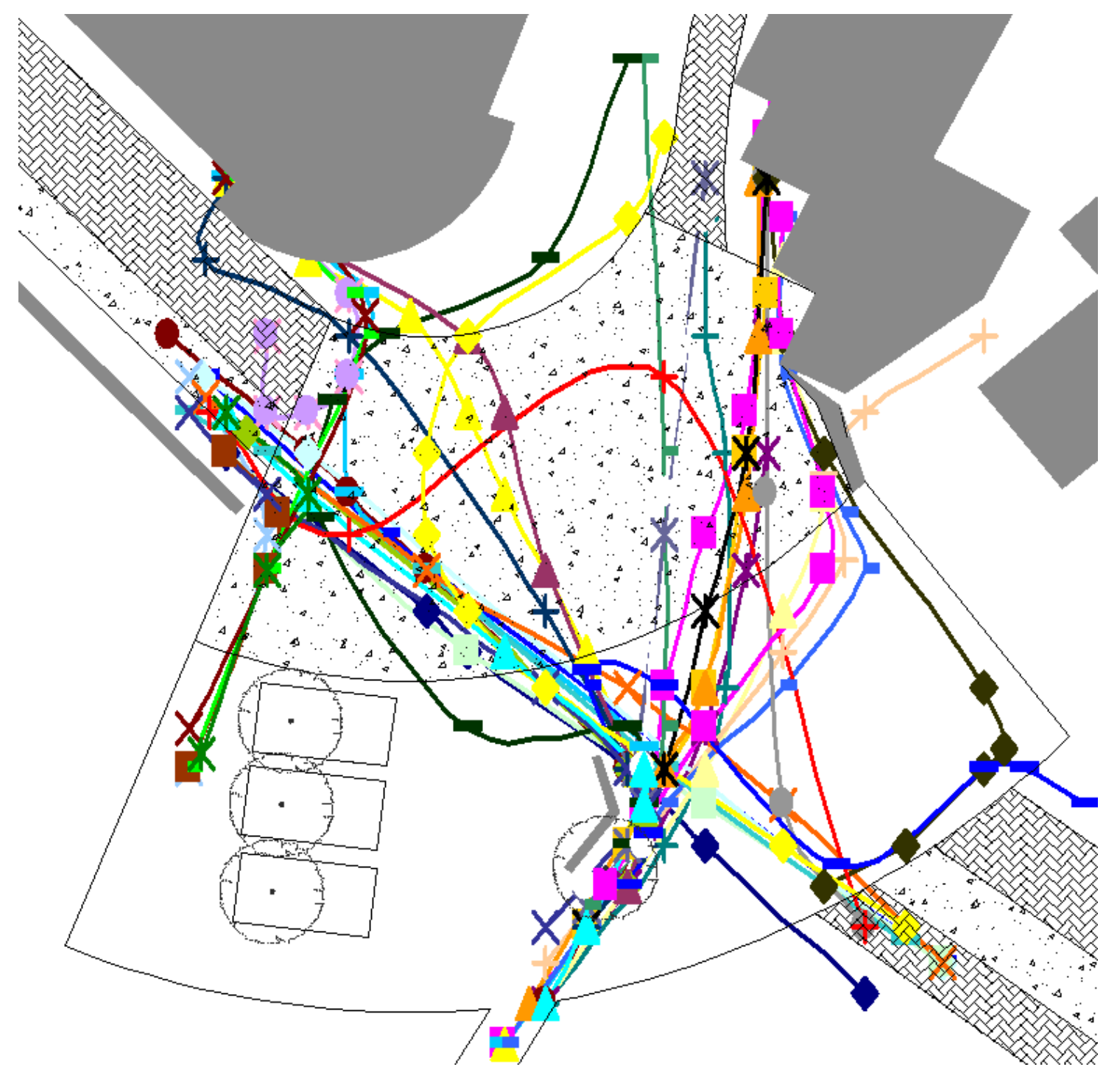

Figure 94: Elwick Square female paths 


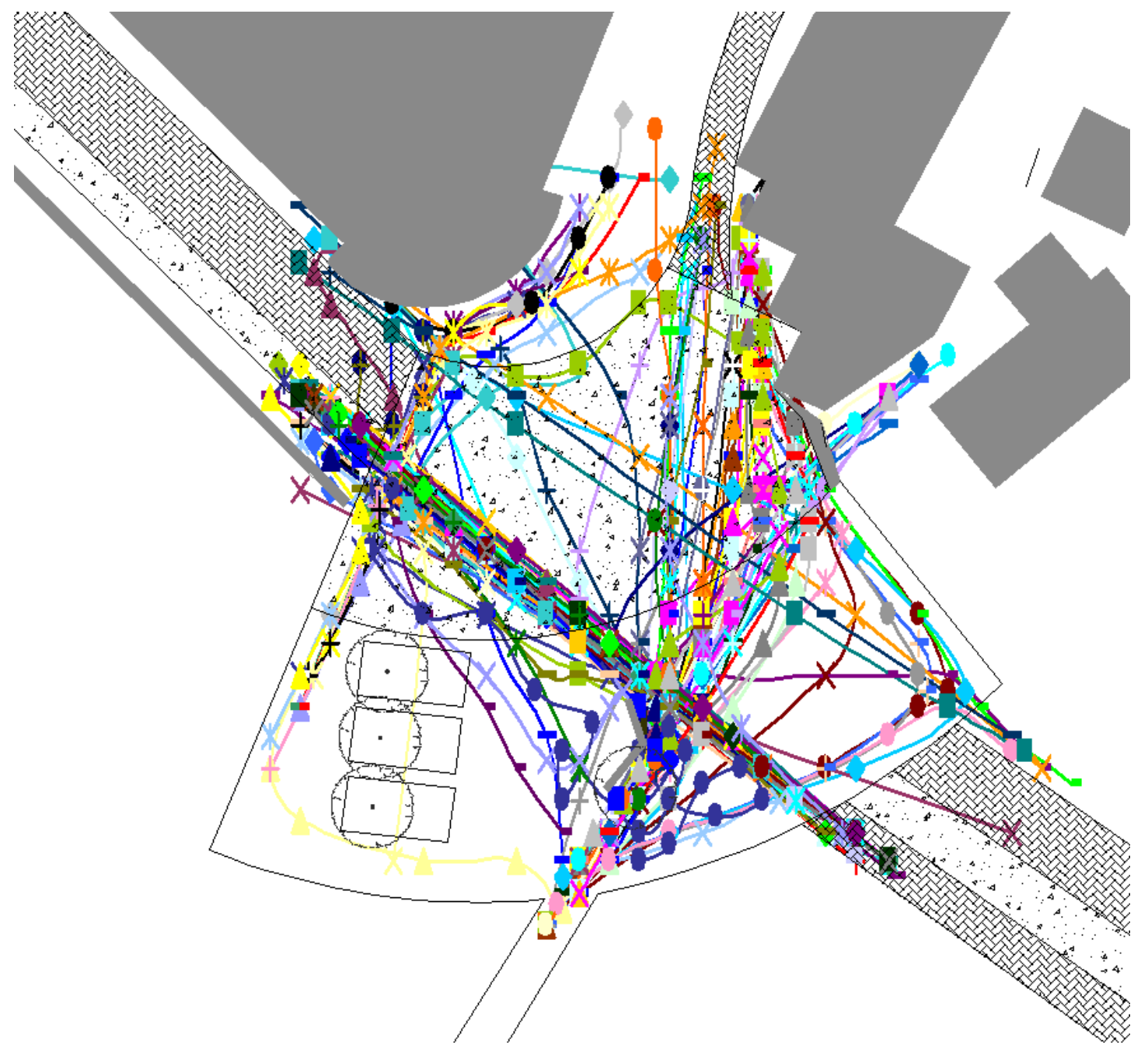

Figure 95: Elwick Square male paths 


\section{Poynton}

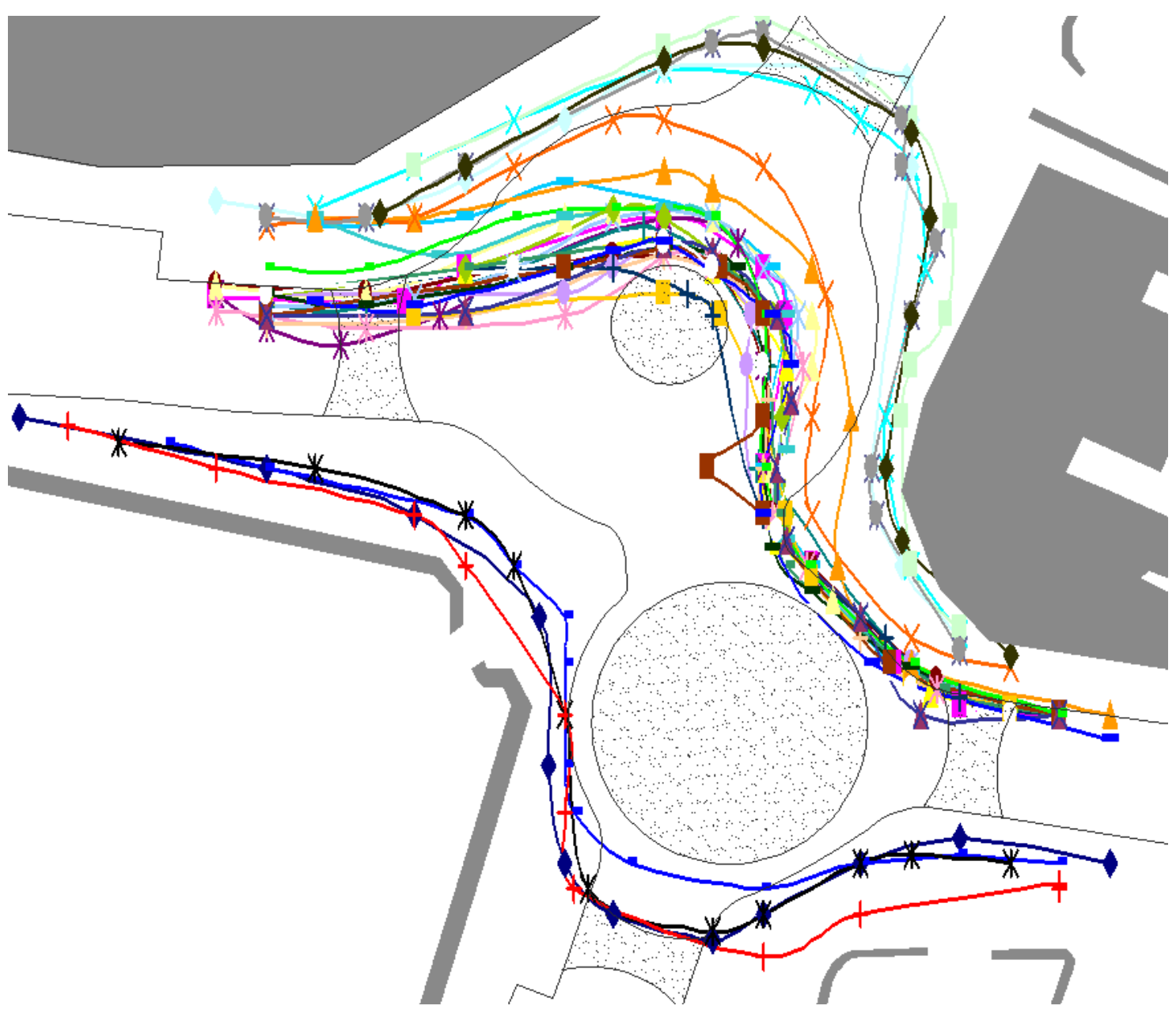

Figure 96: Poynton west to east 


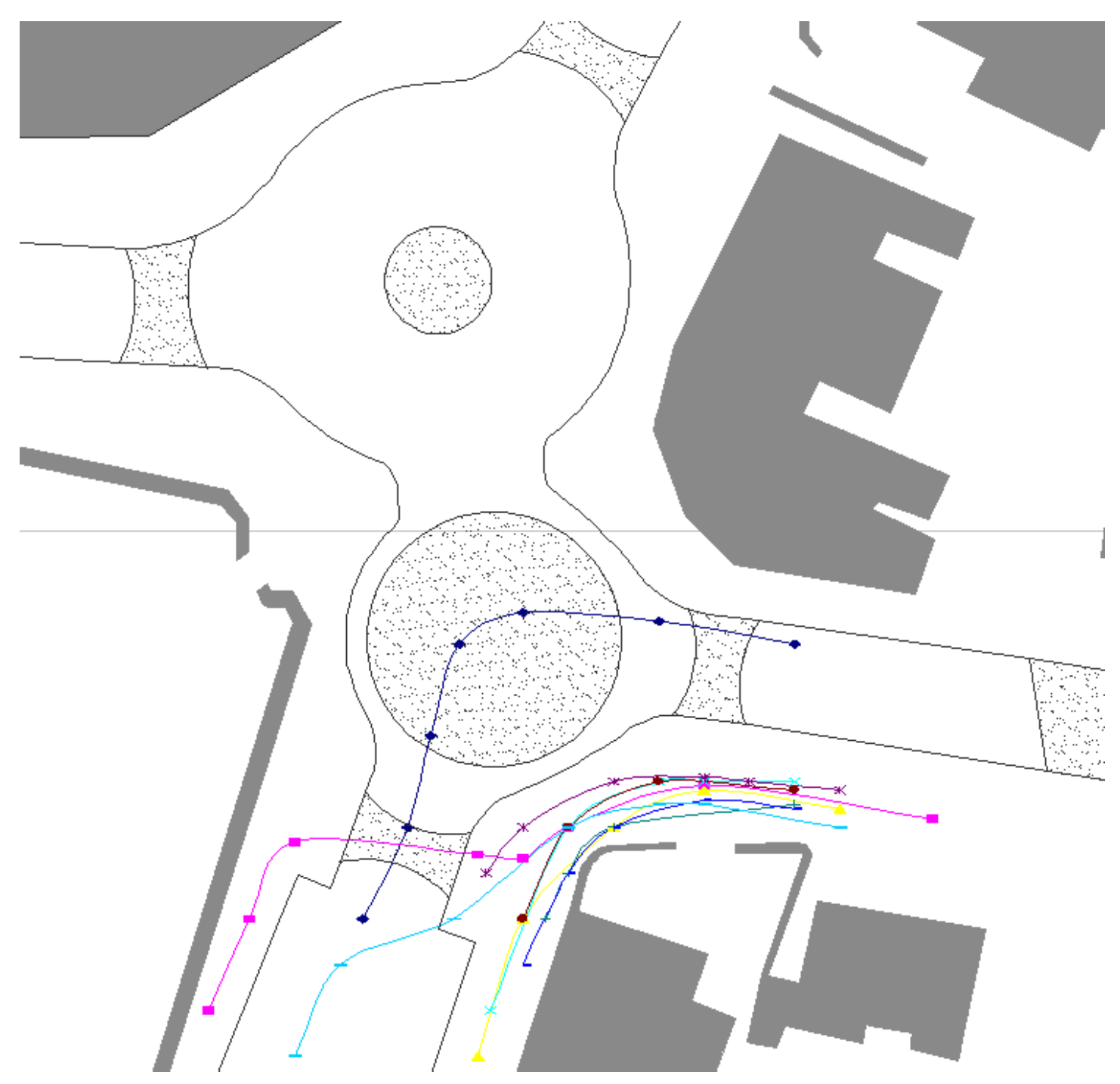

Figure 97: Poynton southwest to east 


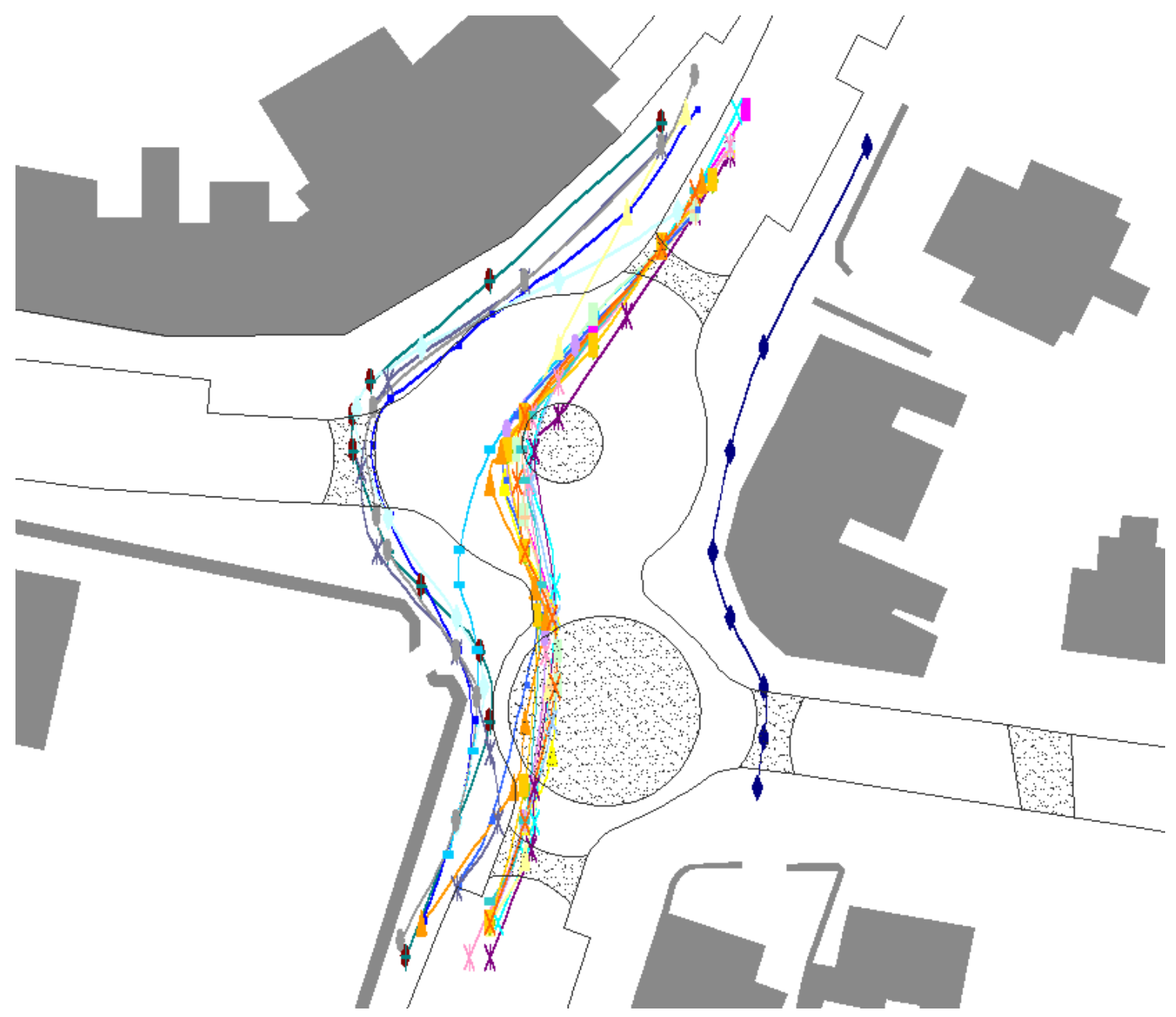

Figure 98: Poynton southwest to northeast OD paths 


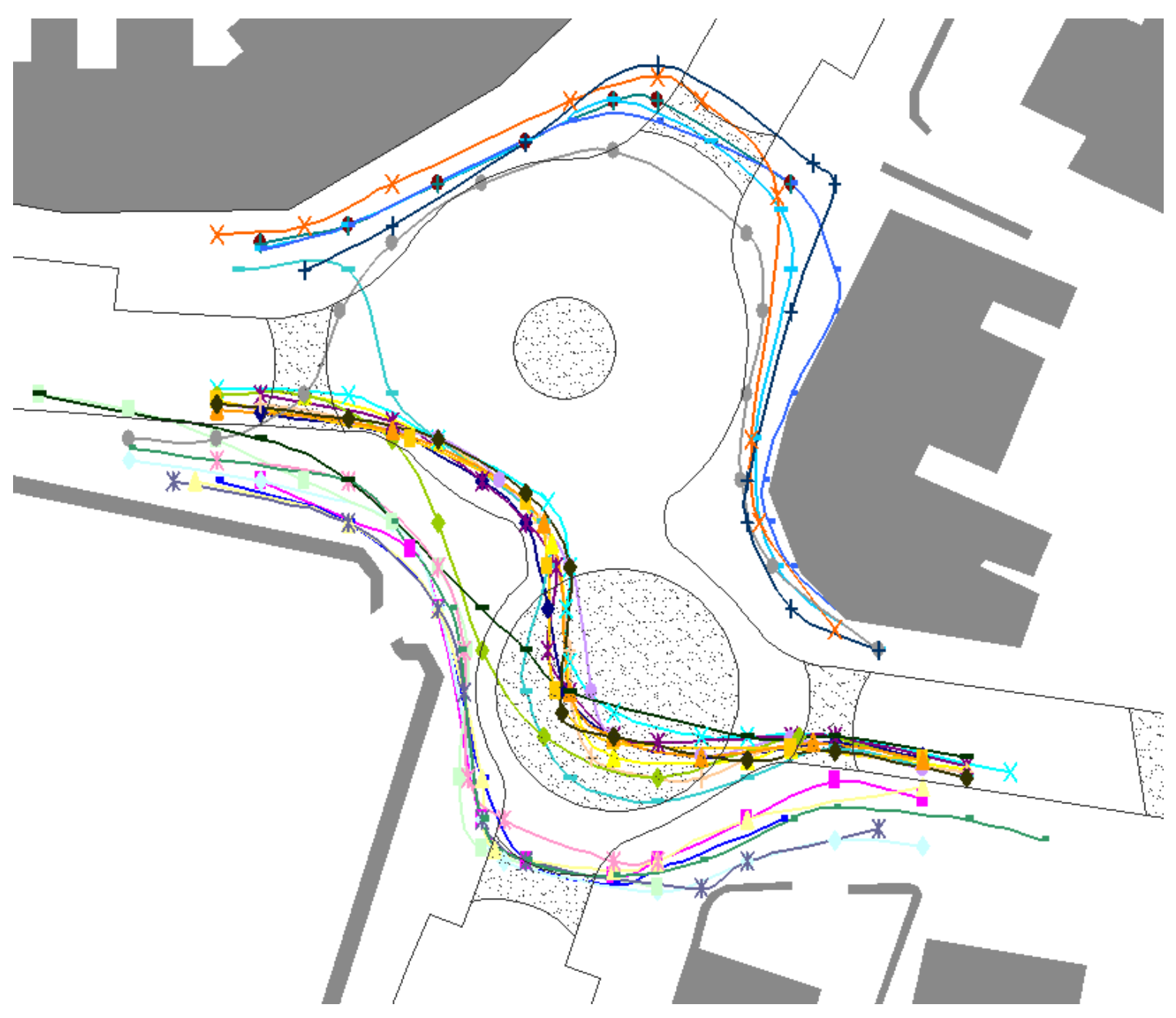

Figure 99: Poynton east to west 


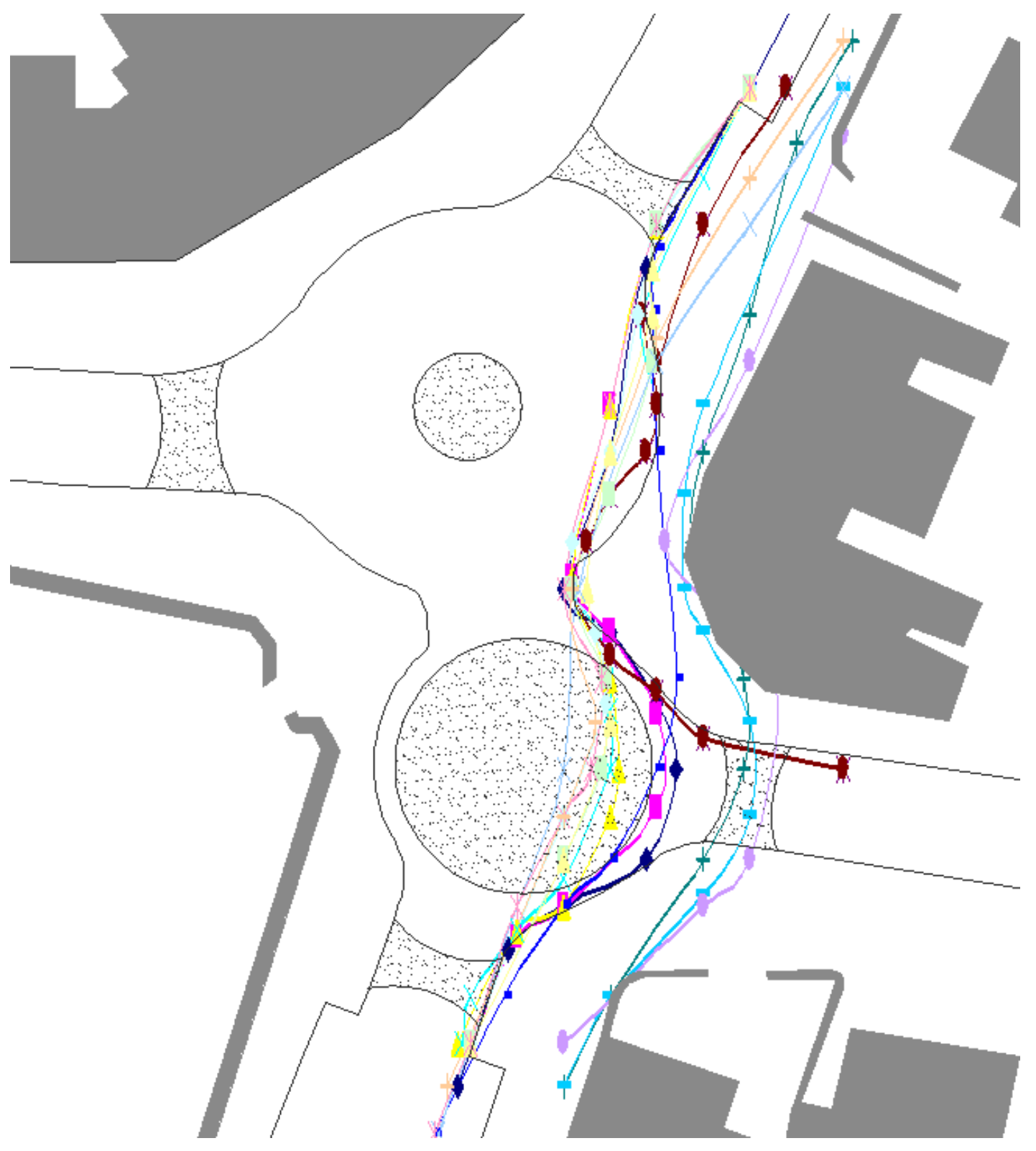

Figure 100: Poynton northeast to southwest 


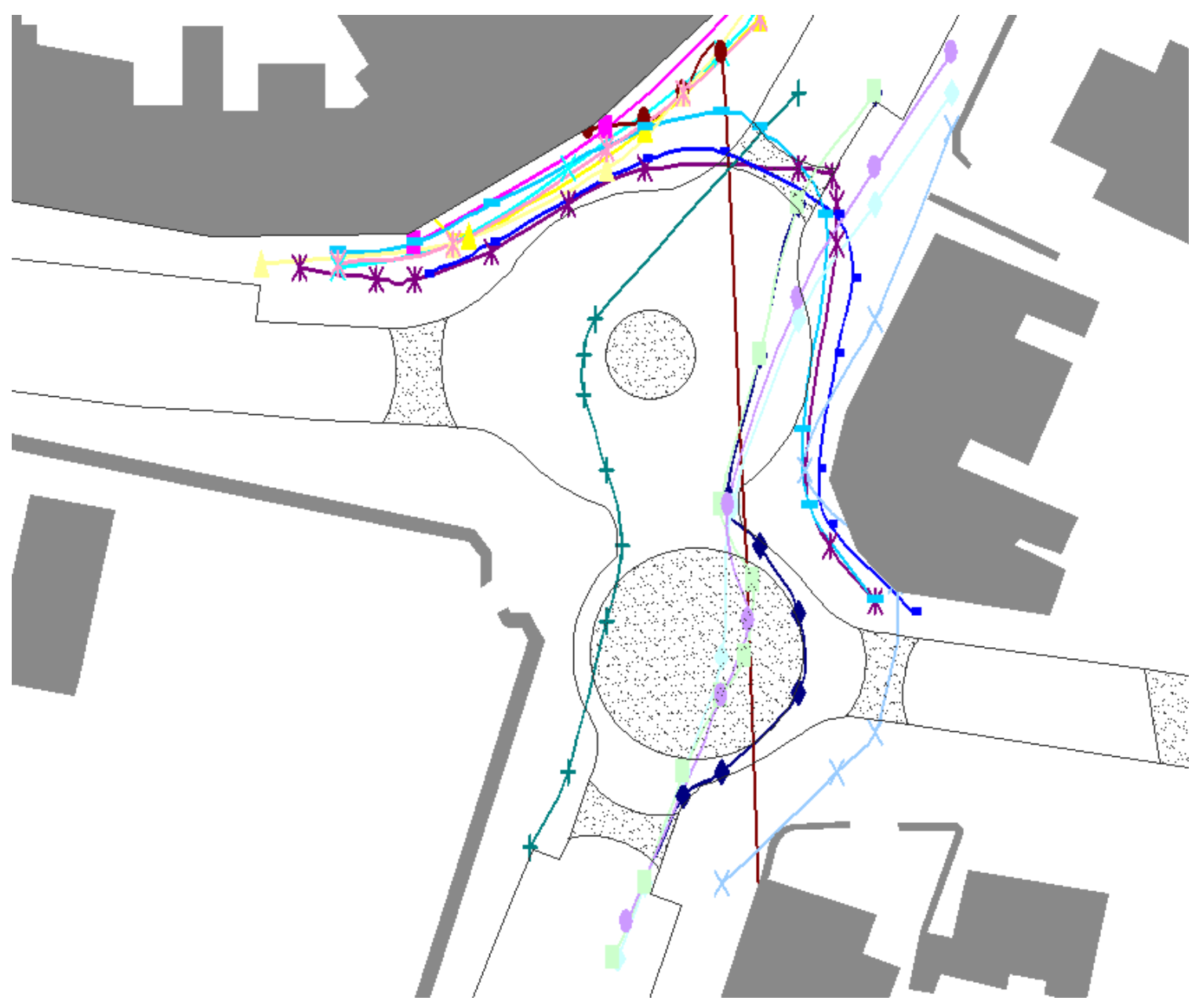

Figure 101: Poynton female paths 


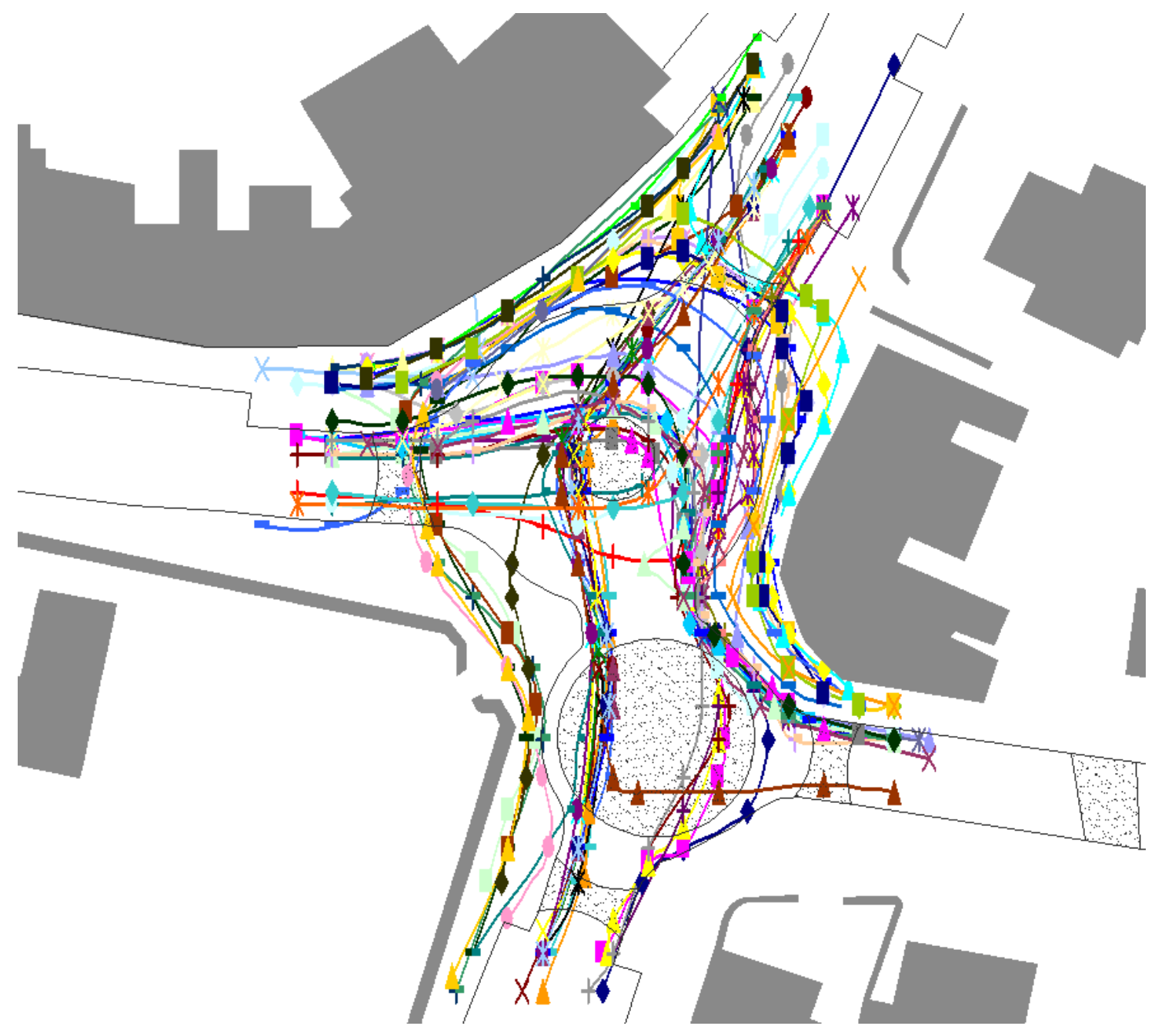

Figure 102: Poynton male paths 


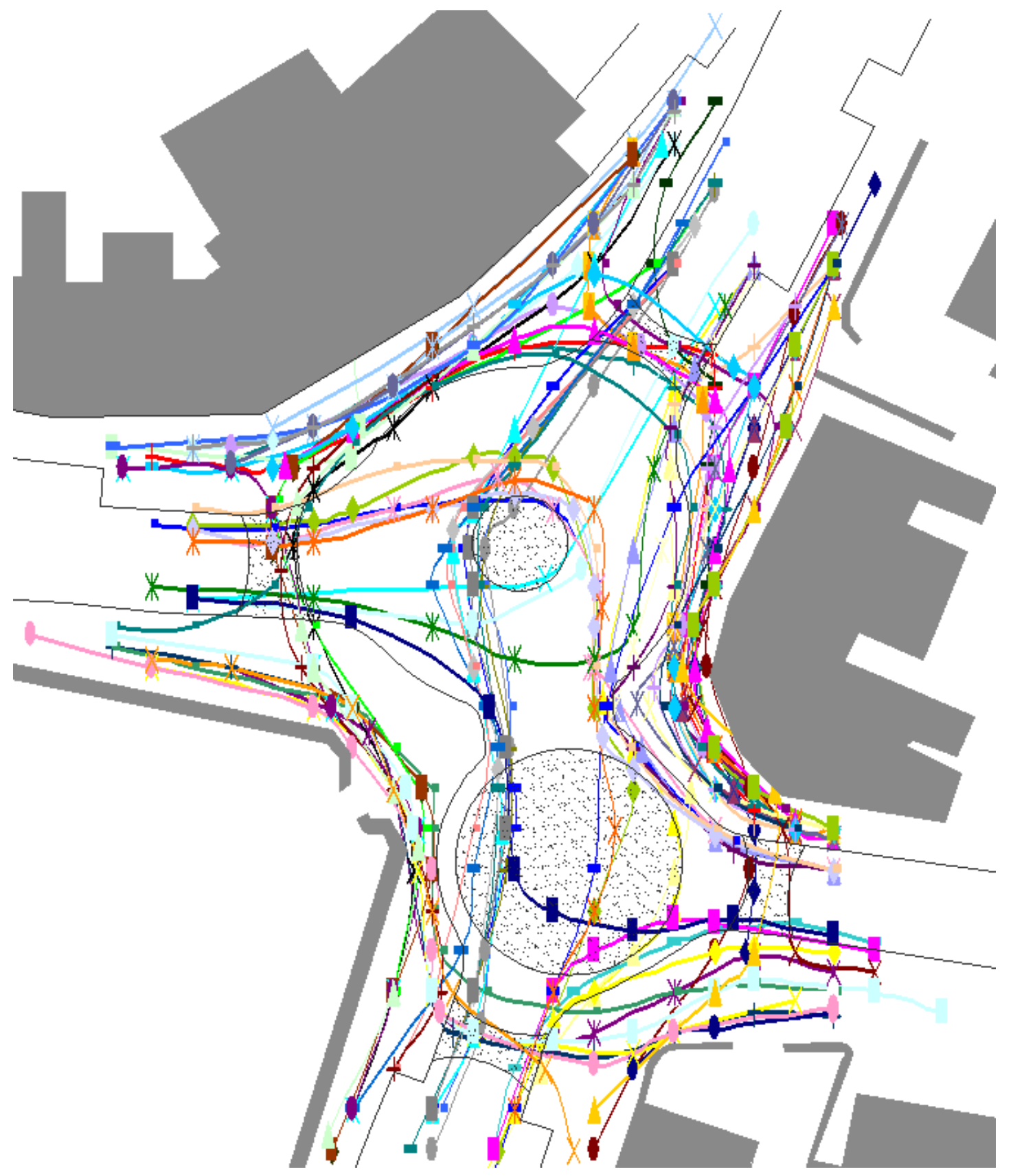

Figure 103: Poynton flat bar paths 


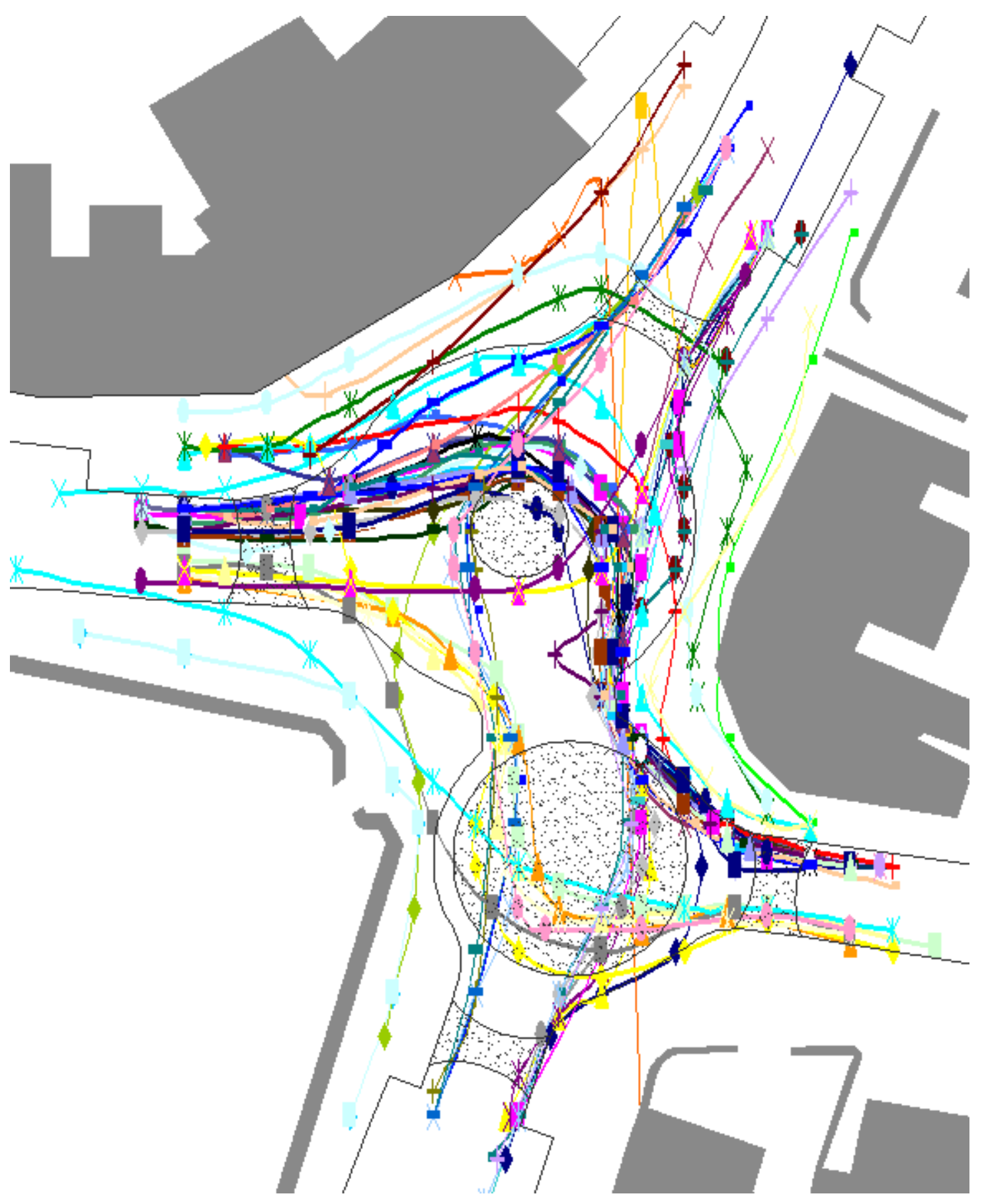

Figure 104: Poynton drop bar paths 


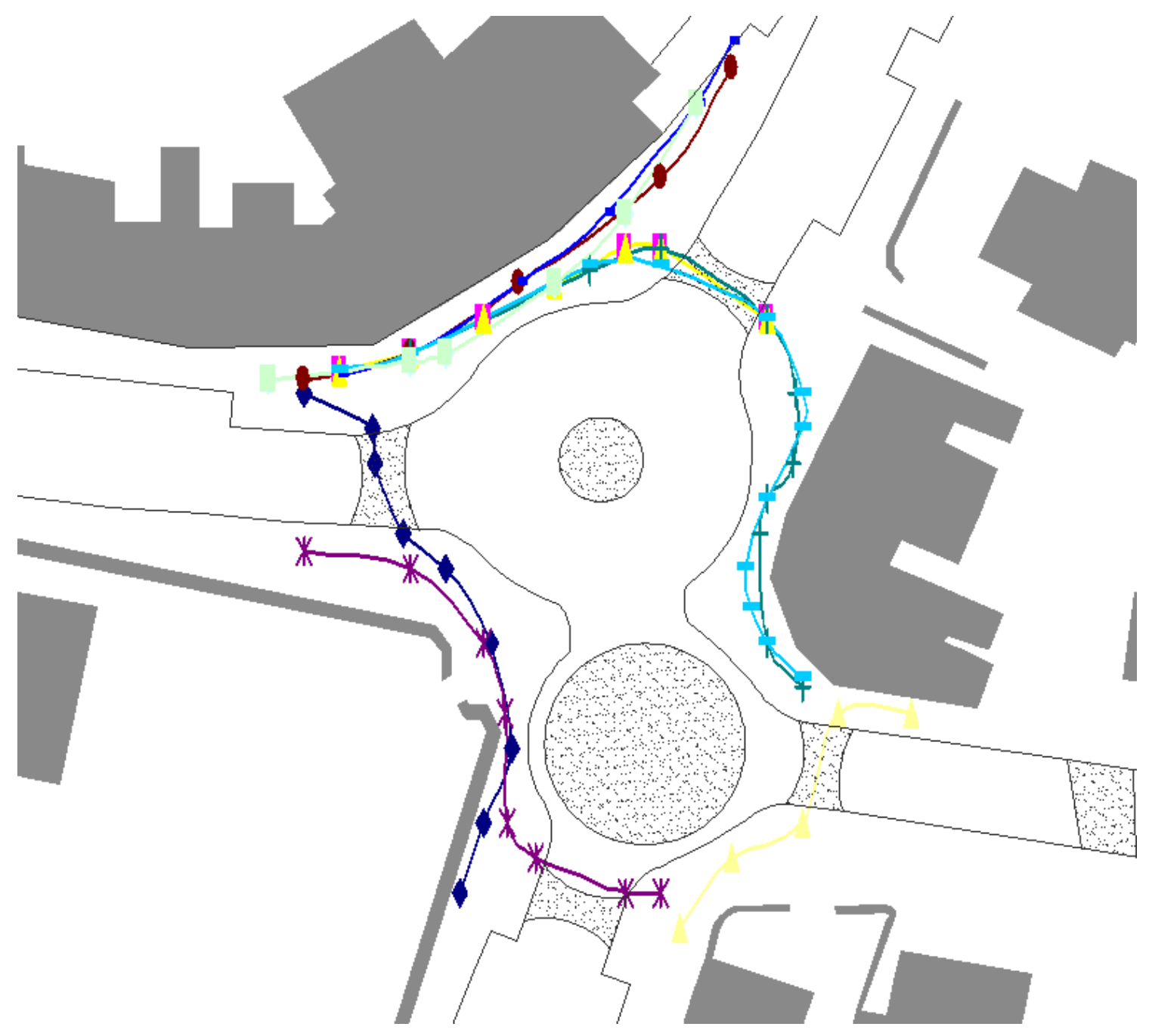

Figure 105: Poynton other bikes paths 


\section{Coventry}
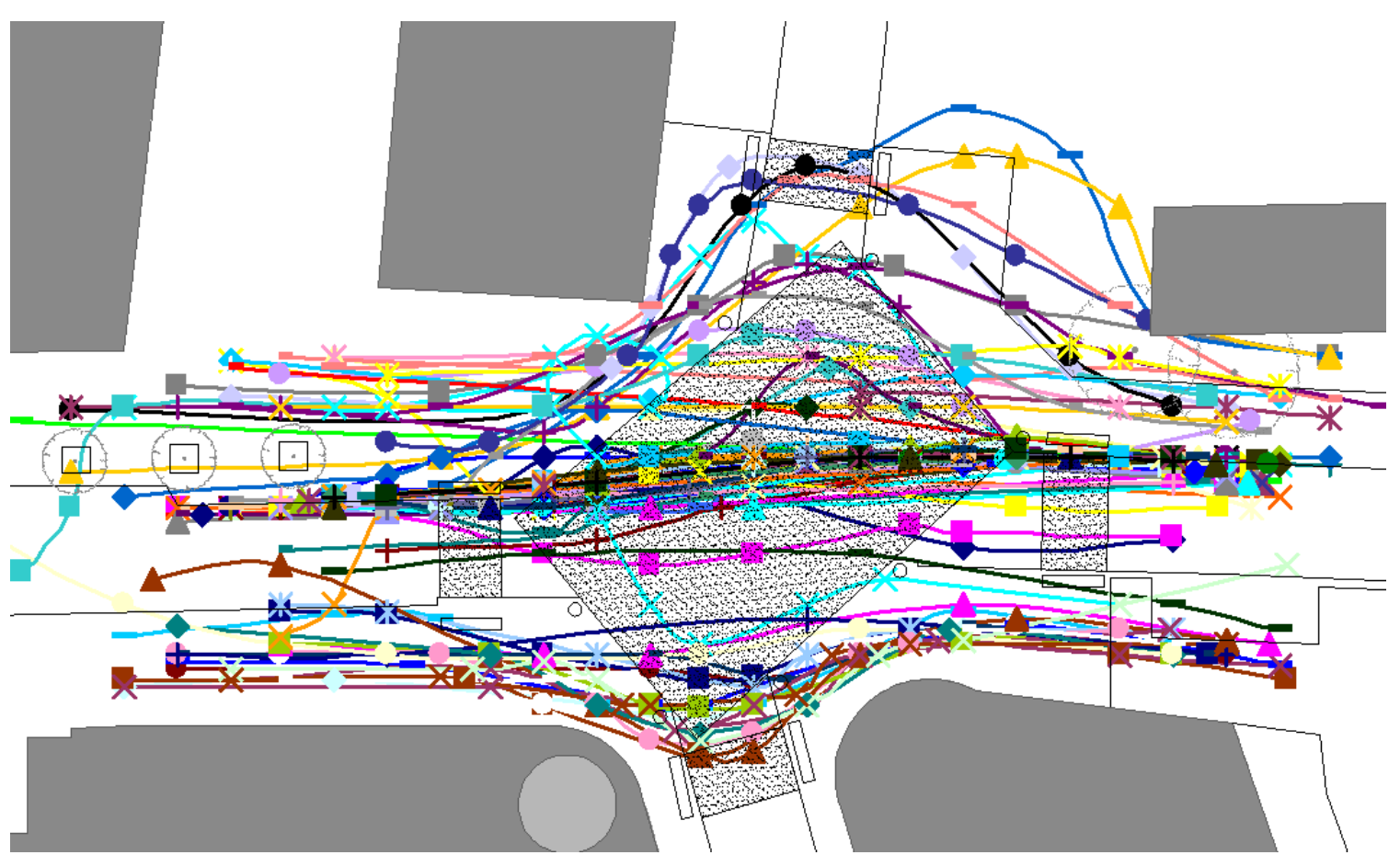

Figure 106: Coventry west to east 


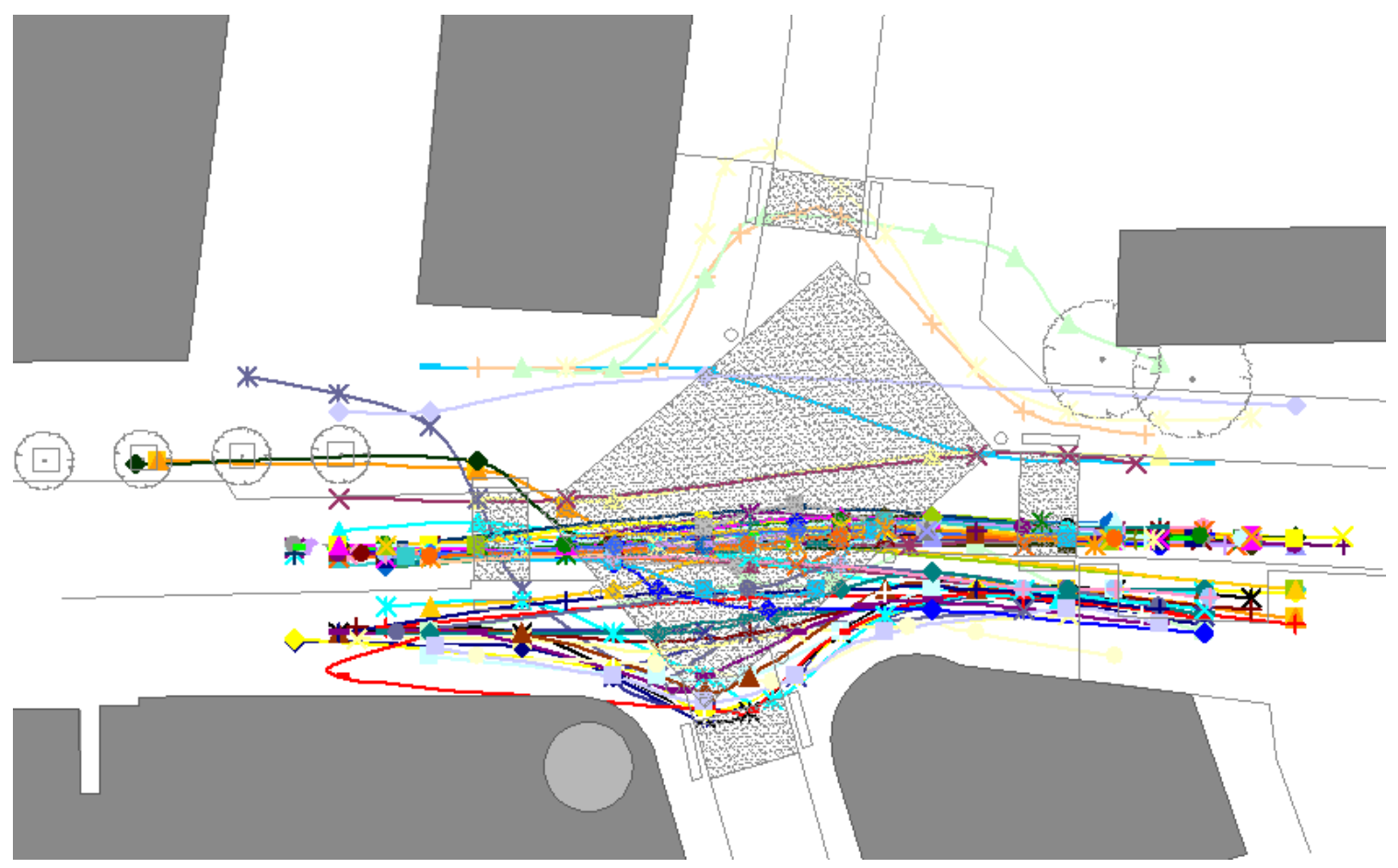

Figure 107: Coventry east to west 


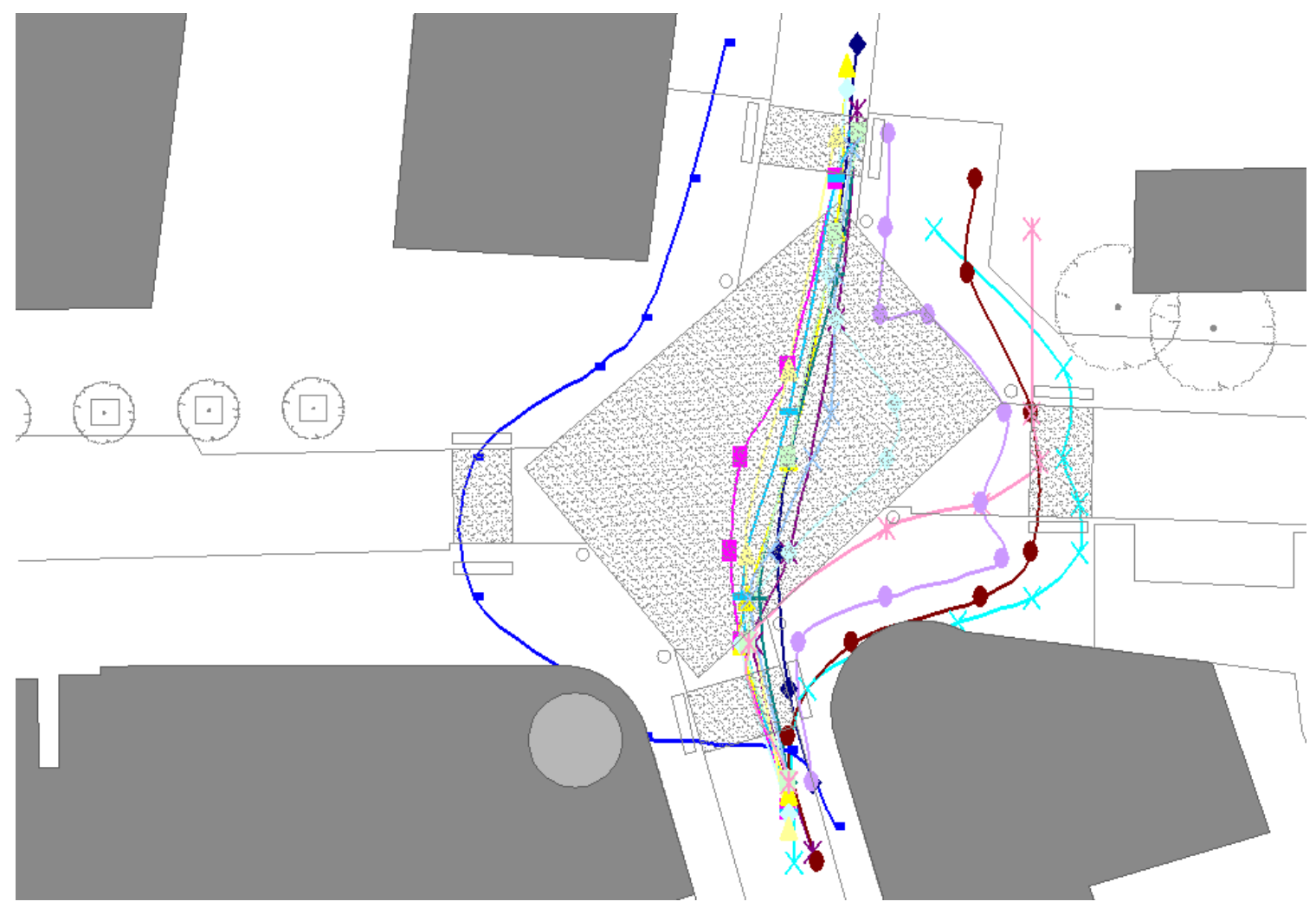

Figure 108: Coventry north to south 


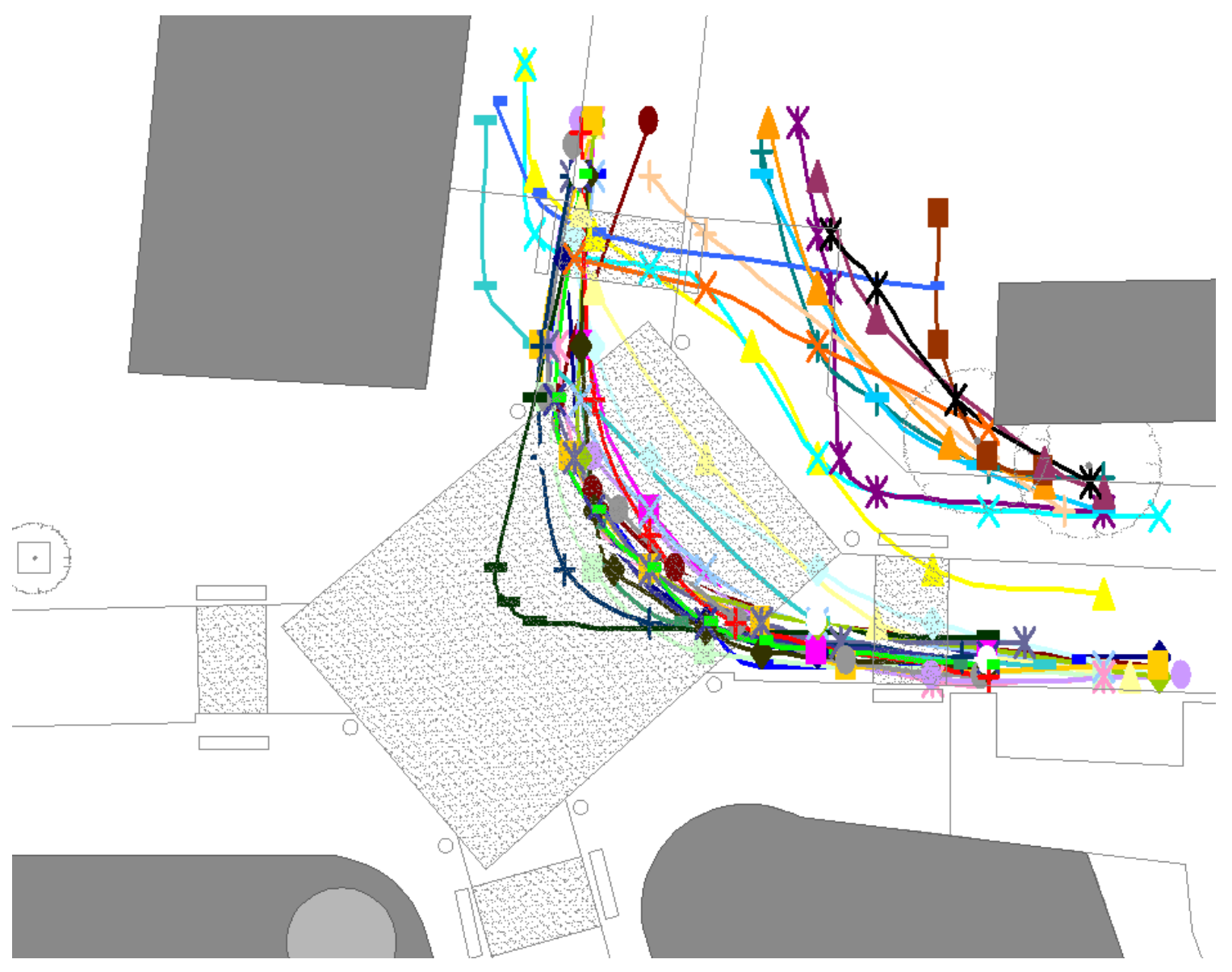

Figure 109: Coventry east to north paths 


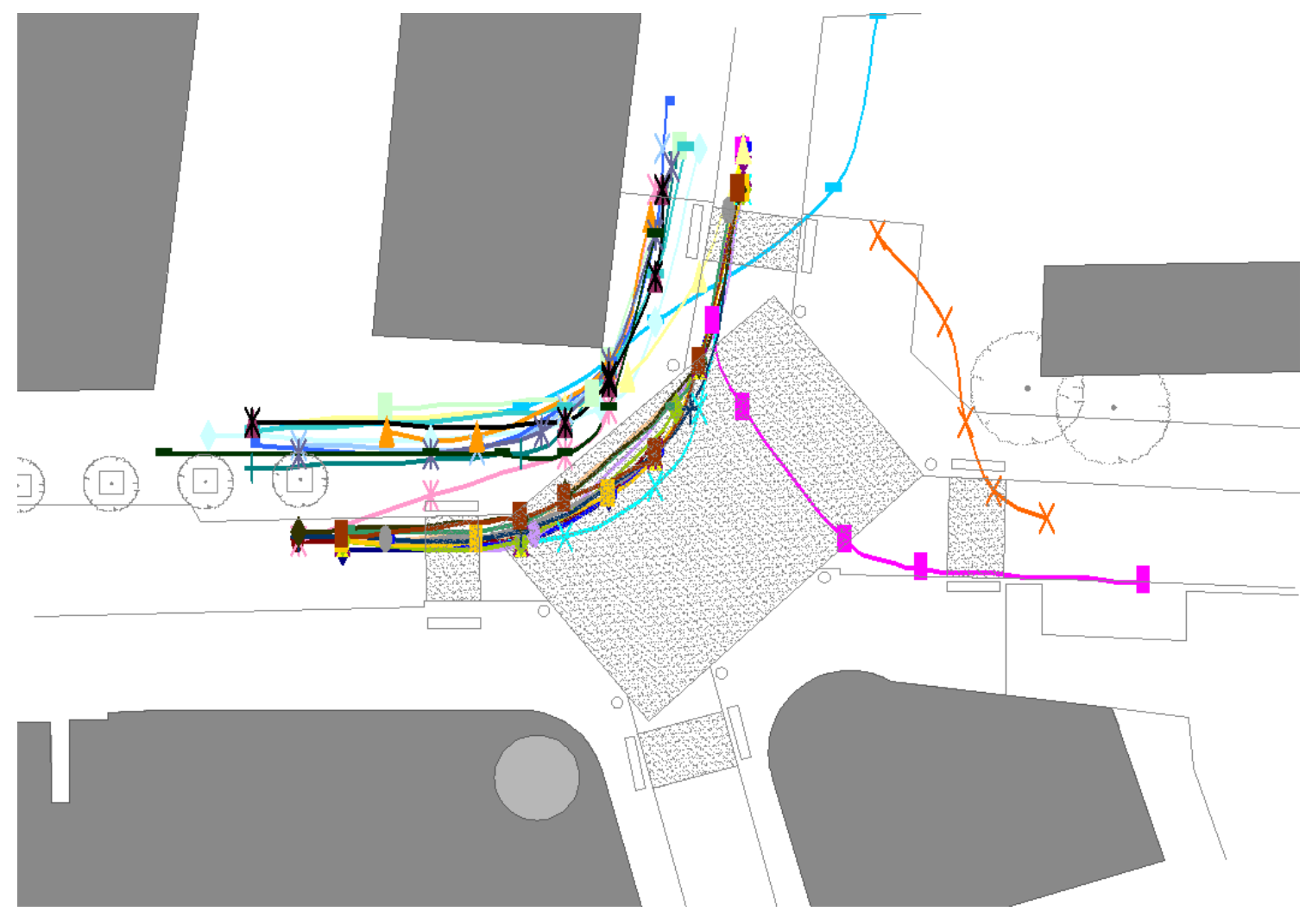

Figure 110: Coventry west to north paths 


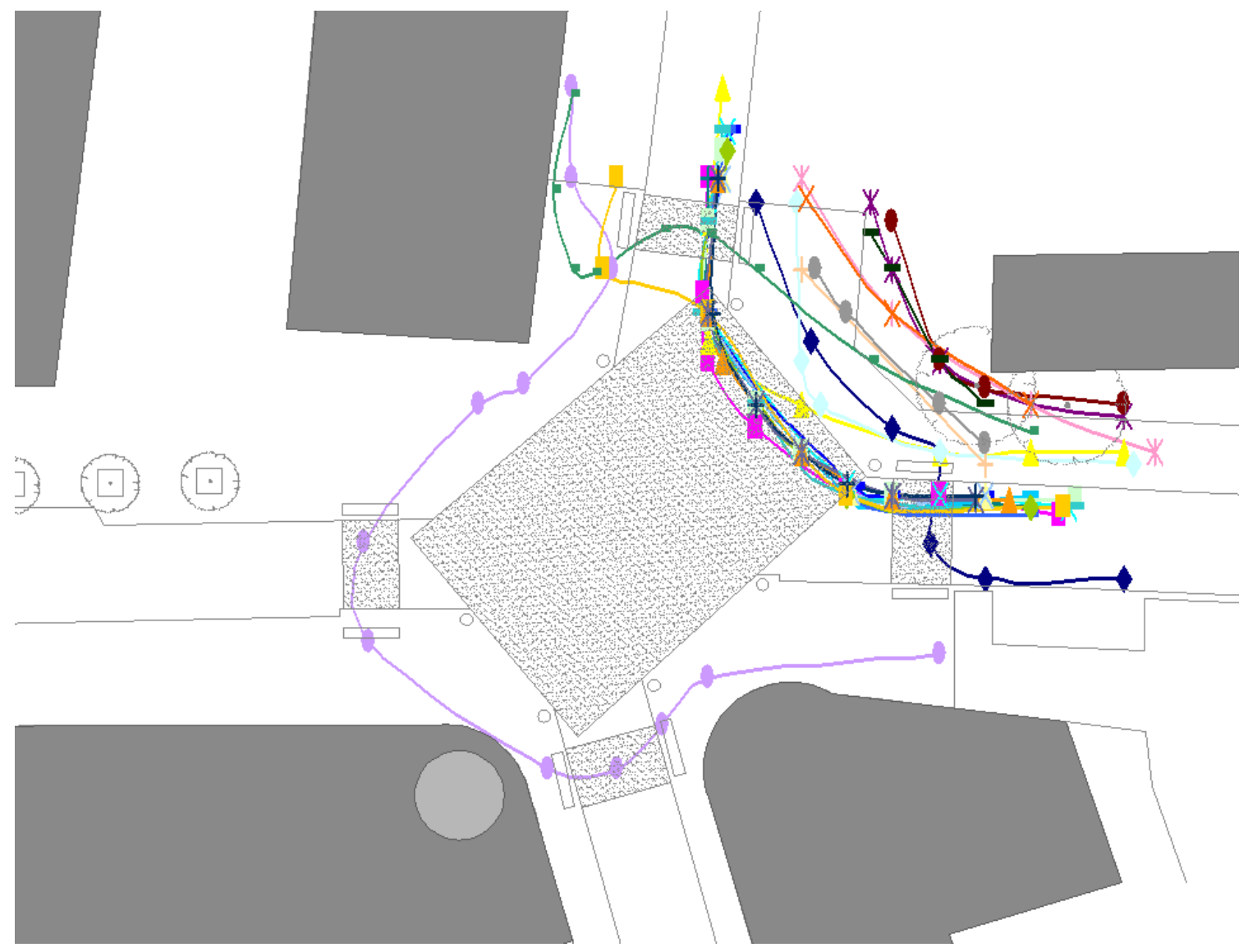

Figure 111: Coventry north to east paths 


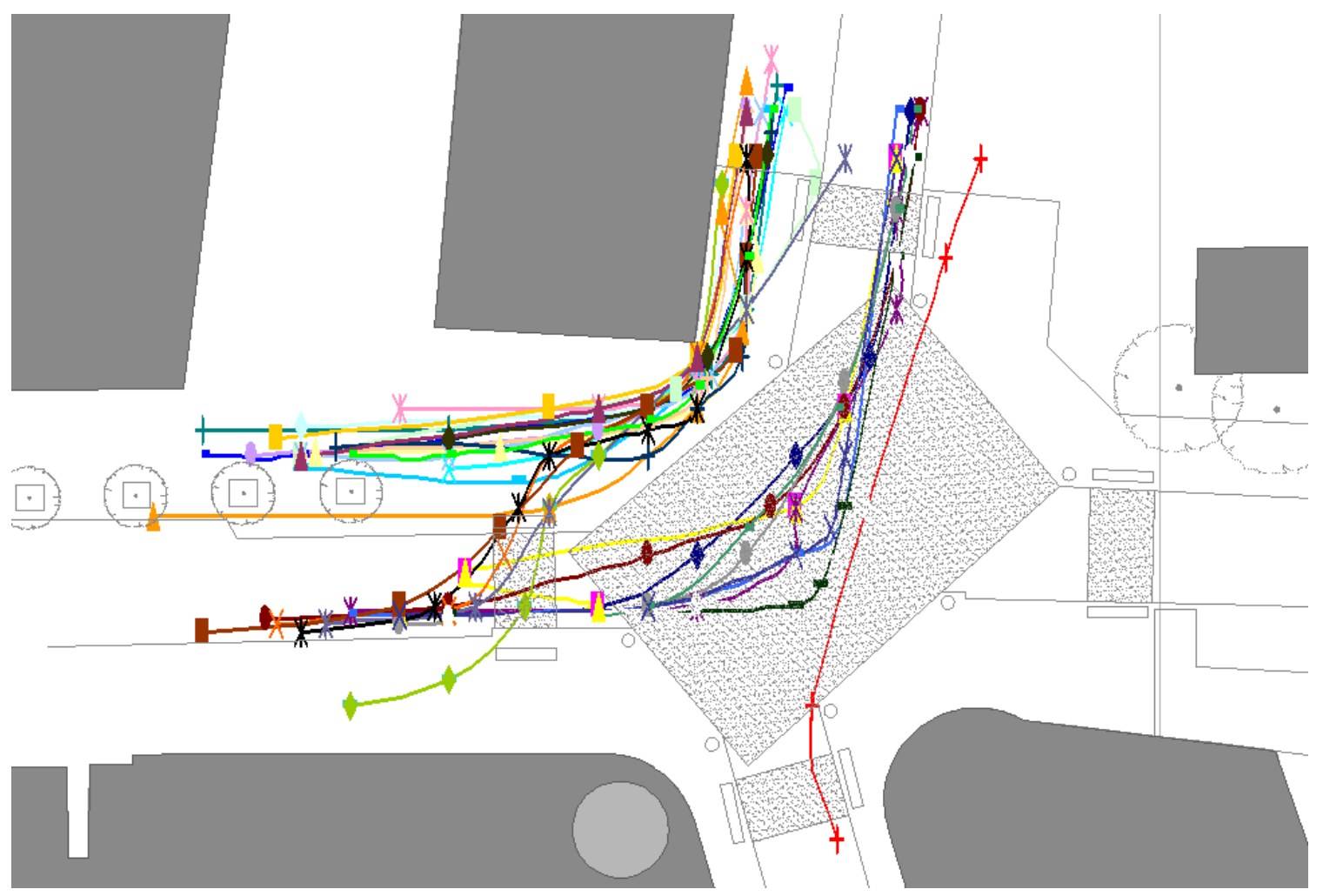

Figure 112: Coventry north to west 


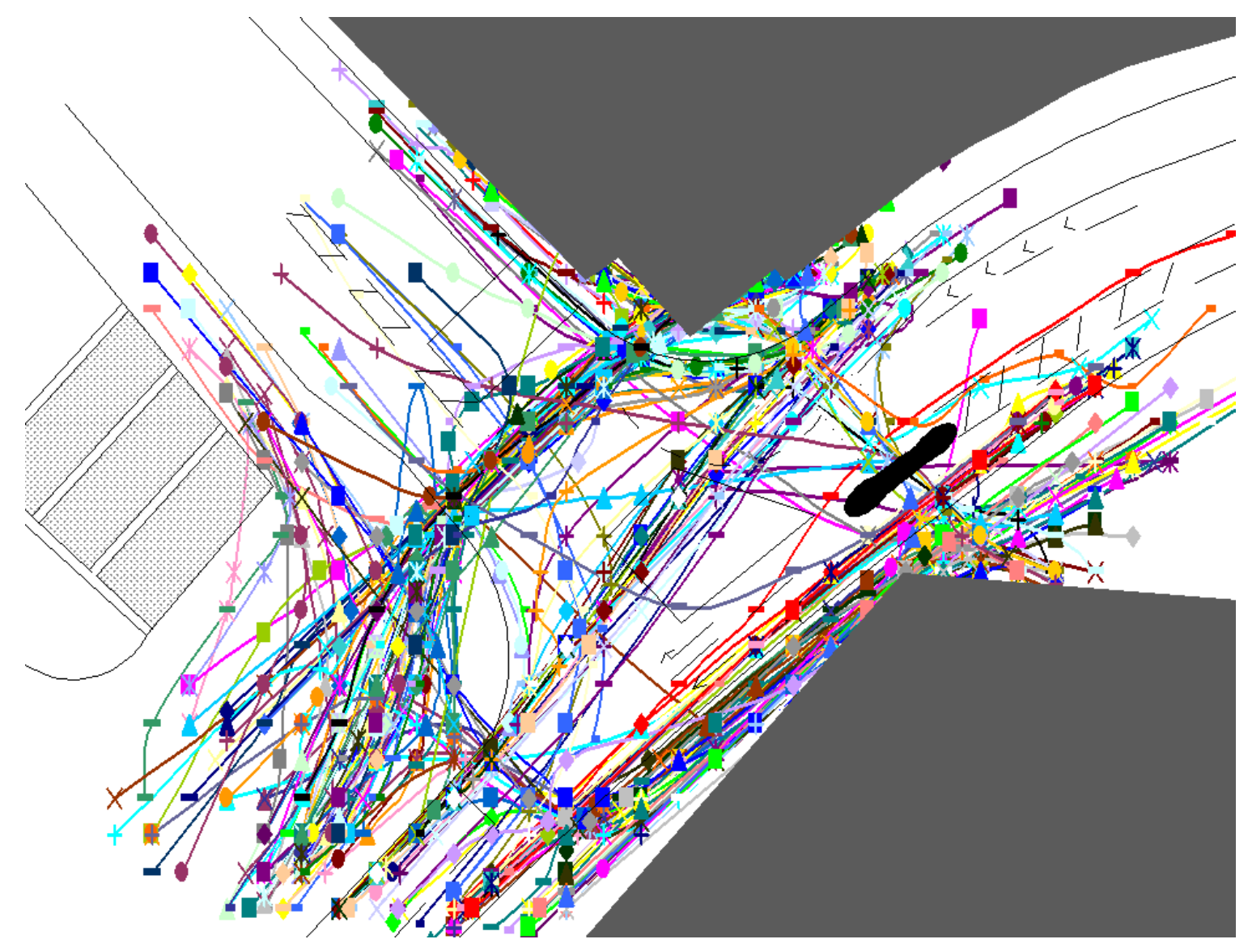

Figure 113: Coventry control flat bar paths 


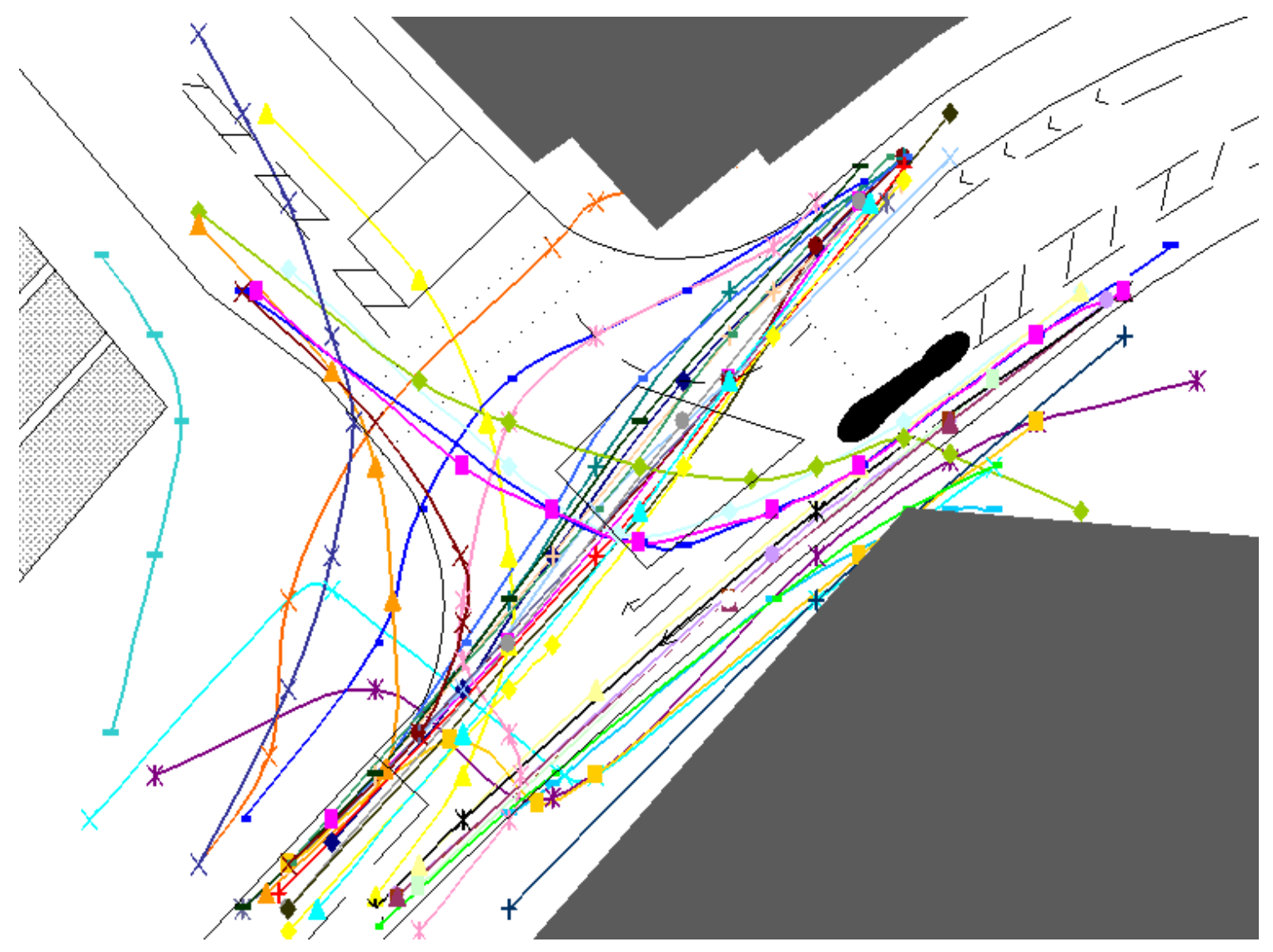

Figure 114: Coventry control drop bar paths 


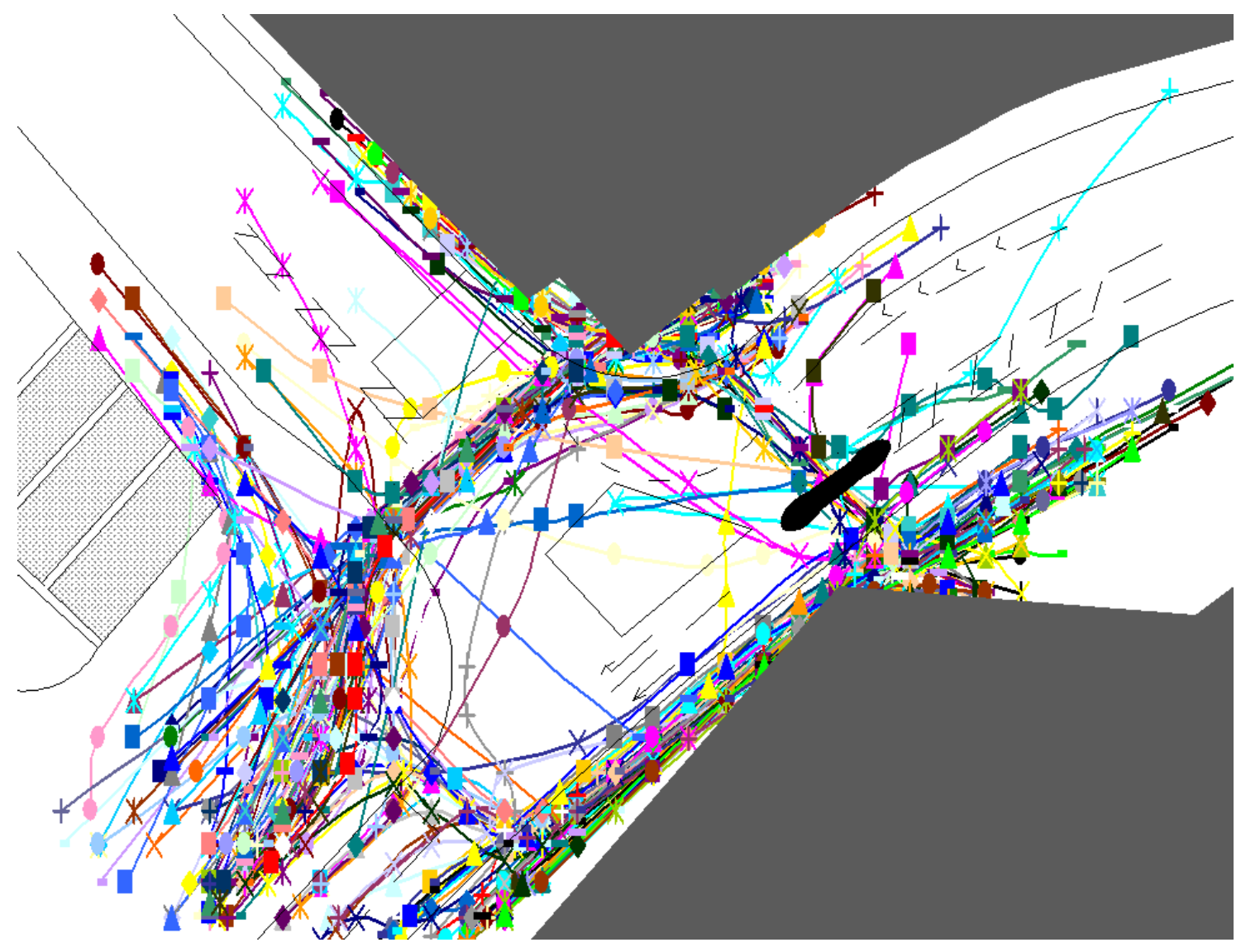

Figure 115: sidewalk use 


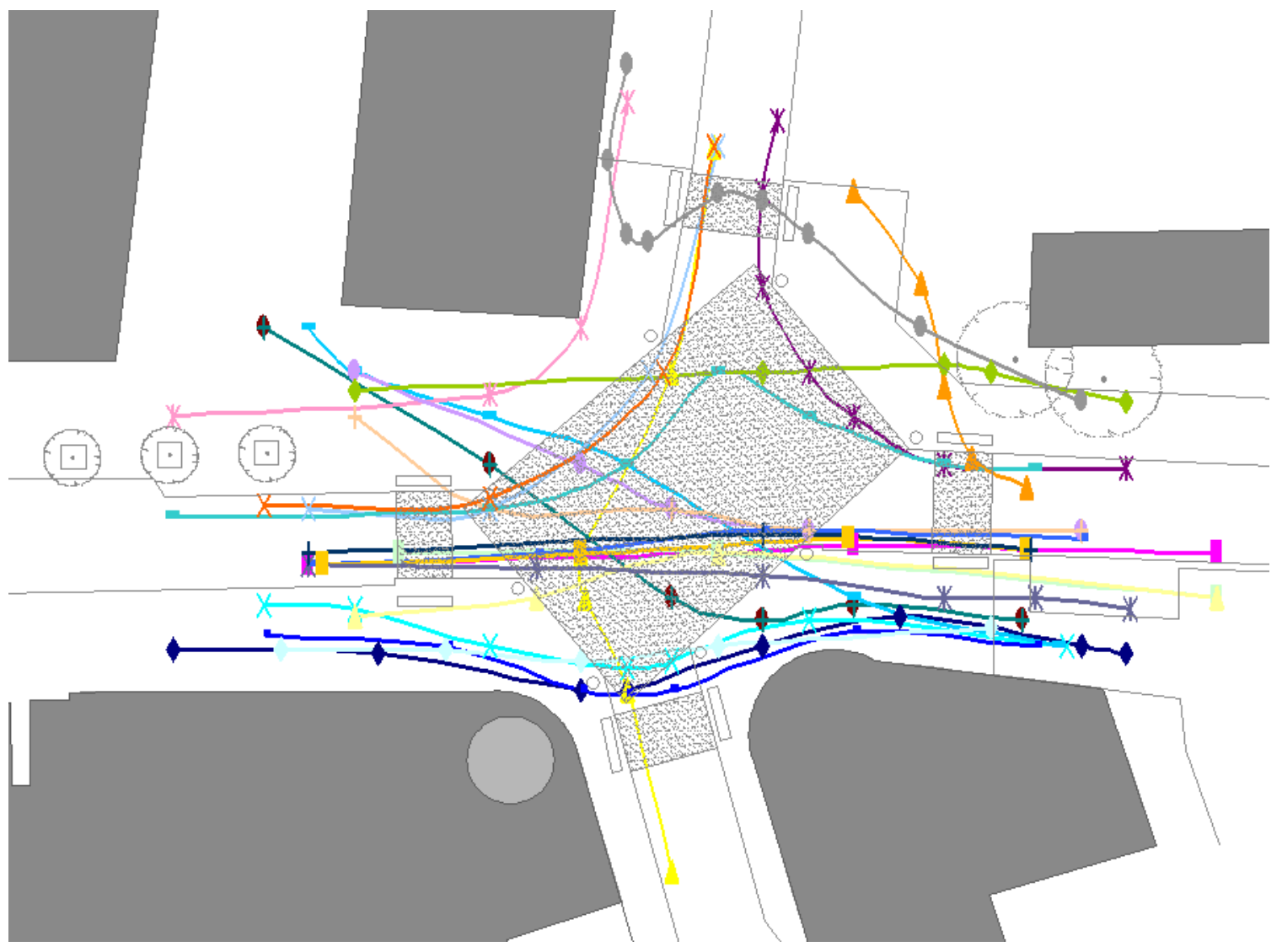

Figure 116: Coventry other bikes paths 


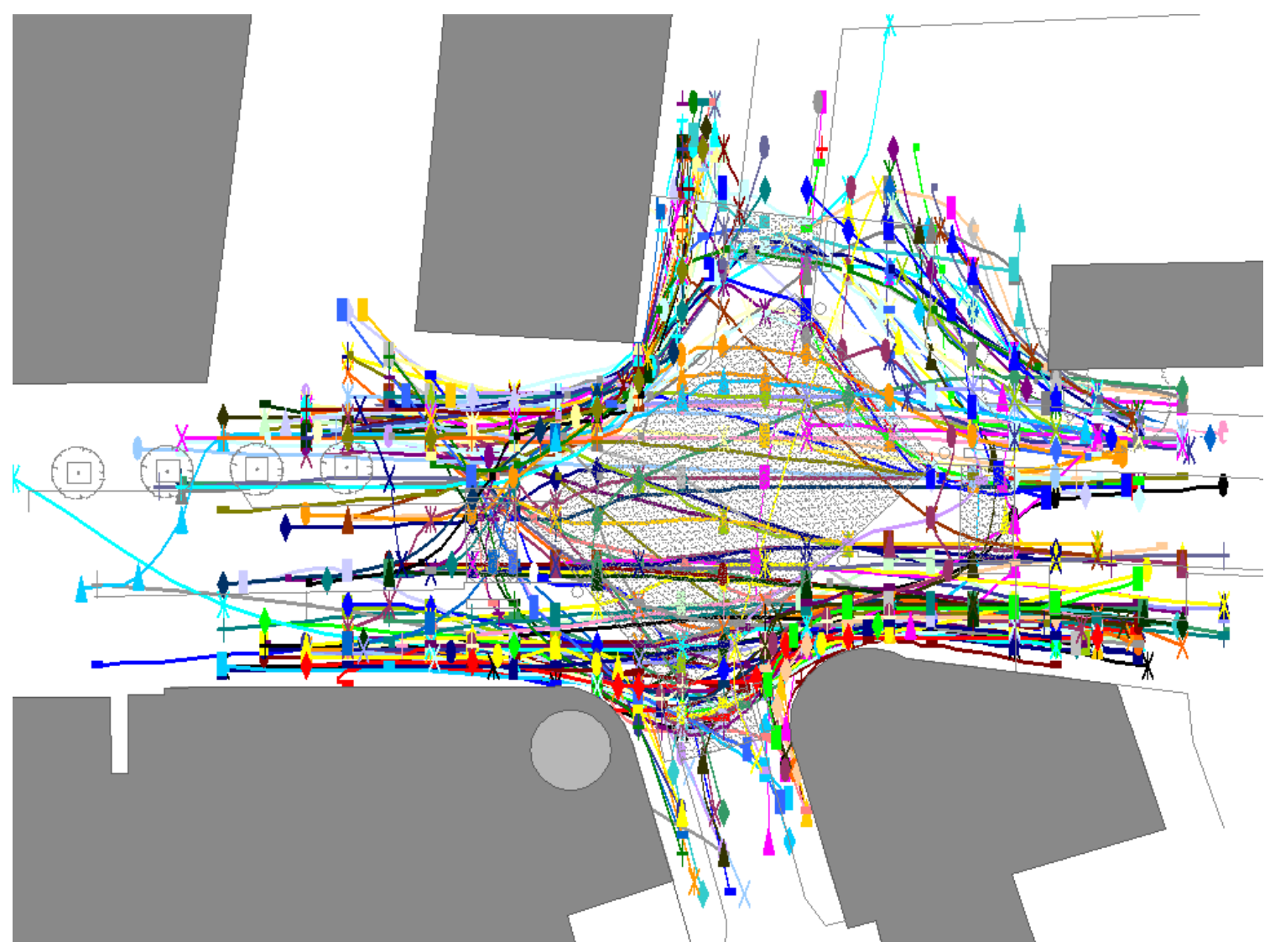

Figure 117: Coventry sidewalk use 


\section{Coventry control}

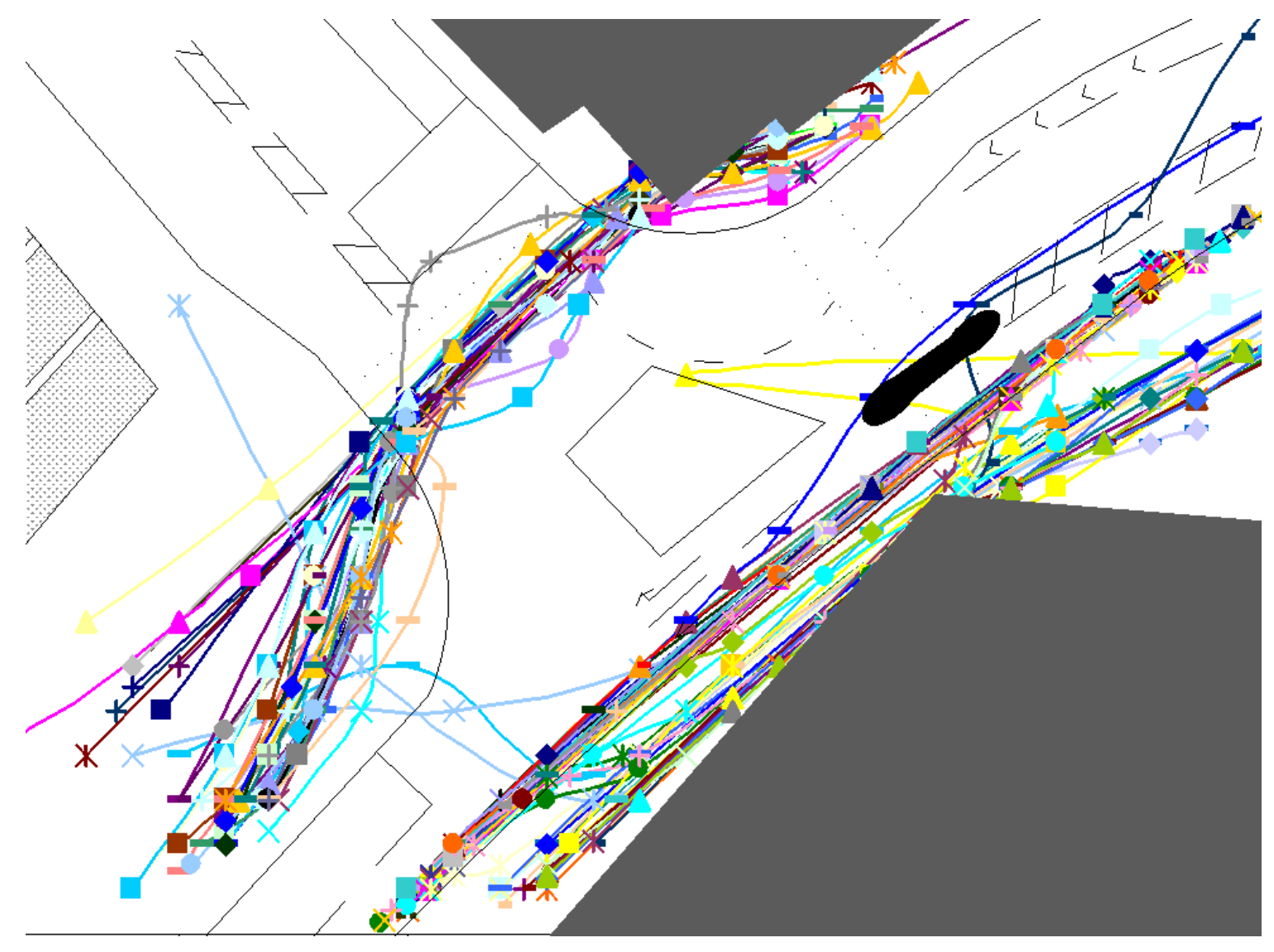

Figure 118: Coventry control northeast to southwest 


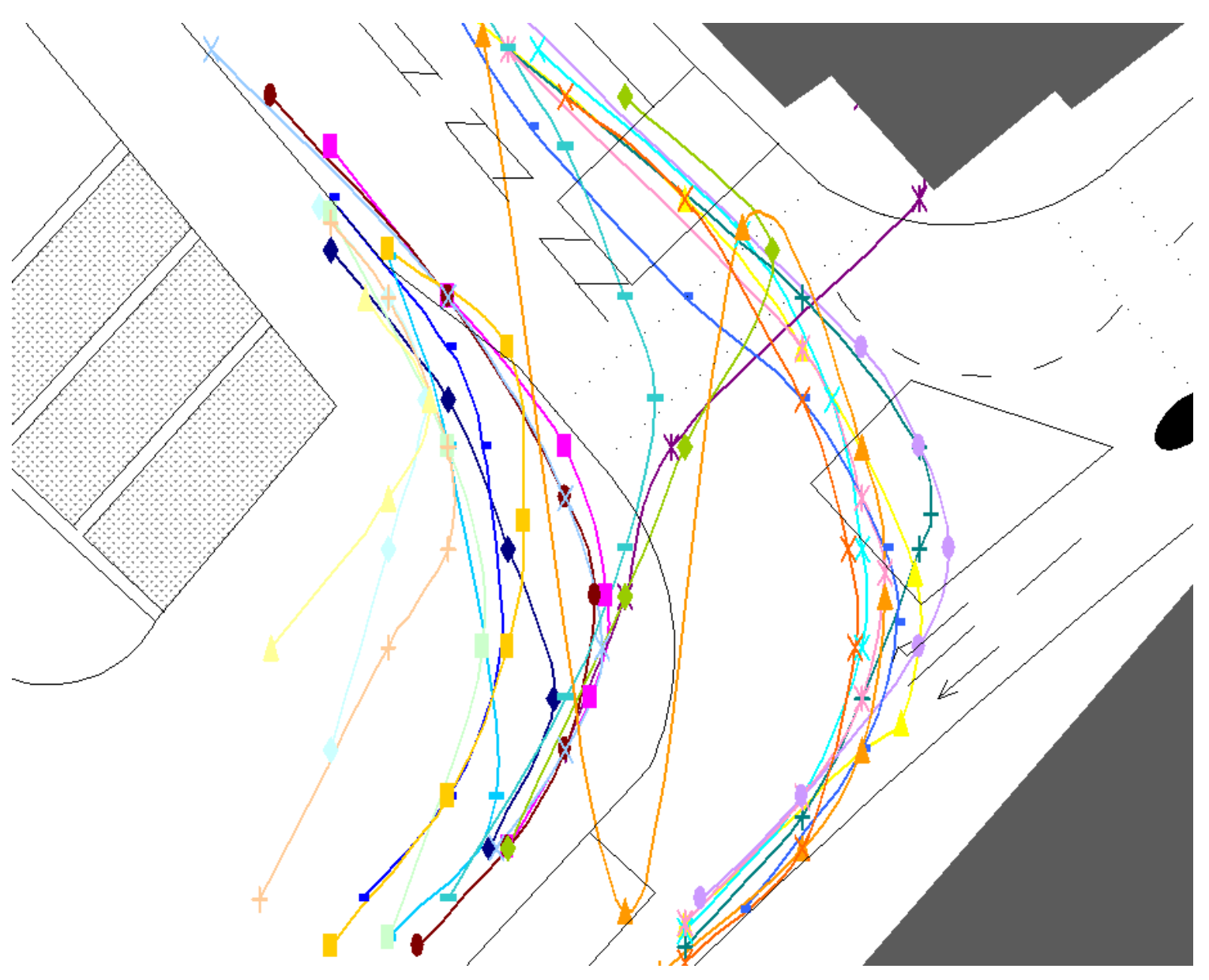

Figure 119: Coventry control northwest to southwest 


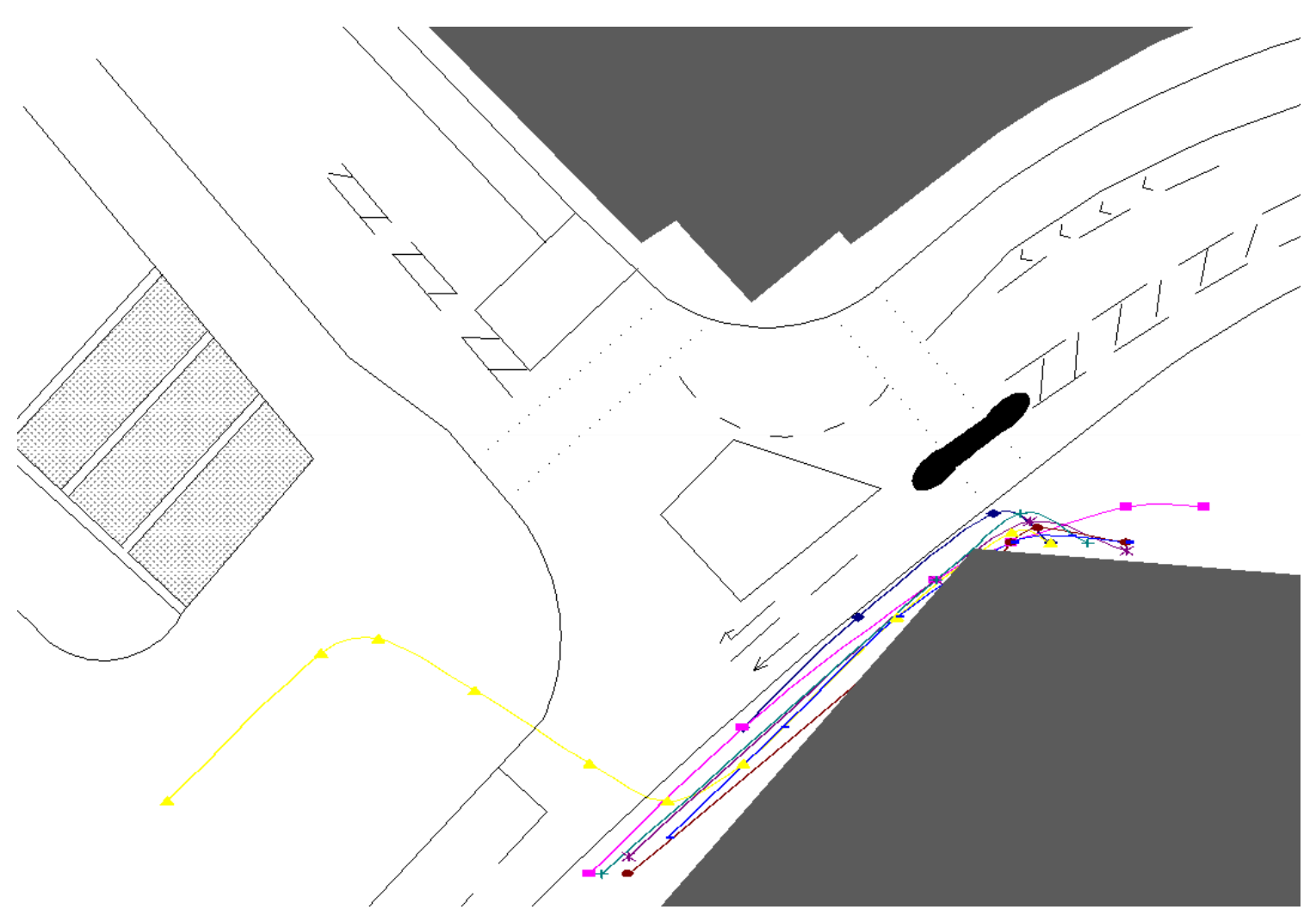

Figure 120: Coventry control southwest to southeast 


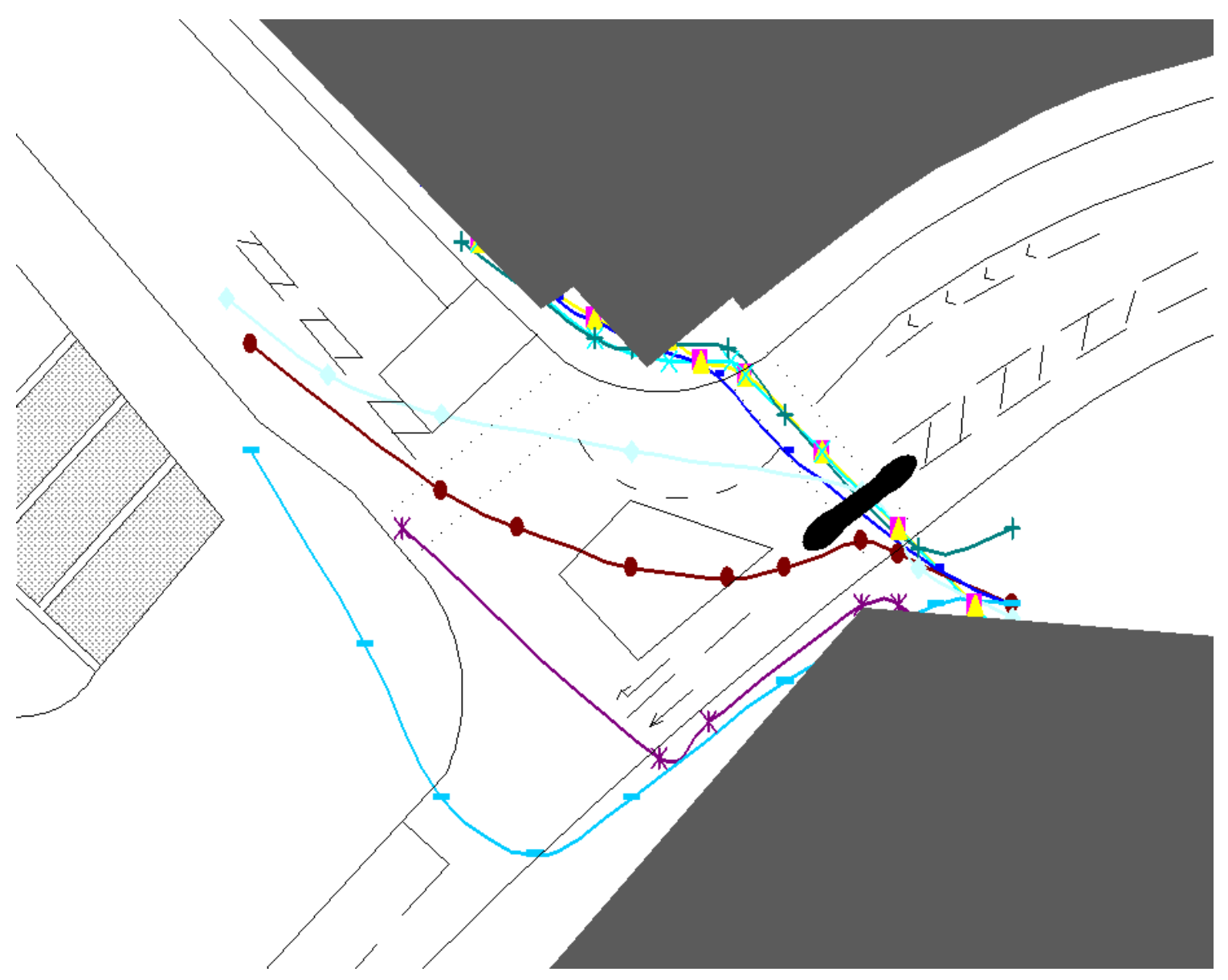

Figure 121: Coventry control southeast to northwest 
Appendix E: Figures regrouped by study site type

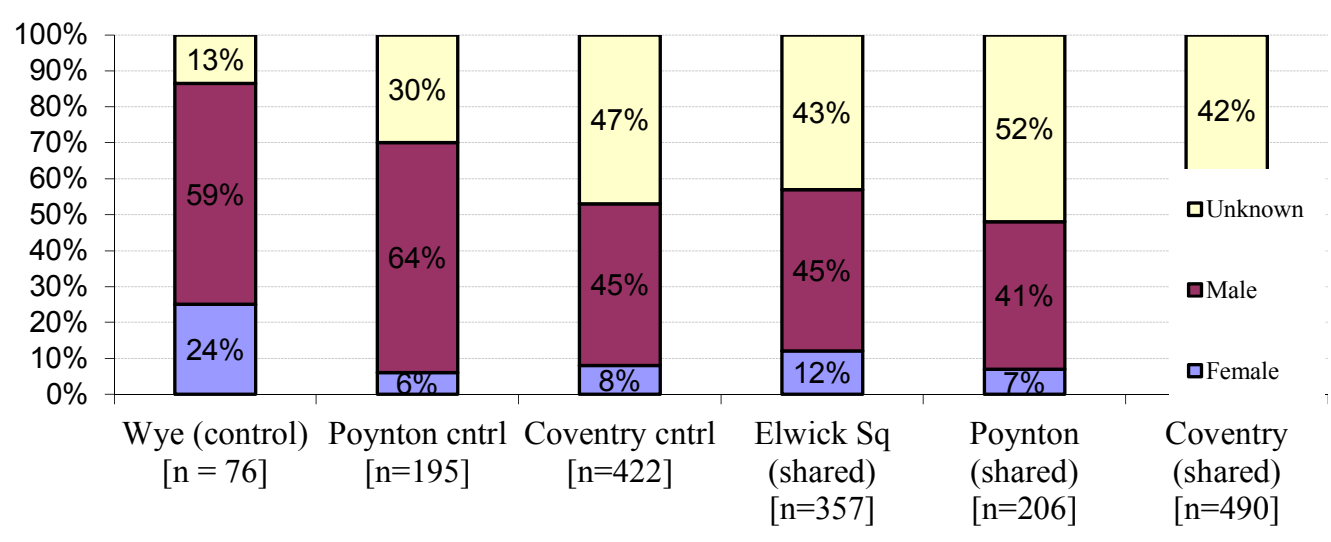

Figure 122: Gender percentages by site type

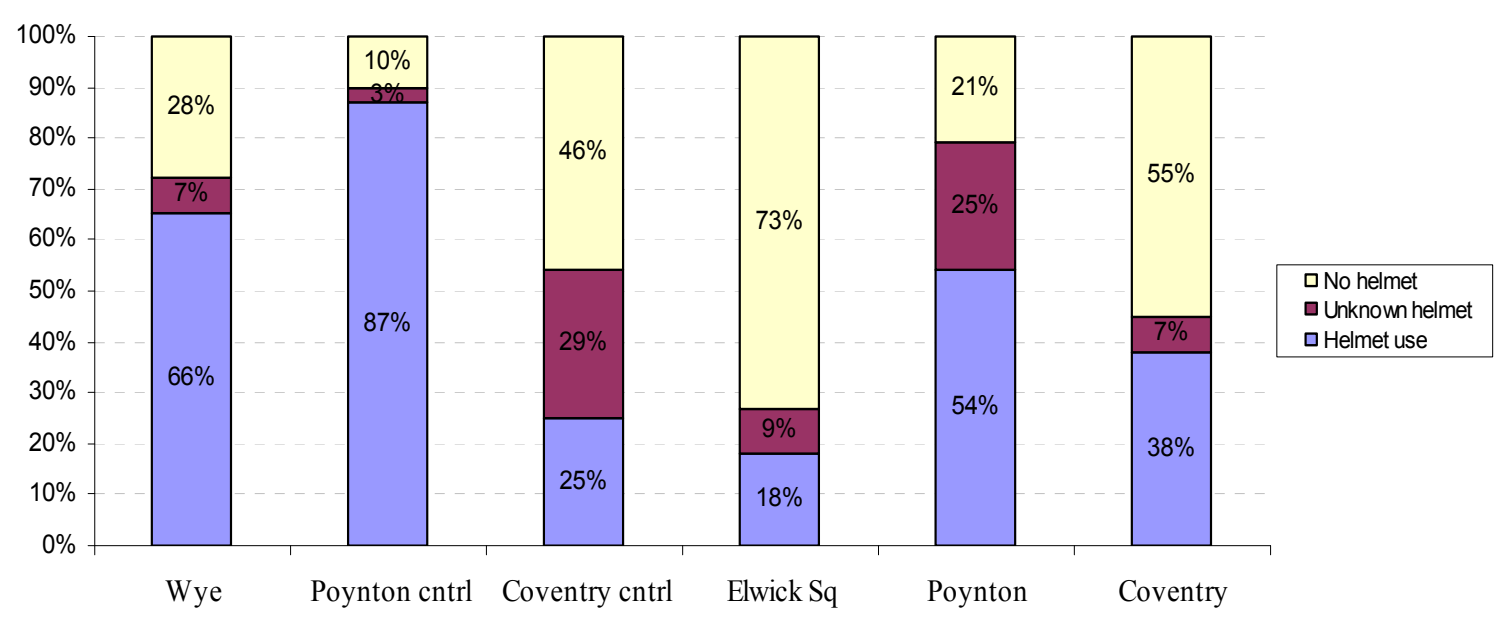

Figure 123: Helmet use percentages by site types 


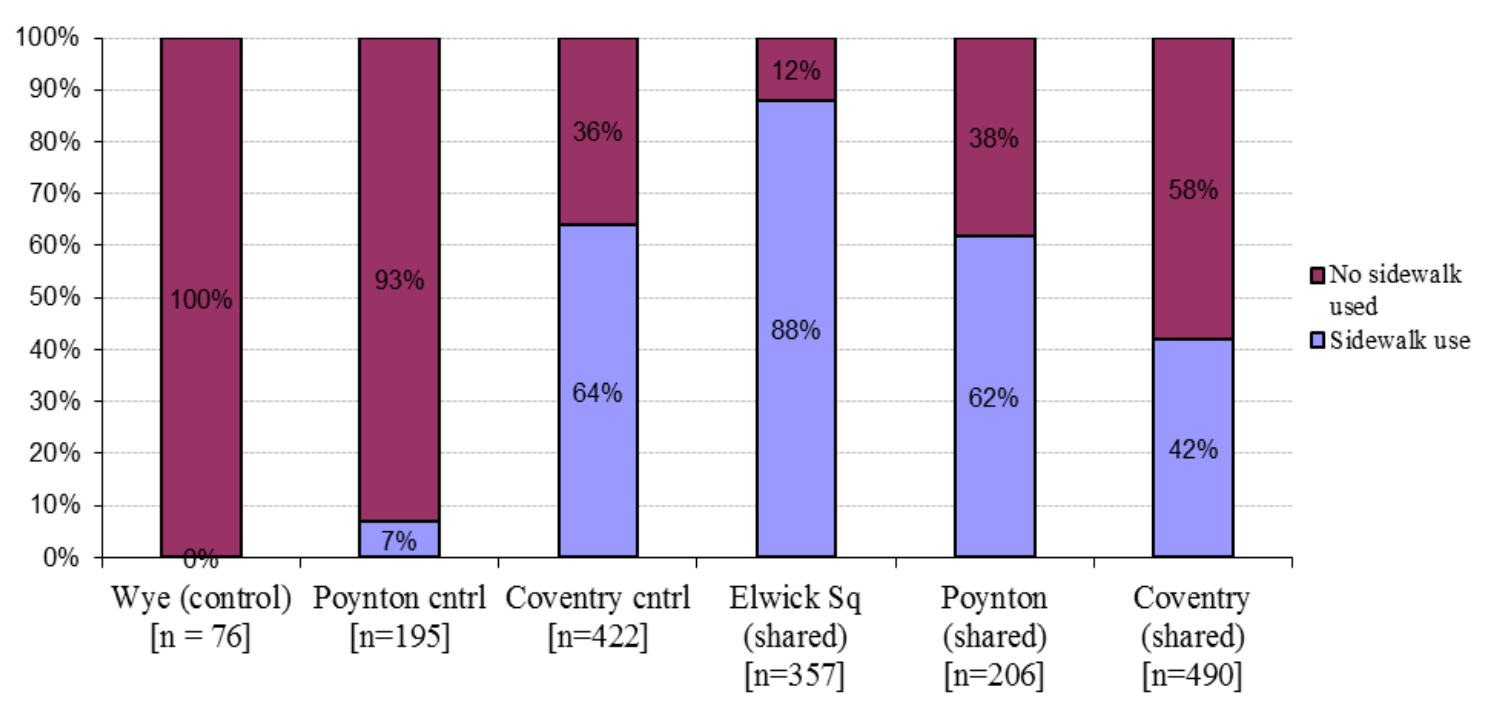

Figure 124: Sidewalk use by site type

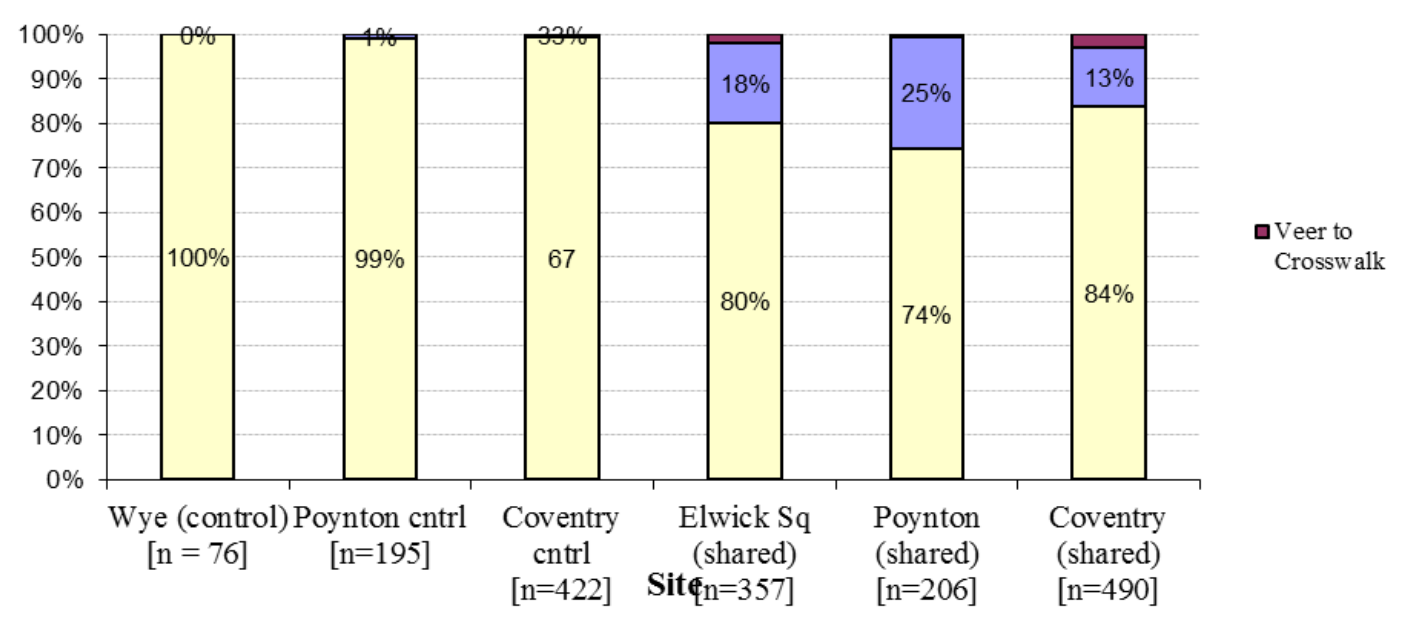

Figure 125: Crosswalk use by site type 